Hir 281910

\title{
IN COLORS AND HOW TO JUDGE THEM
}

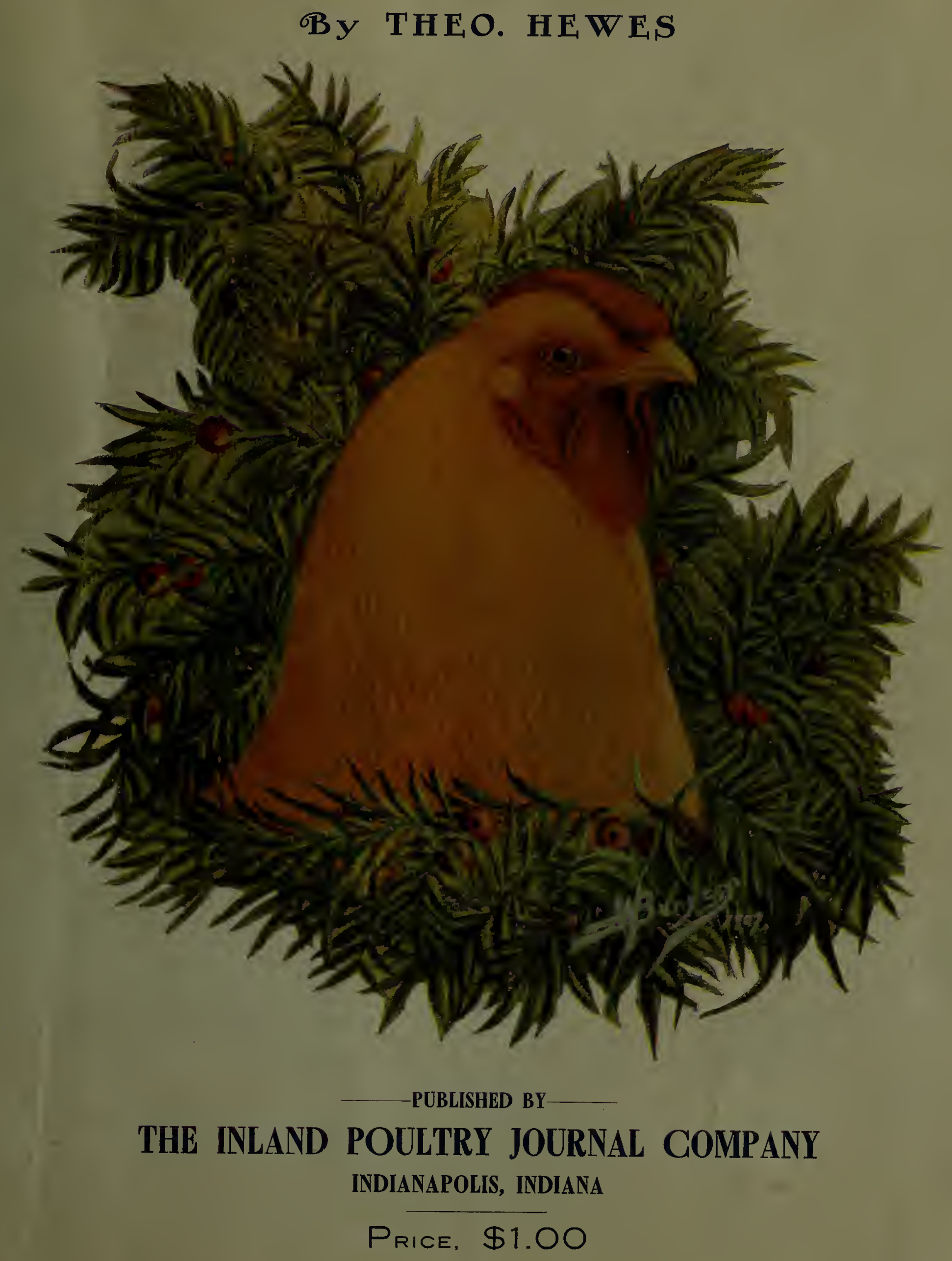




\section{LIBRARY OF CONGRESS,}

COPYRIGHT OFFICE.

No registration of title of this book as a preliminary to copyright protection hils been found.

Forwarded to Order Division MiAY 231910

$(.1 \% \%, 5,1(x) 1-5,(4 x)$.

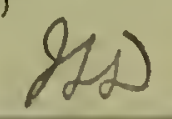



COPYRIGHTED BY

INLAND POULTRY JOURNAL CO.

INDIANAPOLIS, INDIANA

I 908 


\section{WYANDOTTES IN COLORS}

AND

\section{HOW TO JUDGE THEM}

CONTAINING

TWELVE REPRODUCTIONS FROM OIL PAINTINGS, TOGETHER WITH MANY BLACK AND WHITE ILLUSTRATIONS. ALSO HALF-TONES OF SOME OF THE BEST LIVING SPECIMENS

A FULL AND COMPLETE DESCRIPTION OF SCORING IS GIVEN BY THEO. HEWES AND ILLUSTRATED BY

I. W. BURGESS, FORMING A MOST VALUABLE GUIDE TO ALL THOSE INTERESTED IN THIS THE GREATEST OF ALL AMERICAN VARIETIES 




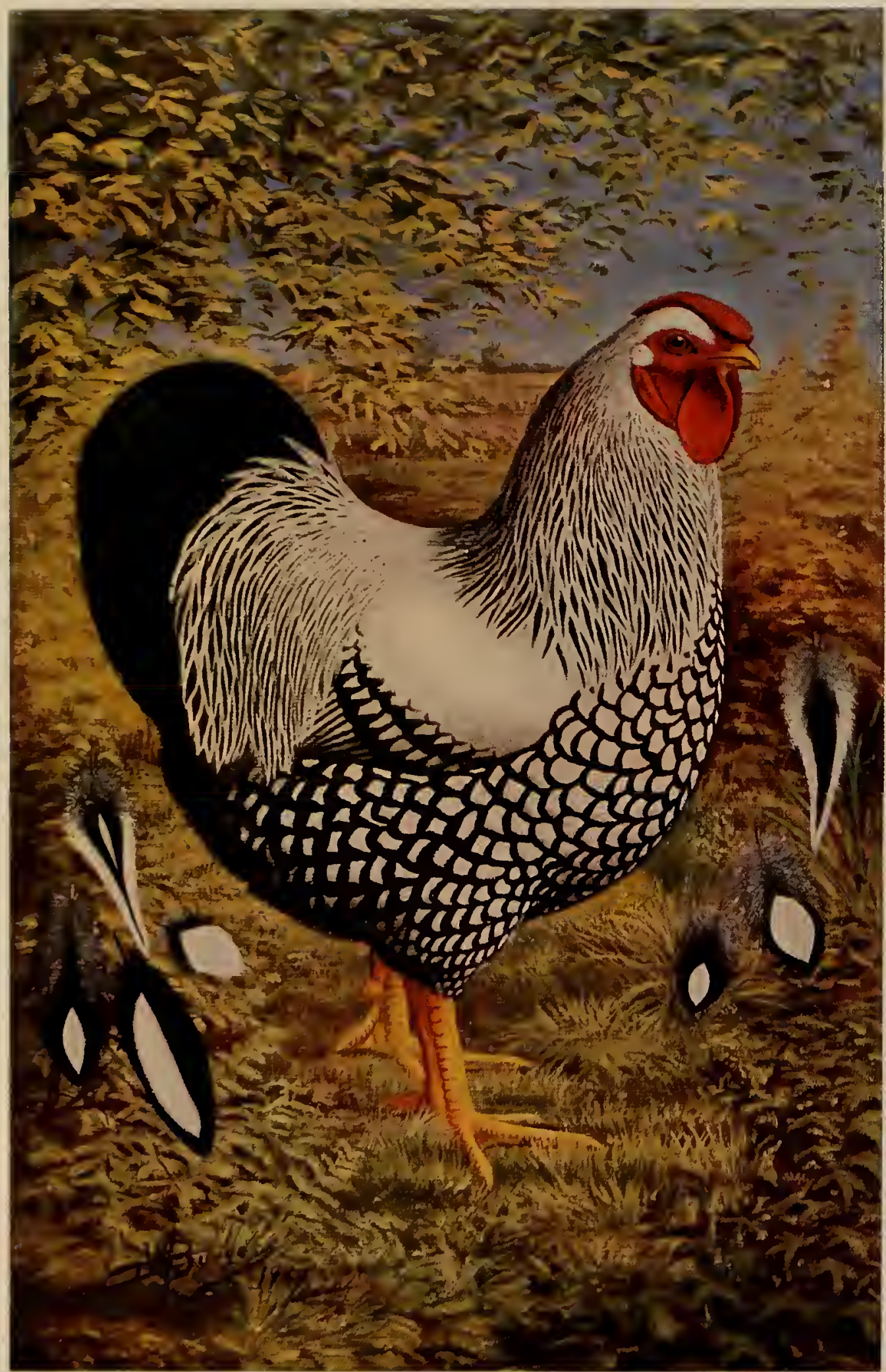

SILVER LACED WYANDOTTE MALE. Urawn to Conform to Standarr Shape and Color as luescribed by the American 


\title{
WYANDOTTIES IN COLORS
}

\author{
And How to Judge Them-A Thorough Description of Color and Shape-Defects \\ of All Varieties, With the Correct Valuation of Same-How and hen \\ the Several Varieties Originated.
}

By THE0. HEWES.

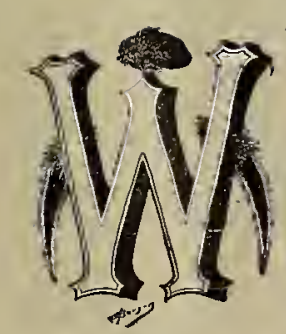

HEN by accident the blood of several breeds of fowls was mingled, each adding a little and losing much of its own strength in the offspring, there was none to predict that these crosses, brought together no doubt by merest accident, would give to the poultry fanciers a foundation for one of the most popular breeds of fowls the world has ever known. But such is true, and there is not today, nor never has been at any time, a single person that could give an absolutely correct account of the crosses that produced the first Wyandottes.

Hundreds, yes, thousands, of pages have been written concerning the origin of this breed, but they contain nothing that can be taken as positive facts. It was the general make-up of the original Silvers and the peculiar shape and color as found in them years ago that gave a sort of solution to the puzzle.

Certain breeds entered into them; this we know, because crossing of these breeds has given us something that very much resembles the original birds. We say resembles, but not exact counterparts, and we know that one or more outside crosses was bred into them, but what these crosses were no one can tell. It might have been one breed, or it might have been another, as several outside crosses have brought about practically the same result; but the chances are that the cross that brought them nearest to perfection was none other than some common barnyard fowl that years before may have had some fullblood crosses in its ancestors.

We have read theories by the hour-in fact, until we have had the headache, but in nine cases out of ten the writers were not heard of until ten years after the breed was established, and in the majority of cases they are from men who have never bred a good Silver Wyandotte in their lives and are only guessing or trying to make others believe something they do not believe themselves, or tell us as fact something that was told to them as theory.

Doubleday, Page \& Co. made the strongest effort of any publishing house to get at the facts of the breed's origin, but after reading their book and weighing all the evidence submitted we must agree that it is all guess work after all and the writers are simply stalling or willfully misleading.

It is now more than a quarter of a century since the writer first became interested in this breed of fowls. They were then known as the American Sebrights, and their origin then, as now, was surrounded by darkness. It was clearly evident at that time that the blood of the Dark Brahmas and the Silver Spangled Hamburgs was in a great measure responsible for the color. Whether the Hamburg cross was from a full-blooded fowl or from a fowl that had been formerly crossed with a Hamburg, we could only guess. And it is well to mention a fact here that many writers seem to have overlooked, i. e., the color of Hamburgs as bred twenty-five or thirty years ago. We did not find the elegant spangles on them that we do today, but many-in fact, nearly all-of the females were decidedly laced or crescentic in marking, especially in breast, back and wing bows. A cross of this variety with a common white fowl would no doubt have given us a fowl that again crossed with the Dark Brahmas would produce off- spring that would show a number of laced females anc dark-breasted males, and the early Silvers gave us many birds of this kind, the male running nearly solid black in breasts, with very small diamond-shaped centers, while the female, no matter how well laced in other sections, was invariably crescentic on breast.

The top color of both sexes shows undisputed traces of Dark Brahma blood-the silver surface of male with dark stripe in neck and saddle and the natural tendency to double or triple lacing in the female, and this defect, or characteristic, is not entirely bred out of the females yet, as two careless matings will demonstrate to the satisfaction of any one who wants to experiment.

\section{First to See Their Merits.}

No one man did more to create and maintain an interest in this valuable breed of fowls when they were first introduced than the late B. N. Pierce, who, by the way, was one of the first judges to recognize the merits of the fowl and did much to shape its future, both as to color and outline.

When the writer was but a boy he had many conversations with Mr. Pierce in regard to the Silvers. The color fad in those days was a very dark bird with small, narrow centers. Mr. Pierce always argued against this. His idea twenty years ago was that the bird should have clean, open centers, with narrow lacing of black, but the breeders who tried to produce them were disappointed in finding an outside lacing of white, making a sort of triple-laced feather.

When I explained this to Mr. Pierce his remark was: "Keep on trying; some one will get it right, and you might just as well be that breeder as not. It's coming to it in time, and if we can't do it our English cousins will." And they did.

While the breed is American in origin, it was the Eng lish breeders who first got the open centers fixed, but what they did to shape in getting this color was awful. The open-center birds imported from England resembled a cross between a crane and an ostrich, and the males haa a brassy, copper surface that we had been discarding as worthless, but they did possess the clear, open centers, and from the cross of the long-backed, long-legged males on our best American-bred females we were able to produce a fair per cent. of good-shaped specimens, with grand open centers on both sexes.

While we will not concede anything to our English cousins in the way of origin, we will have to admit that we took them into partnership to fix the color, and, so long as we are in the dark as to how the breed was first produced, the less we boast about the origin the better.

But as a final shot on the breed's origin, we will refer to a few statements made by men who tried to learn years ago where and how the breed did originate.

In June, 1886, the Rev. Charles L. Ayers, then a prominent breeder of Silver Wyandottes and a close student, had this to say of their origin:

"It is somewhat singular that the origin of so popular and meritorious a fowl as the Wyandotte should be so obscure.

"After a diligent inquiry I can find no witness ready to testify relative to Cochin, Bantam or Hamburg-Brahma 


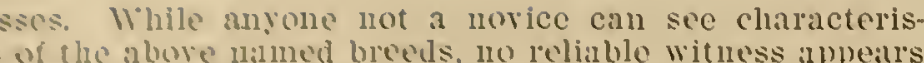

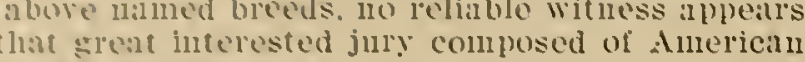
puiltryisen.

mensonialo to conclude that any combination Some persons who worked Where are they? of 111 in inestiwations: In the ournal Mir. .. Y. Bicknell asini "119andottes were bred in Oneida county, New whin they were originated.

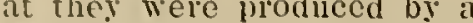
Wirer cross. Mr. George F. Hull testifies: II. ${ }^{2}$. She got them from Sand Lake, one seems to know who took them there. came from the Western part of the State, The probable care so fas I hare been able to where the first ones were, so far as I hare been able to They were an aecidental cross, and no one has so fir inclosing stamp, to every one whose address I could obtain who was then breeding them or had them. I tried to find out from them what they knew as to their origin, and all who answered were frank they linew no more than I did. I believe so far as absolute eertainty as to the origin of the Wrandottes is concerned, it must always remain a specu. lation.' Mr. L. Whit dottes in 1872 were known as Sebright Co chins. I first found them at Honeoye, $\mathrm{N}$. Y. I thought at that time I could see all of their future popularity and the result has proved my prediction true. In January, 1877 I gare them the nam of American Sebrights. .Ir. F. A. Houdlette was the first to sug gest Wrandotte. As to their origin I made strict search in the and e a c h in quir brought a different the ory, and on following up the matter I would find them all to be mere guesses.' Mr. D. think no man living knows when or how Wyandottes originated. Some ten years ago, when Kidder, of Northampton, and $m y-$ self we re breeding them, then known as Sebright Cochins, wrote wherever I could hear of them in order to trace them back, but the lines diverged

instead of converging and I at last gave it up as hopeless.' These testimonies from the early and prominent breeders carry weight. If they had no light to give, where shall we look for it? We may reason on probabilities, as Mr. Felch does, trying to answer Mr. Bicknell. But one fact would give us more aid and comfort than several assertions or repeated sayings that this characteristic must have come from this or that breed or mixing of breeds.

If men who were directly interested in this breed twenty-five or thirty years ago were unable to learn positively how they orisinated, it looks rather presumptuous for some of our present-day theorists to try to make one bslieve they have held the key to this important secret all these years. So let us take all this late moonshine with it grain of salt, giving the writers eredit for nicely spm stories and get down to present-day facts-to one of Americal s greatest commercial and tancy fowls.

The name Wyandotte seems to have been an accidental one as the breed when first recownized by the poultrymen was known as American Sebrights, Sebright Cochins, Moonees and by several other names, each section of the country where they were bred having a different name for them -American Scbrights being the most common. This name they derived from their American origin and peculiar Sebright lacing; as up to the time the Wyandottes were discovered there was no large breed of fowls having the peculiar lacing of the Sebright Bantams.

There was some discussion as to what name they should have when they were first talked of as a Standard fowl and we are in doubt as to who first snggested the name of Wyandottes, but our oldest writers on the sub. ject give the credit to Mr. Fred A. Houdlette, who was for years one of our best breeders of this variety.

The name Wyandotte was given, as we understand it, in honor of a powerful tribe of American Indians that had, in many instances, shown their friendship for the white race. Some of the remnants of this tribe are still living, but whether they are aware of the fact that this fowl was christened in their honor we are not able to say.

The Early Silvers as I Knew Them.

In my first acquaintance with Silver Wyandottes I knew them as a breed nearly, if not quite, as long in back and body as our Plymouth Rocks of today. They were somewhat deeper in body and the females carried their breasts lower down, but the males had a decidedly erect c a r ri a ge, many of them equal to the Indian Games of today. In color they were much darker than now, the winning specimens at our best shows having very small diamond shaped centers that were nearly covered by the dark lacing. There was no lacing on body of either males or females, and this marking did not appear for several years after they were admitted to the Standard. There was also a constant fading out of color and the mixed white and brown penciling in back of females was common, even among the winning birds, for more than fifteen years after they were considered a Standard fowl. In fact, there were but few American fanciers able to eliminate this defect until the English cross referred to was used.

While the English cross on American-bred birds improved the clear white in centers of feathers, it lightened the under-color of both sexes, and quite a few of the chicks came pure white in plumage. While the Albinos showed up in nearly every strain of Silvers we have any record of they were by no means common until the English cross was used. Then we had them in great numbers. From one mating of strictly choice birds there were nine white chicks hatched in a litter of twenty-four, showing nearly 33 per cent. 
The second cross-i. e., the cross of half-English on American birds-reduced this percentage very materially, but even now we get a few white spots from nearly every strain that has English blood in it.

In Figs. $1 a$ and $2 a$ we sbow a type of Silver Wyandottes that was winning the prizes in the mid-West shows as late as 1885 , and this shape and color were considered by many

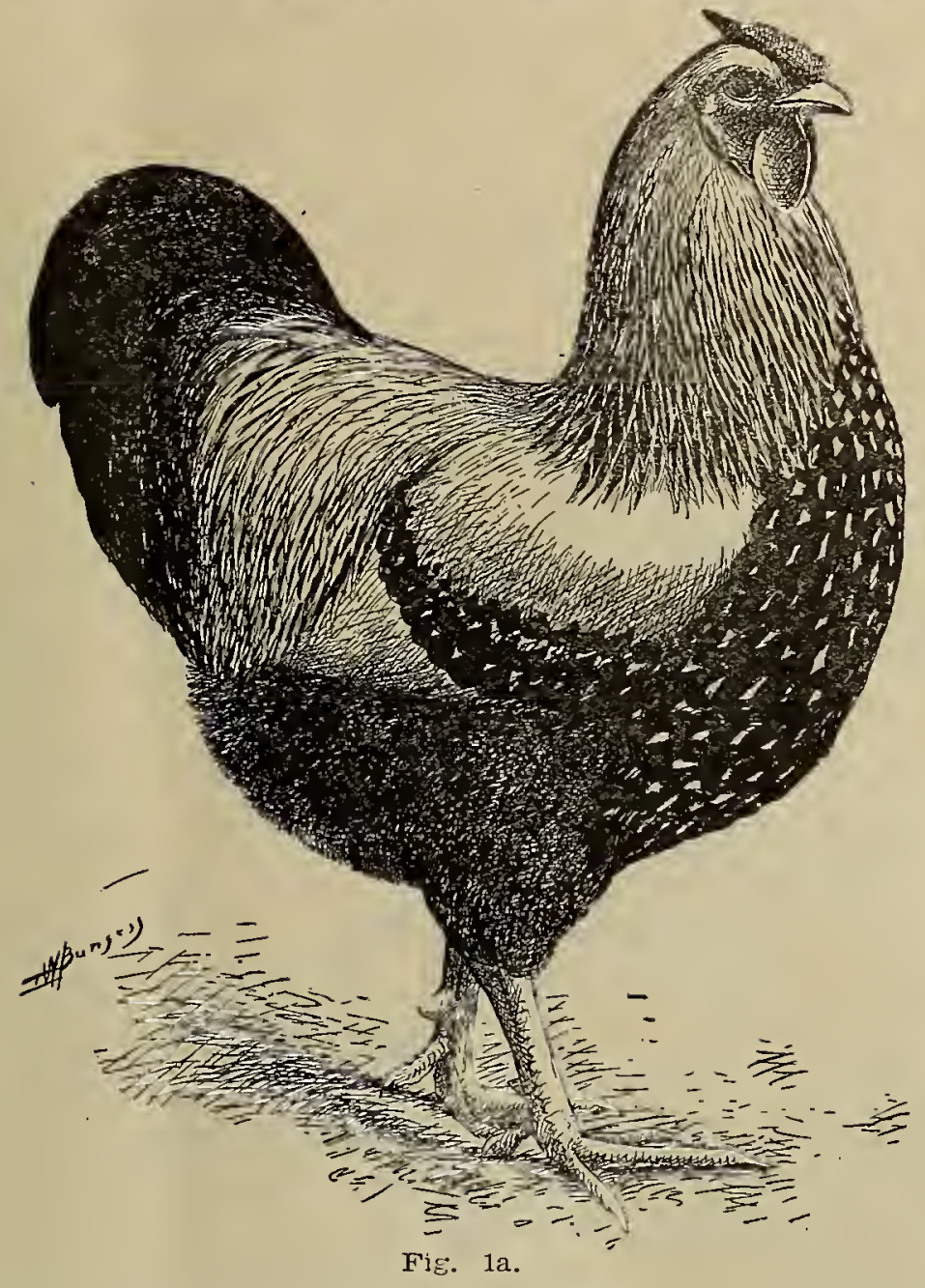

OLD-TIME WINNER.

as about the proper thing for Silvers. You will note the long back and body, the small diamond-shaped white centers in both sexes and the peculiar spike to comb. At this time the comb of each sex showed a distinct spike and in our best specimens this was carried nearly on a straight line with the comb, not so erect as that of the Hamburgs, but very nearly so. Gradually we have bred away from this, until today the comb proper terminates in a spike and the entire comb follows the shape of the skull.

By careful selecting we have bred a comb onto our best birds that is broad and full in front and gradually grows smaller as it approaches the rear, as shown in the two color-plates presented here.

In color we find a number of both sexes that carry the clean white oval centers with distinct narrow lacings of black.

When we look back to our old Silvers and consider the way they were mated, we often wonder how we made as good progress in breeding them as we did. We were discarding as worthless the only male birds that were really of value and were setting a task for our females that in the light of present-day breeding it is really a wonder that we did not destroy them completely. We were using males with solid black stripes in saddle, with only a small margin of white on surface, and we were then discarding the males with laced secondaries and wing bars, the most important color sections from a breeding standpoint that are possessed by the males.

Look at the saddle feathers of male birds (as shown in color plate of male) with nice diamond-shaped centers of white, and you can see how a male with this color assists the female in perfecting the large open centers so much admired by breeders of this variety.

\section{Study the Drawing.}

In the color illustrations Mr. Burgess has given to us as nearly true to life pictures as we find it possible to produce. The outlines conform to Standard descriptions and are in no way overdrawn when ideals are considered. The feathers that are reproduced on the plates were selected for us by the best informed breeders and represent the true surface and undercolor as described in the Standard.

If the shape and color as found in our illustrations are carefully studied and the two sexes mated as shown in these plates, then the breeder of Silver Wyandottes need have no fear of going backward in his effort to reach the top.

We believe that Mr. Burgess as a Wyandotte delineator surpasses any other artist now before the public. We have watched his work closely from the first crude sketch he. made up to the finished work in the color plates that will illustrate all the popular varieties of the Wyandotte family, and we feel that in less than five years since this boy left the farm he has done more to portray Standard poultry than any one artist in America in twice the time. His worls from the first has been done with the Standard as his guide; he has not allowed the hobbies of specialty breeders to influence his judgment and he has made a fad of no one breed that in after life might influence his work, as it has others. He has aimed at all times to keep up with the Standard-makers in their word description and assist them to put before the American fanciers the correct types of Standard fowls.

No one breed of fowls has so many popular varieties as the Wyandottes; no one breed that has given a better account of itself in all parts of the world; no one breed that can come nearer filling the wants for egg, broiler, roaster and of the fancier at the same time; no one breed that will do better under all conditions. In fact, as an allround fowl the Wyandotte in its several varieties stands today, and has for years, in the front row, no matter from what position you view them-medium in size, between the two extremes; quick to mature; early to lav; good allyear-round egg producer and the fancier's fowl par excellence.

With these facts before us, we offer no apology for giving them the prominence we do in this book. They have

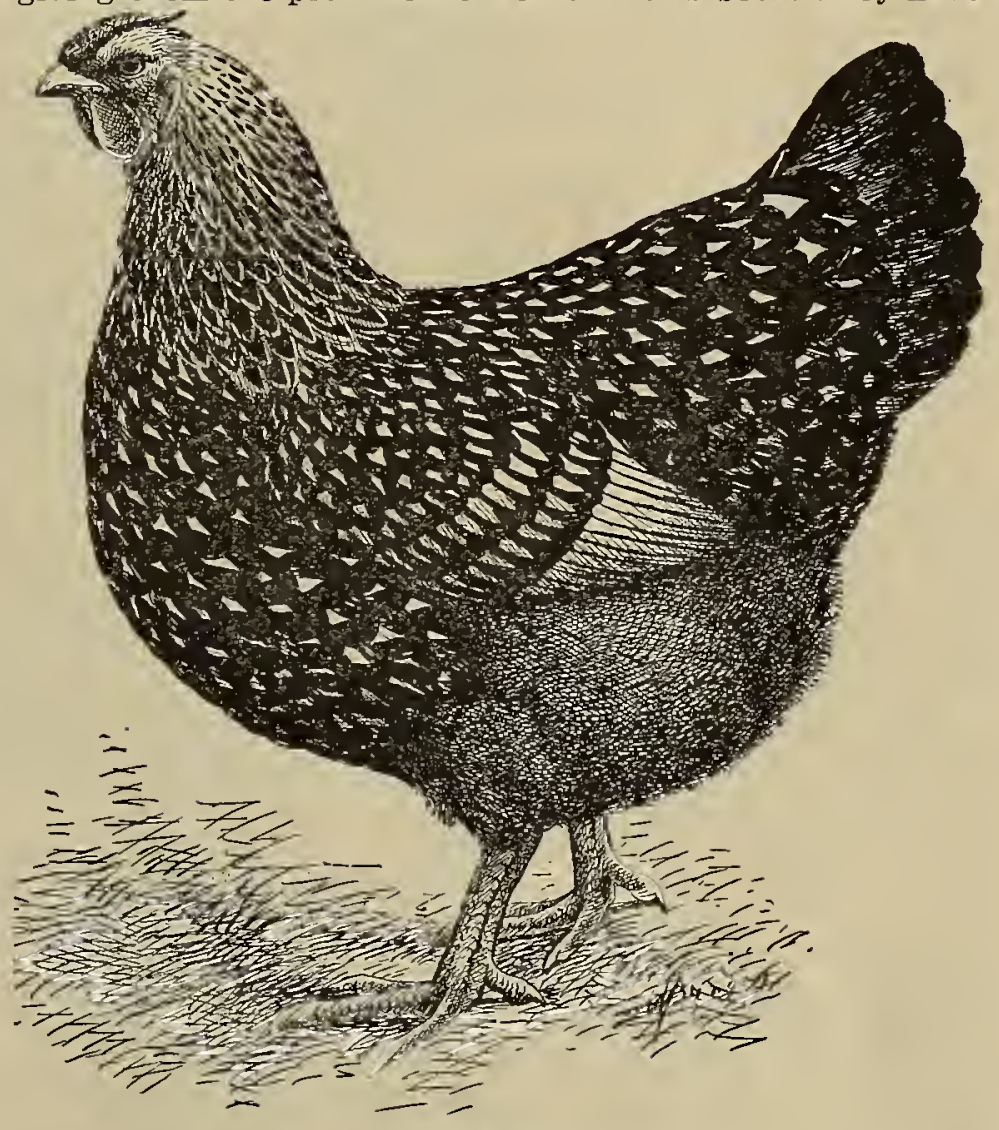

Fig. $2 \mathrm{a}$.

OLD-TIME WINNER.

earned it by their own merits; they have proved their worth. Now let's prove we are worthy of them by a closer study of the several varieties and the defects we find in them today.

It is not to set ourselves up as teachers, but if possible to harmonize the opinions of all lovers of fowls, that we are putting out this work. Let us understand just what constitutes defects, and we have made one step in the right direction; then let us learn how to value the defects, and we have made still another; and when we learn how to mate to avoid these defects, we have reached the goal which is sought. 
The Standard descrintion of llyandottes in shape is one of the best in the Amerlcan Standard of Pertectionin fact. thele is but one better in the book, the one referred to being cochins, this heing decidedly the best word descrintion ever framed tor any breed or varlety of fowls. dne to the fact that it was framed by men who linew what constituted perfection in this breed and hat no seltish ax to sint.

The present Wyandotte Standard was framed by three of the best posted liryundotte jndges in this comntry-J. H Drevenstedt, the late T. E. Orr and $W^{2}$. C. Pierce. But this conmirte was hamdicanped in a way by being compelled to report to a sencral committec, and some changes were made by this general committec, but notluing that in any crent measure anfected the general tcxt of the book.

Yo one thing has been so detrimental to thc Amcrican Standard of Perfection as the persistent efforts of some members of the American Ponltry Association to constantly inker with the work that from a fancier's standpoint they know absolutely nothing about. No one not thoroughly rarieties with shape charts, as the shape description is the same in all of then and the discomnts in Silver Wyandottes womld fall equally as heavy on any other variety.

In color the Silver's and Goldcus can be handled under one liead, addug only a lew separate illnstrations to cover some few defects found in the one that are not prevalcut in the other.

Symmetry and shape wlll be disconnted in the Silver Wyandottes only as the same cuts will answer for all other varieties.

IIc shall now talie up the breed, beginning with the Silver's, and follow it through in the order they were admitted to tlic Standard.

It is well to remember that absolutc perfection will never bc attained in the breeding or illustrating of standard poultry. Thcre will always be somcthing lacking in our choicest specimens, and no picture, no matter how well it fills the eye, is within itself perfection. A line there, a touch here and a little morc harmony in the forming of the several sections could be added to the best illustrations

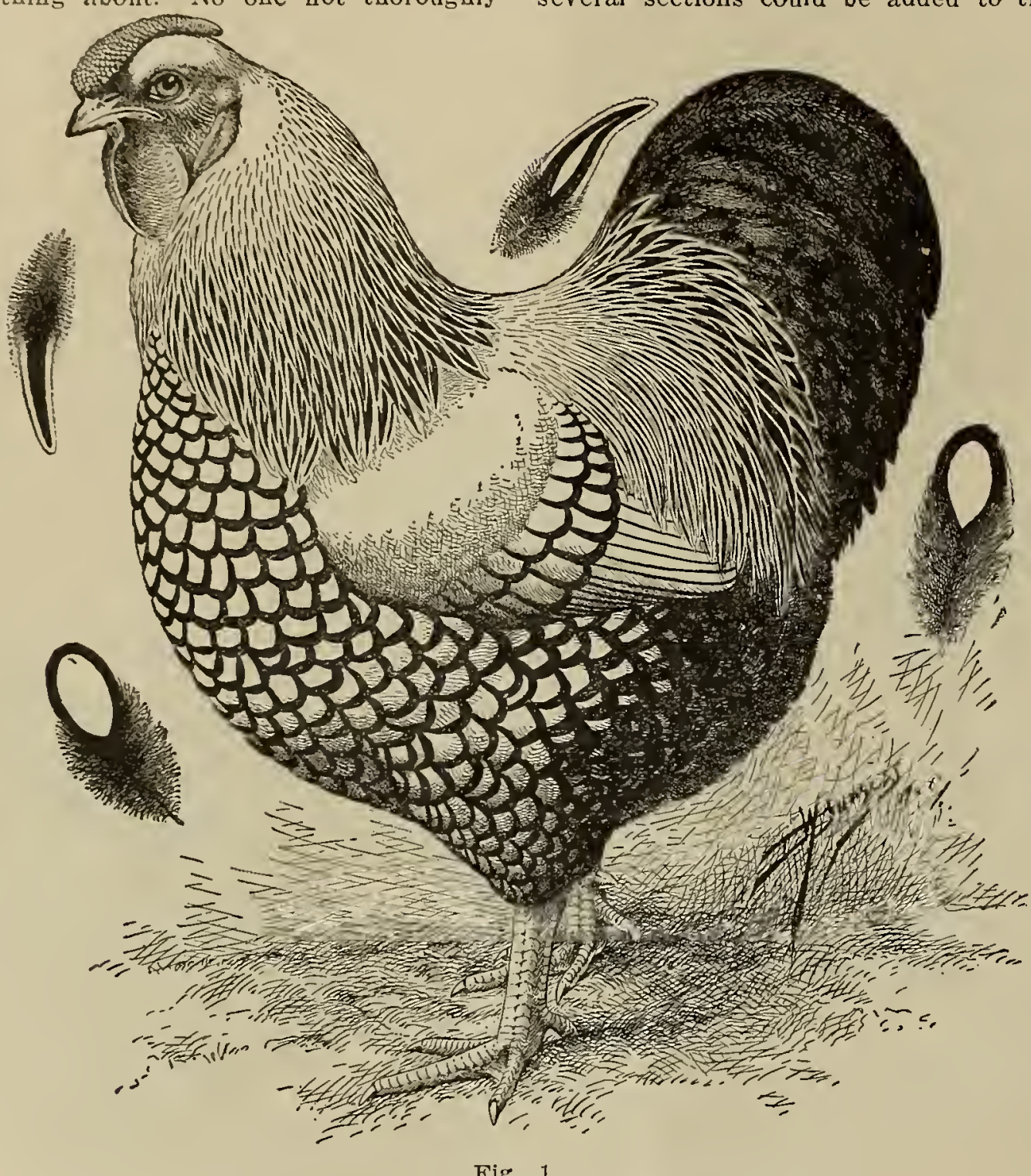

STANDARD SILVER LACED WYANDOTTE MALE.

posted on the breeding and judging of fowls has any business on the Revision Board.

The text of the experts should have careful proof reading by some one who has given this line of work years of study and sufficient time should be allowed them to see that every change in the description of a section, in order to make it grammatically correct, does not in any way alter the meaning of the original description.

A Standard for the popular breeds, gotten out in this way, will need general revision not oftener than once in ten years.

In this work of describing and valuing defects it is our aim to so far enough to make it plain to the beginner, and if some descriptions seem to the fancier to be too longdrawn out, please bear in mind that there was a time in your own llfe when this same description might have saved you many days of worry and some money as well

In the outlines it will not be necessary to illustrate all that have been made or will be made. Constant study of the best photos we have in our office of the winning specimens that we have found in America's leading shows, in order to harmonize nature's best in all of them still leaves room for improvement. A line no thicker than a pencil mark makes a radical difference in an outline, Only those who live day in and day out in an artist's studio have the faintest idea of the hard, patient work that is required to furnish the readers with the illustrations that are found in this book. For years the writer and the artist have worked together, each in his own way trying to help the other. In submitting his work here we do so believing that the outlines and color plates are the best that ever appeared or are likely to appear for years to come, and in this work Mr. Burgess and the writer have striven to give to the poultrymen of America a book that will live after we are gone, and if we have succeeded in this we will feel well repaid for the work we have tried to do right. 


\section{SILVER WYANDOTTE MALE.}

\section{Symmetry.}

This one word means more than all else when the awarding of prizes is under consideration, and when a judge ignores it he ignores the most important eight points in the entire scale of points. No matter how much he may know about the awarding of prizes, if he doesn't know the full meaning of symmetry he has not yet learned the A B C part of poultry judging, and is not qualified to award prizes at any exhibition where the American Standard of Perfection is used as a guide. This one section, properly understood, is the keystone of the poultry judging structure. Without it the scoring of fowls is a farce, and when we see judges cutting every bird alike on symmetry, no matter how good or how inferior the specimen may be, we cannot help but think the judges should go to school a while and learn something about the work they are accepting money for and doing wrong. Our Standard describes symmetry as "Perfection of proportions; the harmony in all the parts or sections of a fowl, viewed as a whole, with regard to the standard type of the breed it represents."

"The harmony in all the sections, valued as a whole, with regard to the breed it represents"- that's the whole thing in a nutshell. No two breeds have the same shape, and perfect symmetry in one is defective in the other. A perfect outline is perfectly symmetrical. One single part of that outline out of place destroys the symmetry to what ever extent the part is defective. A bird may be good in neck, back, breast and body, with a tail entirely too long for the breed it represents or carried at such an angle that the entire symmetry of the specimen is destroyed.

The framers of the Standard realized fully the importance of symmetry, and in their general description of Wyandotte shape they have given a text that is not surpassed in the general description of any breed.

"The Wyandotte has a shape peculiarly its own; it is emphatically a bird of curves. Fanciers should strive to maintain this short, broad back and deep, round body. These characteristics exceed in value the color considerations and are found in the typical Wyandotte at all ages, whether alive or dressed. Its curved, close-fitting comb adds to the symmetry of the breed."

In scoring Wyandottes, always remember this one important point- that it is a bird of curves; that it is short in neck, back, body and tail. The breast is broad, deep, round with a low set keel. These are Wyandotte characteristics that are found in no other breed, and it is only within the past few years that we have found specimens that conform closely to this Standard description.

Where neck is long, or too straight, the out is from $1 / 2$ to 1 ; when scantily feathered $1 / 2$ out; where back is too long or too narrow $1 / 2$ to 1 out; where back is roached 1 to $1 \frac{1 / 2}{2}$ out; tail too long or too high $1 / 2$ to $1 \frac{1}{2}$ out; breast flat and narrow $1 / 2$ to 1 out; body too long or too narrow $1 / 2$ to 1 out. If legs fail to join properly onto body, or are too long, making the specimen look stilty, $1 / 2$ to 1 out; knockknees $1 / 2$ to $1 \frac{1}{2}$, as in degree.

\section{Weight.}

This section in all the American varieties is vastly important, due to the fact that the framers of the American Standard have decided that the best type of specimens are those nearest to the standard weight in both males and females.

The standard weight for all varieties of Wyandottes is: Pullets, 51/2; hens, 61/2; cockerels, $71 \frac{1}{2} ;$ cocks, $81 / 2$, and in instructions to judges the Standard says: "In all varieties of fowls, old and young, except Bantams, also in all varieties of turkeys, ducks and geese (except ducks prized for their small size), when specimens are equal in score, the prizes shall be awarded to the specimen approaching nearest to standard weight. If both pecimens are overweight, yet have an equal score, the one nearest standard weight shall be awarded the prize. All American varieties shall be cut for excess of standard weight at the same rate per pound, or fraction thereof, as underweight; provided. however, that one pound of excess shall be allowed."

This last clause in the Standard was brought about by some breeders striving to breed the Wyandottes and Plymouth Rocks beyond their natural size, and in that way spoiling the type of the breed. One pound leeway, we have found in the three years' time the Standard has been in effect, is enough, and overweight, or overfat, birds should be discounted if we expect to maintain the symmetrical outlines so much desired in the Wyandottes, as well as other varieties of the American breeds.
In scoring this section the Standard instructions are to cut two points per pound for any deficit from Standard weight, or in that proportion. As an illustration, should a bird be one pound under weight, it would be discounted 2 points, while if one pound over weight, no discount will be allowed; but if two pounds over weight, then it would be discounted 2 points, but if one pound over weight and another specimen with the same score, correctly at weight, the latter would win over the heavier bird. A bird being three-quarters of a pound under weight would be discounted $1 \frac{1}{2}$ points; one-half pound under weight, 1 point; one-fourth pound under weight, 1/2 point.

\section{Condition.}

This section is valued by the Standard at six points, and refers to the health of the specimen, condition of plumage, shape of comb, wattles, ear lobes and legs. Should a bird be sick to the extent of endangering other specimens, it should be debarred from the exhibition room. If symptoms of roup, or swelled head, appear, the bird should be cut from $1 / 2$ to 2 points, as in degree. If bird shows signs of injury, caused from fighting or frost, the out is from $1 / \mathrm{g}$ to 1 point. If plumage is soiled or broken, showing clearly that the owner has been careless in preparing the bird for exhibition, the cut is from $1 / 2$ to 1 . Scaly legs should be discounted from $1 / 2$ to 1 ; torn wattles $1 / 4$ to 1 . Dirty plumage does not add to the attraction of an exhibition and should be punished to whatever extent the judge considers the bird is lacking in proper finish for exhibition purposes, ranging from $1 / 2$ to 2 points, as in degree.

\section{Head.}

This section, while having a valuation of six points, is not often discounted. However, there are defects that show up in quite a few specimens, especially in the varieties where foreign blood has been introduced in order to secure correct color.

We present here a number of defective heads which will enable the reader to gain a good general idea as to what defects might be met with in the several varieties of the Wyandotte family.

In Fig. 1 is shown what we consider a well proportioned

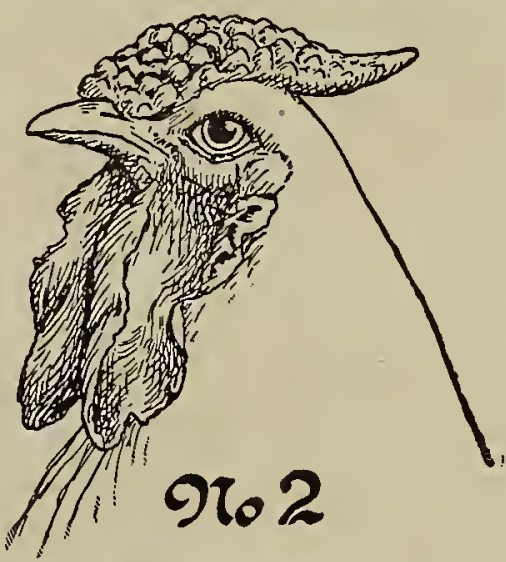
head for this breed, and one that fills the Standard requirements. The description of this section is: "Head-Short, strong and rather broad."

In Fig. 2 is shown a head that is too long and narrow; the beak is straight, more after the style of the game. There is not enough room above the eyesin fact, it is wrong in every way and should be discounted 2 points.

Fig. 3 shows a head that is too long, both in head and beak; also too narrow and shallow over the eyes.

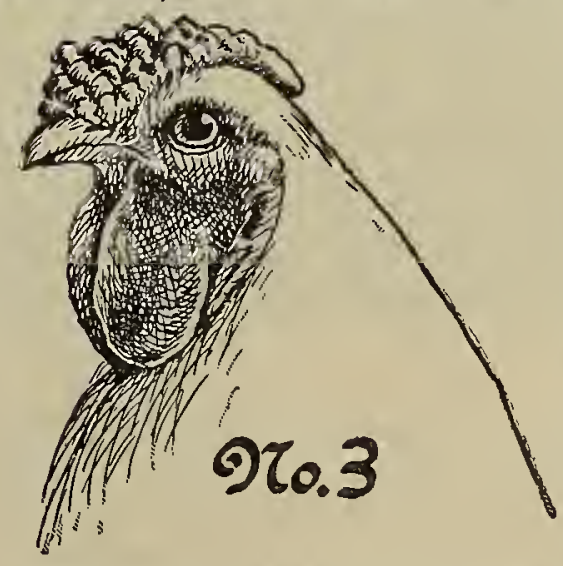
A head like this should be discounted 1 point.

The eyes are also included in head section, and it is well to consider them in connection with other defects. If the eye is blind, $1 / 2$ out; if eye is entirely missing, leaving a hollow socket, the cut is 1 . In color, the Standard calls for "rich red or bay." If eye is light, failing in the bright color so much admired by breeders of this variety, the out is $1 / 2$; if showing a white watery coloroften termed by poultry judges "fish eye"-the out is $1 / 2$ to 2 , as in degree.

Comb.

This section in all varieties of the Wyandottes is one of the most important from an exhibition or breeding 


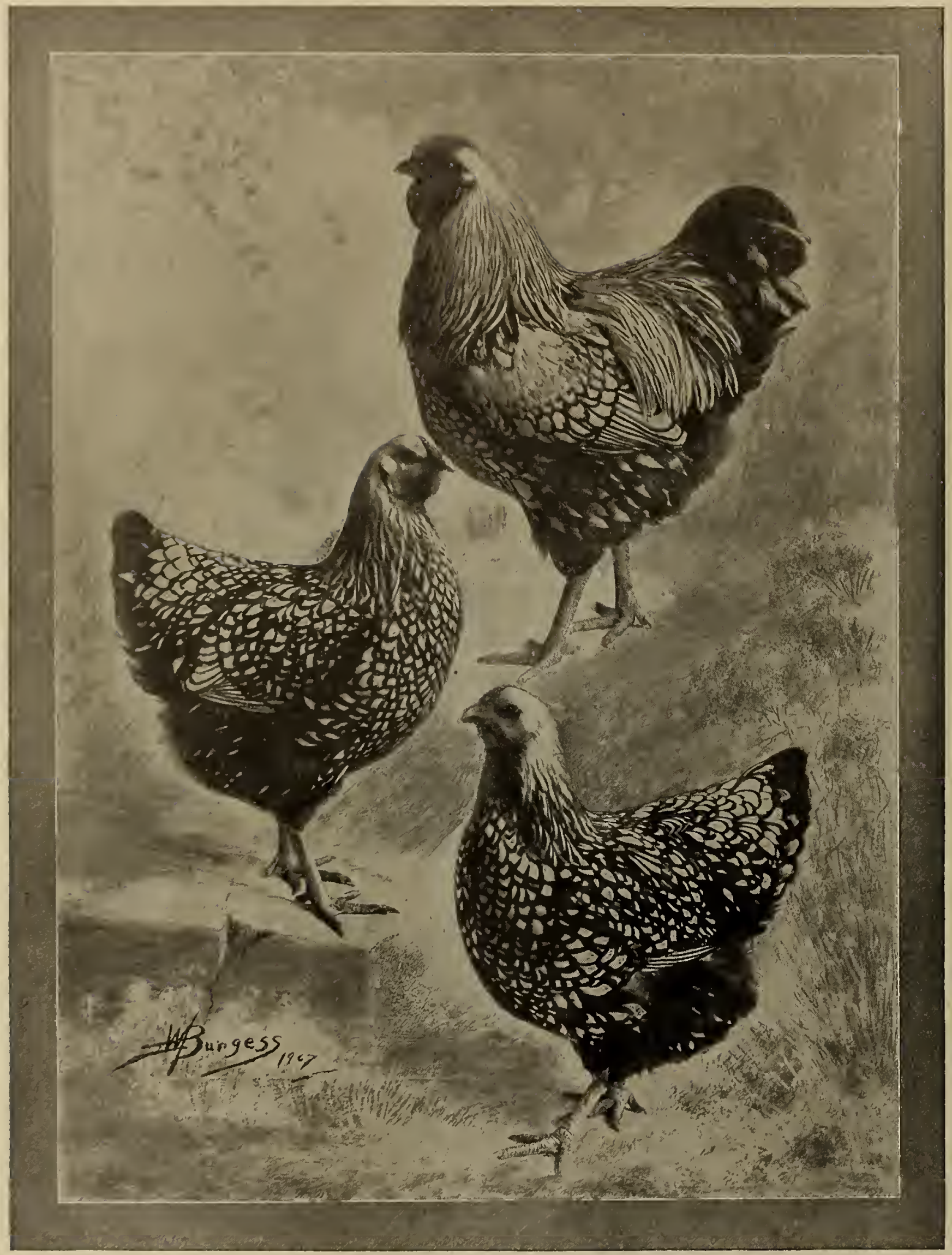

SILVER WYANDOTTES.

Therrs is no better example of what painstaking breeding will do with this popular variety of the Wyandotte family. The birds lllustrated here regrescnt one of the best show strains of Silvers in this or any other country. They are bren in line from a show strain that for fifteen years has been in the moncy in the best silver Wyan in tle Shrws in America. The cockerel is a grandson of the first prize pullet at the great wyandotic show held Is a cream of the bretdinis ls represented in this stock. He can show an egg record of nearly 200 eggs in ten months. 
standpoint. Possibly no one section is given more consideration or more thought by the breeders than comb, although there is a valuation of only eight points attached to it.

We again refer our readers to Fig. 1, where we have illustrated what we believe to be the ideal comb for Wyandottes of all varieties. It is well balanced, follows the curve of the head nicely, and is just such a comb as our Wyandotte breeders have been striving for for years, and, let it be said to their credit that quite a few of them in the past few years have pretty nearly, if not quite, flled the description.

It is pretty hard to harmonize the opinions of all breed. ers on this one section, as the comb in some instances really marks the several strains of Wyandottes that are prominent winners in America today, and of course when a breeder has established something that is characteristic of his strain he naturally insists that it is the proper outline, regardless of whether it fits the Standard or not. And we caution judges, and especially the young judges, that in awarding prizes they are to follow the instructions of the American Poultry Association and not the whims or fads of some individual breeder.

Another point we wish to emphasize to amateur judges is that the eight points allowed for comb are for shape alone, and when you cut a comb 1 point, you are only cutting $1 / 8$; when you cut it 2 , you are cutting it only $1 / 4$; when you cut it 4 , you are cutting only 50 per cent. It is well to consider this carefully, because the comb, according to the other sections of the bird, should be cut harder than any other section. Remember there is no valuation to color, and when you cut 1 you are figuring on the basis that $7 / 8$ of the comb is perfect; and when you cut but $1 / 2$, you are leaving $15-16$ as perfect.

The Standard says, in describing the comb of the Wyandotte: "Rose, low, firm on head; top oval and surface covered with small, rounded points or corrugations, the former preferred, terminating in a small but well-defined spike at rear, the entire comb and spike curving to conform to shape of skull." Note the words "terminating in a spile at the rear." In other breeds having rose combs the spike is independent of the comb, joining to the same at the rear. In the Wyandotte the spike is a part of the comb proper, the comb growing gradually narrower as it approaches the rear and finishes in a spike, which should be set straight and evenly on the rear of that section, the spike as well as comb to conform to the shape of skull.

We will now take up the sections, using several illustrations, many of them rather exaggerated, but there is no comb illustration in this article that will not be found in the course of a year's judging on some of the speciimens that are entered in competition for the prizes.

In Fig. 2 is shown a comb very much after the Hamburg style. It is too high in the center, the spike runs straight without conforming to the shape of the head. It is too shallow in front and has a sort of a feminine look. Such a comb should be discounted 3 points.

In Fig. 3 is shown a comb that is not all bad. In fact, there are many worse ones on exhibition every year during the show season. The comb is too shallow in front and the corrugated points are uneven and

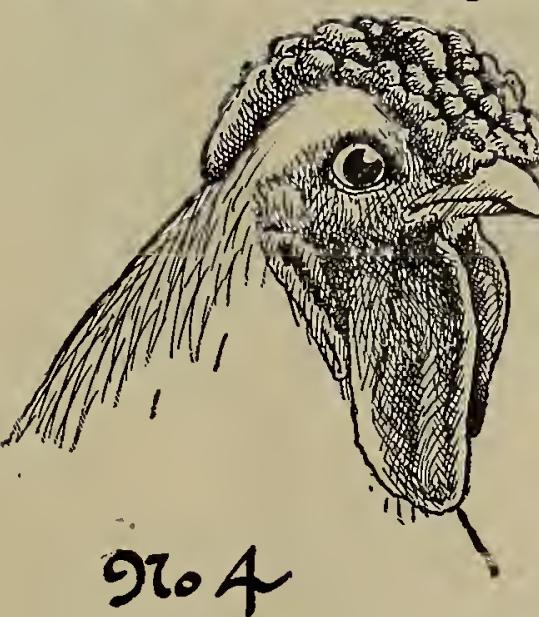
the comb is a trifle narrow behind. For general conformation, starting and winding up, it is fairly well proportioned but the uneven surface would give it a discount of 2 points.

In Fig. 4 is shown a comb that is too long and follows the neck too far down and the corrugations are loose and uneven. A comb like this should be cut 2 points1 for uneven corrugations in front and 1 for the extra length of spike at rear.

Fig. 5 is again too much on the Hamburg style. Instead of comb finishing in a spike, this spike is set on like that of the Hamburg and is nearly free from corrugations

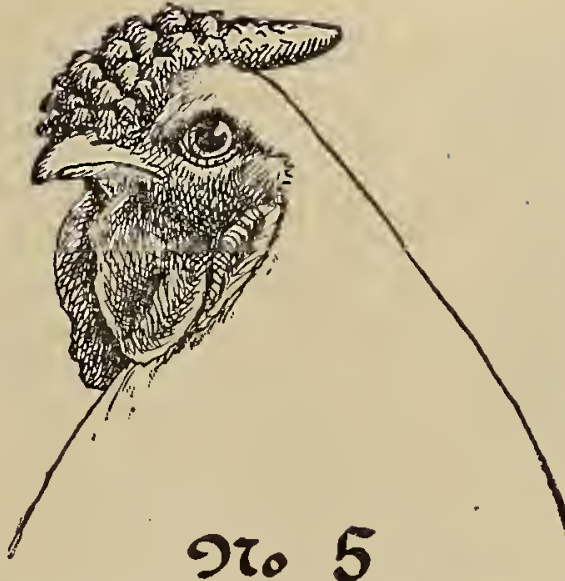

or points. The comb is too narrow and too thin in front. Such a comb should be dis. counted $2 \frac{1}{2}$ points.

Figure 6 is similar to Fig. 5, but is higher in center, forming a sort of a ridge over the head; spike fails to run down and is scantily covered with points and should be discounted 3 points.

In Fig. 7 is shown a comb that in many respects conforms closescription, but still it is defective, as it is too high in the center and corrugations are not even. A comb like this should be discounted 1 point.

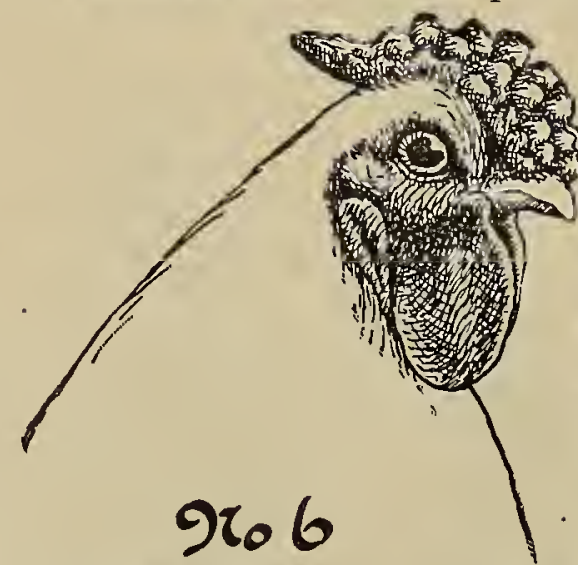

Fig. 8 is one of the old-style combs, quite popular a few years ago, and the corrugated points are invariably deep. Many of the specimens at that time had no spike at all, or if a spike, simply a corrugated point extended at the rear. We seldom see a comb of this kind now, and when we do we cut 4 points- 1 for uneven surface, $11 / 2$ for deep corrugations and $11 / 2$ for poor spike in rear.

In Fig. 9 is shown a comb something after the style of Fig. 8, but this one is wide in front, runs down over the eyes and beak, too wide in front and too

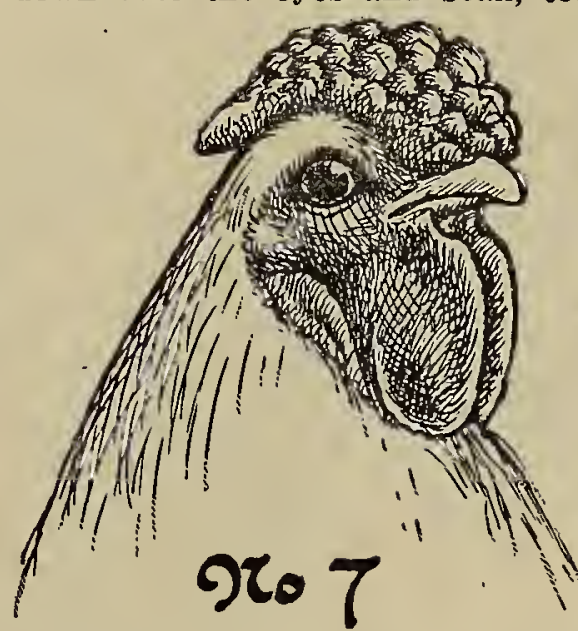
high in center. A comb like this is bad from a beeder's standpoint and will be severely discounted as a show bird. The sight is more or less obstructed and the spike in rear is slightly to one side. This comb should be discounted 3 points.

In Fig. 10 is shown a comb which is badly defective-one that the average breeder would say is imaginary and ex. ists only in the eye of the artist. But such is not the case. Combs as bad, and sometimes worse are found in the show room. It is too big, extends down over the eyes almost to the tip of the beak, is hollow in the center and all the rear portion is smooth on

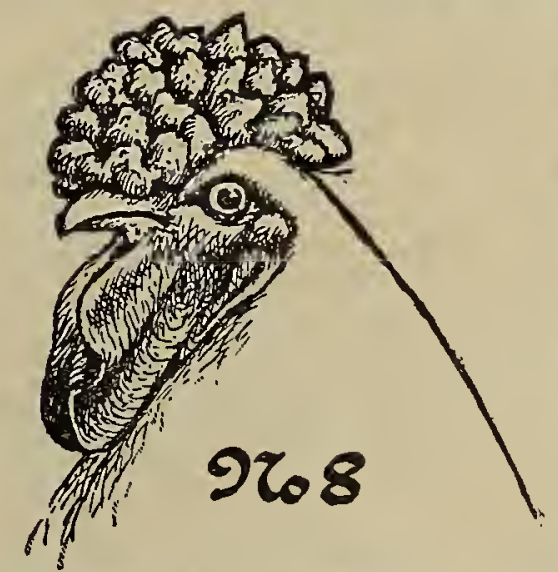
top. This comb would disqualify the specimen, as it projects over the eye far enough to obstruct the sight, and should a cut be allowed this comb would be discounted 6 points.

In Fig. 11 is shown a comb that, aside from smooth surface, is a very good one and comb that will reproduce well in the breeding yards. This comb was a popular one with the White Wyandotte breeders several years ago, especially in females, many first prize specimens showing this smooth surface. However, as they are being bred today this should be discounted 1 point.

In Fig. 12 is shown a comb quite common in all varieties of the Wyandotte. It is hollow in the center, and that part showing depression is smooth on the surface. The comb 


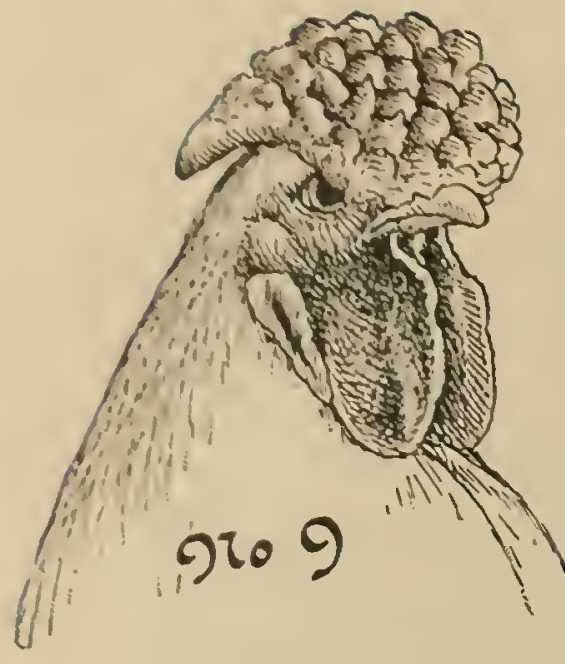

Is a finly gool one aside from the lollow center. The splike in the rear is a little bit too pronounced. ending like an independent spilie rather than tho gradual narrowing of the comb, and shonld be discointed 2 points. We have golle to considerable length in illustrating the defects in this section, due to the fact that the comb will not be taken up again in the other varicties.

Wattles and Ear Lobes.

In some respects this section is not a very important ome, as the preseut Standard has been very lenient with

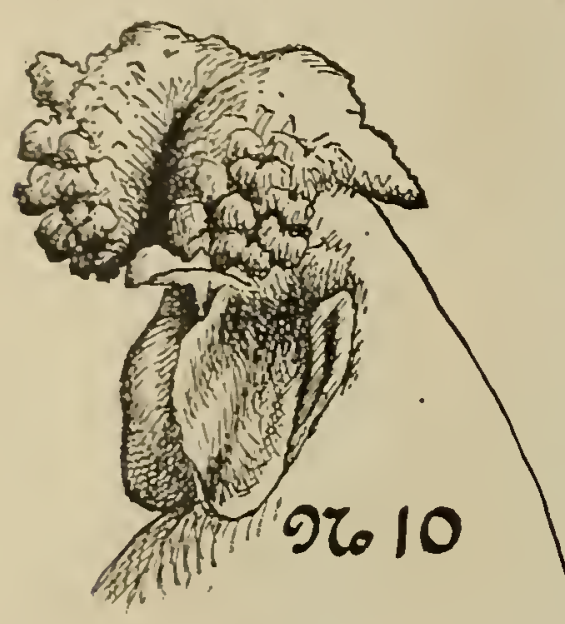
Wyandottes in all varieties in color of lobes, requiring a lobe to be half positive white before the specimen is disqualified. There is a sentiment, however, to correct this, and the next revision committee has been asked to make perm a n e $\mathrm{nt}$ white in lobes in all varieties of Wyandottes a disqualification, the same as in White Rocks. This, however, will probably never come about-in fact, it is quite likely that the next revision of the American Standard of Perfection will eliminate all disqualifications except for natural defects, and the writer

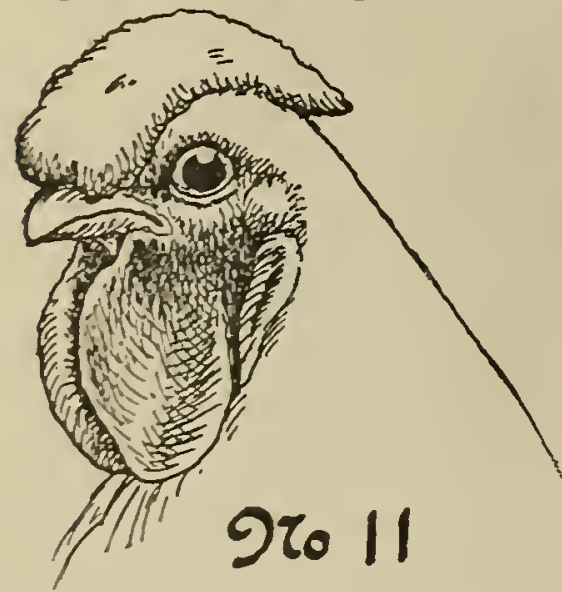
is thoroughly convinced that it is to the interest of better poultry that this be donc.

The Standard says in describing shape of wattles and ear lobes: "Wattles - Of medium length, fine in texture, well rounded. Ear lobes -Oblong in shape, well developed and smooth." This is perhaps as good a description as could be given and fits nicely the best head points that we find in our Wy. andotte males.

The ear lobes must be reasonably large in proportion to the wattles to make the entire section symmetrical.

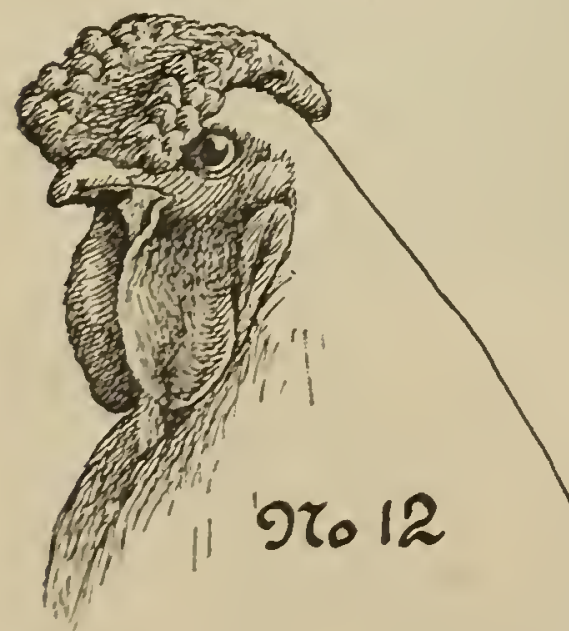

Where wattles are fold ed or wrinkled, the out is from $1 / 2$ to 1 . Where they have been torn in fighting or by accident, the out is from $1 / 4$ to $1 / 2$, as in degree. Ear lobes showing any sign of white should be discounted from $1 / 2$ to 2 , as in degree, and where lobes look suspicious, as though they might have been tampered with, with hot iron or acids of some kind to change the color, the limit of the section should be discounted and the score card so noted. In our illustration (Fig. 1) we show what we belleve to be the correct ontline for wattles and ear lobes on the males of all varieties of the Wyandottes. In our lllustrations of defective combs we will call atten- tion to some of the defective wattles and lobes as illustrited, as it miny assist the reader in forming a good general iden of value of such defects.

lin Fig. 2 are illustrated a wattle and ear lobe that shonld be discounted $1 \frac{1}{1 / 2}$ for wattles and at least $3 \%$ of a point for lobes.

In Fig. 3 is shown a wattle somewhat drawn, failing in the nicely rounded edge, and shonld be discomnted $1 / 2$ point.

In Fig. 4 wattles are too long, poorly folded and one is
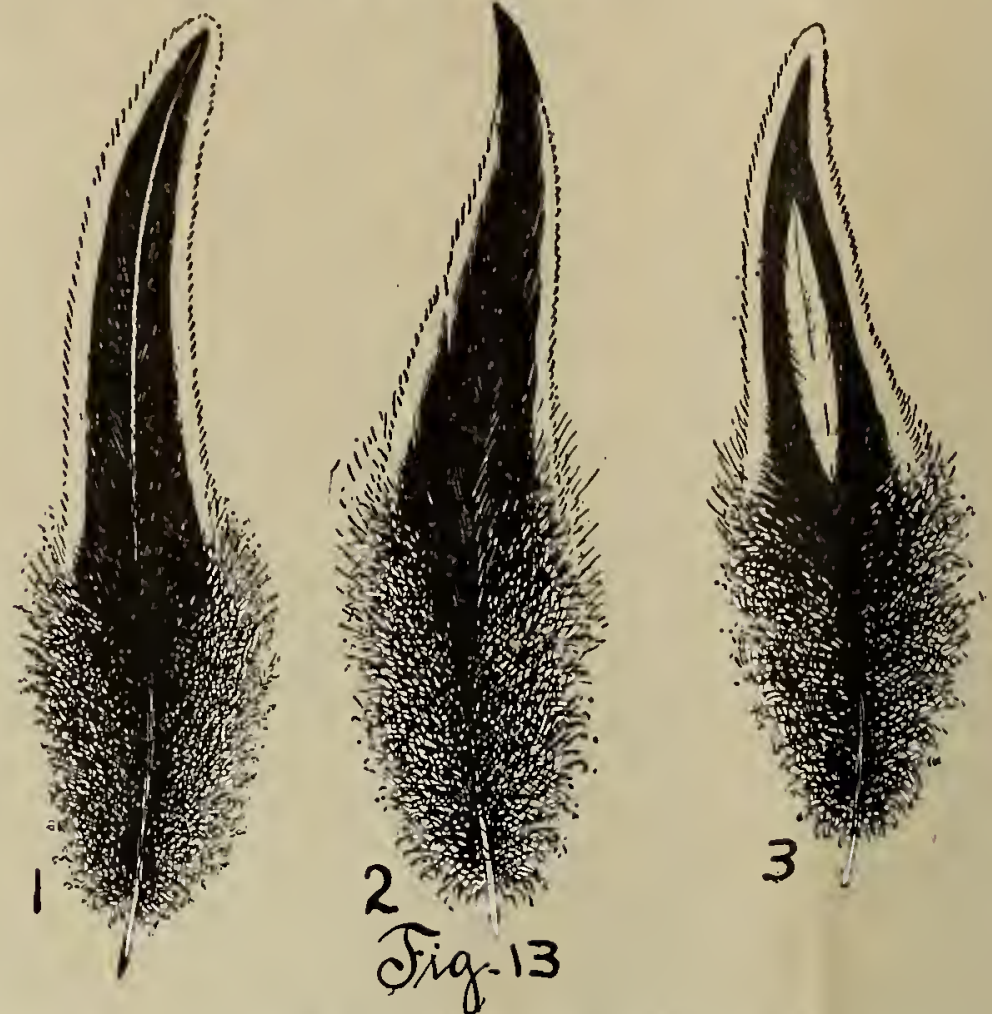

longer than the other and should be discounted $1 / 2$ point

Fig. 5 shows same defect as in Fig. $4-$ one longer than the other. While the wattles are not so long as those in Fig. 4, they are a little drawn or shriveled, and should be cut $1 \frac{1}{2}$ points.

In Fig. 6 the lobes are thin, flat and nearly straight; wattles folded and not properly developed. A wattle and lobe like these should be discounted $3 / 4$ of a point.

Fig. 7 joins poorly onto the head. It is a trifle long for the wattle and is poorly rounded at the bottom. Such a wattle should be discounted $1 / 2$ point.
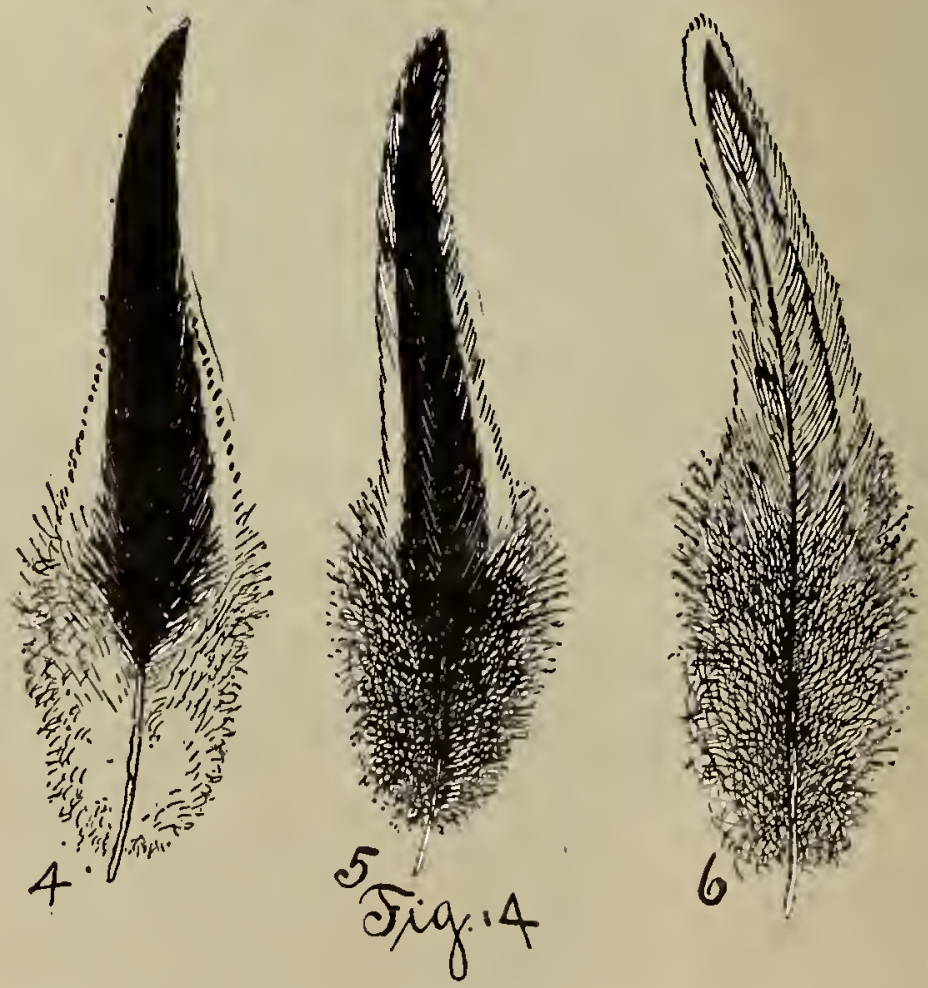

In Fig. 8 we find a long, flabby piece of meat that is joined poorly onto the head, is too wide and badly folded up. This wattle is wrong in every way and should be dis. counted 2 points.

Fig. 9 is very much after the style of Fig. 7 and would be cut accordingly.

Fig. 10 is too long, loose and badly folded and should be discounted 1 point. 
Fig. 12 shows a wattle that fits badly onto the head, is a trifle long, lobes are not well proportioned and run down into small wrinkles at the bottom. A lobe like this should be discounted $3 / 4$ of a point.

\section{Neck.}

This is one of the most important sections in our particolor breeds, and especially so in the color of males. Many breeders will discard a male with poor colored neck, no matter how strong he may be in other sections, claiming that without this section good it is only guesswork as to his power to reproduce.

The Standard is quite plain on this section, both as regards shape and color, and especially so in shape. The neck should be "short, arched; hackle, abundant." In color, "surface silvery white, with a narrow black stripe through each feather, tapering to a point near extremity of feather. The white, free from black or brown edging; shaft of feathers may be white."

This last clause is something of a puzzle, and we are at a loss to understand it, for, as it now reads, either the solid
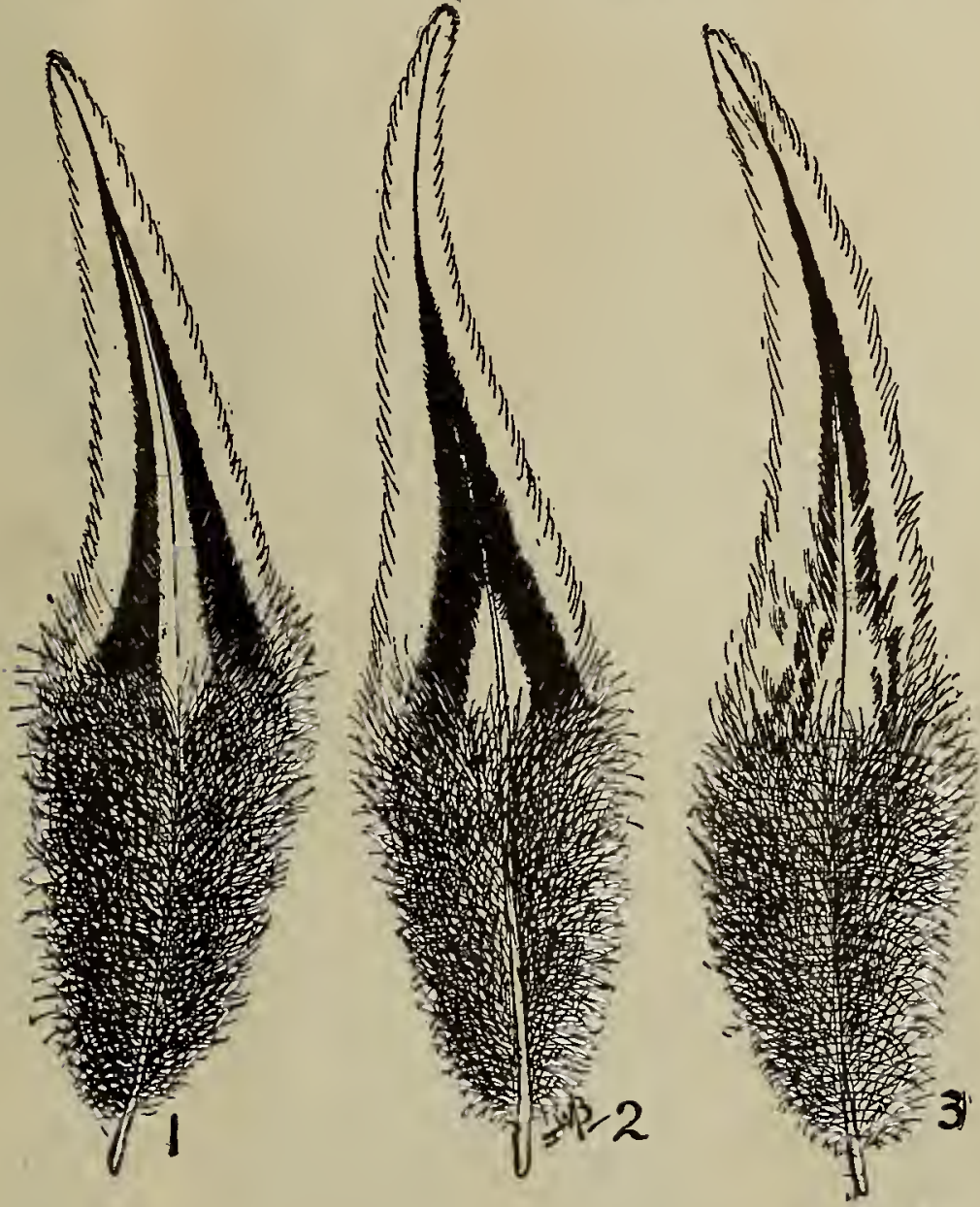

Fig. 15

black center or the feather with the white shafting should be passed without discount, provided the remainder of the reather is perfect.

I have the original typewritten report of the committee and I find the Standard wording correct but I am positive that there was a change ordered in this wording by the general committee which the stenographer undoubtedly failed to put in. My recollection of this is that the latter part of this description was made to read: "Shaft of feather white from near the center to end."* But since we have only the Standard for our guide, I would take it as it reads, but would suggest to old and young judges alike that in case of ties in scores where only one of the specimens has a white shaft to give it preference over the other, as we have found this white shafting of great value in producing the silver surface, as well as the clear open centers in both sexes.

It is seldom that we find a male bird of the Wyandotte family that is decidedly faulty in shape of neck. The most common defect is scanty feathering when the birds are in moult. For such defect, the specimen should be discounted from $1 / 2$ to $1 \frac{1 / 2}{2}$, as in degree. Where neck is too long, the out is 1 ; when too straight, from $1 / 2$ to 1 .

The correct color being hard to understand, we have

*The writer was a member of the Revision Committee. reproduced here for the information of the breeders and judges several feathers taken from the neck of birds that have been placed on exhibition within the past few years. These are found in Figs. 13 and 14.

Feather No. 1 is our ideal of a hackle feather. It is strong in undercolor, has good black center, the white runs entirely around the outside, lacing the end of leather as it should be, and the white shaft shows in proportion as we believe the Standard makers intended it should, and where you find a neck so good as this then it cannot be discounted.

Feather No. 2 is good except at the point where the white lacing fails to run around the end, giving the bird a smutty appearance at the end of hackle. A neck like this should be discounted 1 point.

Feather No. 3 is faulty in the center, the white shafting being entirely too wide, and, while valuable as a pullet breeder, should be discounted in the show room $1 / 2$ point

Feather No. 4 shows two serious defects. It is entirely too light underneath and fails in the white lacing at the end. It should be discounted 1 for the light undercolor and 1 for black at lower end of feather.
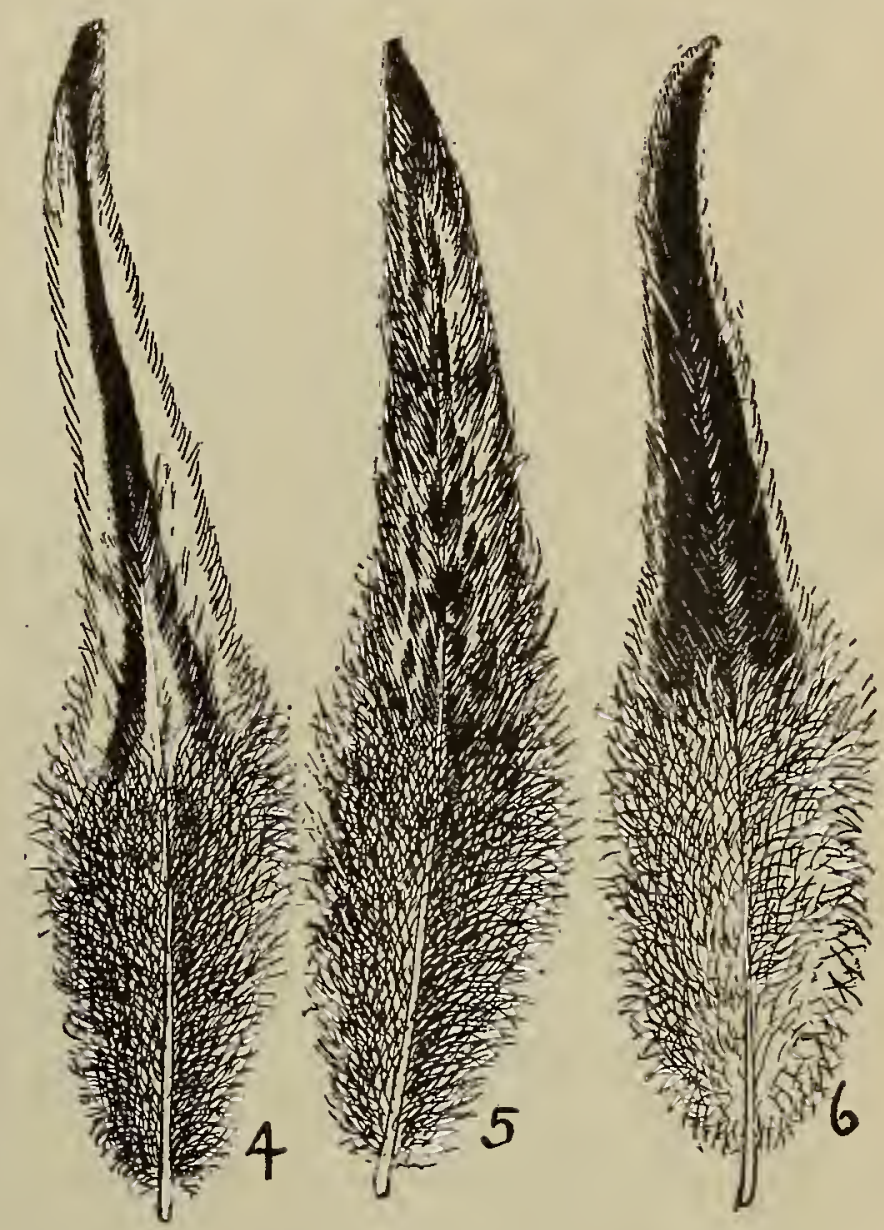

Feather No. 5 has a serious defect and one that is quite often found in the neck of Silver Wyandotte males. The black and white are fairly well proportioned, but there is a smutty, brassy end to the white, giving the neck a sort of a coppery surface color that is very objectionable and should be discounted $11 / 2$ points.

Feather No. 6 is entirely too light, both surface and under. There is no black in it; what little that does appear shows more of a bronze tinge and then runs to the surface on one side. The undercolor is.decidedly too light -in fact, both the white and black are defective, and it should be discounted $31 / 2$ points.

The Standard valuation for color in this section is 6 points, and where the defect is only in the one color, then 3 would be the limit to be cut but in this feather you can discount both the white and black and can exceed the 50 per cent. limit allowed in the scale.

Back.

No section in any variety is of so much importance as the back, both in shape and color. This the Revision Committee fully realized when they made a change in the scale of points, allowing 6 for shape and 6 for color in each of the American varieties. This gives more prominence to back than any other section of a fowl and it is as it should be. 
In shane the standard describes the back as "short brond. flat at shoulders: suddle, broad, full, rising with concale streen to tailo" ln color: "Back. silvery white; saddle silvery white with a black stripe throurh each canther. havins a lapering dimond-shaped center of white; mulercolor, ditrik slate."

ln the gronl of feathers (Fig. 15) will he found a. number that will vive the breder and judge is firir sample of deals as well as several of the defective ones that will be found in the breeders yards or in the exhibition room.

The short foather's composing the back of the malethat is, the fenthers between wing bows, below the capeare black with white lacing. From the center to rear of back they sradually lengthen ont until in the saddle we find a feather long and tapering, dark in undercolor, nicely laced on the ontside with white, with black center, showing a diamond-shape of white in center of black.

This is illustrated in feather No. 1 , and is our idea of the colrect color in Silver Wrandotte males.

In feather No. 2 we find the same feather, only the diamond-shaped center is not long enough, showing entirely too much black. covering up one of the most importanc is well as one of the handsomest features on the back of male. Feather No. 2 should be discounted $1 / 2$ point.

In feather No. 3 we find a defect quite common with the Triandotte and especially those that show nice surface color. Quite often the undercolor runs light and the black is broken up, white running through, the two colors mingling. A back showing feathers like No. 3 should be discounted $1 \frac{1}{2}$ points.

Feather No. 4 has much the same defect, but is even Trorse, as the outside, or end of feather, shows a black, smutty surface, giving the back a rusty appearance, and should be discounted 2 points.

Feather No. 5, while more or less exaggerated, is one that will be found in some specimens. There is no sound color in any part. It is too light underneath, is muddy on the surface, the black and white are mixed. Both colors being defective, the section should be discounted 4 points.

Feather No. 6 is one that is lacking in the diamondshaped center is too white underneath, and, from a breeder's standpoint, would be absolutely worthless. This bird should be cut 1 for light undercolor, 1 for absence of diamond-shaped center of white in black and 1 for width of black, running too much to a point and showing too narrow an edging.

The shape of back is just as important as the colorin fact, it is the keystone to the shape structure, and un less this section is good we cannot expect any large per cent. of good-shaped specimens, no matter how well the bird may be mated; and it is well to note here that females give you the size, but males give you the shape, not alone in males, but in females as well.

In Fig. 16 is shown a back that is entirely too long and too narrow. It is more like the Plymouth Rock type in length, but not wide enough for this variety. A Wyandotte of any variety showing a back like this should be discounted 2 points.

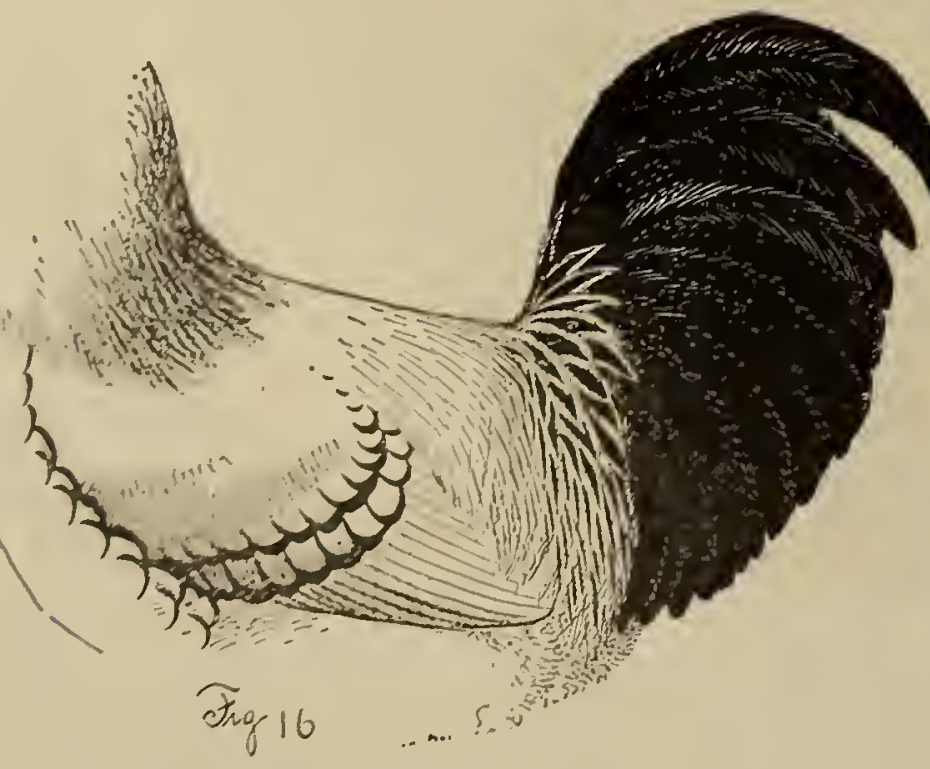

k1g. 17 shows another defect common in this breed -back is too straight, failing in the concave sweep so much desired in back of both sexes. It is broad enough, and

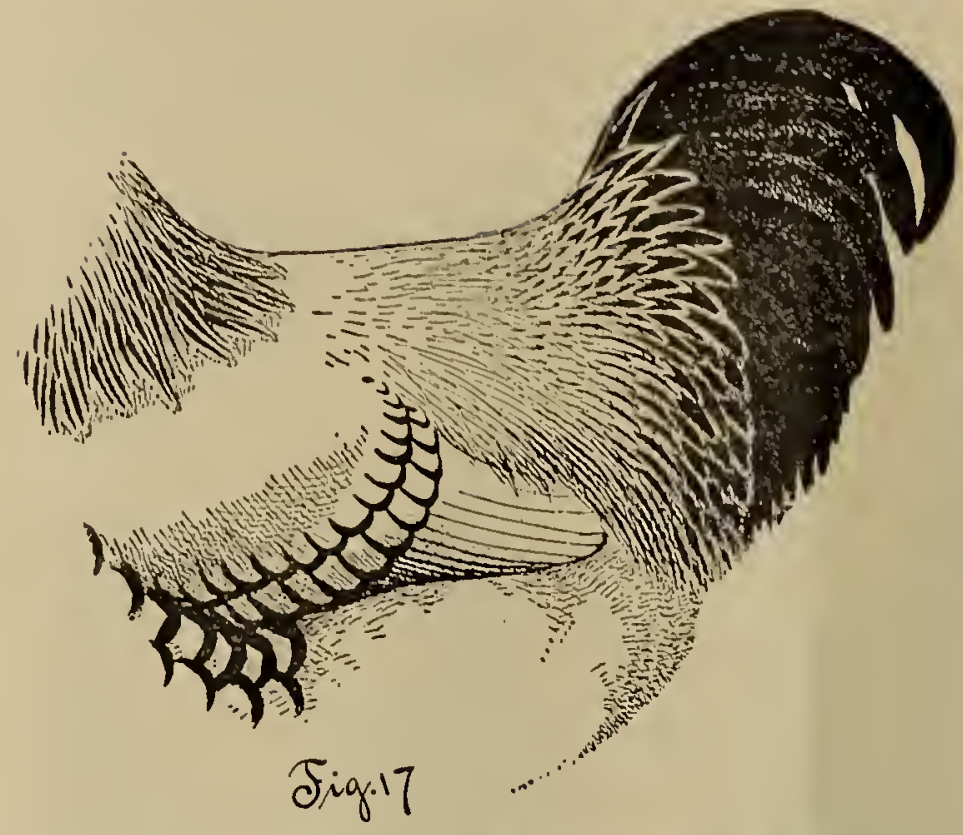

about the right length, but is entirely too straight, and should be discounted 1 point.

Fig 18 shows one of the most serious defects to be found in any breed of fowls. The back is what we call

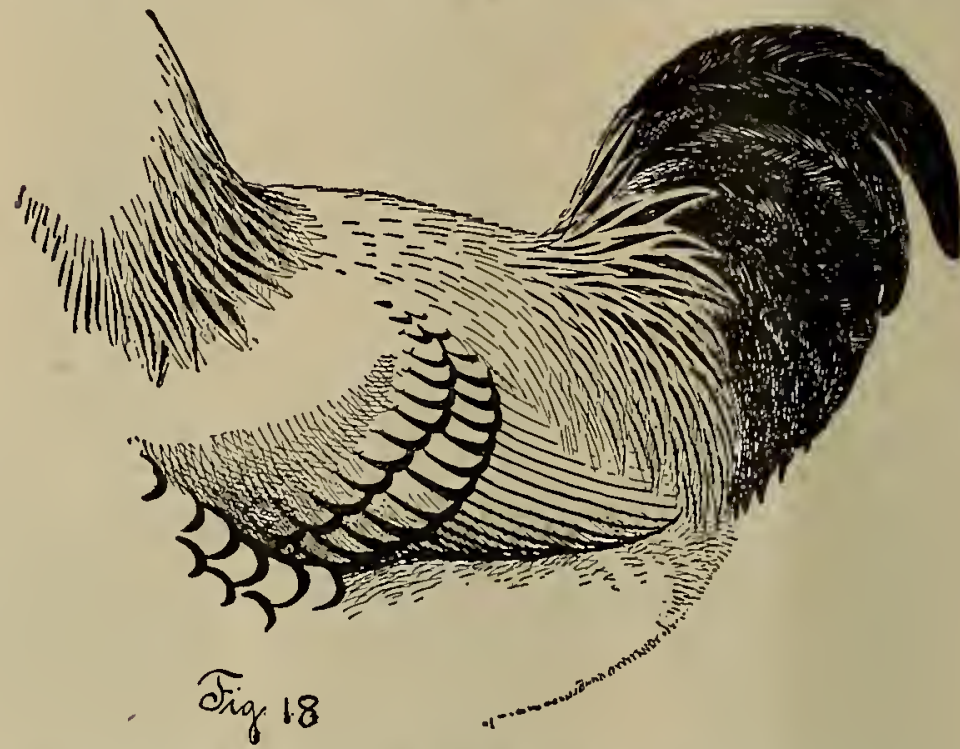

"roached"-higher in the center than it is in the front or rear-a serious objection from a breeding standpoint and an eyesore in the show room, and should be discounted 3 points.

Wings.

This section is valued at 10 points in each of the American varieties, and subdivided-4 for shape and 6 for color color being decidedly the most important and a section in many of the American breeds that has first consideration by breeders and judges alike.

The wing of a Wyandotte male is a very important section from a color standpoint, owing to the fact that for a number of years the Standard has called for a laced bird with a spangled wing bar, and a great deal of trouble is yet experienced by breeders in correcting this error.

The Standard, in describing the color of Silver Wyandotte male, says: "Primaries, black, lower edge white; secondaries, black, lower half of outer web white, with a narrow black edging, wider at tip; wing coverts, upper web black, lower web white, with a narrow black stripe along the edge that widens as it approaches the tip, forming a double bar of laced feathers across wing; wingbows, silvery white; undercolor, dark slate."

While on this subject we wish to call attention to the feathers shown in color plate of male. In the feather illustrating the laced wing bar, shown separately at rear of bird, the white should cross more over the shaft, showing about one-fourth more white than is illustrated in the feather. This error was not noticed until plates had been made. The black lacing on feather is wider on one side than the other, but not quite in proportion to the illustration.

We call attention to this so that breeders and judges may understand that more white will show in the laced bar than is shown in this plate. 


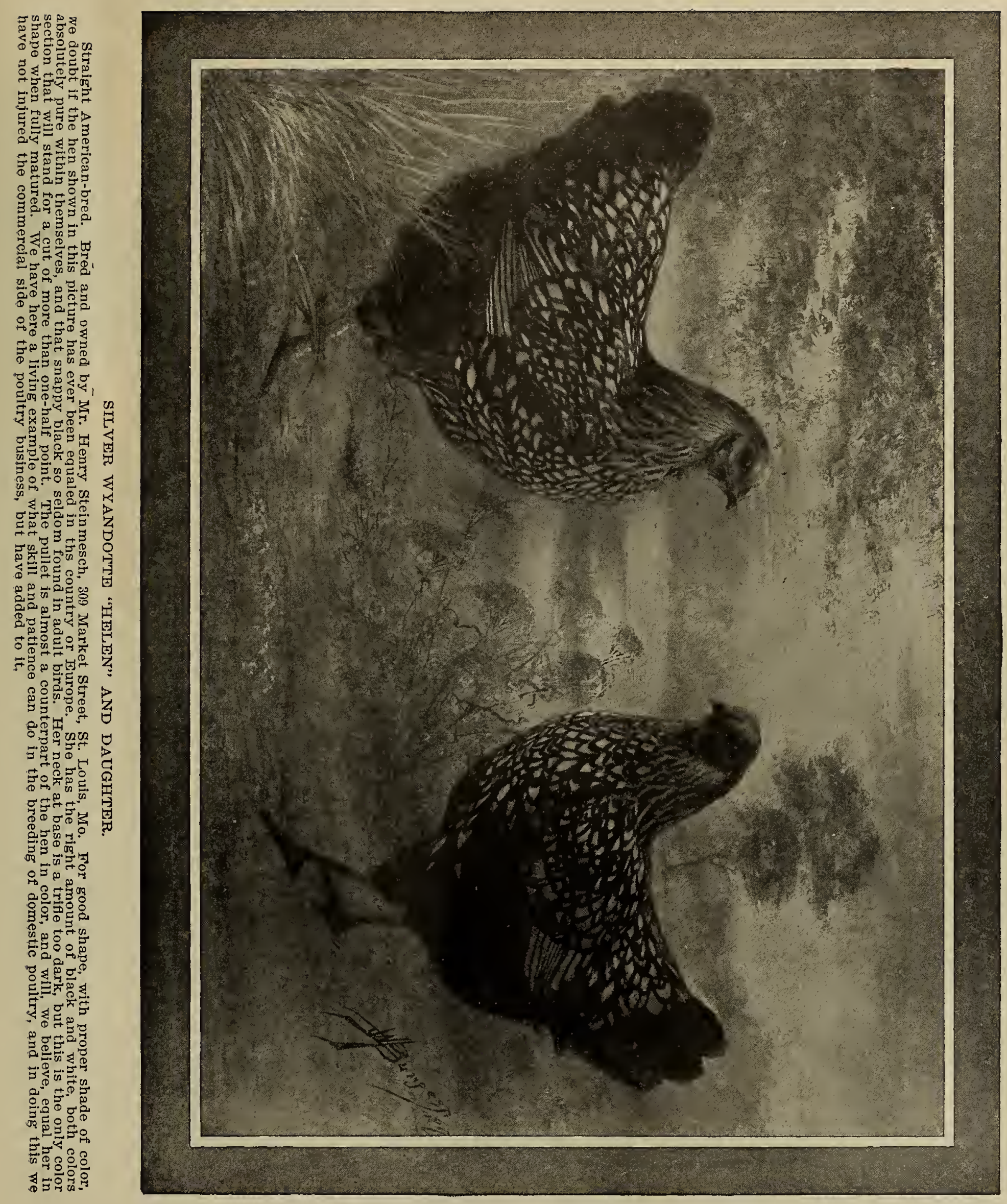


In some of the best specimens that we liave found the secondaries as well ins the ofler foither's directly under. nearli the wing slow a lacing of black on outer edge of whife, simllar to the sebriglit bimtan. and this lacing is

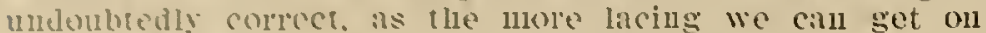
wins the eisier it is to ubtain it on other sections.

In Fin. 1!) is slown a will tlat conforms to onr

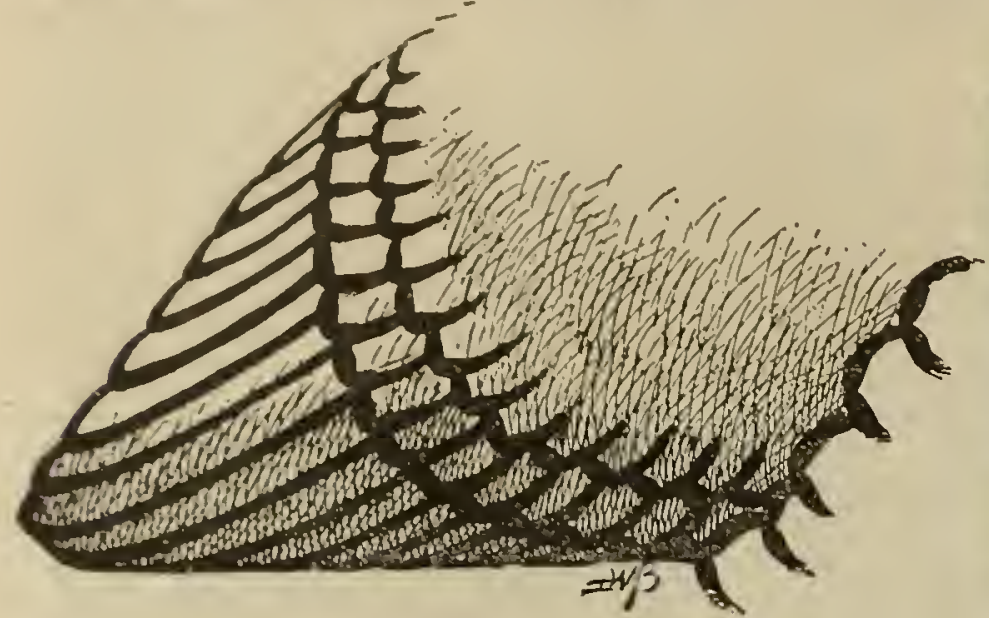

Fig. 19

wide. but if we could get wings as well laced as this we would be satisfied that we were maliing a step in the right direction, and such a wing should not be discounted.

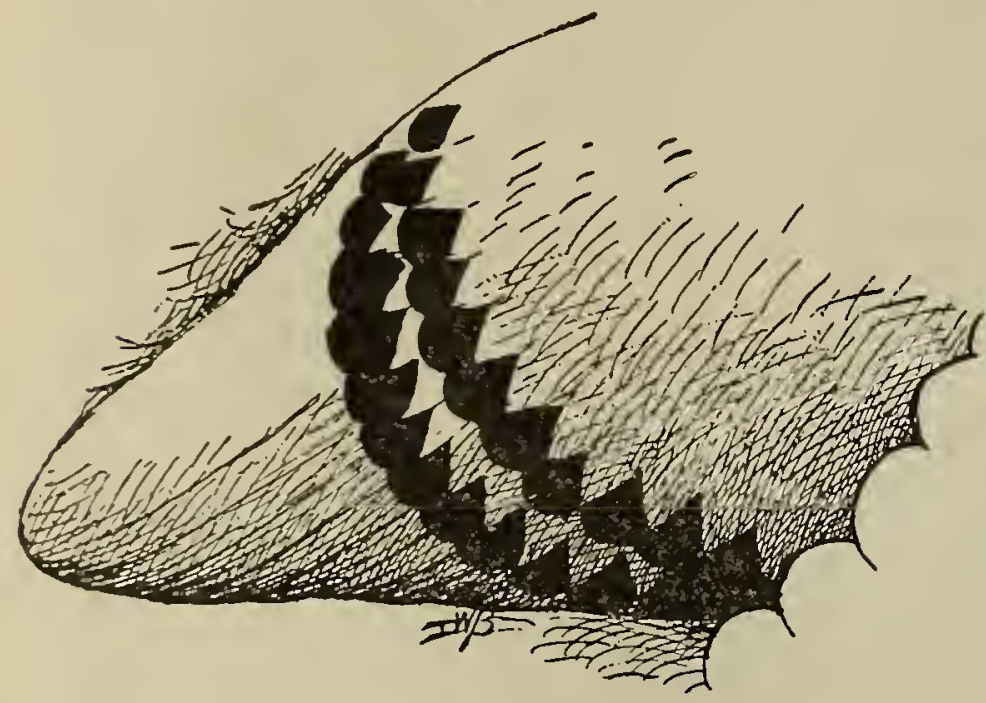

Fig. 20 .

In Fig, 20 is shown one of our old-style silver TV randotte wings_- spangled bar, no lacing on secondaries and just such wings as we considered ideal some fifteen years ago. A male with a wing like this today would not have a look in the show room and the breeders would discard it as worth only its value on the market. It should be discounted 2 points.

In studying the many males exhibited at the different shows the past few years we find that the Golden Wyandotte breeders have surpassed the Silvers in correct lacing. This is especially true in wings, and in Fig. 21 is shown a Golden Wyandotte male wing that is laced like that of a

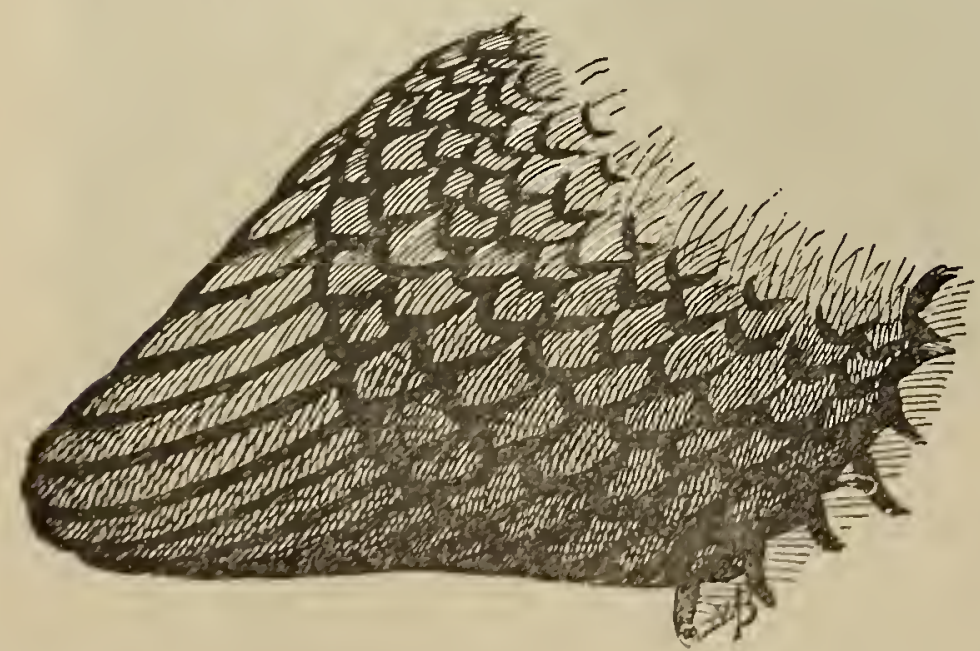

Flg. 21 pullet, and this is not an overdrawn picture, as we have found suecimens showhy as good lacing on wing bow as the one illustrated, and in one case a Silver cock bird was shown at Lansing, Mich., equally as good-in fict, a len-feathered miale from comb to end of tail, very nuch after the style of our Silver Sebrichts.

In Fig. 22 is slown a group of featliers illustrating some of the defects common in liundreds of our Silver Wrandottes.
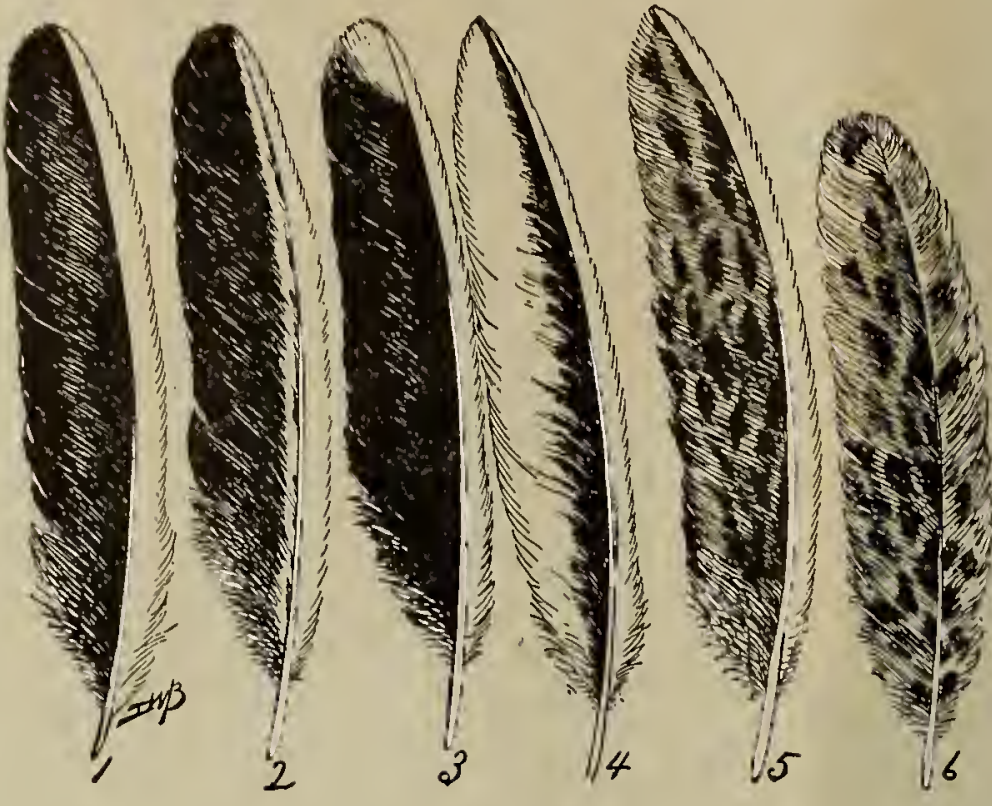

Fig. 2z.

Feather No, 1 would fill our Standard description of flight feathers.

Feather No. 2 shows tracing of white. near the shaft and should be discounted $1 / 2$ point.

Feather No. 3 is too white at tips and should be discounted $1 / 2$ point.

Feather No. 4 is very defective, showing only a trace of black along the shafts, and should be discounted 2 points.

Feather No. 5 shows muddy color, the black and white intermixing, more black than white, and in both Wyandottes and Brahmas would be considered by the breeders a serious defect, and should be discounted 2 points.

Feather No. 6 shows a secondary with the same defect and one that is sometimes found on males of this va. riety, and should be discounted $1 \frac{1 / 2}{\text { points. }}$

In making these deductions it is well for the readers to bear in mind that these discounts would be made if all other parts of the wing were perfect in color, and it is seldom that two or more of these defects appear on the same wing, but in this, as in other sections that are subdivided. you can only cut to the limit the number of points allowed, and in scoring either the Silver or Golden Wyandottes the judge must remember that there are only 6 points allowed for color, and that three of them go to white or gold and three to black, and when a defect shows. in only one of these colors the discount must be made accordingly. As for, illustration, should the black be all good and only the white defective, no matter how bad it might be, it can be cut only 3 points.

\section{Tail.}

This is another section where an addition has been made to the points allowed for color, and instead of having four, as in the old Standard, five points are allowed. This was hardly necessary in Wyandottes, but was considered of vast importance in Plymouth Rocks. But it is well at all times for the judges to remember in scoring by the present Standard that there are five points, and the per. centage must be figured accordingly.

The color of tail of the Silver and Golden Wyandottes. should be glossy black; sickles, same color; tail coverts, black; lesser coverts, black with an edge of white, or gold in the Golden variety.

In view of the fact that this section is usually good, we call attention only to such defects as are most commonly met with.

There are cases, especially in cock birds, where the base of sickles shows white; if only slightly, the discount would be only $1 / 2$ point; if the white in sickles shows beyond the tail coverts, the out would be 1 ; if main tail shows white at base, the discount would be from $1 / 2$ to $11 / 2$, as in degree. 
If breeders are careful to look after the color of their breeding males, keeping always the slate undercolor in mind, there would be little trouble experienced in this section.
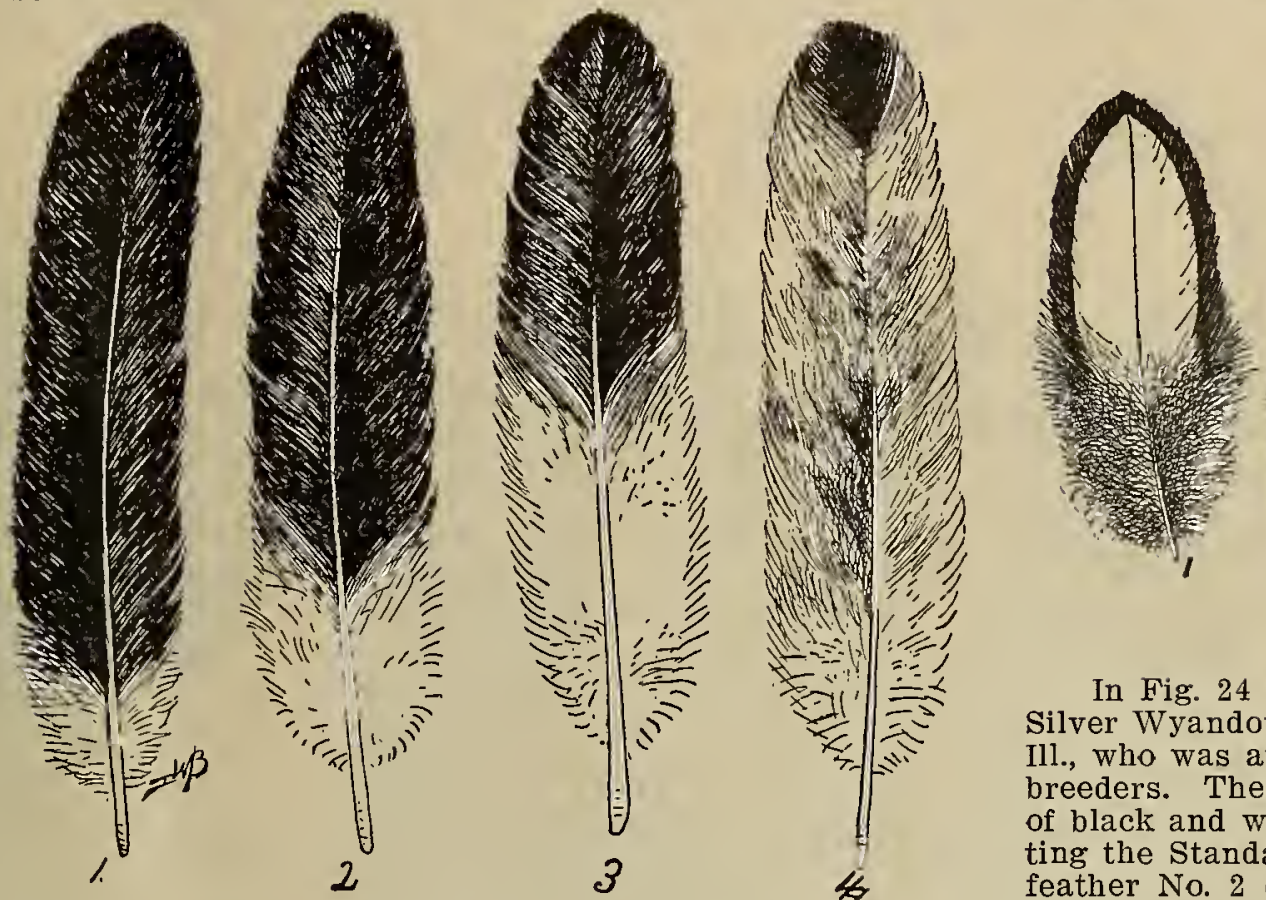

color of slate, realizing that if we get away from the darl in this section we will invariably run too light on surface and eventually lose the most beautiful characteristic of the breed-i. e., the well defined black lacing.

Fig. 23.

To give the amateurs a better idea as to the valuation of these defects, we here illustrate four feathers selected from the main tail of a Wyandotte male. (See Fig. 23.)

Feather No. 1 shows a slight tracing of white at base and would be discounted $1 / 2$ point.

Feather No. 2 shows quite a bit of white and would be discounted 1 point.

Feather No. 3 is nearly half white, still shows some black at the tip, and would be discounted $1 \frac{1}{2}$ points.

Feather No. 4 is nearly all white; what little black there is in it is only strealied through the white, making the section really worse than if no black at all, and should be discounted $2 \frac{1}{2}$ points.

\section{Breast.}

Next to back, breast is the most important section of the Wyandotte, so far as shape is concerned. It is also of great importance as regards color, and especially is this true in males.

To secure good open centers of white with a distinct outer lacing of black, without having the white flecked with black or without a lacing of white on outside of black, is the aim of every Wyandotte breeder; and in describing the color of this section they have set themselves a task that they have found it far from easy to accomplish.

When we find a good silvery surface on neck, back and shoulders, we usually find more or less white in undercolor; and with this white comes another defect in the form of a narrow white lacing on the lower edge of black on breast and body. On the other hand if we breed our birds too dark, and fail in the silvery surface color, we find the white centers in breast are too small and fail badly on body and thighs.

The aim of the Wyandotte breeder is to produce a specimen with clear, open centers on breast, with a very distinct narrow outside lacing of black that carries well down onto the body, the centers gradually growing smaller as they approach the latter. Thighs should have the same characteristics of markings and carried down to hock joints.

The Standard allows 10 points for this section, and divides them equally between color and shape. In describing the color of this section in the Silver Wyandottes (and it is well to remember that the same description will fit the Goldens) the Standard says: "Web of feather, black, with large, oval-shaped white center; lacing, lustrous black, sharply defined and free from white edging, the white centers free from black or brown; under color, dark slate."

In describing body the same description is given, except filling in, where the description is "dark slate," powdered with gray; under color, dark slate. It will be noted in the description of color all the way through that the Standard makers are careful to call attention to the under
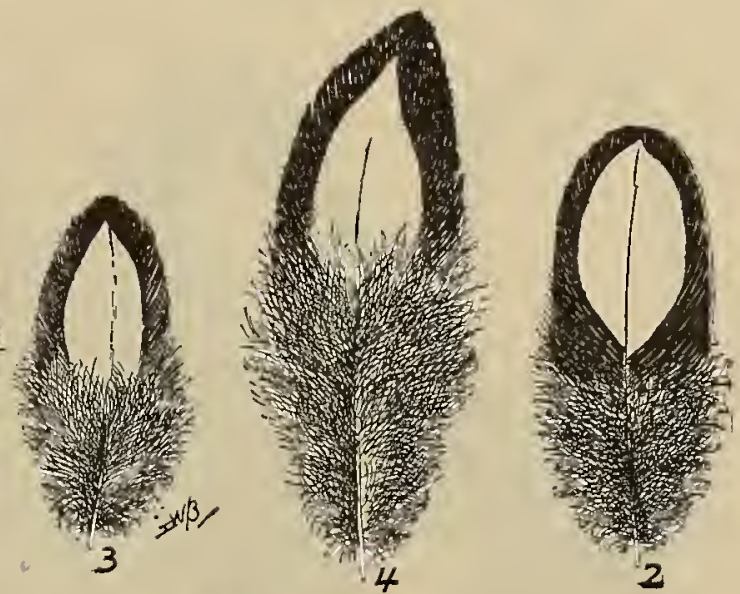

Fig 24.

In Fig. 24 we illustrate some feathers selected from a Silver Wyandotte male owned by Mr. A. C. LeDuc, Chenoa, Ill., who was at one time considered one of the best Silver breeders. These feathers show about the right proportion of black and white. Breast feather No. 1 comes nearer fitting the Standard description of oval-shaped centers, while feather No. 2 of the breast section is a little too pointed and black edging is not quite so even as in feather No. 1. While the illustration doesn't show it, feather No, 2 has the most intense outer edging of black I have ever found on a male bird of this variety. Feather No. 3 of this group is taken from the thigh down near the hock and shows the same style of lacing that characterizes this bird throughout. Feather No. 4 is talien from body. This feather should have more white, as the overlapping of feathers in this section hides the greater part of the white center that is displayed in the picture.

In Fig. 25 is shown a group of feathers that illustrate in part the defects that are met with in both the Silver and Golden Wyandotte male.

Feather No. 1 of this group illustrates our idea of what a perfect feather should be. It has about the right proportion of black and white, or golden and black, as the case may be.

Feather No. 2 is entirely too dark, and the overlapping of this kind of feathers gives the specimen the appearance of having almost, if not entirely, black breasts. A breast of this kind can be serviceable only as a breeder where the females run entirely too light and it is necessary to building up again, but in a show room a breast like this would be discounted $1 \frac{1 / 2}{\text { points. }}$

Feather No. 3 is good in general color, except the lacing of white on outside of black. The new Standard al. lows the judge considerable leeway in color, and a competent judge would cut a Wyandotte male showing frosted feathers like this over the entire breast section at least 2 points.

Feather No. 4 shows good open centers and about the right proportion of black at end of feather, but the narrow lacing of black on sides of feather is not sufficient and under color is entirely too light. A feather like this would be discounted 1 point.

Feather No. 5 is what we may expect if we do not watch carefully the dark under color and allow too much white to creep into our breeding stock. There is a crescent marking at the end of feather, but fails entirely in lacing underneath, and should be discounted at least $21 / 2$ points.

Feather No. 6 has the same defect as feather No. 5, but, in addition, the white center is flecked with black. Breasts like this should be discarded from the breeding pen, as they will invariably disappoint you in breeding, no matter how good your females should be, and in the show room ahould be discounted $3 \frac{1 / 2}{2}$ points.

In view of the heavy cut that is made on feather No, 6 , it is well to call attention to the fact that in using more than 50 per cent. of all the points allowed for color that we have in this feather both the white and the black are defective. If only one of them is defective you can discount only half the value of the section. In other words, if the black is all right and the white is entirely to blame, then $2 \frac{1}{2}$ would be the limit, as there are only five points add what would be termed by breeders "black blood" in 


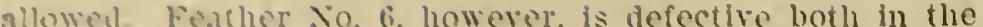
white and hlack-lins enthely a white moder color, and would arve the spedmen a blotehy or blurred surface. In fact, it is unly to be comsidered as in cull
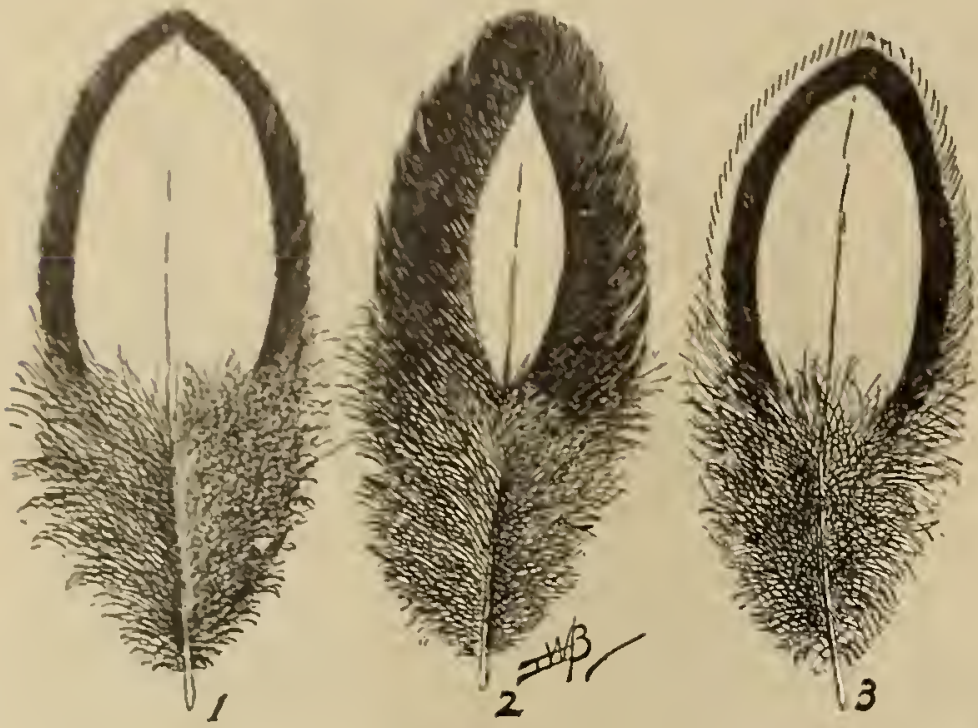

SILVER WYANDOTTE FEMALE.

There was for years such a vast difference of opinion among the leading Silver Wyandotte breeders as to the correct color of the female that amateurs were all at sea, not alone as to breeding, but they were not sure of the color, eren when they were fortunate enough to produce good ones. The bad effect of more than one ideal was not confined alone to the amateur, as some of the best breeders were producing birds of two or more shades of color, so they might better cater to the varying opinions of the several judges that might be called upon to award the prizes on this class. Some favored the large, open, white centers. others the medium in color, and others the narrow, shaft like white centers on back and wing bow. (Sec illnstration of old-time wimers.) Each breeder laid special stress on
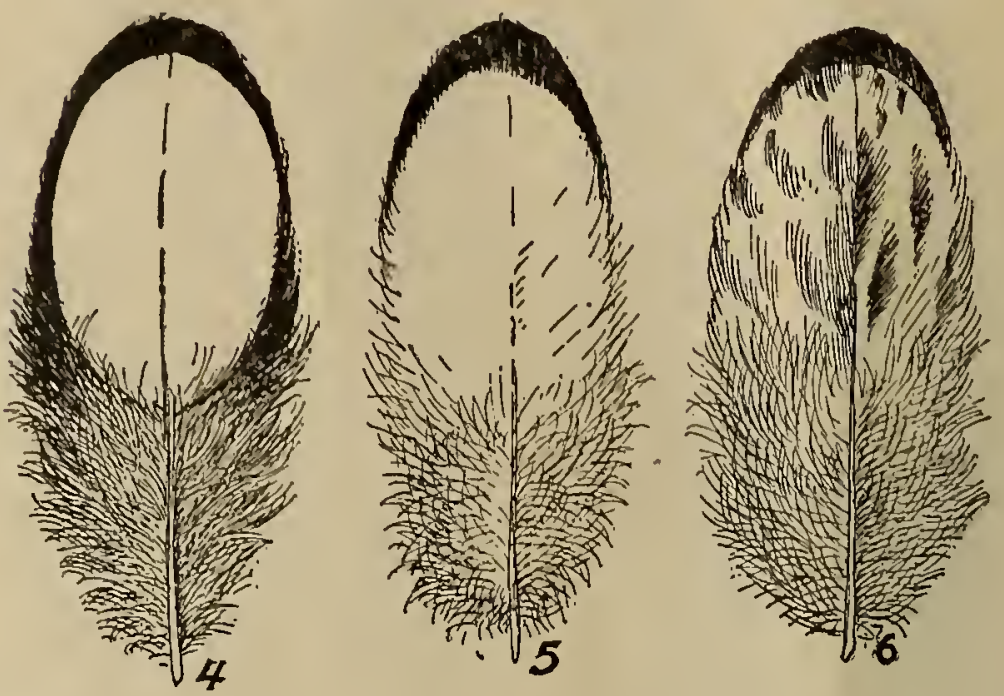

the color as bred by him, and each had a good argument. to offer as to why his ideas were correct and best for the variety.

The sections most at fault in color of female were back and wing bows. These two sections would come bad in lacing, no matter whether bred light or dark. The main defect was the prevalence of double or triple lacing, similar to that found on the back of a dark Brahma female; and quite often the white in these sections would be stippled or marked with black. That there was Dark Brahma blood in the original crosses that made the Silver Wyandotte, and that this cross is on the female side, is proven

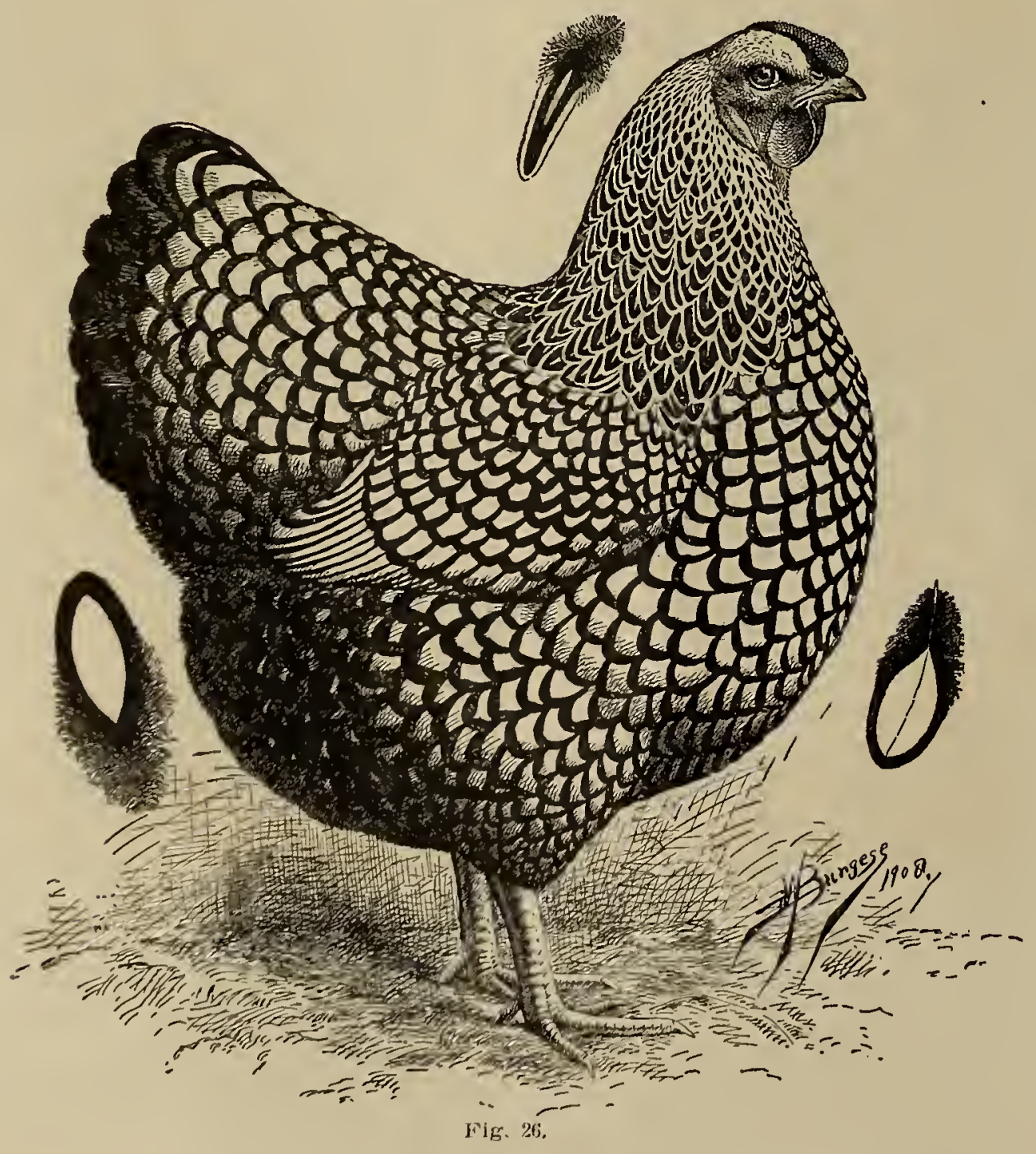

STANDARD SILVER LACED WYANDOTTE FEMALE. 


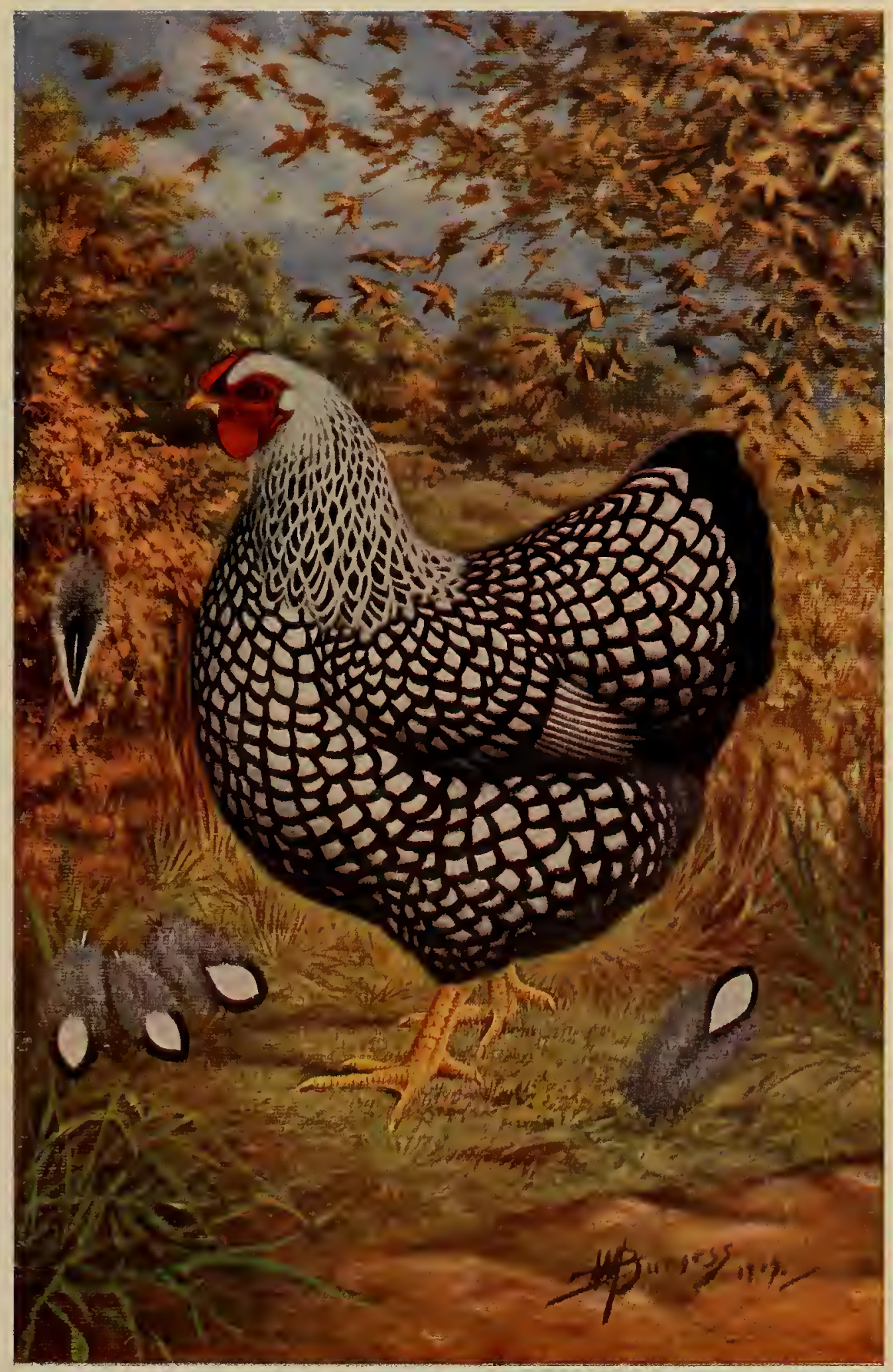

SILVER LACED WYANDOTTE FEMALE.

Drawn to Conform to Standard Shape and Color as Described by the American Standard of Perfection. 

conclusively, even up to the present time, in the yards of our oldest and most careful breeders, as we are continu. ally confronted with this triple lacing on back of hens, and sometimes it shows in the pullets from our best pens, and quite often, indeed, on the hens in their second moult.

There is one peculiarity in Silver Wyandottes that I have not found in other parti-colored birds. This is during the moulting season of the hens. Sometimes the defect will show on early hatched pullets that moult before cold weather sets in, but more commonly on hens in their second or third year. The baclis may be good-in fact, the choicest females in the yards-but as moulting begins you will be surprised to see a lot of double or triple laced feathers begin to show up, and gradually they will cover nearly the entire section and sometimes creep into the wing bows and down the breast. From the choicest fe. males of early summer we find the scrub worth eleven cents per pound in September, and many breeders become disgusted with the variety; but if they will wait a while and watch developments, they are likely to find another transformation. As winter approaches you will notice a few nicely laced feathers on the back of this same hen, and gradually these good feathers push the poor ones out, and we again find the handsome colored specimen that we were so proud of when we mated our pens in the spring.

While this change of plumage does not affect all specimens, I believe nearly, if not all, breeders have noticed this during their moulting season, and especially on the backs of hens. It seems that nature simply offers a sub. stitute in the form of the penciled feathers to act as a covering throughout moult, or until such time as the specimen is in shape to produce better ones.

In Fig 27 are shown three feathers selected from the back of the same bird at different seasons of the year. Feather No. 1 was taken just before the bird began moulting, feather No. 2 was selected during the moulting, and feather No. 3 about December 15th, or after the bird had taken on her winter garments. These feathers do not illustrate the best or the worst of the plumage, but are a fair average of the specimen during the three stages referred to. You will
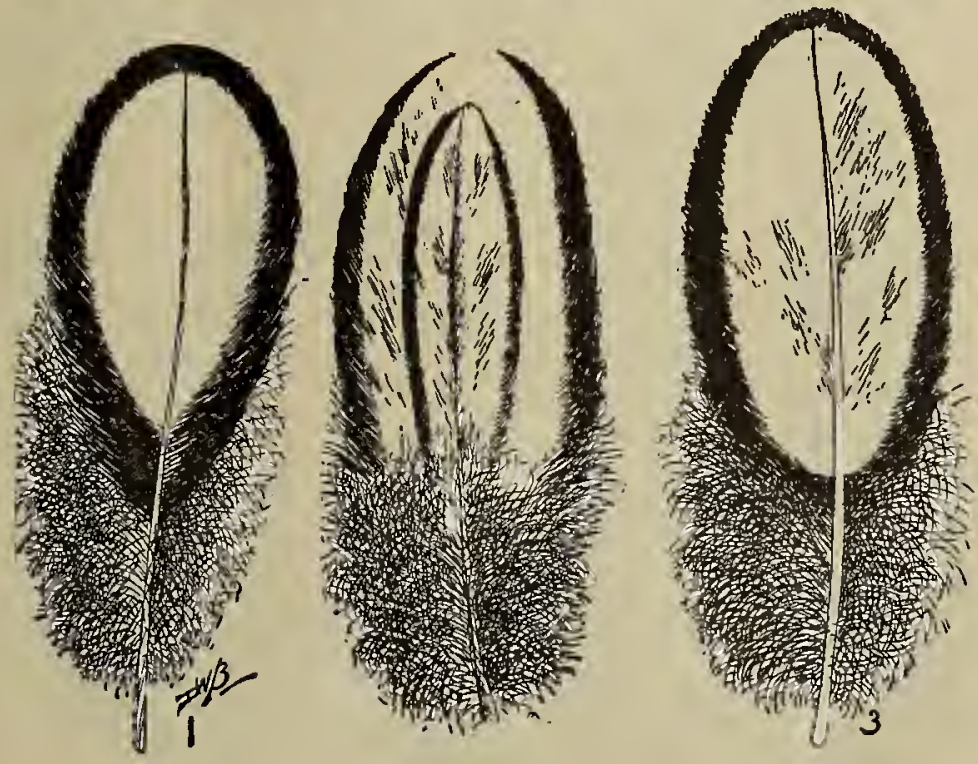

Fig. 27.

notice quite a bit of difference between feathers Nos. 1 and 3. Feather No. 1 has a heavy lacing of black on outside of white; the lower edge of white is diamond-shaped, the white following web of feather and meeting at the shaft. The white of this feather is absolutely pure-not a trace of black-and outside edge is clearly defined. Feather No. 3 has narrow edge of white at outer edge of feather, the lower edge of white is oval shaped, and there are streaks of black in the white center. Feather No. 2 is not only laced, but has nearly every bad feature found in the color of this variety. The top of feather is white, and the entire feather has that faded-out look so utterly disliked by all Silver breeders.

The Standard, in describing the color of the back section of Silver Wyandotte females, says: "Web of feathers, lustrous black, with large, oval-shaped white centers, free from black or brown, the black lacing sharply defined and free from white edging; under color, dark slate."

The reader will note that the Standard describes the white center as large and oval-shaped, and we feel that the committee acted wisely in so describing it, as, from the comal-shaped centers, we have been able to produce our best shcw specimens.
In Fig. 28 are shown two distinct types of feathers, and before proceeding to discuss different sections, to de-
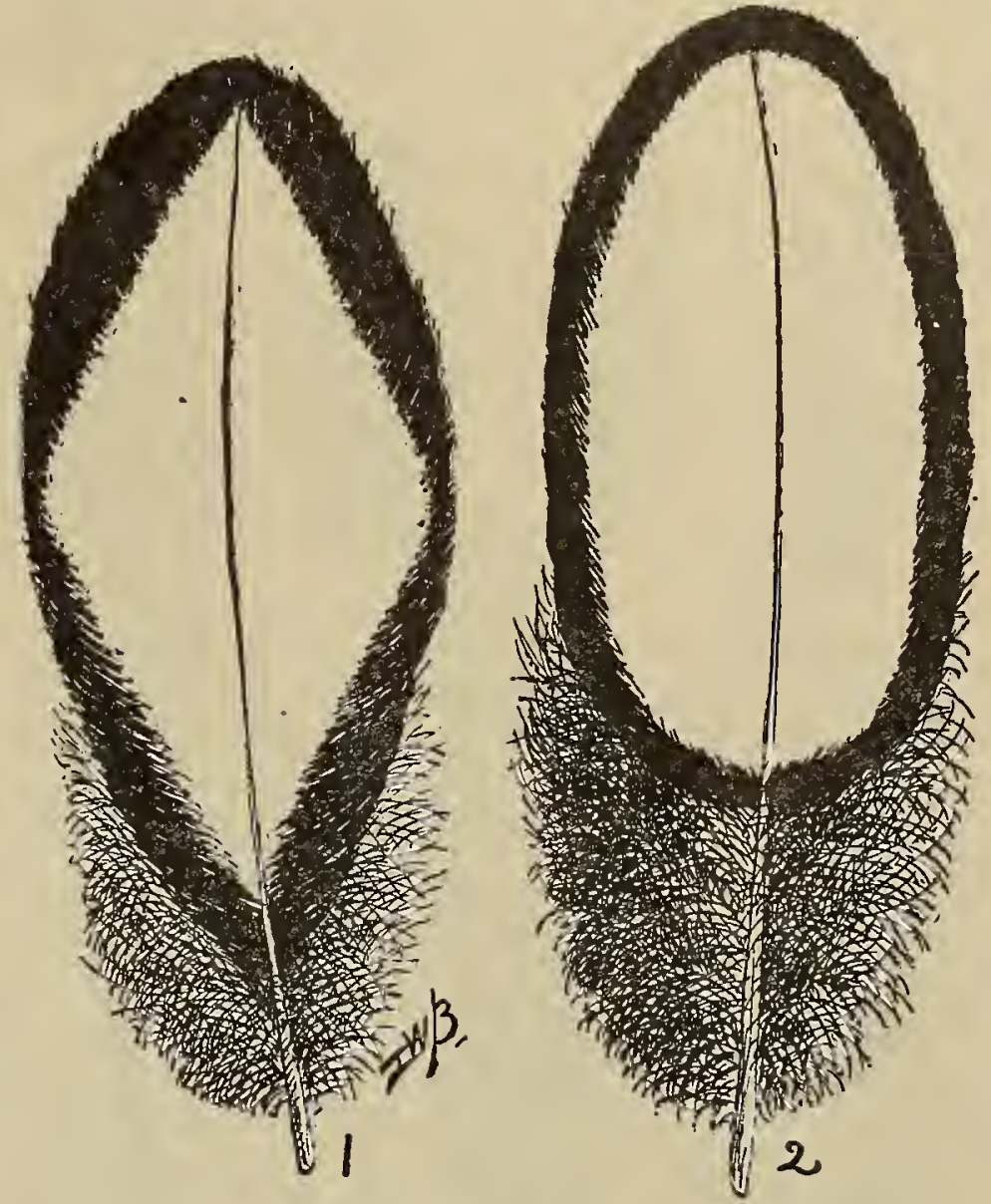

Fig. 28.

scribe and illustrate the defects, it is well to study these two feathers and get a better understanding in regard to them.

Feather No. 1 has the diamond-shaped center with only a small margin of black on the sides, and is somewhat lacking in under color, the white extending too far down in the web portion. Feather No. 1 is rather handsome when viewed by itself, but it will not hold during moult, and there does not seem to be enough black in it to reproduce in the hen; the white will break through in the two sides, leaving a crescentic finish to the tips; the black will fade at the end, losing the luster so much desired by the breeders of this variety.

In feather No. 2 we find the large oval-shaped center described in the Standard. The black edging on surface shows the same width around the upper edge of feather and along the sides, but this white does not extend so far down as in feather No. 1, showing more slate in under color and a better luster to surface. A feather like No. 2 will hold its color during the season and is fan more likely to moult in well from year to year-in fact, it is the feather that our Standard makers believe to be best for this variety, and one that every breeder should strive to obtain.

\section{Neck.}

In all varieties of parti-colored birds there is considerable stress laid on color of neck; in fact, many breeders will examine this section first when considering a specimen for the breeding pen, both male and female, and many birds otherwise good are discarded on account of defective color in this section. That a well laced neck on a Silver Wyandotte, male or female, adds much to the beauty, goes without saying, but it is just as true that the best laced females do not always make the best breeders. This the old-timers have learned and quite often birds that an amateur would consider just the proper ones to breed from are thrown out of the breeding yards.

In Fig. 29 are shown four neck feathers, reproduced here to illustrate this point.

Feather No. 3 fits the Standard description for color, and is described as follows: "Silvery white, with a black stripe through each feather, tapering to a point near extremity of feather; white, free from black or brown edging; shafts of feathers may be white; under color, dark slate." 
The noder will unce that the Stamdard says the sluafts

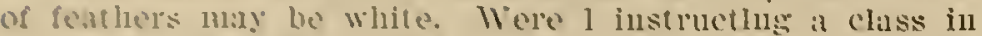
breving silver 11 yalulotes, I would so still further and

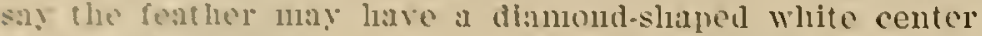
w115 .15 if showed a sood dilli under color, with correct outside lacing.
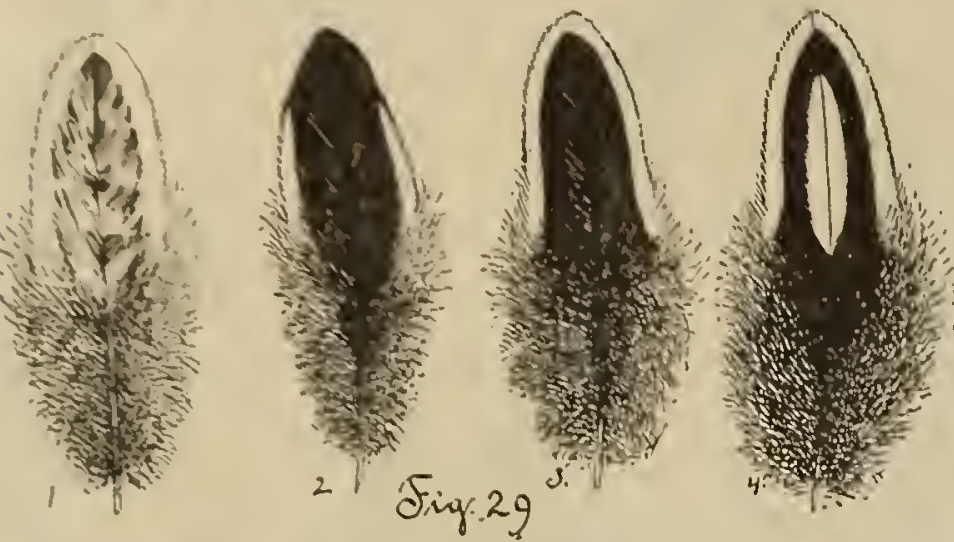

Feather No. 4 would be my ideal for a breeding female, especially were I expecting good open lacilg on back, breast and wiug bows of pullets. In the Standard description of color, you will note these words: "Under color, dark slate." Don't overlook this important feature if you wish to establish a strain of reliable breeders. Remember that pule black is just as essential as pure white. I would cut blos'n, ol l'usty color, in black just as much as I would brass. or straw color, in white. Always lieep two things in mind in breeding Silver Wyandottes if you expect success: Filst, a good slate under color in all sections; second, a nice, clean outer lacing, free from foreign color.

Aroid using a male or female with a hackle feather, like feather's Nos. 1 and 2 in Fig. 29. Feather No. 1 is too light, lias no distinct lacing, the black and white are both defective, and should be discounted at least 4 points. Featler No. 2 has a defect that was at one time quite common in this variety, the black running to the end of the feather and lacing stopping short, giving the neck a smutty, black ring at base of hackle. This defect is not so common now as formerly, but we occasionally find specimens showing it in more or less degree, and when such defects do appear they should be severely punished, and I would advise breeders to discard them entirely where the best of results are expected. When an extreme mating is desired, they can be used with fairly good results - that is,
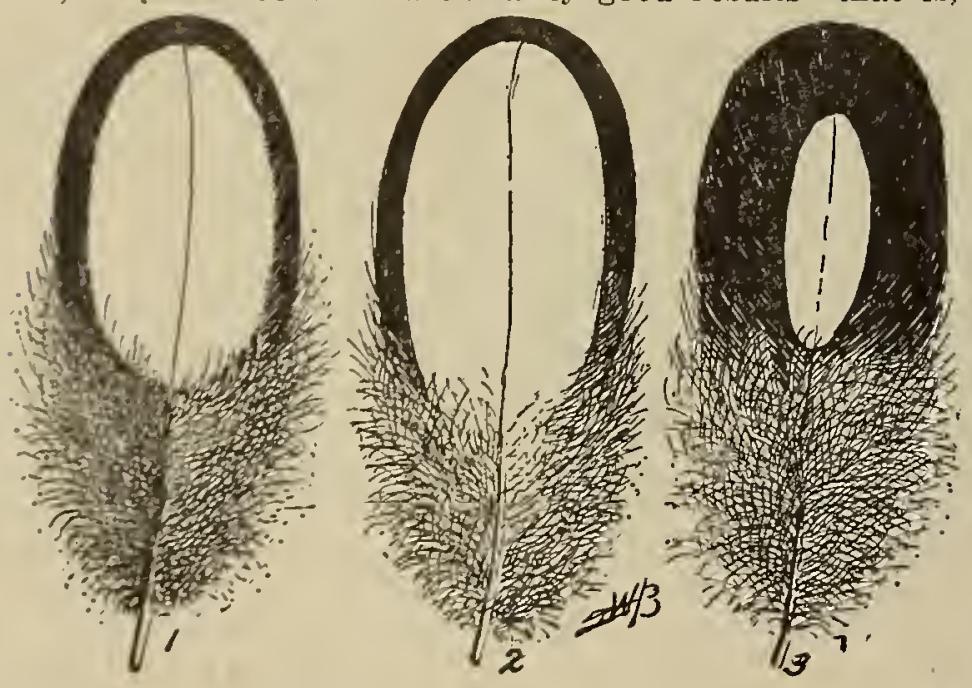

Fig. 30

when the opposite sex is very light in hackle. This style of lacin's might be used for one cross in order to strengthen the black, but even then it is not sure of success, and, as a rule, the best results follow by using the colors as defcrlbed by the Standard. A neck showing feathers like No. 2 should be cut $1 \frac{1 / 2}{2}$ points.

\section{Back.}

In all parti-colored breeds back color is of vast im. portance, and it is rare indeed that a specimen of any of the varfeties passes without discount in this section.

Silver Wyandotte fomales are especially faulty in this, no matter how good they may bo in the breast and wing hrows. To find a hen or pullet that is absolutely correct in back lacin:s is so rare that it causes no end of comment and is talked of for months by the leading breeders of this varlety. There are so many little defects that creep into this one section tliat one is sometimes tempted to advocate the change of the color description and see if we call decide on something that naturo will assist in perfectins. But to change the color, in our opinion, would materially injure the beauty of the bird, as nice, open white centers, free from black penciling, witl distinct onter lacing of jet black with sound under color, is the handsomest pluniage that we could adopt. The old Dark Bralmia blood tlat was in the original cross that made up our Silver Wy. andotte will come to the surface, and this section seems to liave a neculiar tendency to slow it nore than all others.

'To arrive at perfection in this breed we must study the matings as carefully as an expert painter would study col. ors in mixing for a particular shade. We must lave a suffcient anount of white to make the nice oval centers. At the same time we cannot overlook the dark under color if we expect the black to hold.

In Fig. No. 30 is shown a group of feathers that illustrate a few of the several defects that the breeders of this variety are constantly confronted with.

Feather No. 1 fits the Standard description of color in this section and is the one breeders are trying to obtain.

Feather No. 2 shows a defect that is quite common in the large open-centered varieties. The outer lacing is good. but breaks away at the bottom, and under color is too light. A feather like this should be discounted 1 point.

Featler No. 3 shows a defect common in this breed when too dark matings are resorted to. The outer lacing of black is good and shows a surface that fairly glistens in the sumlight, but the centers are entirely too small and should be discounted $1 \frac{1}{2}$ points.

Feather No. 4 is good in the white center, but black edging is irregular and runs out at the tip, making the black look mussy and irregular, and should be discounted $11 / 2$ points.

Feather No. 5 shows the tracing of the Dark Brahma color so peculiar to this breed, and one that few, if any, of our females are entirely free from. A back showing plumage of this kind should be discounted three points.

Feather No. 6 shows a defect that is quite common in Silver Wyandotte females. The white center is about the right proportion, but it is flecked with black and outer edge is not as clear and distinct as it should be. Backs like this have a mossy color that is an eyesore to Wyandotte breeders and should be discounted 2 points.

\section{Breast.}

The color of breast in all American varieties has a valuation of five points, and on Silver Wyandottes we find
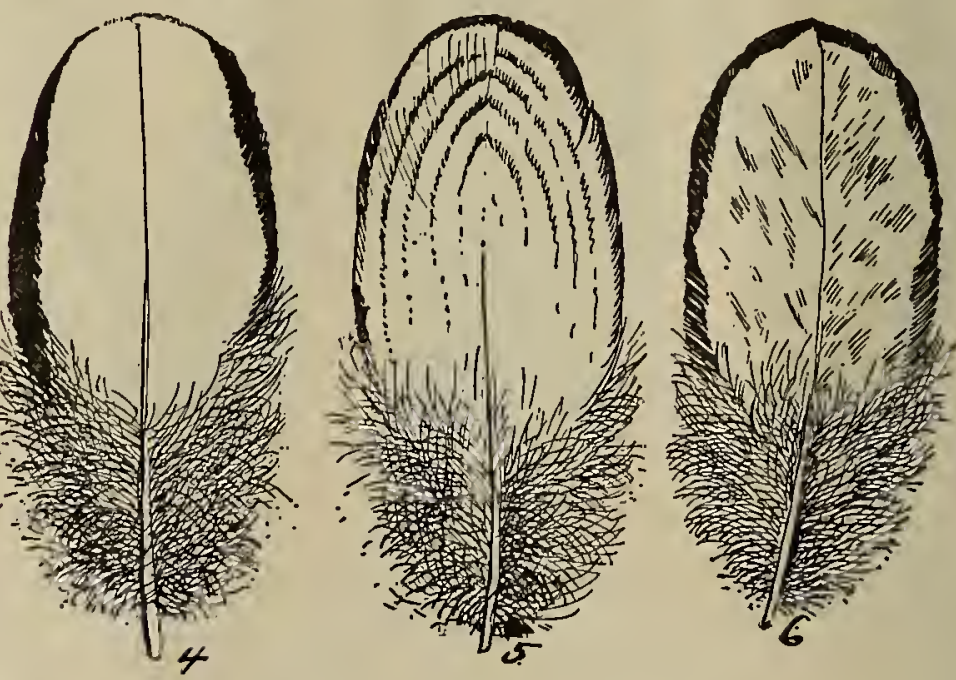

some crescentic-marked feathers that fail to show the lacing entirely around. Another defect is sometimes found in this variety-a tracing of white on outside of black, mak. ing something in the form of a triple lacing. This is quite oftcn found in females where we have not been careful enough to guard the dark under color.

In Fig. No. 31 are shown three feathers illustrating the defects referred to.

Feather No. 1 is taken from up near the throat, and shows the crescentic markings, and should be discounted $11 / 2$ points. The white in this feather is all right, but is lacking in black, and for this reason does not receive as much of a discount as it would if both colors were defective.

Feather No. 2 shows flecking in white center, and should be discounted 1 point. 


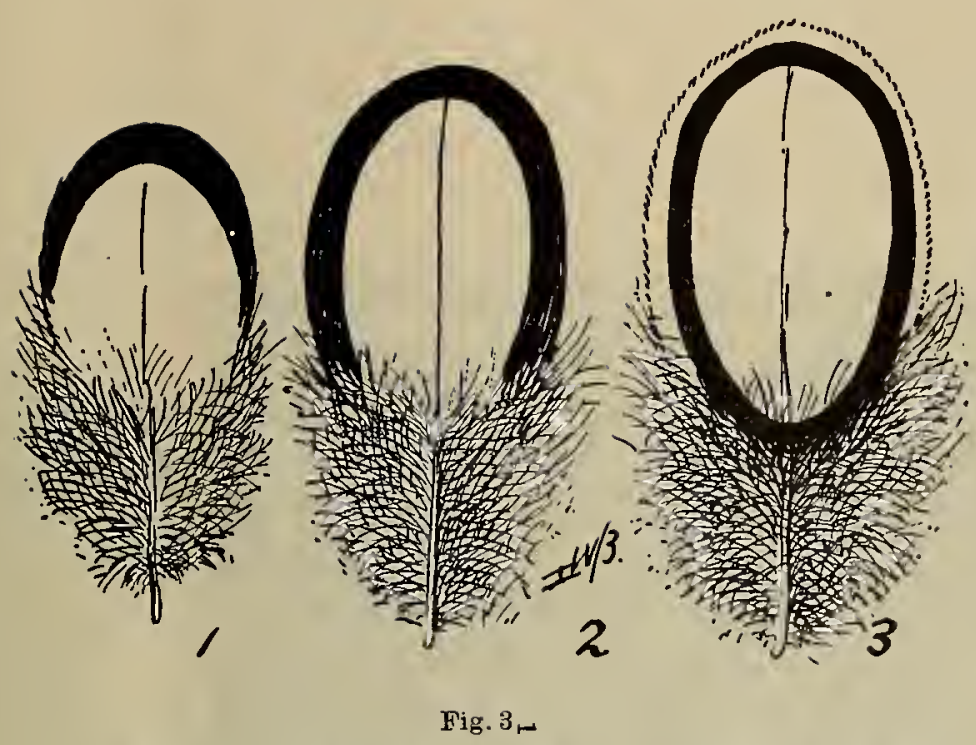

Feather No. 3 shows the outside lacing of white, and should be discounted $1 \frac{11}{2}$.

\section{Body and Fluff.}

The way Silver Wyandottes have been bred for the past five years we can find but little fault with the color in this section-in fact, several specimens that the writer has handled the past twelve months have passed without a discount-and are as near standard as we will likely ever breed them. These feathers do not seem to be subjected to as rough usage as those on breast and back, and for this reason we believe they show better in the adult specimens. It is the constantly breaking of feathers on back and breast that is responsible for the many defective ones to be found

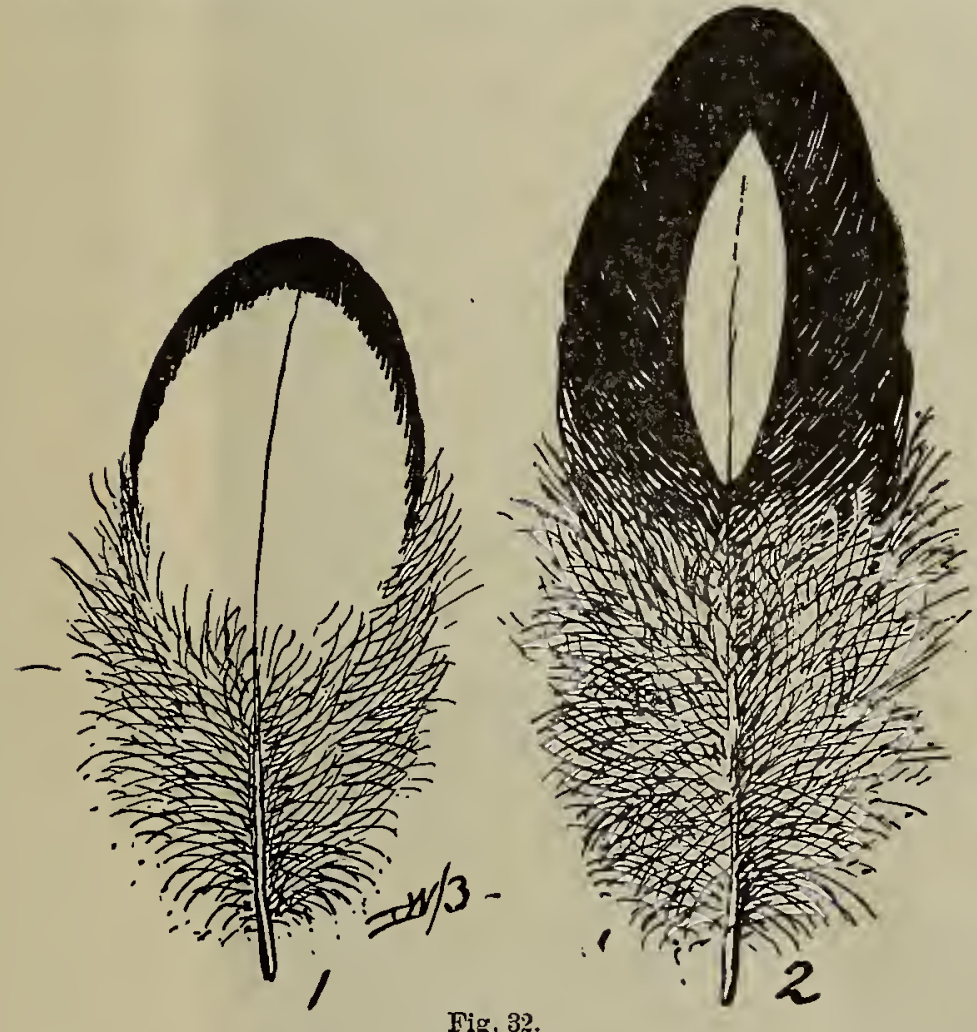

in these sections, especially in back; body and fluff, not being subjected to this rough usage, present the best color Sometimes on the body of a female we will find feathers that have failed to lace entirely around. This is on the upper portion in front of legs. Sometimes the black lacing around the thighs is too heavy and does not show the white center on the surface so much desired.

In Fig. No. 32 are shown two feathers that illustrate these points.

Feather No. 1 is taken from the body, and should be discounted 1 point

Feather No. 2 is taken from the covering of thighs and is too small in white center, and should be discounted 1 point.

\section{Wings.}

The present Standard is more severe on color in this section than the old, giving 6 to color and 4 to shape, the old Standard allowing only 4 for color in all American varieties. The shoulder, or wing bow, should be laced similar to the back-nice, open, white centers, with clear, distinct white lacing running entirely around the point, free from white edging and showing dark slate under color. The flight should be black except on the lower web, where white edging appears. The secondaries on our best bred specimens are showing the lacing entirely around the feather, and this, we believe, is as it should be, both in male and female. A lacing of white with good solid black makes the handsomest wing, and when we see specimens showing this we know it is obtainable, and we would advise fanciers to breed for it in our Silver and Golden Wyandottes as well as in our Sebright Bantams.

The descriptions that we have given of defective feathers in back and breast will answer for wing bows, when allowing for the difference in the shape of feathers from these sections.
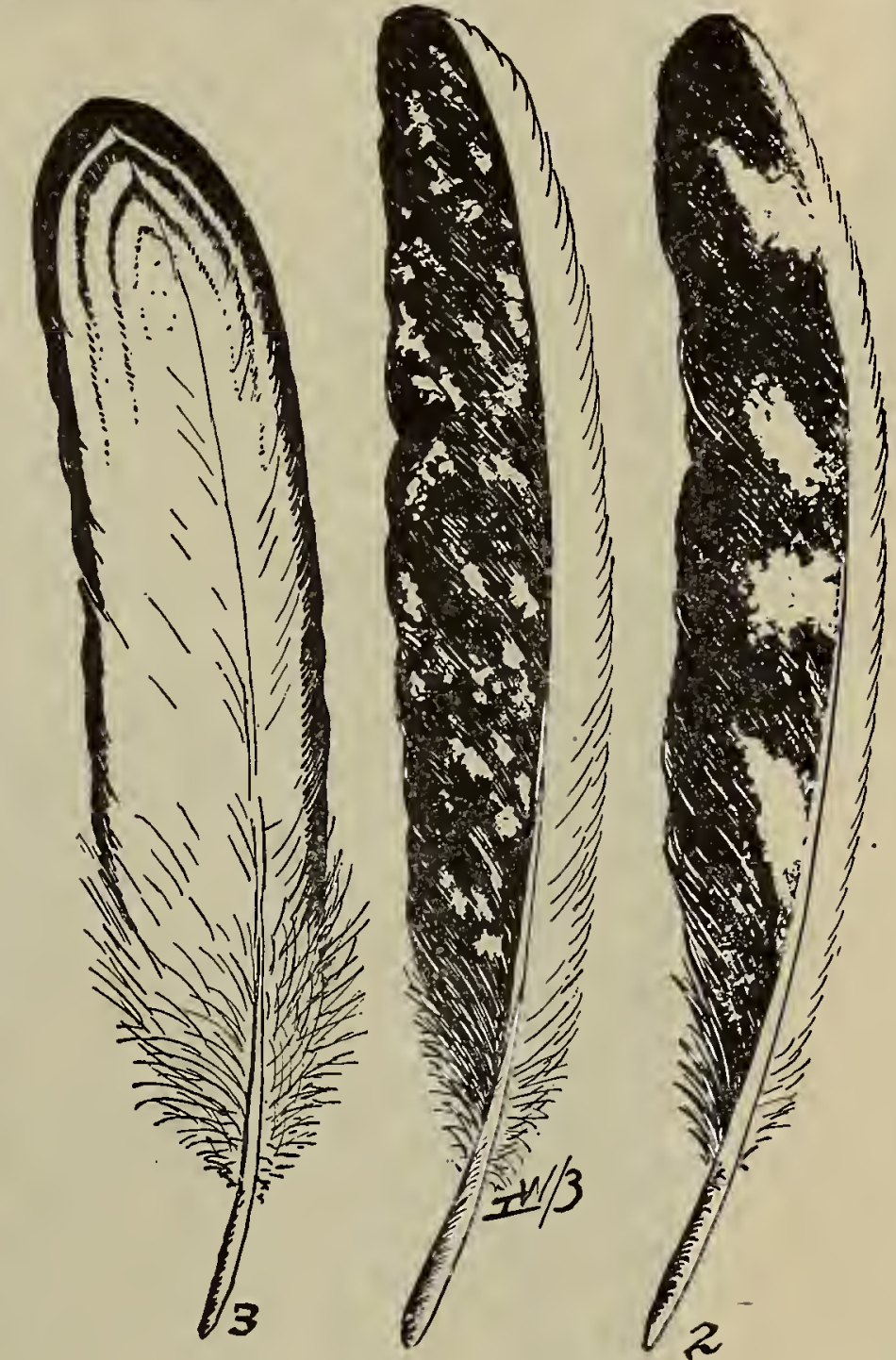

Fig. 33.

In Fig. 33 are shown some defective flight and secondary feathers.

Feather No. 1 is a flight feather where the white intermingles with the black, and in such proportion that it is decidedly objectionable from an exhibition standpoint, and wousd fail in the breeding pen in producing good males or females. Where the white creeps into the black, or the black into the white, it should be clear and should show the individual color solid, and where defects of this kind appear, they are not considered so seriously by the breeders, but when it flecks up the two colors mingled, as in feather No. 1 , it should be discounted $1 \frac{1 / 2}{2}$ points.

Feather No. 2 of this group shows as much white as feather No. 1 , but it is clearly divided, and 1 point would be a severe discount.

Feather No. 3 is from the secondaries and shows a defect that is sometimes found there. The ends of feathers wili have a tendency to show the Dark Brahma color in a line of tracing of brown or black, and should be discounted 1 point. The Standard allowing 6 points for color in this section, it is well for the breeder to remember that not all of these 6 points can be applied to any one part of the wing, and we believe that dividing the wing into three dis- 


\section{Something of Special Interest to Silver Wyandotte Breeders.}

In tlie group of feathers on the opposite page we liave illustrated colors that under test do not fade, or, to malie it plain to the beginner, the style of lacing that can be depended upon to stand the test of moult and still retain the pure white centers and clean outer lacing of blacli.

IVe ask that you study this plate carefully, as we consider it of more value to the breeders of Silver and Golden Wyandottes than all other illustrations in the book combined.

We have here the foundation to the structure that the prominent breeders of this country and Europe have spent a quarter of a century in building, and, realizing fully the importance of these feathers as an absolutely safe foundation to build upon, we have taken nothing for granted in these sections.

The editor has personally visited the yards of the breeders where the birds are bred. I know the hens they were selected from, have studied them carefully as pullets in their first adult plumage, then again as hens in their second year and still again as hens three years old. Have also had the pleasure of handling $t \pi^{\circ}$ of them while in moult, right at a time if there is any change it would show, and at no time in the life of these females has the plumage faded or shown the black, splotchy appearance in white that is so prominent in so many Silver Wyandotte females.

When viewing these feathers please bear in mind that they were selected from hens four years old, Bands Nos. 336 and 318 .

The feathers were furnished us by Messrs. A. and E. Tarbox, Yorkville, Ill., who bred the specimens and still own them-in fact, it is doubtful if one could get a price on some of these females, as they figure they are the result of a life's work and are a foundation for the future.

In selecting these feathers we have made no effort to take the best individual feathers from the several sections, but we are giving our readers the benefit of each just as they show on the females, and we call special attention to them, both as to surface and under color, as it is from such feathers and no other that we can give reliable information as to just how much black and white can be depended upon to re produce year after year and hold the color both as pullets and hens and reproduce itself in their offspring, and for the guidance of our rearlers we call attention to the color of the pullets bred from these individual hens, showing that like will produce like when properly mated, and a sufficient amount of the blood of the strain retained.

The editor is under many obligations to Messis. A. and E. Tarbox, and we lnow the Wyandotte breeders of this country will appre ciate what they are doing in the right way to encourage the breeding of this variety and assisting in maintaining it to the highest point of perfection from an exhibition standpoint and it is well to note that in bringing out this color the commercial value of the fowl has not been impaired in any way, as hen Band No. 318 has an egg record equal, in fact surpassing many of the contesting pens that have been so highly touted by breeders of other varieties. The fol lowing figures explain the chart of feathers in detail:

In this group of feathers we have the correct amount of white and black, with sufficient slate in under color to hold the black lacing in all sections during the moult of the hens.

From an educational standpoint we consider this plate of feathers by far the most valuable illustration in this book. They were selected for us by Messrs. A. and E. Tarbox from their exhibition and breeding hens that we know positively have held their color through two or more moults.

Figs. 1, 2 and 3 illustrate the back, breast and wing bow of the second hen at Scranton Pa., January, 1907; 4, 5 and 6 illustrate the back, breast and wing bow of first hen at Chicago, January, 1908, and this same hen was winner of first as pullet at Chicago, December $1904 ; 7,8$ and 9 illustrate back, breast and wing bow of first hen at Chicago, 1907, also second hen at Chicago, 1906 (this hen was illus trated in the December, 1906, Inland Poultry Journal, showing an egg record of 175 eggs in 264 days); 10,11 and 12 illustrate the back, breast and wing bow of fourth hen at Chicago, January, 1908, and daughter of first hen at Chicago, January, 1907; 13,14 and 15 illustrate the back, breast and bow of a daughter of first hen at Chicago, January, 1907; 16,17 and 18 illustrate the back, breast and wing bow of second hen at Chicago, January, 1908, and daughter of first hen at Chicago, January, 1907.

Please note this plate is an absolute reproduction of the feathers forwarded to us by Messrs. A. and E. Tarbox. There have been no retouching or changes. This plate of feathers is worth many dollars to breeders of Silver Wyandottes as a chart in the mating up of the breeding pens. Messrs. A. and E. Tarbox have spent years in learning the very thing that they are practically giving you free. 


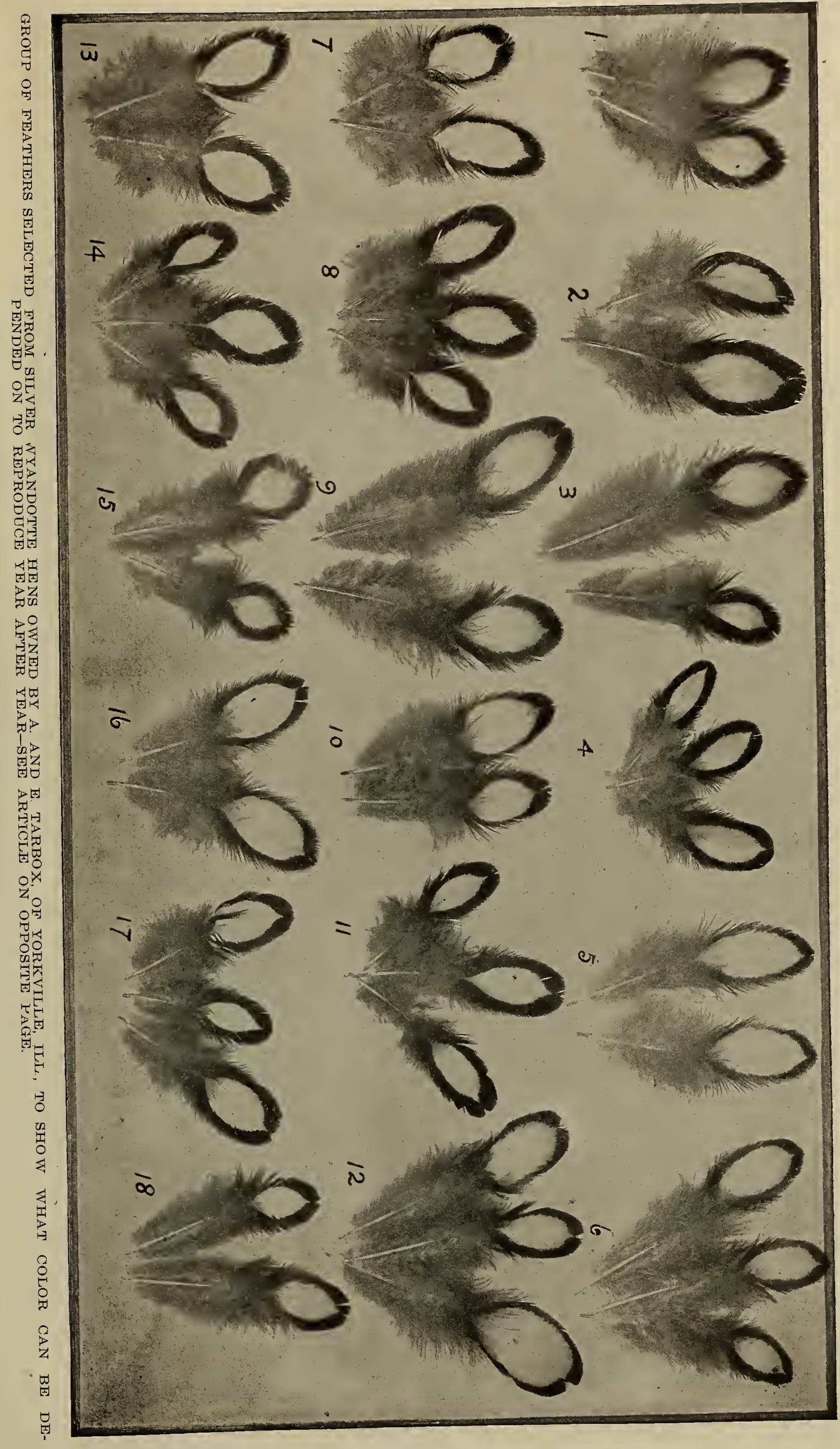




\title{
GOLDEN WYADOTTES.
}

\author{
Their Origin and the Breeds That Were Used to Produce the Color-Some Ancient Bistory From Men \\ Who Were at One Time Prominent Breeders of This Popular Variety.
}

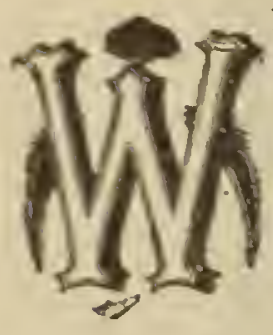

HILE the origin of the Silvers must always remain iu doubt, we seem to liave what might be termed official records of the crosses that made up the first Goldens, or, at least, the Goldens that were first recognized as exllibition specimens and the ones whose blood lines can be traced to many of our prize-winning strains of todas:

But old as that variety is and carefully as they have been bred by our leading fauciers, they are With fen exceptions further from Standard type, so far as sliape is concerned, than any Wyandotte that is recognized by the American Standard. In fact, the writer has found but few birds of this variety that filled the shape require. ments, while many of our winning specimens would come nearer the Plymouth Rock description in back, tail and body, and quite a few of them even reaching the Java type, especially in females.

We believe the breeders of Golden Wyandottes appre ciate our efforts to harmonize the shape of their variety, as outlined in our color illustrations, and it is up to the men who have given years of thought to producing correct color to shorten up the backs, necks, tails and bodies of their Goldens and make them conform to Standard descrip tion, or go to the Revision Committee of the American Poultry Association and demand a Standard description for shape that wili fit the winning specimens. If, in your opinion, backed by years of experience, you cannot shorten up this variety of the Wyandotte family to where the Standard demands, it should then be insisted that a Standard be made for your variety that you can breed to without in. juring your birds.

In looking up the early records of the Goldens, giving full consideration to the opinions of breeders who were themselves financially interested in the booming of this variety, we took the following from Pierce's Wyandotte Culture, believing this comes nearer telling the truth about the origin of this breed than anything that has yet ap. peared in print. Knowing all the parties quoted from, we have no hesitancy in giving it full credence, believing that these men, like ourselves, are striving to give to the public correct information as to how the variety was first produced.

As to color, we will refer our readers to the colored illustrations and the individual feathers that appear in each picture, as we believe our artist has portrayed a correct idea of what ideal plumage should be, and please bear in mind that these pictures are not run to represent the birds of any breeder, but the artist's idea of what the correct If yandotte should be, as described by the American Standard of Perfection.

Following is the quotation referred to, and we believe our readers, and especially those interested in Golden Wy andottes, will find much that will interest them. The letter from Mr. Commings was written in 1884, when this variety of the Wyandotte family was first introduced to our American fanciers as a show bird.

\section{B. N. Pierce Notes.}

This is truly a new breed, and desiring to know more about it, we requested MI, E. S. Commings, of Rockford, Ill. who is breeding them, to furnish us a history of their origin, which he has kindly complied with, as will appear in his own words:

"Many years azo Mr. Joseph McKeen, of Omro, Wis., by the crossing of several varieties of fowls, produced a brilliant black-red variety, with low rose combs and brilliant yellow legs, that we called 'Winnebagoes.' They were excellent fowls, combining beauty with utility, and might have been properly termed fancy fowls. Mr. McKeen has never attempted to get them recognized by the $\mathbf{A}$. P. A. or admitted to our Standard, but was wholly content to breed them in line for the sole pleasure they gave him as an evidence of how these lower forms of animated nature can be molded by the creative fancy of man.

"These fowls in many respects resembled our Wyandottes. In '79 Mr. McKeun procured several settings of American Sebright eggs of that veteran breeder, L. W. Whittaker, of North Adams, Mich. He was more than pleased with the appearance of the beautiful fowls that matured from the eggs that hatched. Being thoroughly posted in the Standard varieties and knowing that each Silver variety had its counterpart in a Golden variety, the idea naturally occurred to him that if he could only color the snowy white to a beautiful gold that he would have a Golden Sebright, or, as time has determined, a Golden Wyandotte. Selecting some of the very best of his American Sebright pullets, he bred them to a fine cockerel of his Winnebago variety. From the first the result was, although not wholly satisfactory, enough so to persuade him to continue the work of building up this Golden variety. By proper selection the work went on, sometimes discouraging in the extreme, but with the determination of a true fancier, the good results that have continued to grow, until now he has them almost thoroughbred. I became interested in them almost three years ago and am doing my mite to help the good work along. But it seems that Mr. McKeen was not the only one that conceived the idea of producing a Golden Wyandotte. The same spring he was commencing this work G. L. Buskirk, of Odell, Ill., by crossing with Black Red Standard varieties, produced some very good results in cockerels. but not as good pullets. Procuring some foreign blood of Mr. McKeen, this year will determine the value of the cross.

"But fully a thousand miles from either of these gentlemen, in Waynesboro, Pa., nearer by far the home of our Standard variety, curious as it may seem, the same idea was born in the mind of Jacob Ryder. He, too, has shown himself to be a skillful breeder in producing another family of the Golden Wyandottes, related in no way to either of the other families. Strange as it may seem, the type is very nearly the same in these three matings; in each we find the same golden color in pullets, the same rich golden bay color in cockerels, the lacing is of a brilliant blue-black, such as we find in the wing coverts of the peacock. Spealing as a fancier, setting aside all pecuniary interest, I honestly believe here is a breed that will create a greater boom among our fraternity than any fowl that has ever appeared. They have not only their beauty to recommend them, but they have good sterling qualities, are better layers than their Silver cousins and are larger fowls."

Mr. W. E. Shedd, of Waltham, Mass.; a breeder of another strain of Golden Wyandottes, writes us that his stock origirated with a farmer, who asserts that they came by crossing two strains of Silver Wyandottes. Mr. Shedd further says they are very handsome and breed true to feather.

GOLDEN WYANDOTTES - SOME ANCIENT HISTORY.

(From "The New England Farmer," August 2, 1890. By A. F. Hunter.)

We gave a short account of this comparatively new breed in our general article on the Wyandottes in the December number, in which we statéd that they were enjoy- 


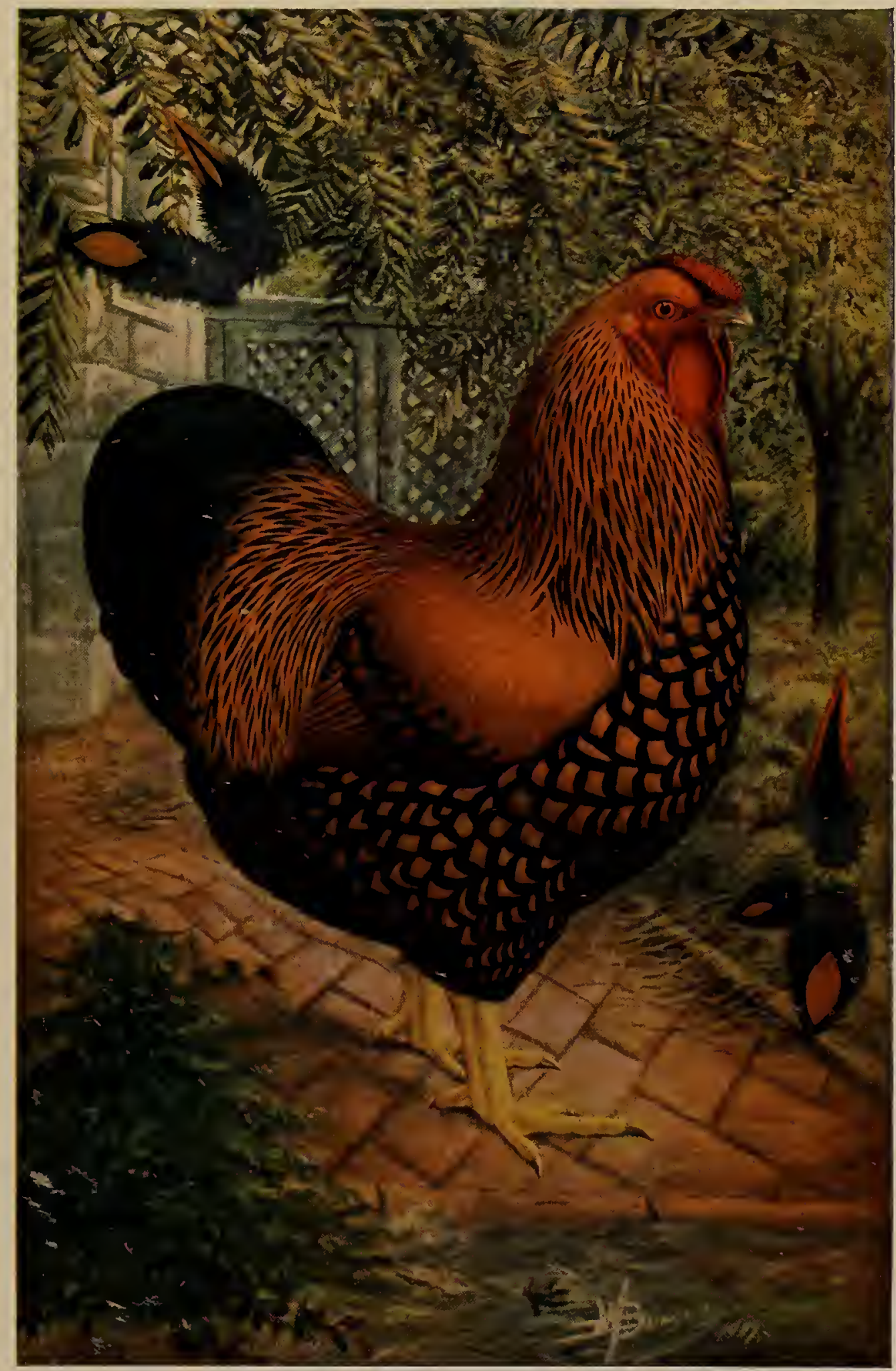

GOLDEN WYANDOTTE MALE.

Drawn to Conform to Standard Shape and Color as Described by the American Standard of Perfection. 

ing one of the most remarkable "booms" ever known to the poultry fraternity, and quoted some strong expressions of opinion as to their great merits. We were, at that time, hardly prepared to adopt all the enthusiastic plaudits of Mr. Kuenne and other writers, who claimed for them that they were unrivaled as both summer and winter layers. We had not then "summered them and wintered them," and, besides, it is usually wise to discount the encomiums of a poultry enthusiast. Under these circumstances we feel that we owe it to this breed to say more in their favor, and, in fact, we cannot speak in too strong terms of praise of their remarkable qualities.

They are all their lovers claim for them. Their fine shape, beautiful markings, rich plumage and generally highbred carriage assure them the admiration of every beholder, and long since enthroned them in the position of prime favorites of our yards. They are remarkably beautiful, and are unrivaled for attractiveness. Mr. Kuenne says "they are perfectly docile, may be handled at pleasure when sitting, and for rearing chicks are unequaled." Their docility and gentleness attest the truth of this statement, although we did not verify it by allowing any of ours to sit; their eggs were too much in demand for that. Their laying qualities are remarkable, and it is within the bounds of truth to say that they closely rival, if they do not equal, the Leghorns in this. . Our pen of seven pullets has laid twentyseven eggs in four consecutive days-two days of seven each, one day of six, and the next day seven again-which is a great yield. And not only have they been great layers, but their eggs have been remarkably fertile, hatching out a very large percentage of fine, healthy chicks. Of three hens sitting on their own eggs only, two hatched every egg, and the other eleven chicks out of twelve eggs, and it has been rare indeed that we have found an infertile Golden Wyandotte egg. The chicks when hatched were no less remarkable, evidencing a high degree of vigor and "gimp," were quickly on their feet, were foraging for food in the liveliest manner, and showing by their prompt fledging and rapid growth abundant evidence of thrift and early maturity.

These remarkable qualities were so manifest my curiosity was excited to learn more of their origin, and I addressed a note to Mr. Joseph McKeen, the originator of the breed, asking him about them. He says:

"The Golden Wyandottes are more than one-half Silver Wyandotte blood. The Winnebagoes were the top cross, although it crossed both ways the first season. When we cross a Silver Wyandotte male on a Black-Red, or Buff female, the chicks of both sexes, according to my experience, will be all, or nearly all, silver color and black combined. If we cross the Winnebago, or other black-red male, on Silver Wyandotte females, the progeny will be, males, silver; females, bay or buff. Strange, is it not, how males take the color of the dam and females the color of the sire? So, you see, it was necessary to use the Winnebago male on the Silver Wyandotte females to produce Golden Wyandottes; at least, this is the shortest road to the desired end. The Winnebagoes were, when I bred them, a large, black-red fowl. Some of the males had black breasts, others (and these pleased me the most) were a deep reddish bay, all but the tail, which was a very shiny greenish black. They were rose combed, legs clean and yellow. Some of the chicks, however, came single combed, and showed slight traces of feathering on shanks. Soon after I started to breed Golden Wyandottes I dropped the Winnebagoes.

"Why the Golden Wyandottes have so much vigor I do not understand, but think they must take a good deal of it from the Winnebagoes, as they are a remarkably strong, hardy and vigorous fowl. Those that have kept them praise them very highly. I fear you will grow weary in reading this long letter, which, when I commenced, I thought would be short.

Yours truly, "JoSEPH MCKEEN.

"Omro, Winnebago County, Wisconsin."

The last paragraph of Mr. McKeen's letter is in answer to my direct question as to whether the great vigor and strength of the Golden Wyandotte chicks were due to that of the native Winnebago blood. One point which he clears up is that the Winnebagoes were the "top cross." It has usually been stated that a Silver Wyandotte male was used on Winnebago females. Another point is that somewhat more than half the blood is of the Silver Wyandottes.

\section{THE ORIGIN AND CHARACTERISTICS.}

(By Wm. L. Stroud in "The California Cackler," April, 1890.)

In the autmn of $1880 \mathrm{I}$ was visiting my friend, Joseph McKeen. Not belonging to that class that "despises the day of small things," we were given to a fondness for breed. ing fine chickens, which had led us to a mutual acquaintance and friendship. As we were going through his poultry houses I caught sight of a beautiful cockerel of glossy golden and black - the golden predominating. Mr. McKeen said to me: "What do you think of my undertaking to breed a new fowl upon the basis of that bird crossed with the Sebright?" We were then breeding what were called "American Sebrights," obtained from Mr. L. Whittaker, of Michigan. This black-red fowl he had some years previous produced by crossing some of the Standard varieties, among them Buff Cochins, and called them "Winnebagoes." He had disseminated them among his neighbors, who had called them the "Golden Farmer." In the spring of 1881 I was again with Mr. McKeen, just as the first brood of new hopefuls was ready to be cooped. (A part of the brood was from eggs out of a laced hen of immense size, that was to be mine.) I carried home the whole brood, and reared it until about half grown, when it began to show the golden lacing. Mr. McKeen then took it home, expressing satisfaction at what seemed to promise a fulfillment of our expectations. This is the brief little record of my hand in rearing the prototype of what now surpasses what I ever expected to see-the Golden Wyandotte.

Upon that basis Mr. McKeen has been bringing steadily to perfection this breed, which, in our estimation, for all purposes, rivals all others. In his own words, "They com. bine beauty with utility in a marked degree." No other fowl pleases me so well as these. I think it safe to say that no other variety ever met with such universal favor by fanciers, and all classes that are at all interested in poultry. What in all the poultry world could be more beautiful than a flock of fully matured, choice specimens of Golden Wyandottes, with their red rose combs, clean yellow legs, large and symmetrical bodies, dressed in the most gaudy plumage of golden and greenish black that glistens in the sunlight? Dr. W. E. Scott, of Ontario, has a beautiful five-acre orange grove in bearing. He visited our Hermosa ranch a few weeks ago to see our flock of Golden Wyandottes, and thought they surpassed for beauty anything in the chicken line he had ever seen; that he could grace his orange grove with nothing so appropriate-as a flock of such birds, and determined to banish all other fowls and give them free range of his paradise. Mr. McKeen began to send out his annual circular in 1884, announcing his new acquisition, but offered no birds or eggs for sale until about 1886, which year he exhibited them at Chicago, where he sold a trio for $\$ 75$, and a few other birds at fancy prices. No one sees these golden beauties but to admire them. Enough has been written in their praise to fill a moderate sized volume.

One poultry editor in May, 1886, predicted the Golden Wyandotte "the coming fowl for fancy," and it has been much improved since, though perfection is as yet a thing anticipated. To chronicle the opinions of leading fanciers would monopolize too much of the Cacklel's valuable space. Those who have seen specimens of the Silver Wyandotte can imagine their general appearance, with the white changed to a golden bay. They are a little heavier than the Silvers, which some think is a fault, but we think it a virtue. Their yellow skin and legs render them a desirable fowl for the table or market. When other fanciers learned what Mr. McKeen was doing they began to make experiments to the same end, but I think none of them has been able to produce anything to compare with his.

At the session of the A. P. A. in January, 1888, the Golden Wyandottes knocked at its door for admission to the Standard. Some objection was at first offered because several strains under this name were seeking admission, some of which had but recently come into existence, bred by crossing with the Hamburgs, and inferior in size and general character. These are still being disseminated as Golden Wyandottes. The McKeen strain of Golden Wyandottes came into existence by no accident, but with the idea of producing just what they are today, but with a success rather more than anticipated.

One writer in 1888 says: "The Golden Wyandottes are unquestionably one of the most handsome varieties of the poultry list, and an ornament to any lawn"; that "the most indifferent person to the beauties of the feathered tribe could not pass a flock of Golden Wyandottes without a glance of admiration." "Nor," says this writer, "is their beauty the only cause of their deserved popularity. Another virtue of vast importance is their great laying qualities." From what we know by experience we think their excellent qualities have not been overstated.

(It is clearly evident that Mr. McKeen was the originator of the Golden Wyandottes. It is just as evident that 
thelr orimtn was no happen clunec. but was due to lntellisont methols ln matlus, with a thed pulpose in mind.-Fe.)

\section{REFER TO SILVER WYANDOTTES.}

In our illustrutious and description of Silver Wyana covered. We believe. erory pliase of the Golden wyandotte that wonld be of general interest or information to our reatlers.

The Mllustrations of the two varieties, as to shape, and the word description of color, are the sime in all sections excont substituting "solden bay" for "white": "powdered "ith solden bay" for "nowdered with silser gray" in thighs and into and "dark slate or dark slate powdered with solden bing" in under color.

Is is not our intention to eliminate any description that nill he of ceneral use to our readers, but repetition would be of no benefit and take additional space.

There are two things in reference to shape of this popular variety of the Wyandotte family that we desire to call attention to, and they are length of body and back, Golden 11 yandottes, with but few exceptions, luave been faulty in this respect, dne, perhaps, to the Winnebago blood that wias first introduced to give the color. The bird is lonser in back of males and the tail carried a little more uprisht. However, the breeders of this variety are gradually bringing the lines closer together. During the last two seasons there have been quite a number of winners at the leading shows that were almost perfect in color that showed short backs, deep bodies, witl short, well sprcad tails.

We call attention here to our color illustrations of male and female that fill our idea of Standard outlines, and in color they are as nearly correct as it is possible to reproduce by the thrce-color mrocess, and it is well to note at this time that the reproduction of perfect color under this system is always more or less faulty. We can reproduce in oil an absolutely perfect color of any breed or variety, so far as the original oil painting is concerned, but, in trying to reproduce these colors under the three or four-color process, ink will not in every instance feed as it should, and one color is apt to overlap another, even when the best presses and pressfeeders in the country are doing the work, and a line, no wider than a hair, of one color on another makes a decided difference in the looks of a picture. However, we believe that the illustrations will give to our readers as nearly a correct idea as it is possible to give, and we know if any of you are fortunate enough to produce specimens as good as the ones illustrated, in shape and color, you need have no fear of competition in the best slows of America. We wish to call special attention to the feathers that are grouped around the color pictures. They represent our ideal, both as to shape and color, and are well proportioned in black and gold. 


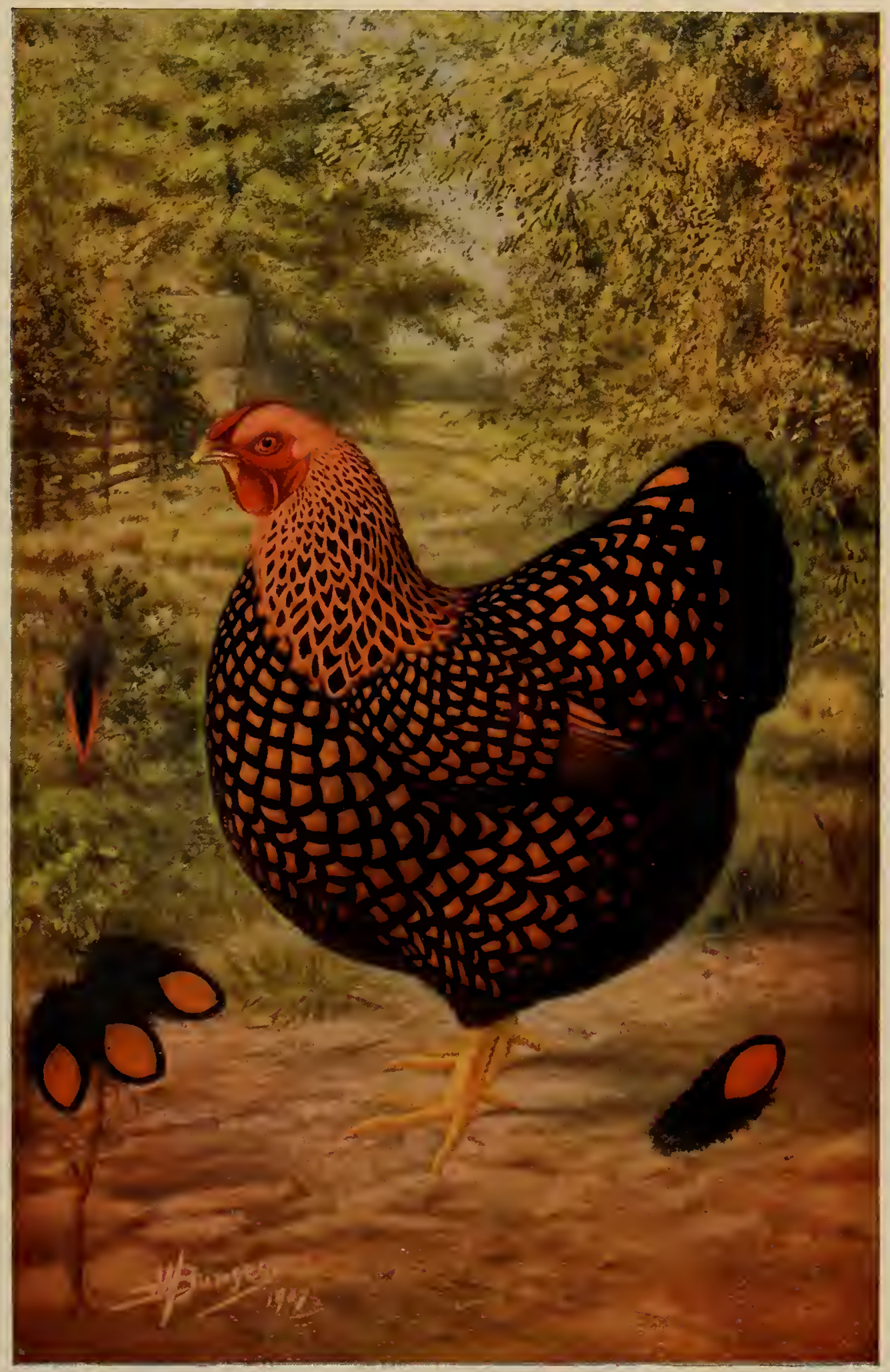

GOLDEN WYANDOTTE FEMALE. Drawn to Conform to Standard Shape and Color as Described by the Americau 




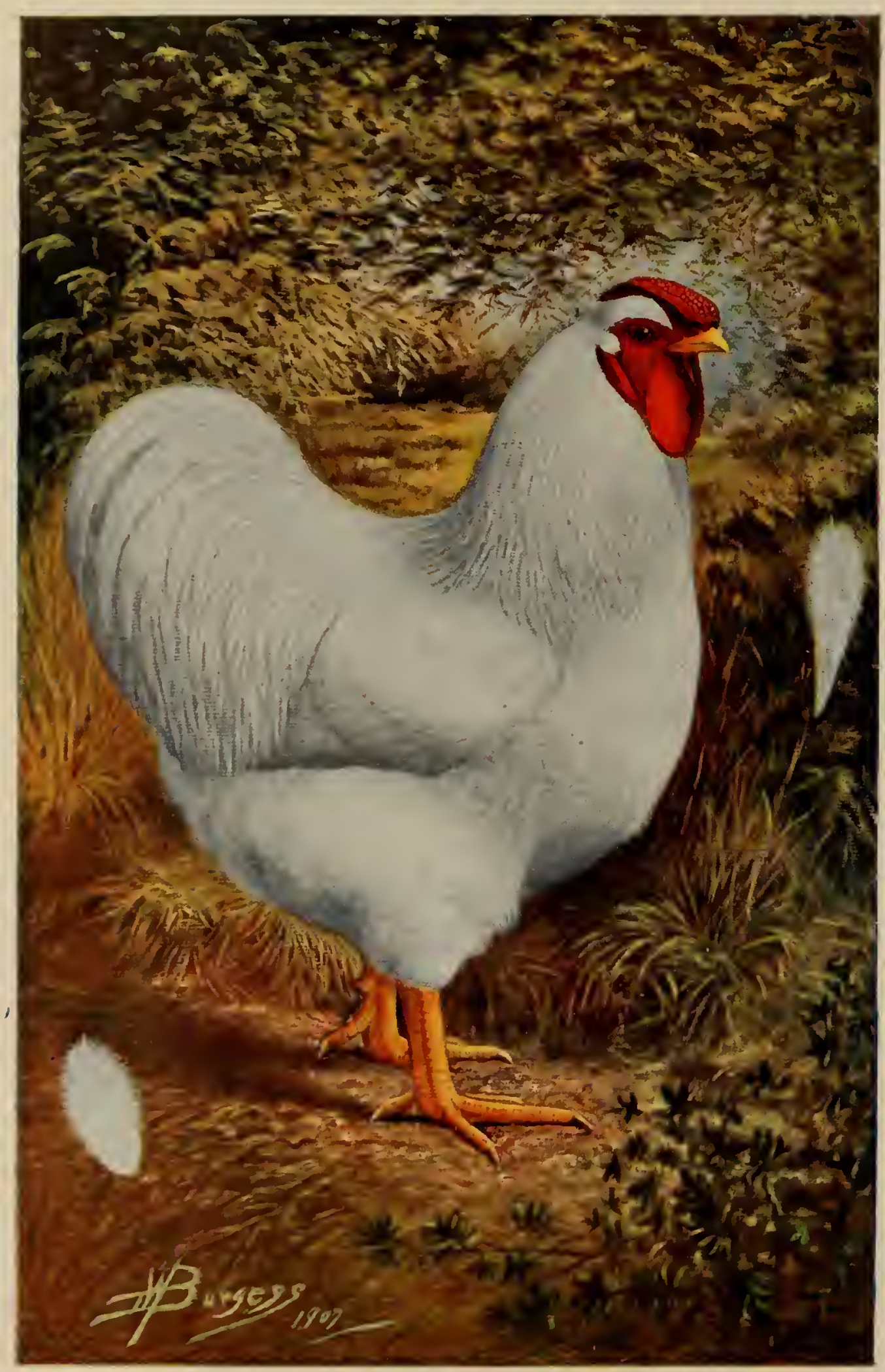

WHITE WYANDOTTE MALE.

Drawn to Conform to Standard Shape aud Colol as Lescribei by the American Stanilard of Perfoceliem 


\section{WHITE WYANDOTTES.}

\section{The Only Variety That Owes Its Origin to the Original Silvers-No Out Crosses Used in its Make-Up -Brassy Surface the Defect Hardest to Overcome.}

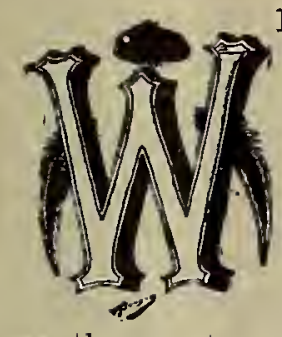

HILE WE are looking up the record of the several varieties of the Wyandottes, that have come prominently before the fanciers in the past twenty years, and diving into old and musty records in our efforts to find out just what breed or breeds entered into their make-up, it is a real pleasure to find a sub-variety that is in truth a thoroughbred.

The Whites can claim that distinction, as the most prominent strains of this variety today owe their origin to true white sports from the Silvers.

When the Whites were first introduced, a few breeders tried and did succeed in a way in producing a white fowl with a rose comb, but the best of these came from crosses of Rose Comb White Dorkings on very light colored Silver Wyandotte females and very inferior white birds with rose combs. But these matings, so far as the writer is able to learn, were never satisfactory. The shape was defective, while the fifth toe, so long bred into the Dorking family, would insist upon reproducing itself, and the top color of both male and female had enough brass in it to make a book agent look lonesome-in fact, the brassy surface of both sexes, and especially of the males of the White Wyandottes, no matter how produced, threatened for a time to kill this now popular variety.

Along in the eighties, about ' 85 to '87, when the writer was much interested in the Silver Wyandottes, there were reports current in regard to Albino sports from Silvers. The breeders of fancy fowls were not so numerous then as now, and fanciers that exhibited one breed or variety for a number of years became well acquainted with one another through correspondence, and when these white sports began to make their appearance, the Silver breeders in the Midwest kept in close touch with them. Inquiries developed the fact that in nearly every instance the white sports came from the very darkest matings of Silvers instead of the light matings, as one would naturally squppose.

The first one to make an appearance in the writer's yards was in the spring of ' 87 or ' 88 (I am not positive as to date, as some of the records are lost) the pen that produced them was a cross of the Haynes and Orr strain. The chick, pure white except some ticking-in fact, nearly if not quite as good in color as the average female of today, proved to be a pullet and matured into a fine shaped hen.

The same season Mr. Hugh Meeks, of Bonaparte, Iowa, an old friend of the writer's and for a number of years a prominent breeder of Silvers, had a sport from one of his pens that proved to be a cockerel. The following year the writer mated these two birds together, and from this cross producd several chicks that matured into well shaped specimens.

From these birds, I mated the second year a pen of as good White Wyandottes as there was in the country at that time. In females I found but little fault with them, but the males were far from satisfactory-to me, at least. They were invariably brassy, and in saddle and hackles showed a number of black feathers the entire length so they could be noticed on the surface.

After three years with them, and not being able to eliminate this defect in the males, I gave them up, believing at that time they would never become a fancier's fowl.

While I was experimenting with the Whites other breeders took them up, some selecting birds from my yards, others working on strains of their own that had originated in their own yards, but, so far as I am able to learn, all having the same trouble with color of males as the writer. However, others were more persistent than I and held on to them, and finally succeeded in getting rid of part of the brassy surface, but it is only within the past ten years that any one could honestly boast of a stay-white male that would hold its color throughout the summer months. Finally they did succeed in doing this, and today the pure White Wyandottes are as common as pure white fowls of any breed, and their popularity is not equalled by any white fowl in this country or Europe.

The slight ticking in plumage is still with them, and no doubt will be for many years, as the black blood in their ancestors will persist in coming to the surface and is in reality more of a mark of thoroughbred than otherwise; but time, skill and patience will eventually eliminate this minor defect, and the efforts of the breeders of this variety to bring about this result will be time well spent.

No variety of the Wyandotte family can equal the Whites in shape. A glance at the color plates in this issue, as compared to the many half-tone reproductions from the winners at our big Western shows, tell the story of perfection better than any word description we could give.

One. would think there was not much of an opportunity to discuss color or criticise it in a breed that is described as pure white, and were it a fact that all specimens of this variety were absolutely pure in color there would be nothing to consider in the way of defects, and the scoring of the fowls would be a matter of shape. But no breed of fowls is absolutely pure in color, no matter whether white or black, and White Wyandottes are no exception to the rulein fact, are one of the most defective white fowls in color that are recognized by the American Standard. It has been only within the last few years that we have had what might be classed a "stay-white" bird, one with plumage that conld be depended upon to be free from brass or rust during the summer months. This defect alone has caused perhaps more worry on the part of White Wyandotte breeders than any other one thing, but it is not the only defect in color by any means. The fowl being a true sport from the Silvers, naturally has black blood in its origin, which we may expect to crop out occasionally, if not in a solid black fowl, in some feathers from the different sections.

While it is the aim of the American Poultry Association to guard against awarding prizes to birds that show plumage other than white, it is a notorious fact that there is not one White Wyandotte out of an even thousand that is bred without some ticling, and when we find an exhibit where every bird in the class is absolutely free from this, we can gamble on it that somebody has looked them over carefully before they were put in the show.

The Standard gives us a valuation for cutting brass in plumage under the head of "Cutting for Defects," on pages 29 and 30 , where it says: "Brassiness in all varieties, in each section where found, one to two points. Creaminess of plumage or quill in white varieties, except where specified creamy white, in each section where found, $1 / 2$ to $11 / 2 . "$

With these instructions before us, it is an easy matter to discount the surface and under color of the fowl, so far as brass, sunburn or cream may affect them.

Flecking in plumage is a different proposition, and must be gauged differently. The Standard, under the head of "Disqualifications of White Wyandottes," says: "Red, buff or positive black in any part of the plumage is a disqualification." The description seems plain enough, but there is a vast amount of difference in the opinion of the judges as well as breeders as to what constitutes positive black, and we have here in Fig. 35 (feather No. 1) a defect which, while not common in White Wyandottes, is one that is often 
net with. and we would not disqualify a specimen with this slyount of tickins in plumsso. but would cut the limit of (1) pormes in any section where it is found, the sume as "le would with brass.

fouther No. 2. in same group. lias no more black than fencher $\mathrm{xo}$. l, but it is so formed in the feather that we believe the juldse would be allowed to tlinow out the snecimen whele this amount was found in any section of lic bilet. Howerel. we believe the judges shonld be allowed to use a lietle judgment in matters of this lind, and wen ind is discounted "2 points for this color some think the section has been punished severely enougl.
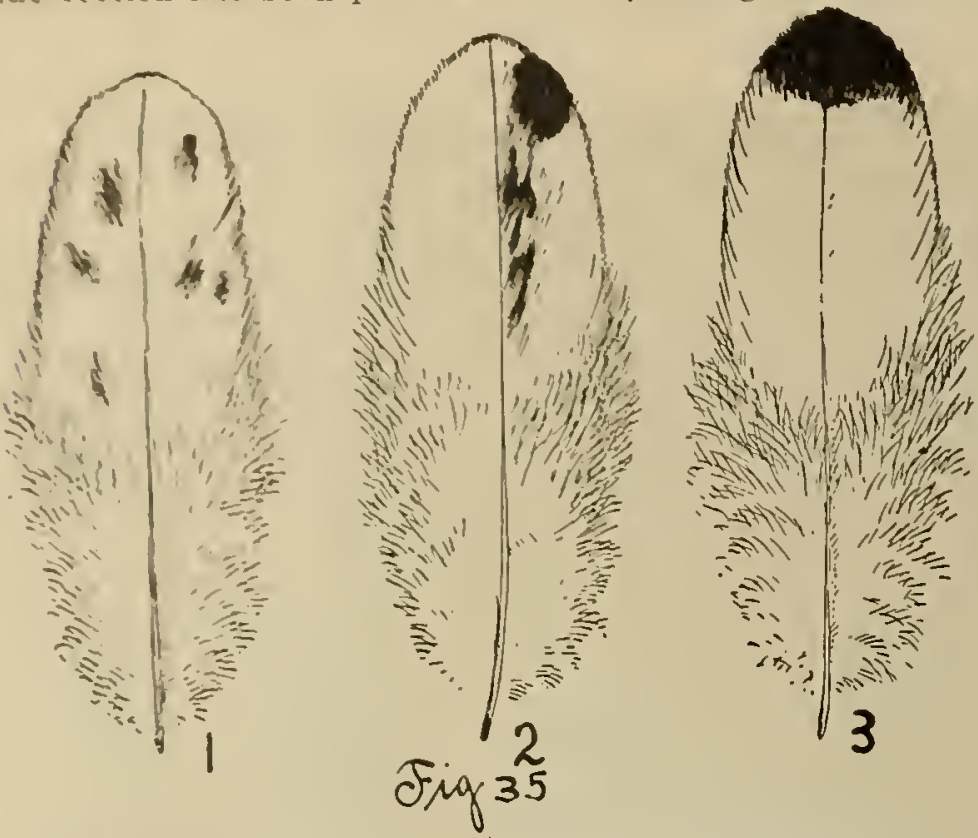

Feather No, 3 is clearly disqualified, the entire end of feathel passing each side of the quill and for a half inch down in the feather is black. It cannot be taken for brown or gray, but is positively black, and should disqualify the bird.

In Fig. 36 feather No. 1 is a sample taken from the saddle of an exhibition cockerel. This bird won a prize and quite a bit of criticism was called forth on account of it. The judge claimed that it was not positive black and the other good sections of the bird overbalanced this serious defect, and we believe, according to the Standard description, the judge sustained himself in his decision. Feathers like this are quite often found in the saddle, hackle and tail coverts-in fact, we quite often find them much worse than feather No. 1.

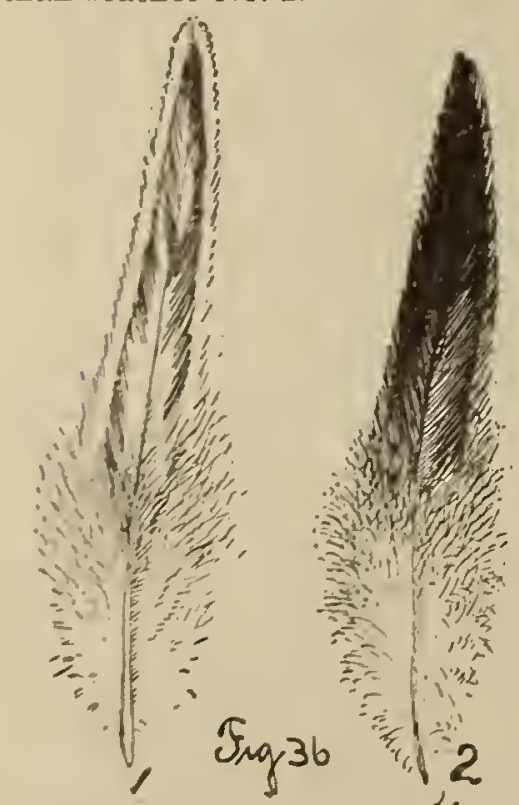

Feather No. 2 in same figure, was selected from a cockerel that had passed muster in the breeder's yards and was being prepared for exhibition. The birds had been carefully handled and this feather did not show on the surface, but on second handling, drawing the feathers through the hand the wrong way, developed the feathers black nearly the entire length and positive black over half the length of feathers.

We do not know what effect a feather like this would have on the breed. ing of White Wyandottes, but we do believe that if every specimen, male or female, were discarded from the breeding pens on account of a little ticking and occasional disquali- fyine feathers, some of the best birds that ever graced our American shows would be sent to market.

While we do not encourage faking on the part of any one, it is a notorious fnct that so long as the Standard reads as it does, and white birds breed as they do, then it is necessary to leave eiglity-five per cent. of the best White Wyandottes at home or do a little faking in order to get them in shape to pass muster under the severe critics who are awarding prizes today.

It is these little disqualifications that creep into Standard description that make breeds and varieties suffer alike that has convinced the writer that all disqualifications, except for natural defects, should be eliminated from the Standard. We really believe as they read today they are a hindrance in breeding, and many times the best specimens do not win a prize. Neither do we believe it would have any serious effect on the producing of pure white fowls in White Wyandottes or any other variety. No matter whether they disqualify or not, the breeder does not want them there and has done everything in his power to eliminate them, but should a choice exhibition pen, containing one male and four females that otherwise would win a prize in strong competition be disqualified because one single specimen had one black feather that had been overlooked, it is carrying the thing too far, because one feather doesn't represent more than one ten-thousandth part of an individual specimen, and that one feather not only disqualifies that bird, but the other four in the pen with it, and we shall recommend to the American Poultry Association at its next revision meeting that all disqualifications except natural deformities be eliminated from the book.

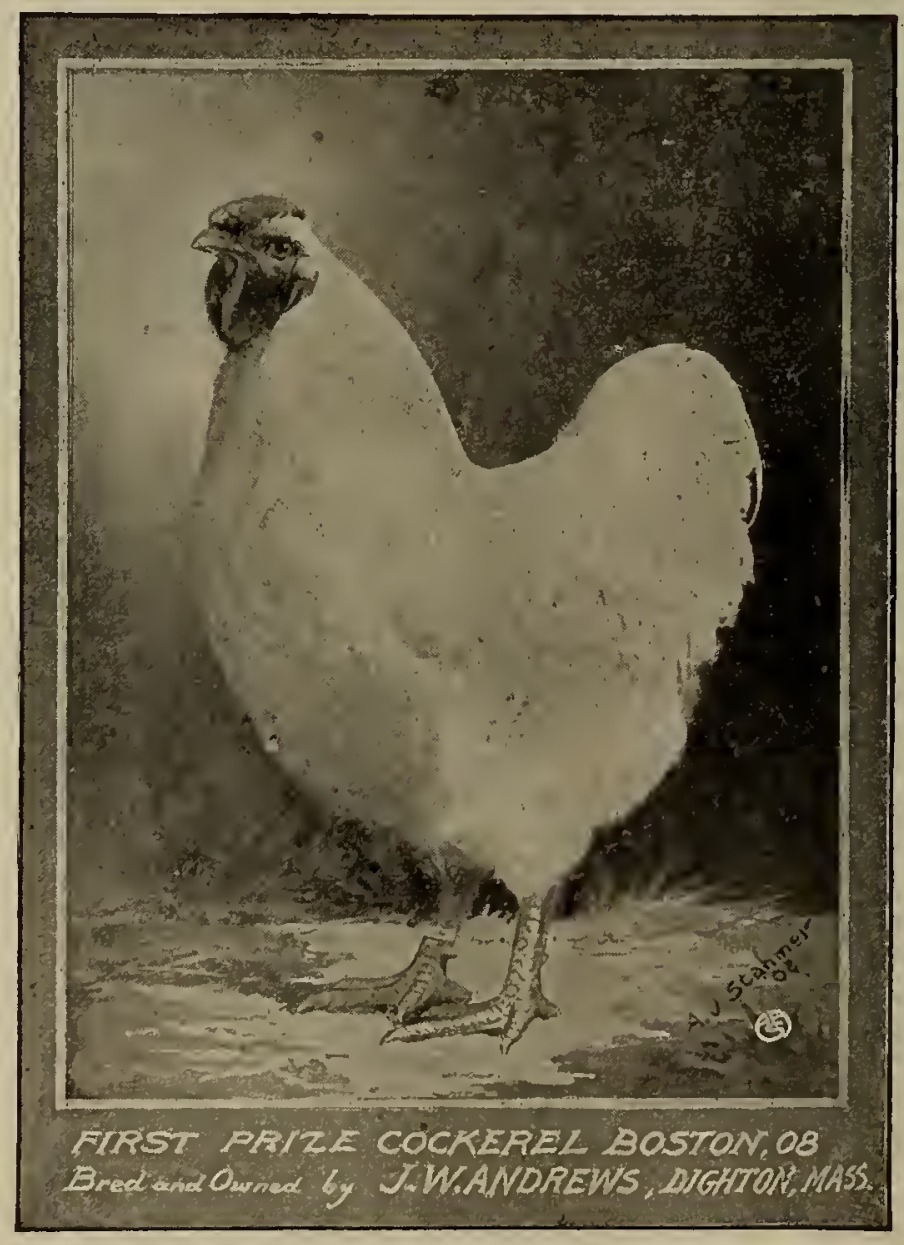

\$HITE WYANDOTTE COCKEREL. 


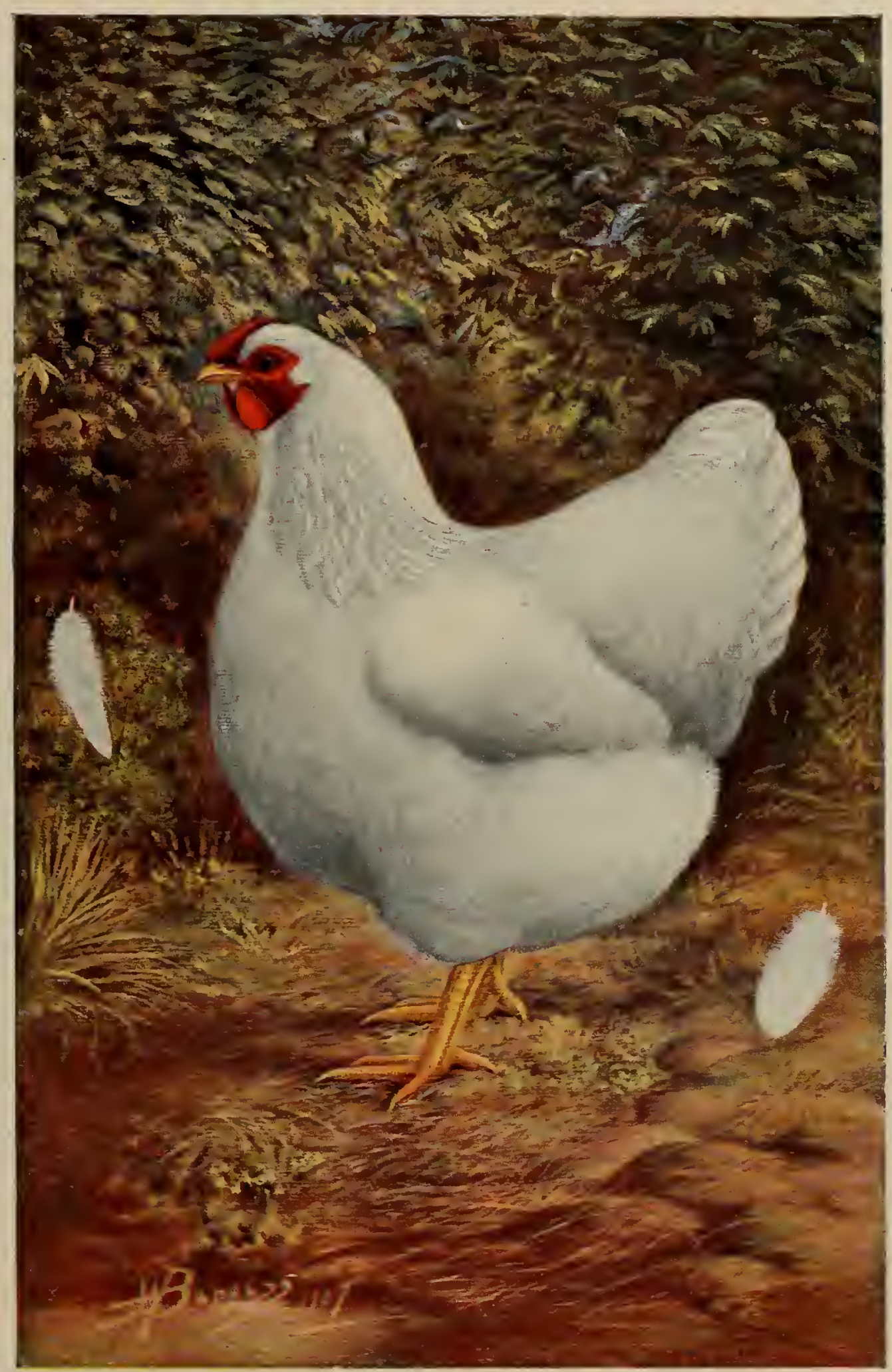

WHITE WYANDOTTE FEMALE.

Drawn to Conform to Standard suape and Color as Described by the American Standard of Perfection. 




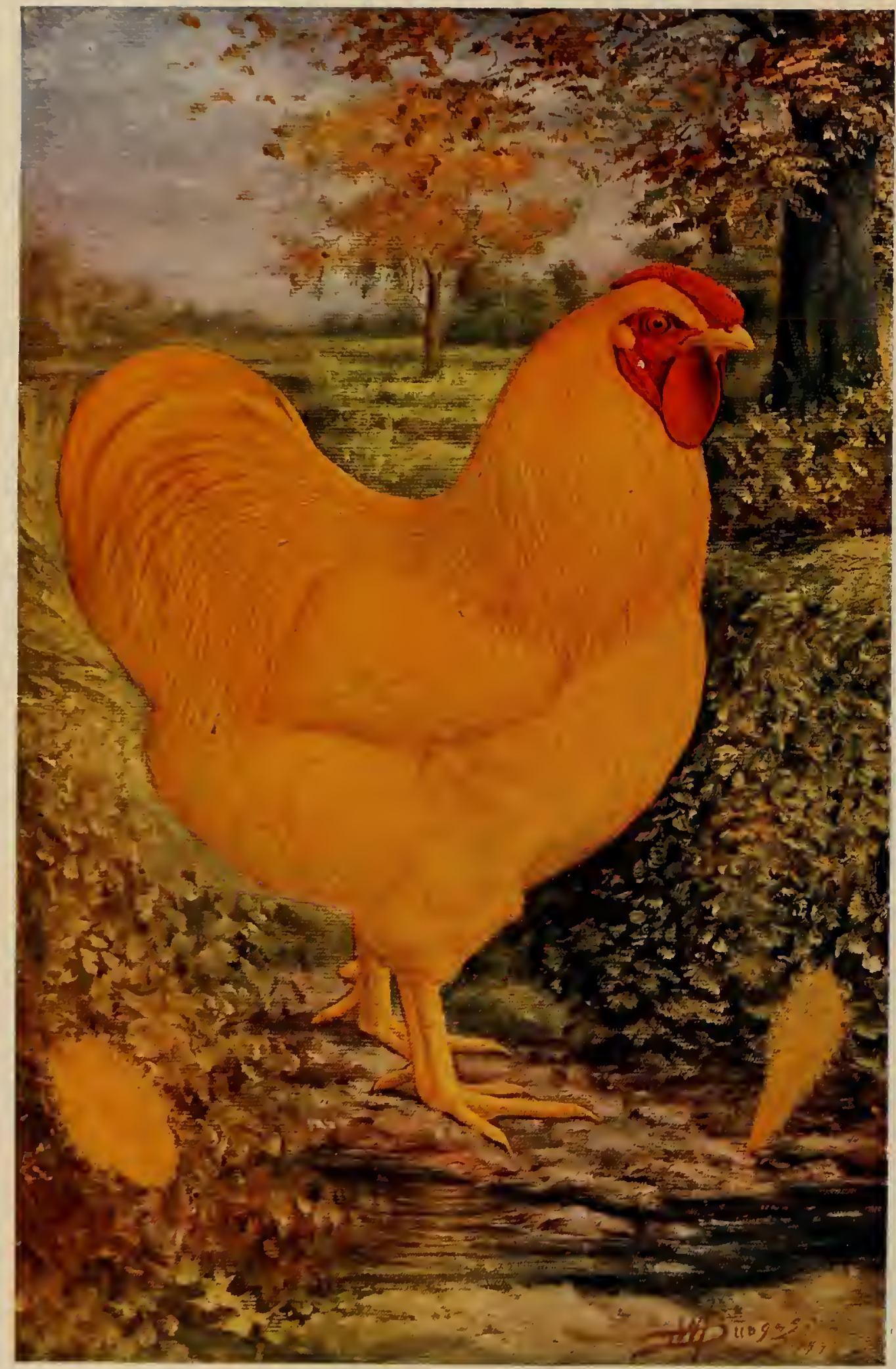

BUFF WYANDOTTE MALE.

Drawn to Conform to Standard Shape and Color as Described by the American Standard of Perfection. 


\title{
BUEE WYANDOTTES.
}

\author{
One of the Solid Colored Varieties That Had More Out Crosses Than Any of the Parti-Colored \\ Varieties of This Breed.
}

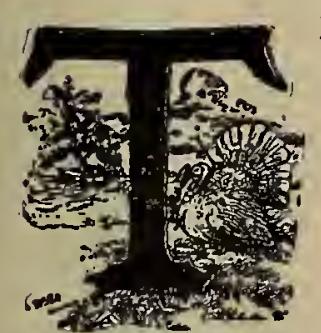

HIS variety of the Wyandotte family has had many ups and downs since it was first introduced to the public as a Standard variety. The out-crosses that entered into its makeup were perhaps as varied as any parti-colored variety of the Wyandotte, if not more-in fact, when they were first introduced there was as wide a difference among the fanciers as to what really constituted buff color as there is today on the correct color in some of the new varieties, such as Rhode Island Reds and Buckeyes. The writer's first acquaintance with the Buffs as a fancy fowl dates back to about 1890 to 1892 . At that time a few birds were found in the large exhibitions that showed a tendency to Buff-about as near Standard color of today as the Bourbon Red Turkeys.

Their tails and wings were all solid black and quite a bit of ticking in neck of females and occasionally some of it in the males. The undercolor was either white, bluish white or slate. It was seldom that the best show birds at that time showed sound undercolor, and if they did they were splotchy or mealy on surface.

In conversation with some of the old breeders in reference to the introduction of the Buff Wyandottes, we find that several outside crosses were used and different varieties of the Wyandotte family, or, in other words, different colored Wyandottes were used by different breeders to bring about the buff fowl, some using the Buff Cochin on White Wyandottes, others using this same cross on Golden Wyandottes, and others using this cross on Silver Wyandottes. The fowl known as Winnebagoes was also used in some of the second crosses.

Other buff fowls were introduced, and whenever a breeder could find a fowl of Wyandotte type with rose comb that showed buff plumage, regardless of its breeding, it was introduced into the flock in order to improve the color. By the selection of the best, gradually we could note an improvement, but it is only within the past twelve years that we have had. Buff Wyandottes that were entitled to the name, and really only within the last five or six that we have had real quality that would show and breed well and would hold its color from one season to the other.

The fault of the early Buffs was the tendency to red in both sexes, and where the plumage was otherwise good we would often find them laced with a narrow edging of red. This was especially true where the old Rhode Island Reds had been used in the crosses that produced the strains. These red birds were the ones that were most persistent in producing black wings and tails-one of the defects that our American fanciers have had the greatest trouble to eliminate.

No one section of the country can claim any special honor in bringing out this variety, as they were bred both East and West, and we believe there were just as enthusiastic fanciers in the middle and extreme West as in the extreme East. Looking back now at the early Wyandottes I believe that O. E. Thiem, of Iowa, was one of the first to bring out real quality. Away back in the ' $90 \mathrm{~s} \mathrm{Mr}$. Thiem showed some Buff Wyandottes at Des Moines, at one of the winter shows, that really had Wyandotte characteristics and were buff-that is, buff as the term would apply at that time. Not so brilliant in color or so free from black as we find them today.

This variety, like others of the Wyandotte family, were prolific layers, and the Cochin cross, used to produce the color, gave them length of feather that even to the present time has not been eliminated, and this covering during the winter months proved a benefit to them, as it seemed to give them an advantage over other varieties of the Wyandottes as a winter layer, and in the coldest sections of the country they were shelling out eggs when others of the American breeds were huddled up in a corner trying to keep warm. This fact possibly has done more to make Buff Wyandottes popular than any other one feature, for as a table fowl they are equal but not superior to other varieties of this family, but the large winter egg production has become the talk of not only the fanciers, but the market men as well, and it created a demand that liept the promoters busy trying to improve them.

When the Standard for buff color was adopted at Fisher's Island, bringing all breeds under the same head, the Buff Wyandotte breeders, of course, realized that they had a hard task to perform. If they were going to eliminate all the black and white from this fowl and give that harmonious blending of buff in all sections, it was necessary to discard eighty-five per cent. of the birds that were then winning prizes and confine themselves to a very few choice specimens in order to establish color strains, and in the selection of these few birds the color varied and each fancier believed his was the correct one. Some were a light lemon, others a strong orange, with a tinge of red, while others were quite sound on surface but inclined to show quite a bit of black in wings and tails. The Standard, placing the same valuation on white as black, worked a hardship on these fanciers, and even at the present time we believe it is the opinion of the best buff breeders in America that white and black should not be valued alike; or, in other words, that black is not so objectionable in a buff fowl as white. But be that as it may, we have our Standard to go by, and must abide by it.

In the color illustrations we have taken the color that has been popular for several years in the East. This color was never popular in the West, our best buff breeders claiming that it was entirely too light, and advocating a stronger shade; or, in other words, a rich golden buff. And we believe in this they are correct, and we know that the judges in the Eastern shows are begin. ning to show preference for this stronger color. The judges at New York and other Eastern exhibitions the past few years are gradually drawing the lines in this direction.

Please understand that in issuing these color charts we are doing so to favor the colors as popular today and as representing the shade of color most popular in the leading shows, but the writer favors a little stronger shade -in fact, as Mr. Felch would term it, "About one more dip in the buff inls."

We very much doubt if any strain of Buff Wyandottes will ever be produced that w:ll, year after year, produce a large per cent. of birds with the rich golden buff color with. out black or white in tails-in fact, we doubt very much if it will ever be possible to produce a strain of birds that will reproduce 100 per cent. free from foreign color. The tendency is to go to black if you get your rich surface color, and to white when you breed them light.

The Standard says, "Under color, a lighter shade," and the question comes up, How much lighter shade? The judges are at sea in valuing this defect. The result is that the exhibitors are more at seat than the judges, and between the two there is a compromise in the breeding yards that leads to a disappointed exhibitor the following year.

We believe that the rich golden buff in the Buff Rock winners at the Indianapolis Show (February, 1908) can be followed as the ideal color. If so, we can in time produce Buff Wyandottes, or, in fact, buff fowls of any variety, that will produce eighty-five per cent. pure, as there is enough color to feed itself without depending upon black, while the lighter shade would soon run our color out and we would have to add some other mixture in order to tone it up.

The color charts here help as a guide to a better un. derstanding of a soft shade of buff and the color that is today and always has been popular. But we would ad. vise breeders, and especially amateurs, to be very cautious in bredeing so light a shade, as it is only the experts who can mix these colors and make them hold 
Leonding to our present Standard, the Buff Wyandotte is clissed is in solid eolored bifu. and is so considered when owarding sweenstilies or special prizes, but we doubt if

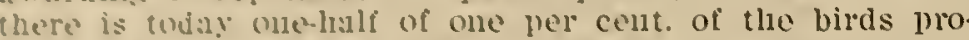
duces that ale sutirely free trom white or blacli-in fact, We nevt witl but fow in the entire season. Whether we will wer be able to climinate these two colors by careful solecthus and breeding wo ale muble to sily; but we can sifoly fivure that it will be mamy years to come, and until it is broughe about it is necessary that we lave a pretty livruta:l understanding of the raluation of these two for aisu colors and how best to discount them in the show roxill.

There is probably 110 better description of color to be found in the stindard than the one describing buff. The standard says: "Plunage-Surface throughout an even sliave of rich, solden bufi, free from shafting or mealy apvearance. Ludar color- A lighter shade, free from foreign color. Other things being equal, the specimen having richest under color shall be given the preference. Black or wite appearing in wings and tail is a serious defect, and the one shall be considered as objectionable as the other."

lie very much doubt if black is as objectionable to the Buff breeders as $w^{\prime}$ ite, but since the Standard so describes it it is necessary to discount it accoldingly.

The sections most affected by white or light under color are back, breast, base of hackle and wing primaries in both sexes, and we show here some feathers selected, civing a fair raluation on such in the show room. (See Fig. 3i.)
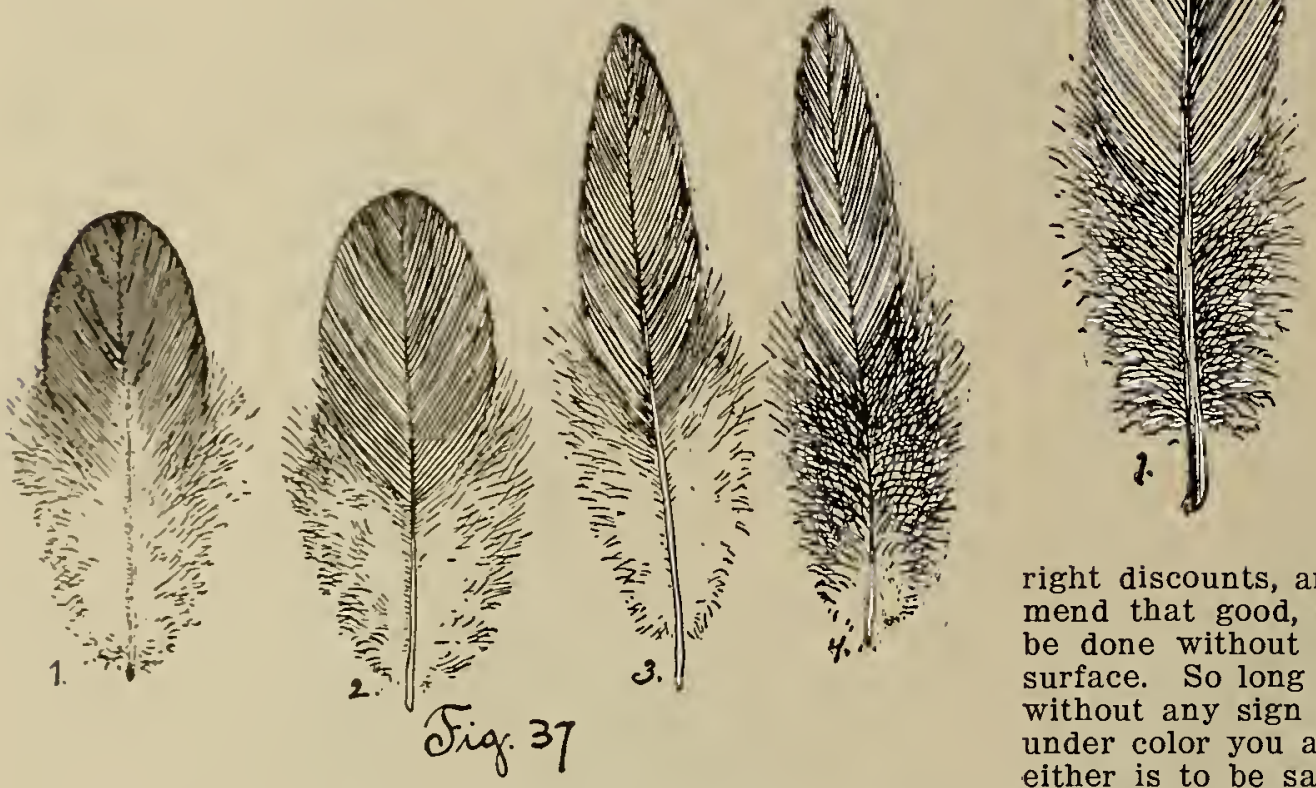

of adult cocks-that is, at the base of the tall-and would be discounted as described above.

Black being a foreign color, as the Standard calls for the buff, would be discounted in proportion to the amount of black in the plumage, for instance, the wing color has a valuation of 6 points, and should the color be sound except the biack and one-third be black, the out would be 2 , but if one-lialf be black, the out would be 3 , or fifty ner cent.

Tail, having a valuation of 5 points, would be graduated accoldingly, and feather No. 1 (Fig. 38 ) would be discounted 1 point; feather No. $2,1 \frac{1}{2}$ points, while feather No. 3 would be discounted 3 points. Feather No. 3 is decidedly defective. It is not only black, but is muddy, mixed with other color, in fact, is an eyesore from a fancy standpoint, and you can hardly discount it enough to place it in the rank it justly belongs. But, with these lllustrations, we believe the reader will have no trouble in arriving at the
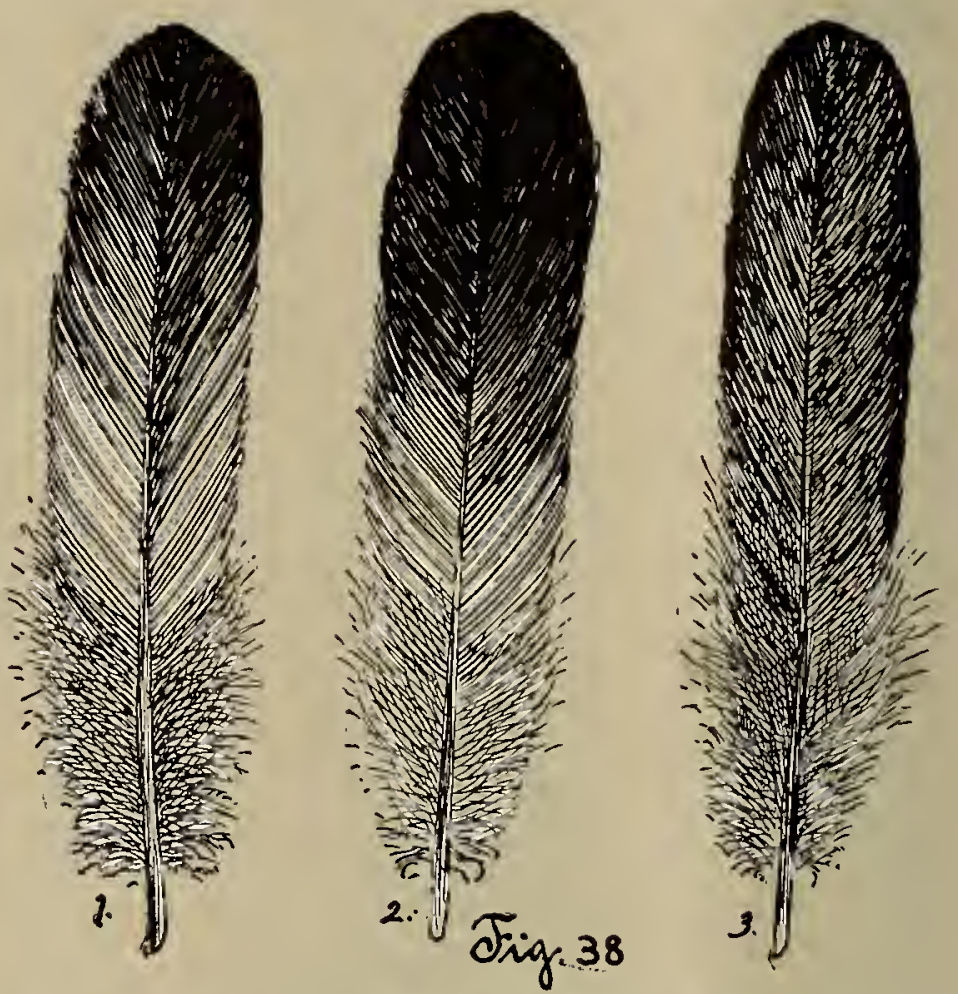

right discounts, and in mating this color we would recommend that good, sound under color be used when it can be done without bringing your red or chestnut shade to surface. So long as good, even surface can be maintained without any sign of foreign color and still retain the rich under color you are breeding in the right direction, but if either is to be sacrificed, then we would recommend that you sacrifice under color rather than surface color, as a splotchy, uneven surface is an eyesore, and even though there may be some defective under color, your specimen shows better and is of more value with some light under color than it would be with a chestnut or red surface.

In the breeding of buff fowls to produce color, no two breeders seem to follow the same rule, one claiming one color will produce and still others going entirely opposite, claiming that two extremes will bring harmony, while still another will breed only from certain strains that have been bred in line for many generations to product certain shades -in fact, the breeding of buff, as we find it, depends largely upon the strain of fowls that you are breeding and what matings have been made prior to the time they come into your possession.

One thing that must be kept in mind at all times is that all sections of a fowl must harmonize-that is, the buff in one section shall be the same shade as in another, as a harmonious blending of buff in all sections is most to be desired. 


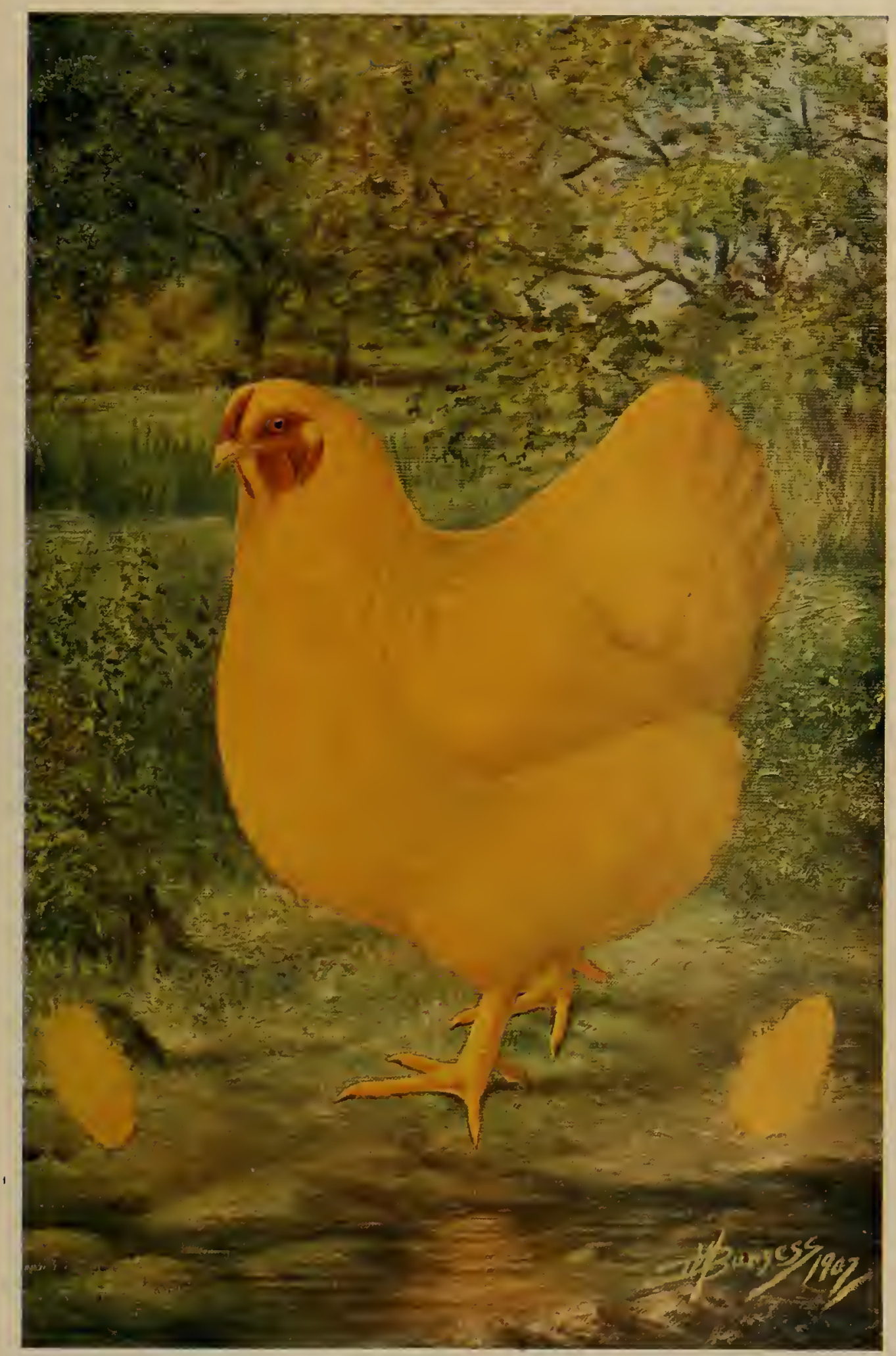

BUFF WYANDOTTE FEMALE.

Drawn to Conform to Standard Shape and Color as Described by the American Standard of Perfection. 



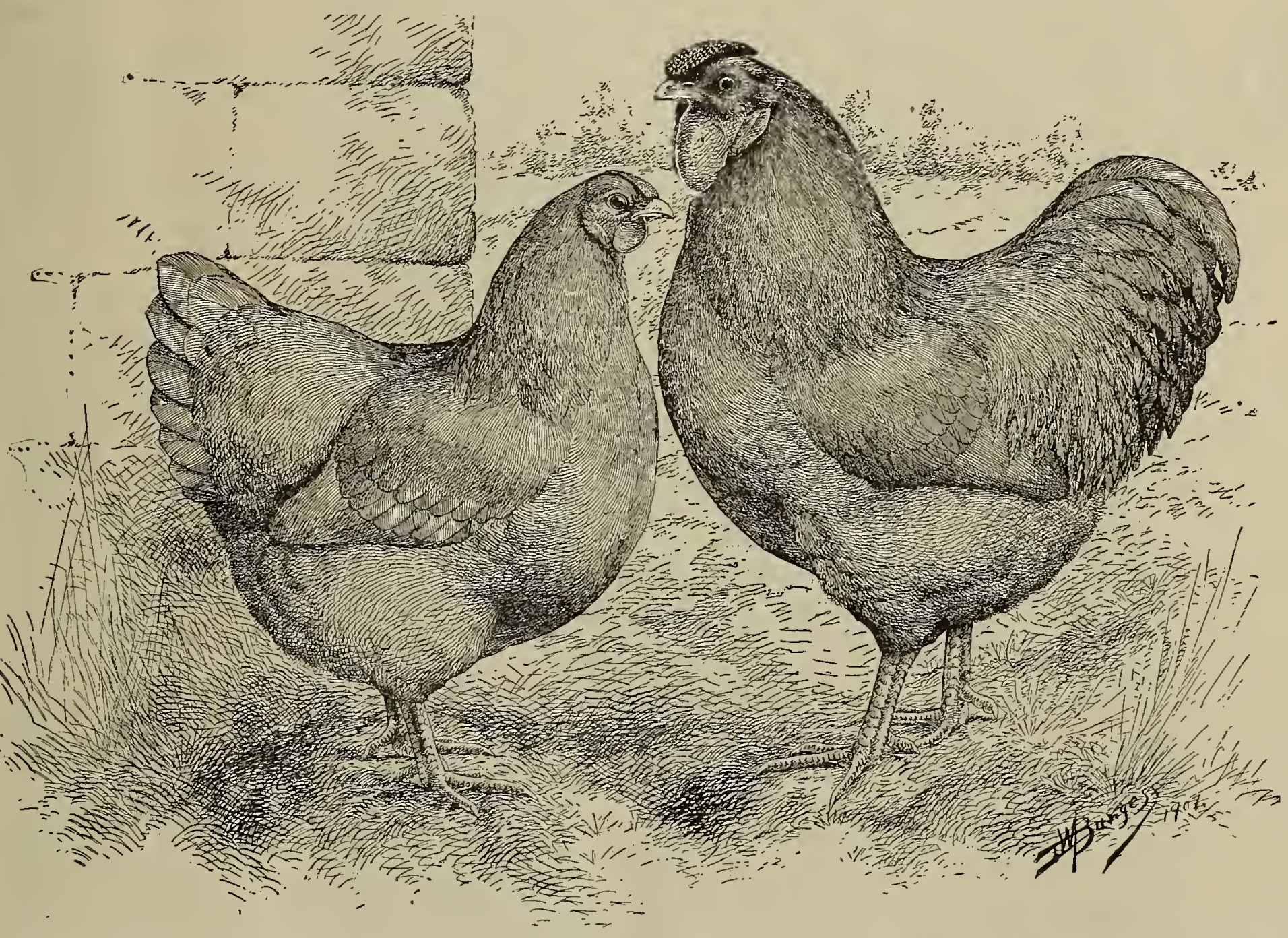

BUFF WYANDOTTE:, WINNERS AT CHICAGO, JANUARY, 1907-BRED, OWNED AND EXHIBITED BY SIMON 


\title{
PARTRIDGE WYANDOTTES.
}

\author{
Their Early History and Origin-The Breeds that Were Used to Produce the Color- \\ A Fight for a Name.
}

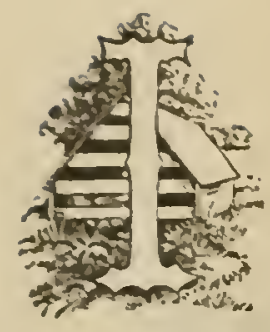

WONDER liow many of our Partridge Wyaudotte breeders of today call to mind the first birds of this variety they ever saw and the impression the new variety made ou them at that time-how many of you made auy notes that you can refel to now? I would gamble on it that not oue out of ten can recall the first ones $01^{\circ}$ have any fixed idea as to the quality at the time they were first exhibited, or how they came to give them any special notice, providing such notice was given. I am going to remind two well luown judges of our first introduction to this variety. At the Midcontinental Show, held at Kansas City in 1S94, there was a coop of these birds shown, I think by Mr. IV. A. Doolittle, of Sabetha, Kan., who was then breeding Goldeu Wyandottes. Mr. Sloots, Secretary of the show, called my attention to the exhibit, saying there was a newfangled iTyandotte entered by some "duck" from Kansas, but he had not been able to locate them. He said: "They are called 'Partridge Wyandottes,' and the only birds I can find are Golden Wyandottes."

At this time Tom Southard, of Kansas City, then a breeder but now well known as a poultry judge, came along, and he suggested that we look them up, and in going down the aisle we met Mr. F. W. Hitchcock, who at that time was one of the best known judges in the West, and invited him to accompany us.

The show was held that year in the old Priests of Palace Hall. This building had a main floor and a large gallery, and in the west gallery we found the birds, and they had not been uncooped. They were shipped in a crate made of paper cardboard, with partitions between each bird. We had to remove them to get a line on the color, and there nas quite a discussion in regard to them and how they had been produced. One of the party claimed that they were only runout Golden Wyandottes; that through careless mating had gotten a lot of lacing in back of females; but when, on closer examination, we found the same lacing on breast and body, as well as wing bows, we had to admit that some one was springing a new one on us.

The females at that time were not nearly so well pen. ciled as we find them today, but they were good for a new breed and had size and shape superior to many of the Silvers and Whites in the same show.

In females the penciling was quite good in wing bow and center of back; the cushion showed quite a bit of strippling up near the tail and the upper breast showed more or less shafting, but lower breast and sides were better than many Partridge Cochins in the same exhibition.

The male was good in neck and back. He showed some red in breast, something after the style of our pullet breculers of today.

Taking them all in all, they were of good quality and shrwed they were worthy of careful study. Later I learned the name "Partridge Wyandotte" had been given them by their orfignator, Mr. O. E. Thiem, of Iowa.

Abont this time the same colored birds were shown by othrer furesedrers in different parts of the country, who named thern "Golden Penciled Wyandottes," the late Ezra Cornel] bring the one, I belleve, to suggest this name. Then frj]rowed some long newsparer controversies as to the rorsurer narns and who was entitled to the honor of first produring and showing the new variety. This controversy rorisably did more to introrluce them than any one thing, as in a very short tirne we found good classes of Partridge Wyardottes in all the larace shows. This controversy was finally ended when the American Poultry Association, at their Chicago meeting, adopted them as a Standard fowl under the name of Partridge Wyandotte, and the Standard, as prepared by the Western originator, Mr. Thiem, was adopted almost to the letter.

As to how the variety originated, we publish here a letter from Mr. Thiem, written especially for The Inland Poultry Journal, which tells the tale in his own words. The writer is under the impression that $\mathrm{Mr}$. Doolittle showed the birds at Kansas City, but whether they were entered in his name or that of Mr. Thiem I cannot say. But be that as it may, the birds leferred to were the original Thiem strain.

\section{CORRECT HISTORY OF THE ORIGIN OF PARTRIDGE WYANDOTTES.}

I have bred fowls since 1850 , and since that time I have seen the advantage of crossing dieffernt breeds in order to establish new breeds or varieties that would be im. provements on the old ones.

I began in 1878 more scientifically and with a certain purpose in view. Not being satisfied with one thing long, I undertook to make several new crosses. It takes lots of patience, labor and time to reach the desired end, and in order to succeed in a shorter time, and more thoroughly, I co-operated with the late James McKeen, of Omro, Wis., who was known the world over as the originator of the most beautiful fowl ever admitted to the Standard of Perfection-now known as the Golden Wyandotte.

The history of this fowl is probably known to the majority of the breeders as a cross between the Partridge Co chin, the Silver Laced Wyandotte and a Game fowl of a deep buff color, with black tail and wings and a clear yellow leg, known as the Winnebago.

In 1880 the Golden Wyandotte was again used as a cross with the Partridge Cochin, and the old Partridge Cochin was crossed to a Winnebago. The offspring of these two crosses was then recrossed with the Wyandotte shape. with the Partridge Cochin color.

It was in 1893 that our efforts were crowned with success, and in $1894 \mathrm{I}$ was able to show the first birds of our labor at the great Midcontinental Show in Kansas City, when we, to our great surprise, learned that other parties a thousand miles away were working in the same direction.

The Partridge Wyandottes, as we have called them, are a strictly American breed. The pullets weigh $5 \frac{1}{2}$, hens $61 / 2$, cockerels $71 / 2$, cocks $81 / 2$.

In $1894 \mathrm{Mr}$. McKeen and I prepared a Standard of this variety, which the American Poultry Association adopted with very few changes.

The Partridge Wyandotte is a very hearty fowl, and really the fowl for our Northern climate. The amount of Cochin blood in them makes it easy for breeders to get them up to Standard weight. The Game blood, which has given them life and activity, has also given them a compact form, and has produced a fowl for the table fit for a king.

The vigor of three different breeds put in one has given us a breed of most prolific layers, which will equal any Minorca or Leghorn, and have outdone the greatest English breed-the Orpingtons-at a contest made by the English.

Many flattering compliments have been paid me by large breeders in foreign countries. Birds sent by me to England, Japan, Africa and Australia have stood a remarkable test in those countries. Having made several shipments to fanciers in Australia, the birds have attracted such wide attention as to induce the Government to try them in an experimental way, and have negotiated with me for the purpose of furnishing fowls for their experimental stations. 


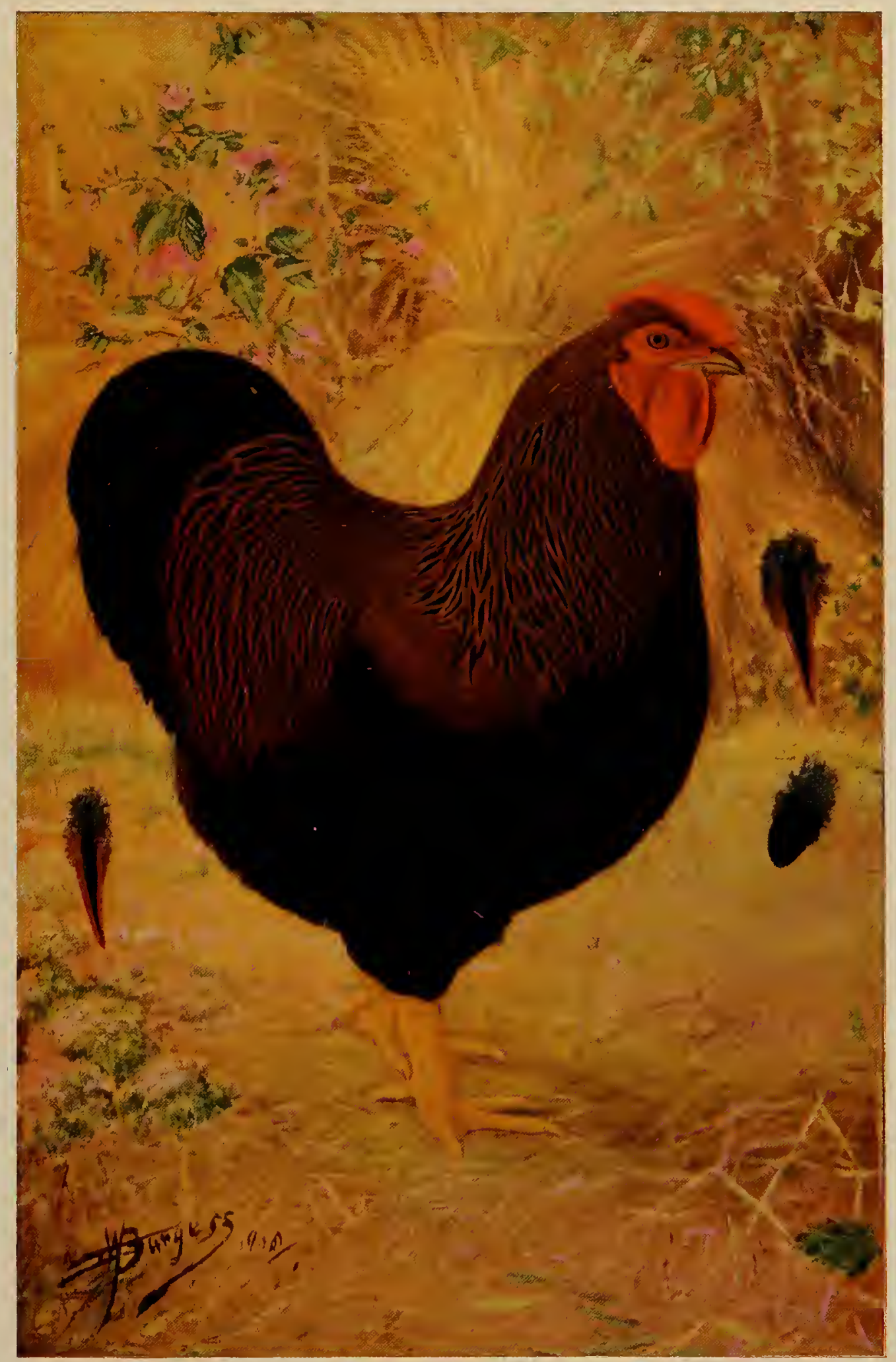

PARTRIDGE WYANDOTTE MALE.

Drawn to Conform to Standard Shape and Color as Described by the American Standard of Perfection. 

After the death of James McKeen, who so kindly remembered me in his will by a nice bunch of our own creation, I co-operated with Mr. W. A. Doolittle, of Sabetha, Kan., who bought the remaining flock of the widow of the late James McKeen. The result of this combination is the present standing of the noble Partridge Wyandottes, which have won laurels at the largest shows in this country, such as Boston, New York, St. Louis, Chicago and Kansas City. Reports coming from different parts of this and other countries saying that they never handled such fowls in their lives is enough to speak well for this new breed.

Long live the Partridge Wyandottes, and we wish the best of success to all breeders of this variety.

\section{Denison, Iowa.}

E. O. Thiem, Originator.

With this description of the origin of the Partridge Wyandottes, which we believe to be the most authentic ever appearing in print, we will now take up this variety section by section, calling attention to the defects to be found in them as to color; in shape, the description of the Silvers will answer for the male in this variety. The female we will refer to and describe the comb and other sections not referred to in the Silvers. cherry red, and it seems that the Standard should go a little more into detail and say what shade of red is most desirable.

Neck, while a very important section in all varieties of the American class, is not so well understood by the breeders of Partridge Wyandottes as it should be, and the discounts are often lighter than we believe the Standardmakers intended them to be. It is no small task to get correct color on necks of parti-colored birds of any variety, and especially is this true where the double mating is resorted to or the color of female is different from that of the male. When we call for striping in the backs of males and penciling in the backs of females, with practically the same word description of color of neck, we have set nature quite a task, and it is only to be expected that the percentage of really fine colored specimens will be few and far between.

In our illustration (Fig. 39) are shown some hackle feathers that illustrate a few of the defects quite often met with.

Feather No. 1 is good in lacing and there is good color of striping on one side of shaft, but the other is broken up, showing more red than black, with the two colors inter-

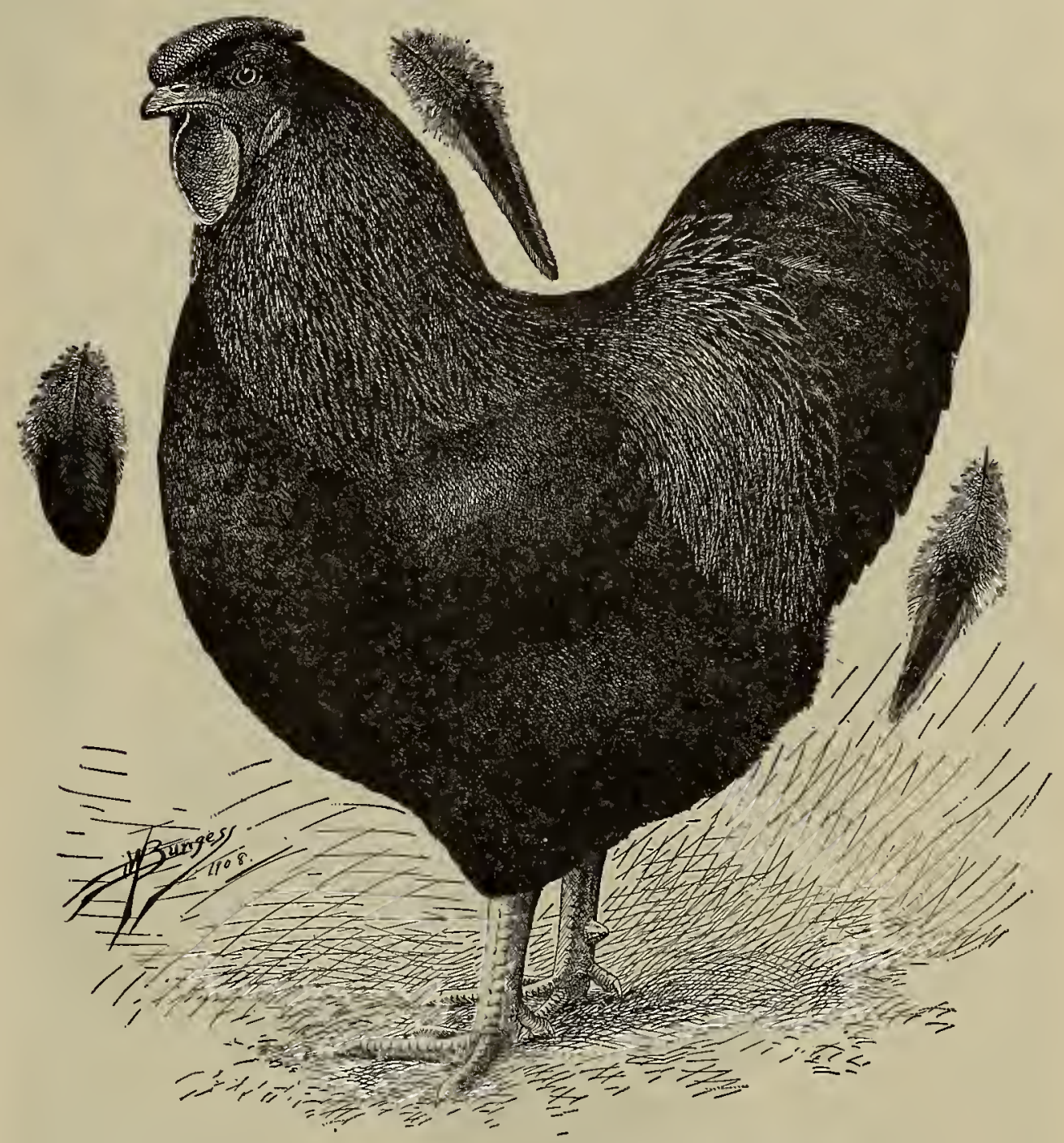

STANDARD PARTRIDGE WYANDOTTE MALE.

Neck.

The Standard describes this section as "red with a distinct black stripe through each feather, tapering to a point near extremity of feather; under color, dark slate."

There is considerable difference of opinion among the breeders as to what shad of red is most desirable for surface color, some wanting a rich cherry red, others a lighter shade, running near to lemon, and others a dark color approaching mahogany. In the best specimens that we have found the color that has shown to the best advantage is a red that is light enough in color to make a contrast between the black striping and surface color. This is stronger than a lemon, but hardly so strong as is classed as mixed. A neck snowing feathers like this should be discounted 1 point.

Feather No 2 shows black enough at end, but does not extend far enough from the point, and should be discounted 1 point.

Feather No. 3 shows a defect common in this variety, especially if strong colored males are used as breeders. The inside black stripe is good, but the color runs to the end of feather, making the lower edge of feather show black with a dark ring around the base. A neck like this should be discounted 1 point.

Feather No. 4 shows but very little sign of striping or penciling, being entirely red. Such feathers are common in the necks of pullet-breeding males, and should be dis. 
counter 3 points when found in competition for mrizes in the show roow.

\section{Back.}

ln this, as in other yorictles of the 11 yaudotte back is ame of the most importint scetions from a color as well as a shape standpulnt, and is one of the hardest to set right. The Illustrition as shown in Fin. 39. representiug defective foifliers in neclie compare furotibly witl the defects that are fommi in the back of males, and would be discounted moprortionately. There is still another defect that is com. moll in bicks of Patridge II yundote males, and that is under colur a creat maur specimens will show wite at mots of foathers mp neal the center of back, which gradu-

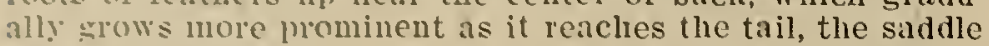
and tiril coverts quite often showing what is termed a "cotton miner color:" This defect is ralued at from $1 / 2$ to $11 / 2$ points. as in degree.

The Standaid description for color in this section is: "Back-Dark red (that is, the portion between the wings, formins the section from cape to where saddle feathers appear). Saddle-Red with black stripe through eacl feather. Under color-Darli slate, red shafts allowable."

The have studied the description of this section sev. eral times, and the words "shafting allowable" are, in our opinion, an error. It is either correct to have it there and all others should be discounted, or else it should be discounted for being there and other color correct. Reddisli sliafting would, no doubt, add to the value of the plumage from a pullet-breeding standpoint, but we doubt rery much if it would were the male intended to head a nen for producing first-class exhibition males. However we can only talie the Standard for what it says, but this is one section that Partridge Wyandotte breeders should malie a note of and instruct your Revision Committee to
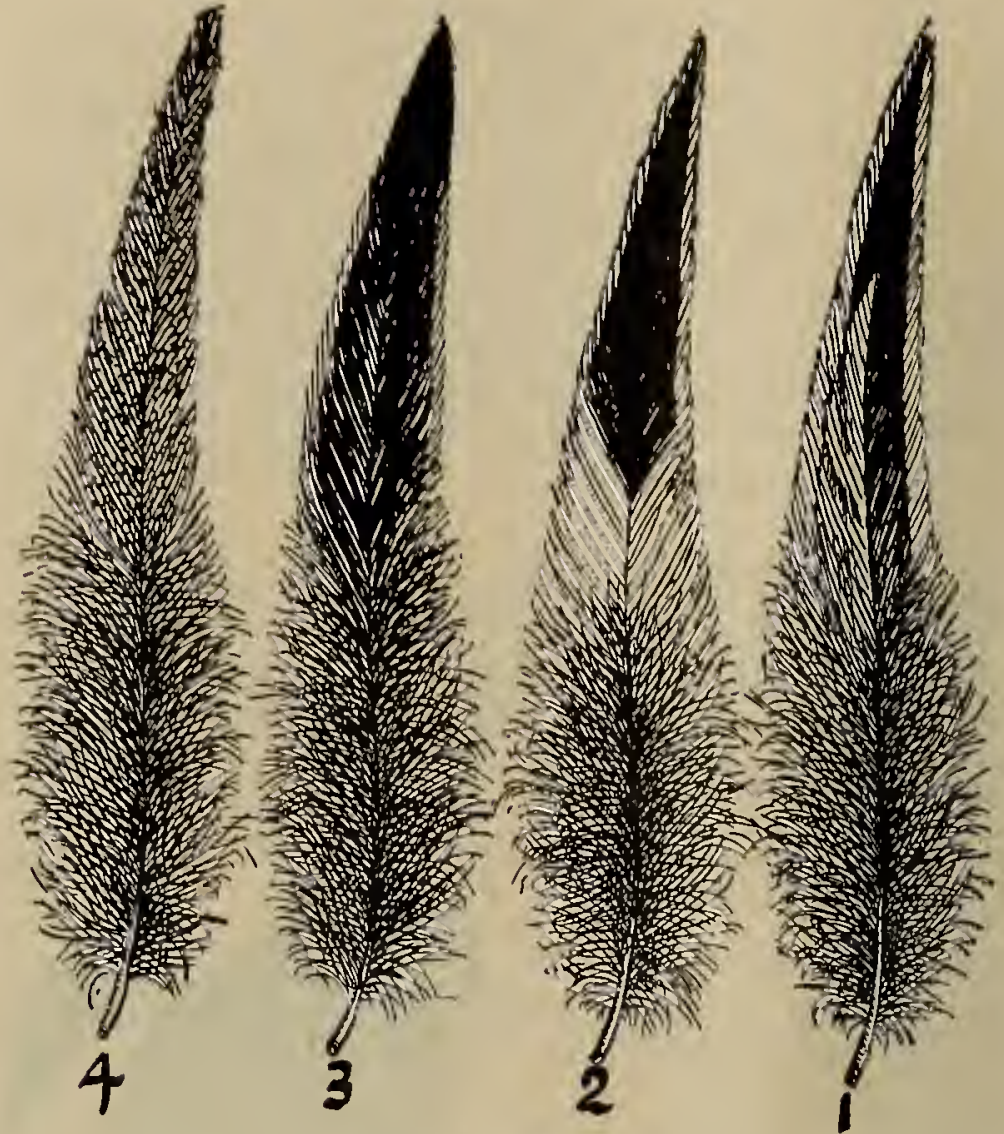

Fig. 89.

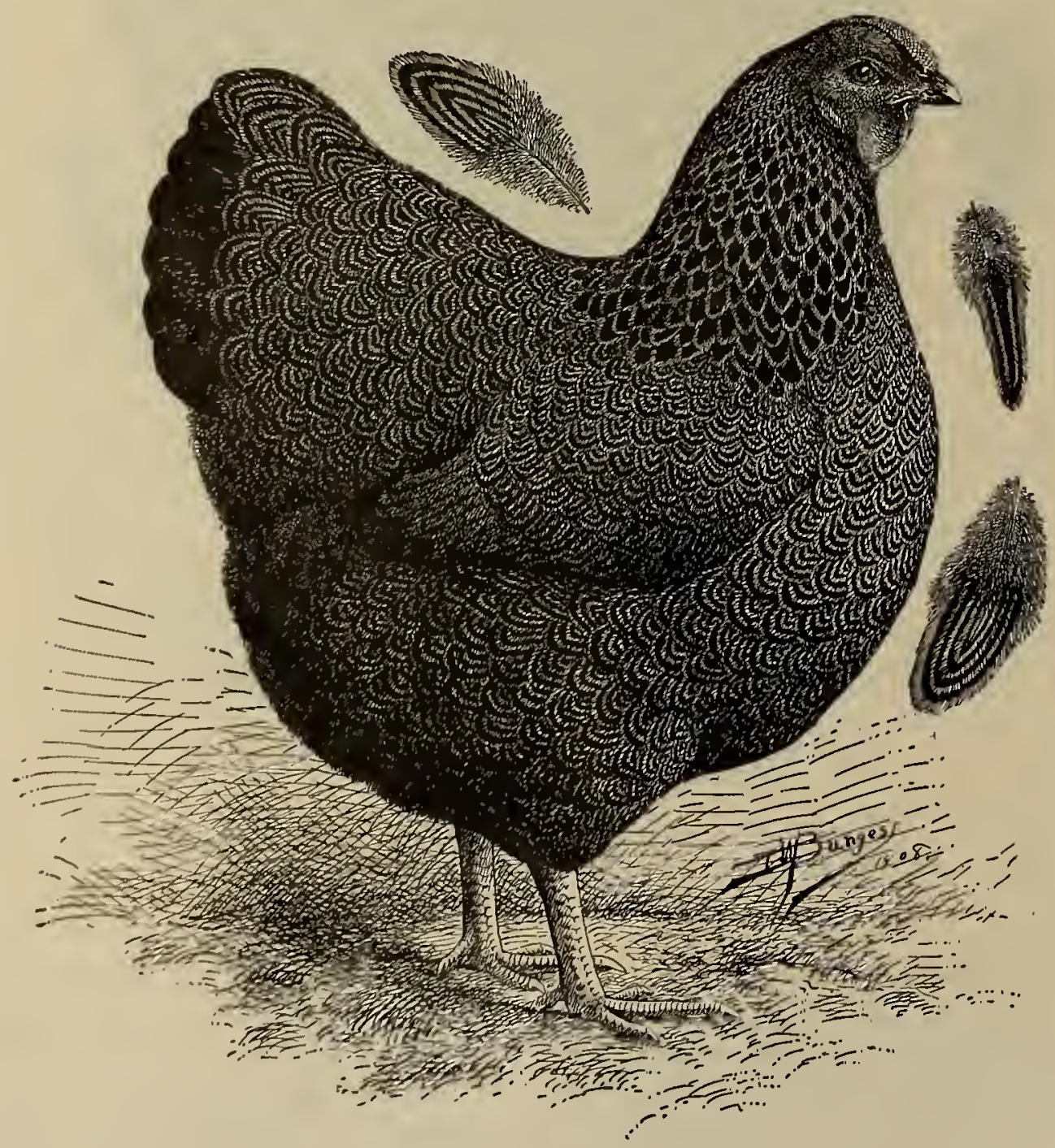

STANDARD PARTRIDGE WYANDOTTE FEMALE.

Gither eliminate this word description or insist on it being considered ldreal. We wili leave this to the breeders of this popular variety to deride, but really we prefer the back without the red shafting. 


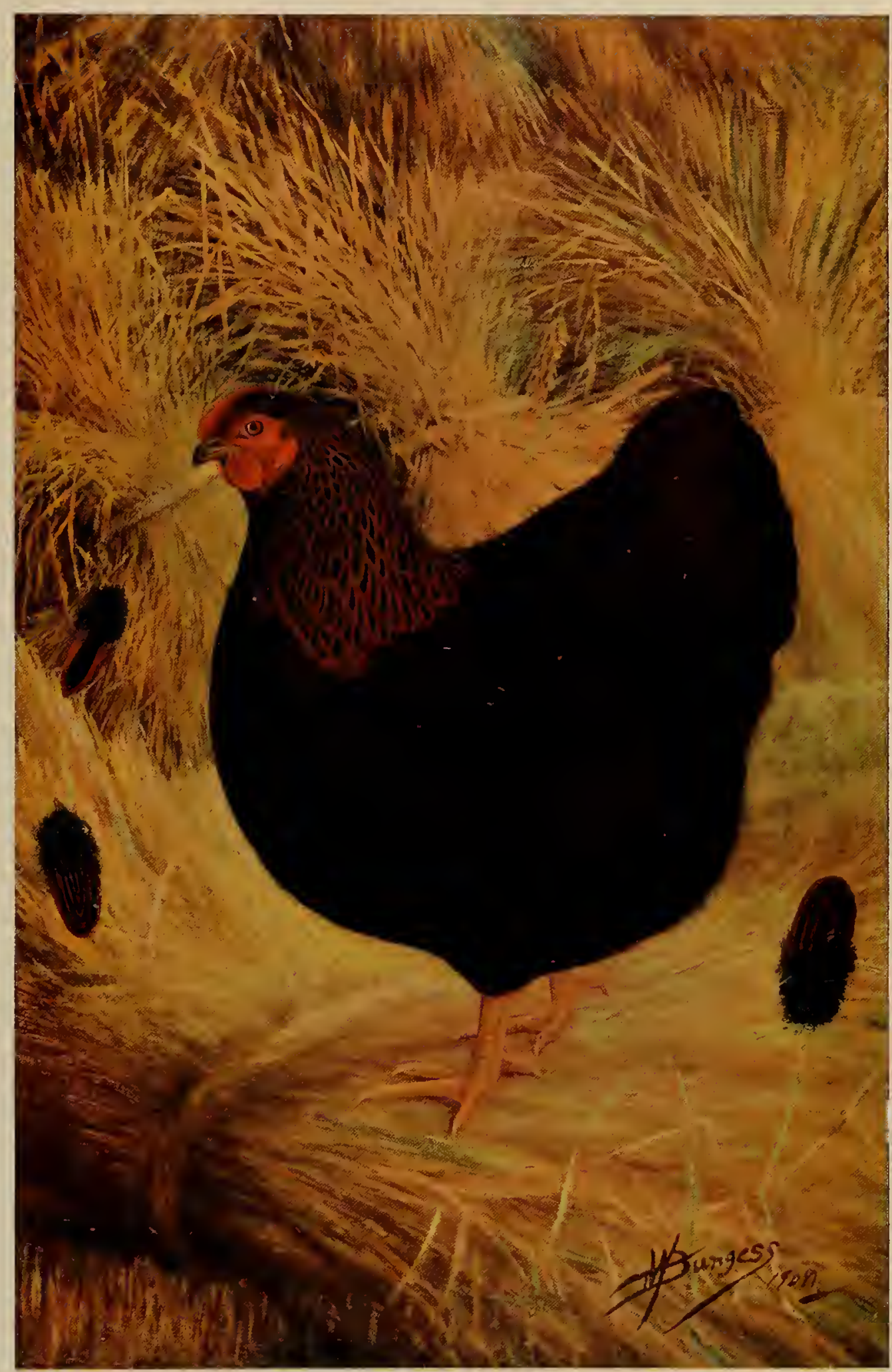

PARTRIDGE WYANDOTTE FEMALE.

Drawn to Conform to Standard Shape and Color as Described by the American Standaré of Perfection. 

Wings.

In color the wing of the Partridge Wyandotte male is not, as a rule, very defective - in fact, it is seldom that this section is cut to exceed $1 / 2$ to 1 point.

The Standard describes it as: "Primaries, black, lower edge red; secondaries, black, the outside web red, terminating with black at the end of each feather; coverts, greenish black, forming a well defined bar of this color across the wing when folded; bows, red; fronts, black; under color, dark slate."

About the only serious defect we find in color of this section is white primaries and purple barring in the wing bar. This purple barring is found in all parti-colored breeds where there is a solid black bar across this section, and when it is found should be discounted from $1 / 2$ to 1 point. When white appears in primaries or secondaries, the out is from $1 / 2$ to $11 / 2$, as in degree.

We have here illustrated two wings that will materially assist the reader in forming an idea as to the valuation. A wing like Fig. 40 should be discounted 1 point, while Fig. 41 should be discounted 2 points, as it shows entirely too much white, and should this color be mingled with red or black, the defect would be even more severe, making it 3 points for the same defect.

\section{Tail.}

The Standard describes the tail of the Partridge Wyandotte male as: "Black; sickles and coverts, glossy greenish-black; lesser coverts, glossy black, but may be edged with red."

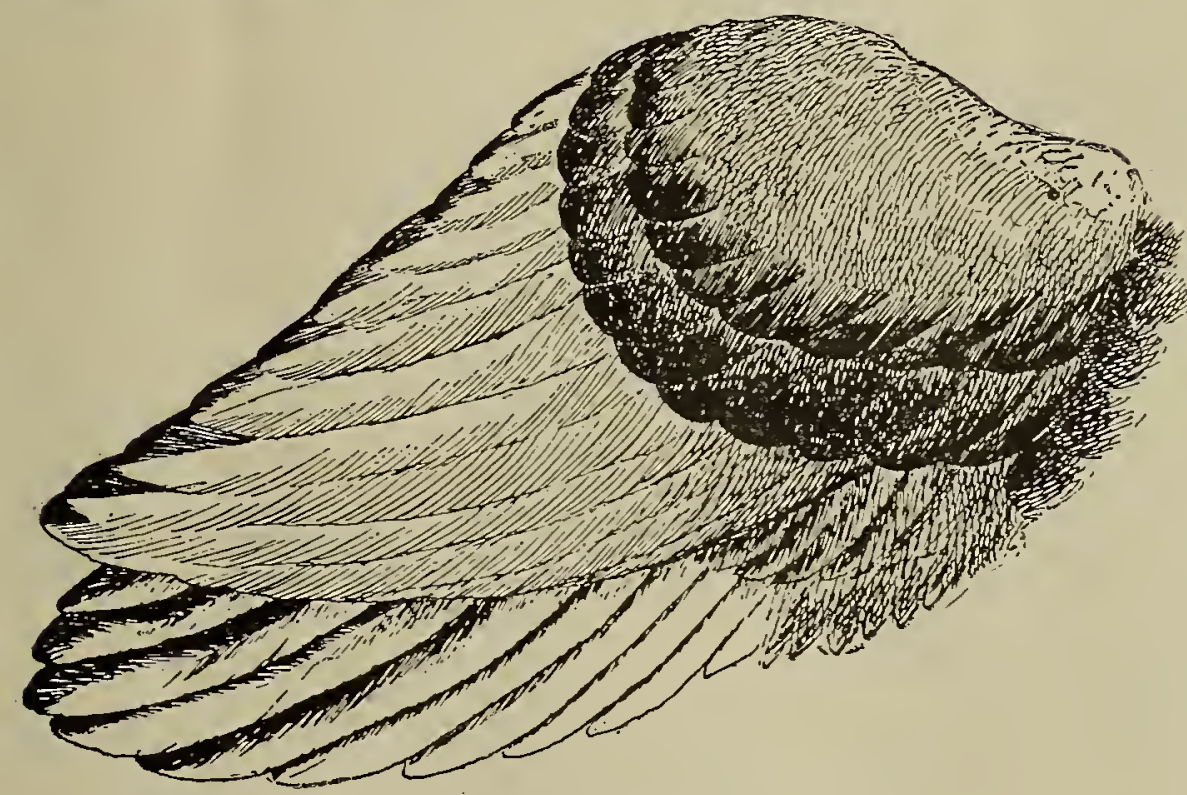

Fig. 41.

As a rule there is but little fault to find with the color of the male, except as referred to, but in wing bows we occasionally find a purple barring across the sickles or tail coverts, and when this defect appears the section should be discounted from $1 / 2$ to $1 \frac{1 / 2}{2}$ points, as in degree. If any white shows at base of tail, out is from $1 / 2$ to 2 , as in degree.

\section{Breast.}

The Standard describes this section as "Glossy black; under color, dark slate." In looking over the best specimens that we find in the exhibition room we doubt if the word "glossy" should not be eliminated from this description, as the color in reality is dead black, and not glossy black, as described, as it is that portion of the bird protected from the sunlight and very seldom shows glossy sheen to plumage such as we find on other sections of the bird. However, this color is easy to understand, and any color aside from black would be considered a defect. It is quite often that ${ }^{\circ}$ we find specimens that have a trace of pulletbreeding blood in them that show red checks or splotches on surface, and especially up along the sides. This color should be discounted from $1 / 2$ to 2 , as in degree, and where purple barring shows up the out is from $1 / 2$ to 1 .

Another defect, while not common in show birds, is sometimes met with, is a light shade in under color, which the Standard describes as dark slate. Where the under color is too light, approaching white or light gray, the out is from $1 / 2$ to $1 \frac{1}{2}$. 
breving lens, and slould be cut from 1 to 1 th. and where the specinen shows this defect to any great extent shonld he debirred from the broding rands, as tosts liave proven liat it will reproduce itselt on the oftspring.

PARTRIDGE WYANDOTTE FEMALE.

Havins in onr cabinct a number of defective neck, head and comb illnstrations of Partridge Wyindotte femiles. II omitted these sections in sliape while scoring the silser 11 vandotte female, and we will now take the mufter 11y, illustrating some of the common defects as found in the averige exlubition, and placing a valuation on same, begimning with head.

This section will require a different description than the male, although the Standard description is the same. The formation of the head at its junction with the neck in the two seres is so differently arranged that we have considered it wise to fully illustrate and call attention to the sereral defects that are common. The Standard reads: "Hend, medium size and carried well up."

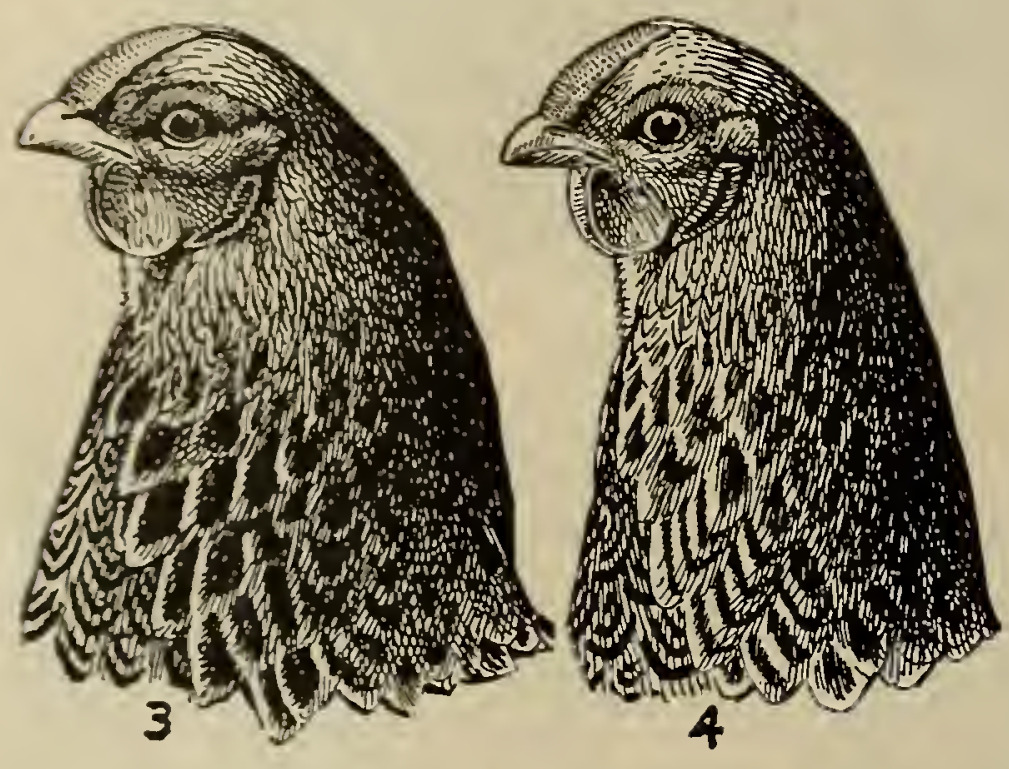

Fig. 42.

In Fig. 42 are illustrated a head, comb and neck that but little fault can be found with. We refer to head No. 3 in the plate. This style fits well the description of the Standard and is the shape sought for by our best breeders. If any criticism could be offered it might be in depth of head over the eyes. This one might be a trifle deeper at this point, but $1 / 4$ cut is sufficient for the defect, and if passed without a cut no severe criticism could be made.

Head No. 4 in Fig. 42 is too slim and narrow at rear, is not round enough and joins onto neck badly. Such a head should be discounted 1 point.
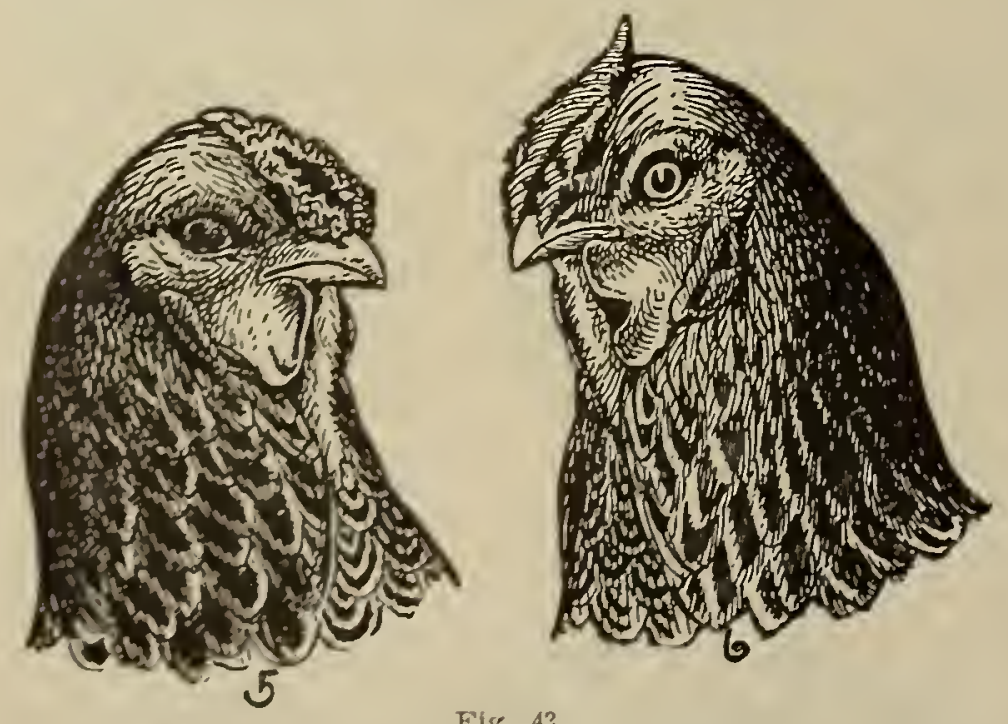

In Fir. 43, heads Nos. 5 and 6 are somewhat after the Brahma type. They are broad in skull, heavy over the
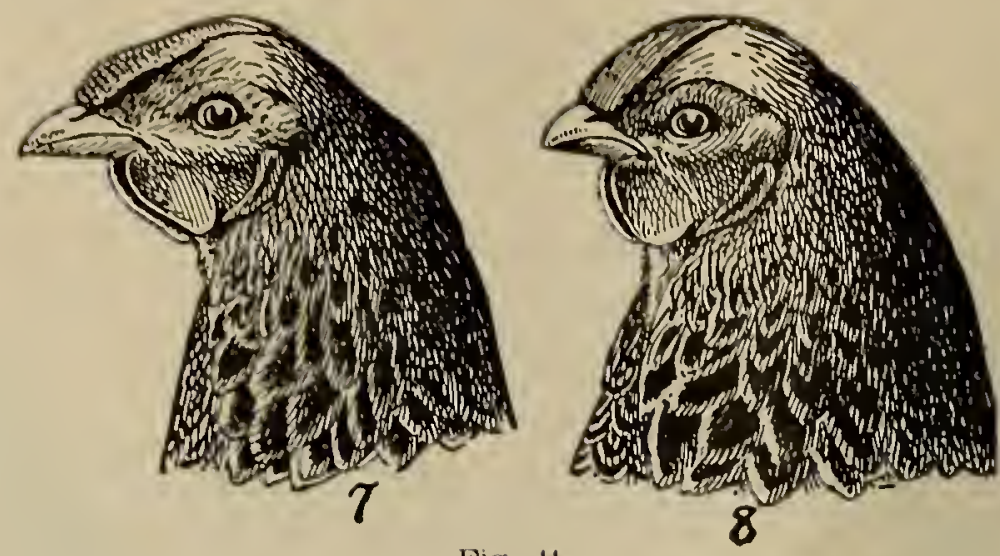

Fig. 44

eyes and very coarse. These heads should be discounted 1 point each.

In Fig. 44, head No. 7, while looking like a freal when compared with tle good ones, is no worse than we sometimes find in specimens of this breed. It is too long and narrow, is not deep enough through beak, is too long and straight, giving head too snaky or sickly appearance, and should be discounted 2 points.

Head No. 8 is good in general shape and is used here to illustrate defect in comb that will be called up later.

\section{Comb.}

While the section of comb has not so much importance attached to it by breeders as that of the male, it is, however, considered an important section even in females, as poor combs, no matter how well mated, are very likely to develop defects in the offspring of both sexes, and especially in the comb of the male. It is, then, vastly important that only good combs be used in the breeding pens.

The comb as illustrated in head No. 3 (Fig. 42) is quite good and very well proportioned for a female. No. 4 is a little high in the center, not quite flat enough on top, and unless carefully mated will produce what we call a "lumpy" comb on the heads of the cockerels.

No. 5 , in Fig. 43 , is about the proper length, but is too wide in front, is hollow in the center, and the corrugated points are too large and coarse. This comb should be discounted $21 / 2$ points.

Head No. 6 (Fig. 43) has a smooth surface, spike turns up at the rear like a Leghorn's; it has a narrow scar through the side and is poorly proportioned in every way. This comb should be discounted $2 \frac{1}{2}$ points. No. 7 , in Fig. 44 , is too long and too narrow, and, like the head it rests on, is too snaky for a comb of this breed, and should be discounted 1 point. No. 8 shows a well proportioned comb. It is the right length and width and ends with nice spike at the rear, but is too smooth on the surface, lacking in the corrugated points so much desired in this breed. This comb should be discounted 1 point.

\section{Wattles and Ear Lobes.}

Here are two sections in the female that have less value attached to them than the male. The wattles and ear lobes are, as a rule, good, even though other parts of the head are faulty. We have found many specimens scoring away down, being defective in almost every section, with almost perfect wattles and lobes. However, there are defects met with, and in order to give the amateur the correct idea of valuation of such defects we have illustrated a few.

In heads 3,4 and 8 are shown well proportioned wattles and lobes, and we would not discount them in scoring. In No. 5 we find the wattles straight and somewhat drawn; the lobes somewhat pinched and small for the size of the head, and should be discounted 1 point. In No. 6 we find the wattles and lobes are heavy and coarse, and full of wrinkles, and should be discounted 2 points. In No. 7 we find a drawn, sickly looking face, with half developed ear lobes and wattles, and should be discounted $11 / 2$ points.

In studying the defects illustrated here, please bear in mind that they would have the same effect on all varie. ties of the Wyandottes and would be cut proportionately hard, no matter what the variety.

\section{Color of Female.}

There is such a difference in the color of the winning females in the leading shows throughout the country that I deem it wise to give considerable space to them, and especially the illustrations showing plumage from different sections of the body. 


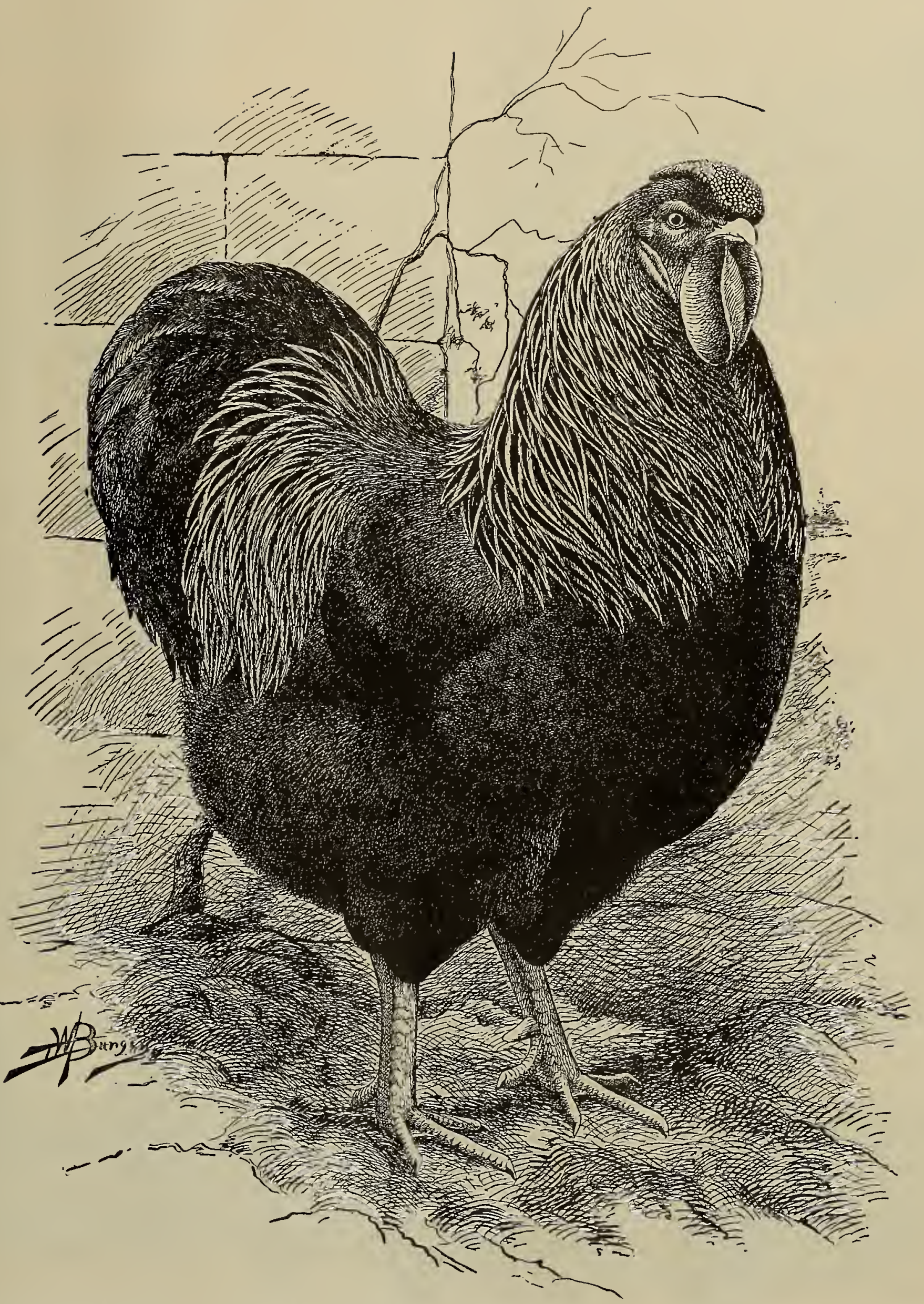

PARTRIDGE WYANDOTTE COCK, FIRST AT GREAT WORLD'S FAIR, ST, LOUIS-BRED, OWNED AND ENHIBITED BY W. A. DOOLITTLE, SABETHA, KANS. 
It is seldon that we find a foatler even from our best

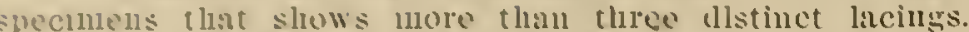
"lere are execptions to the rule, howevero, and oceasionally"

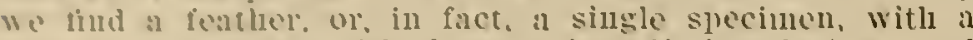
mumber of featleers witle three or four distinet lacings. and whou sucl snecinens alle found tley ale invaliably the hinudsondest bilds in the class, and while no preference, accordins to the standarel description. conld be given them,

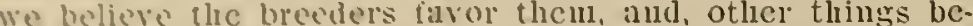
na cqual. in awarling prizes sliould give tleul preference over the domble or tinlo laced. as the case may be.

The standild is not as plain on the point of color as It should be but it is always well to lean in the direction of what secms to be improvemcnt, providing it call be proAnced. In siving preference to additional lacing it is neccssary to talie lnto consideration that this lacing must conform to the shape of the feather. as this is vastly important.
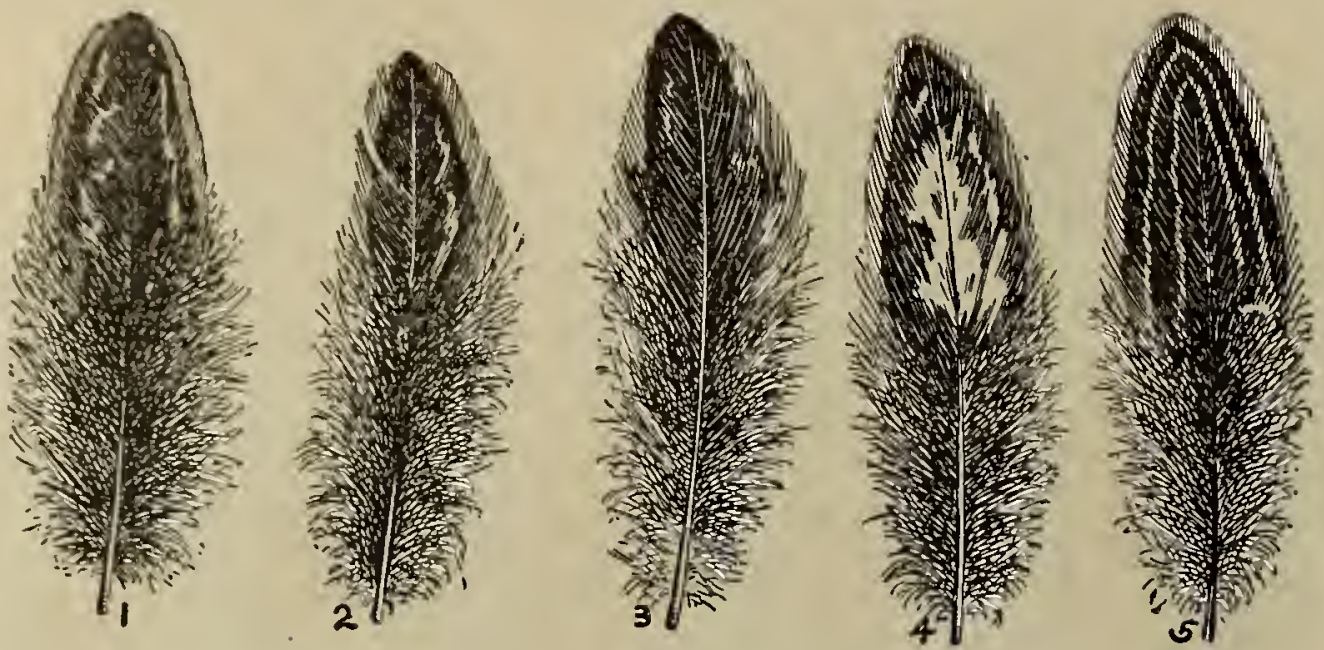

Fig. 45.

The ground color of the Partridge Wyandotte female should be mahogany-red or reddish-brown. The same Standard description follows in back, breast, body and wing bows, and to get the lacing with the correct shade of color is no small task. The Partridge Wyandotte females aver. age fairly good in this respect, especially so considering the short time they have been bred, and in our illustration of Standard Partridge Wyandotte female is shown our idea of surface color, together with the draping of feathers selected from what we believe to be the best Partridge Wryandotte female shown to date.

In head the Standard describes Partridge Wyandottes -Plumage, "redding-brown." This is perhaps as good description as could be given it, and, as a rule, it is a triflc lighter shade-more of an orange color in this section than Fie find in neck and back.

Neck is described as: "Red, with black stripe through each feather, tapering to a point near extremity of feather, and 1 an satlsfied the breeders of Partridge color, no mat. ter what the brecd, are willing to accept this as ideal.

ln No. 1 we find a featlicr that is somewhat broken in color and the lacing fails at the end. A neck showing haclile featliers like this sliould be discounted $1 / 2$ point.

Featler No. 2 is defective on one side of shaft only, with the same blunt point, and should be discounted 1 point.

Featler No. 3 has fewer lefects inside, but has more black at point and slould be discounted 1 point.

Featlicr No. 4 is good in lacing, but shows entirely too much white in centcr, and this whitc or golden color is in such proportion and scattered in such manner over the feather as to make it a serious defect from either an ex. hibition or breeding standpoint, and should be discounted 1 point.
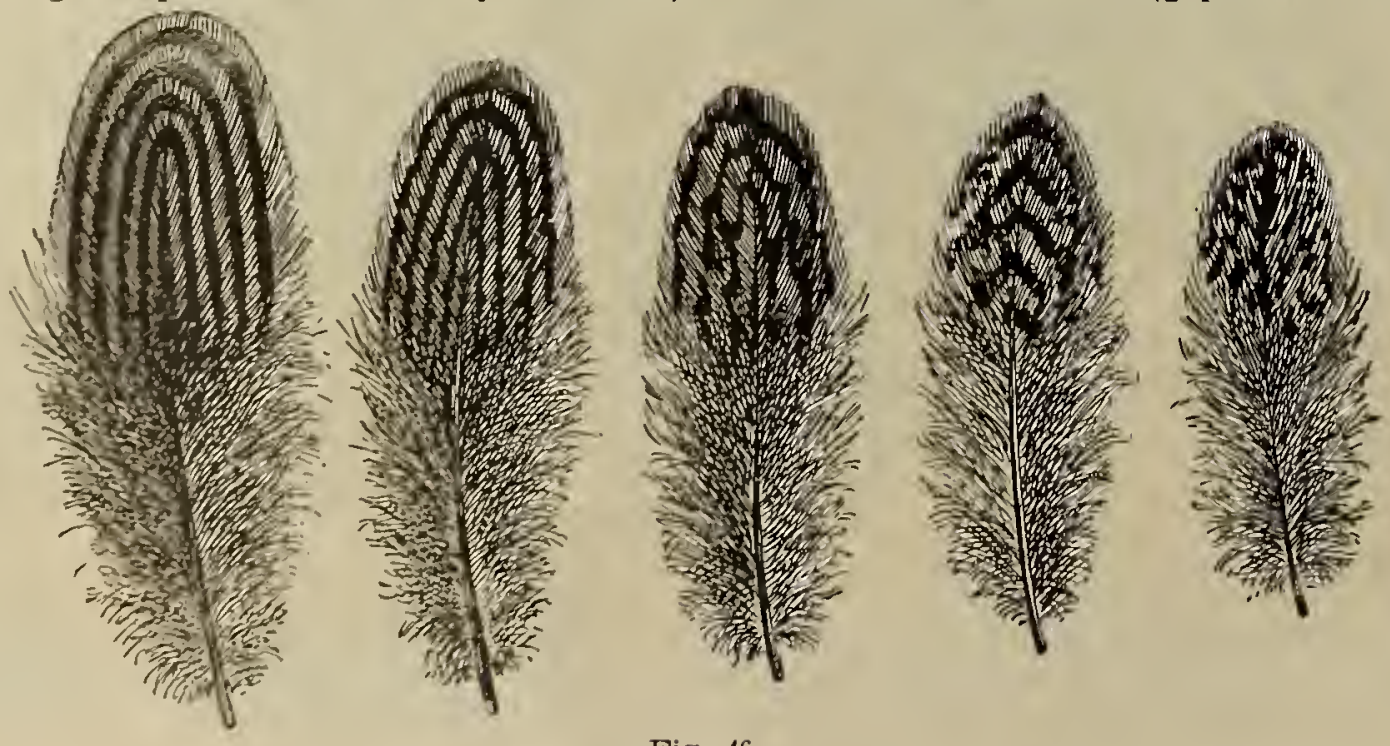

Fig. 46.

the red edging to be free from black; penciling in central Jortion of feathers allowable; under color, dark slate."

In Fig. $4 \%$ is shown a group of feathers that illustrate some of the defects as found in the necks of this variety. Feather No. 5 is what we believe the Standard calls for,
In Fig. 46 is shown a collection of feathers illustrating several of the defects that are found in the backs of our Partridge Wyandotte females.

No. 1 is a perfectly laced feather, and, aside from having more than the usual number of markings, could be classed as ideal.

Feather No. 2 in this collection, while good, does not show as distinct lacing, neither does it go deep enough in the web portion of the feather. A back showing feathers like this should be discounted $1 / 2$ point.

In feather No. 3 we find a defect, the lacing on it being zig-zag, or uneven, and docs not meet at point of center, as they should, but run past the shaft, lower markings being to one side. A back showing feathers like No. 3 should be discounted $1 \frac{1}{2}$ points.
In feather No. 4 is shown a defect that is slightly overdrawn, but one that is often met with in poorly bred specimens. There is no distinct lacing, black and red mixed together, giving the back a smutty appearance. A showing feathers like this should be discounted $2 \frac{1}{2}$ points. In feather No. 5 we have a defect which, while not 
comnion in this breed, is nevertheless met with. The feather is all mottled with a brownish cast, and looks like a feather from a poorly bred Brown Leghorn, as there is no lacing. The only redeeming point is that there is about the right proportion of black and red. A back like this should be cut at least three points.

\section{Breast.}

In Fig. 47 is shown a group of feathers w:th defects similar to those in the back, and feather No. 2 would be discounted the same as feather No. 2 in the cther group: while feather No. 3 is almost entirely lacking in black. Feather No. 4 doesn't show good black or red, has a faded. out appearance, and should be discounted at least 3 points. Here is one case where we take more from color than is allowed for either black or red, as both colors are defective. Feather No. 5 in this group was taken from near the throat, has a pepper and salt appearance, has about the right amount of black and red, but has no sign of lacing, and should be discounted $2 \frac{1}{2}$ points.

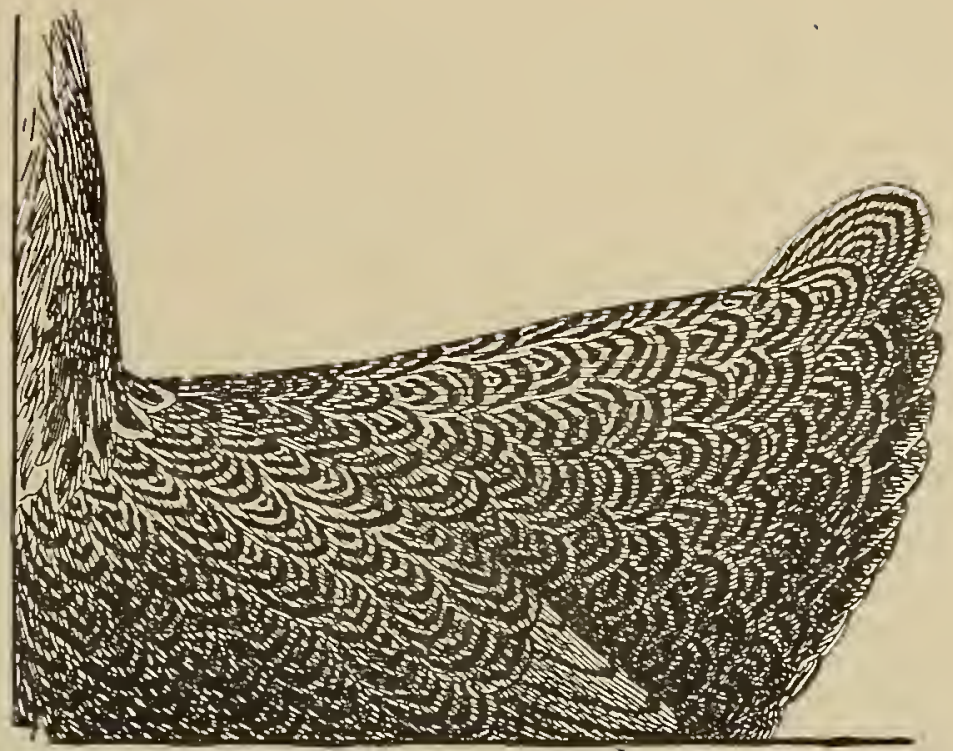

Fig. 49
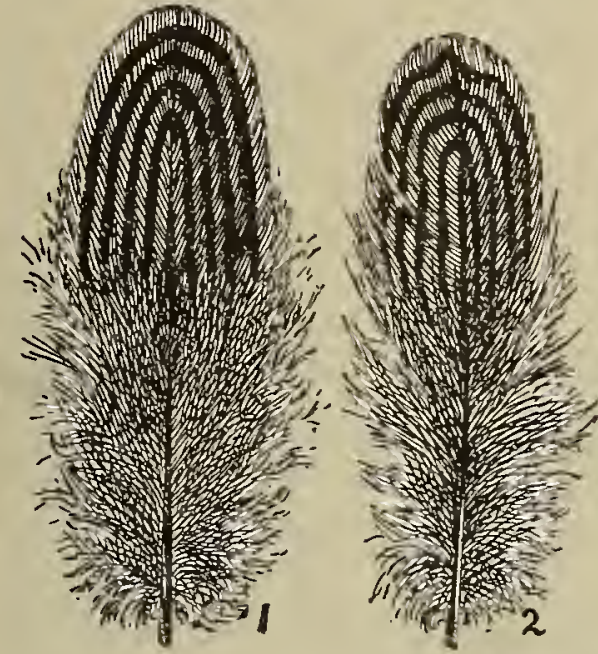

Fig. 47
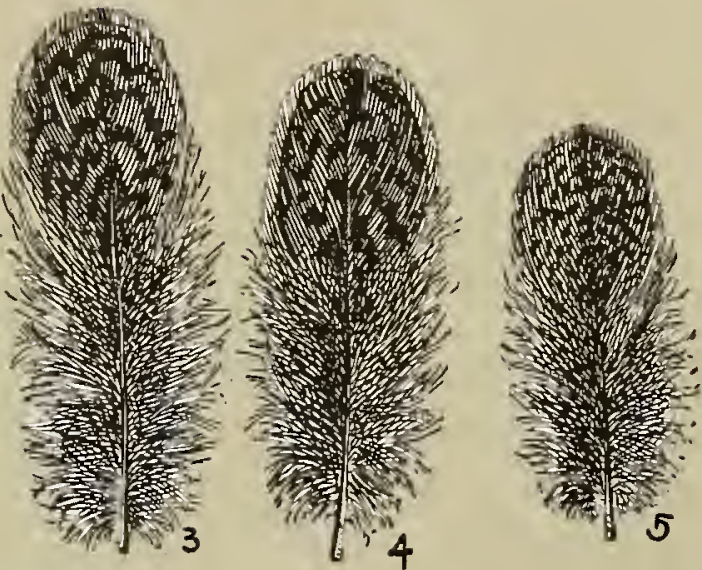

It is well at this time to call attention to some of the defects in shape of back, as found in the different specimens that are placed on exhibition, and give the valuation of same.

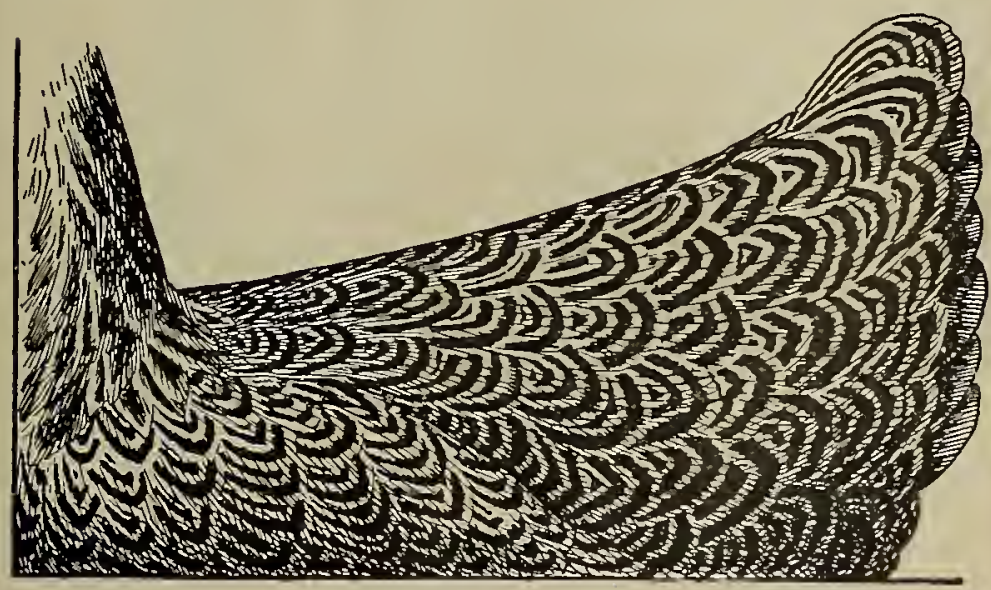

Fig. 49 .

In Fig. No. 48 is shown a back that is too straight and too long for à Wyandotte. This back resembles very much the general outline of a well-bred Light Brahma, except perhaps it is a trifle too narrow, and on a Wyandotte should be discounted $11 / 2$ points.
In Fig. No. 49 we have the same defect, only magnified. This back is practically level, there being no rise, even at tail, and is quite narrow and long, doesn't show broad enough, and should be discounted 2 points.

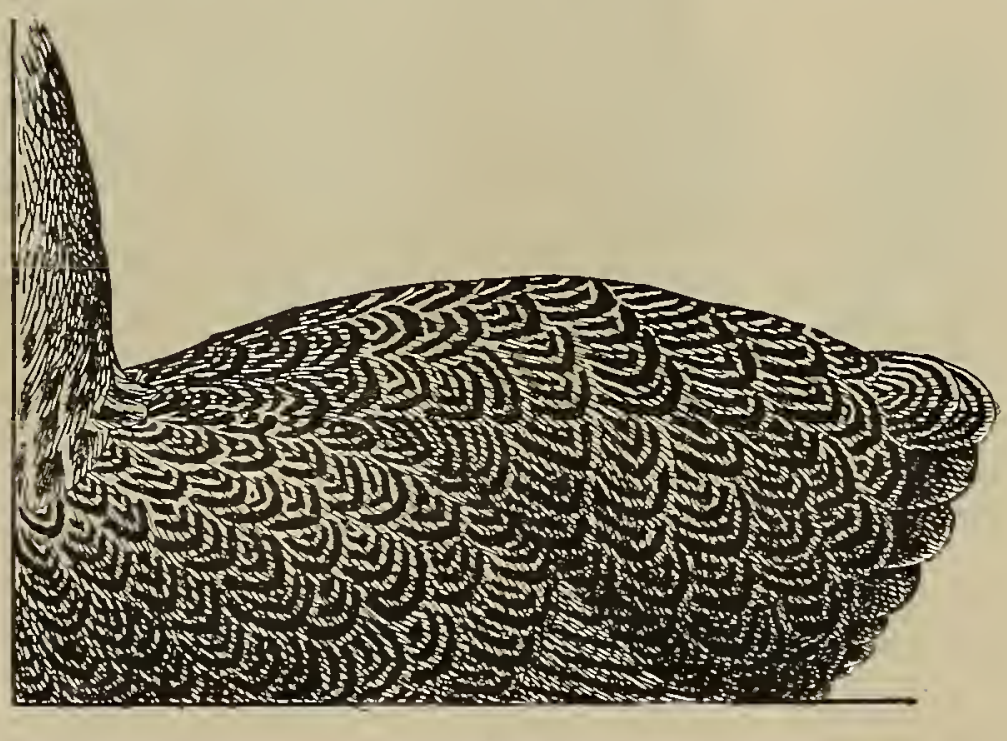

Fig. 50.

In Fig. No. 50 we have what is known as a "Cochin back." It is rather heavy in cushion, rises from shoulder to center of back and then slopes down to tail. While this is somewhat overdrawn, it is a fact we get in our Par- 


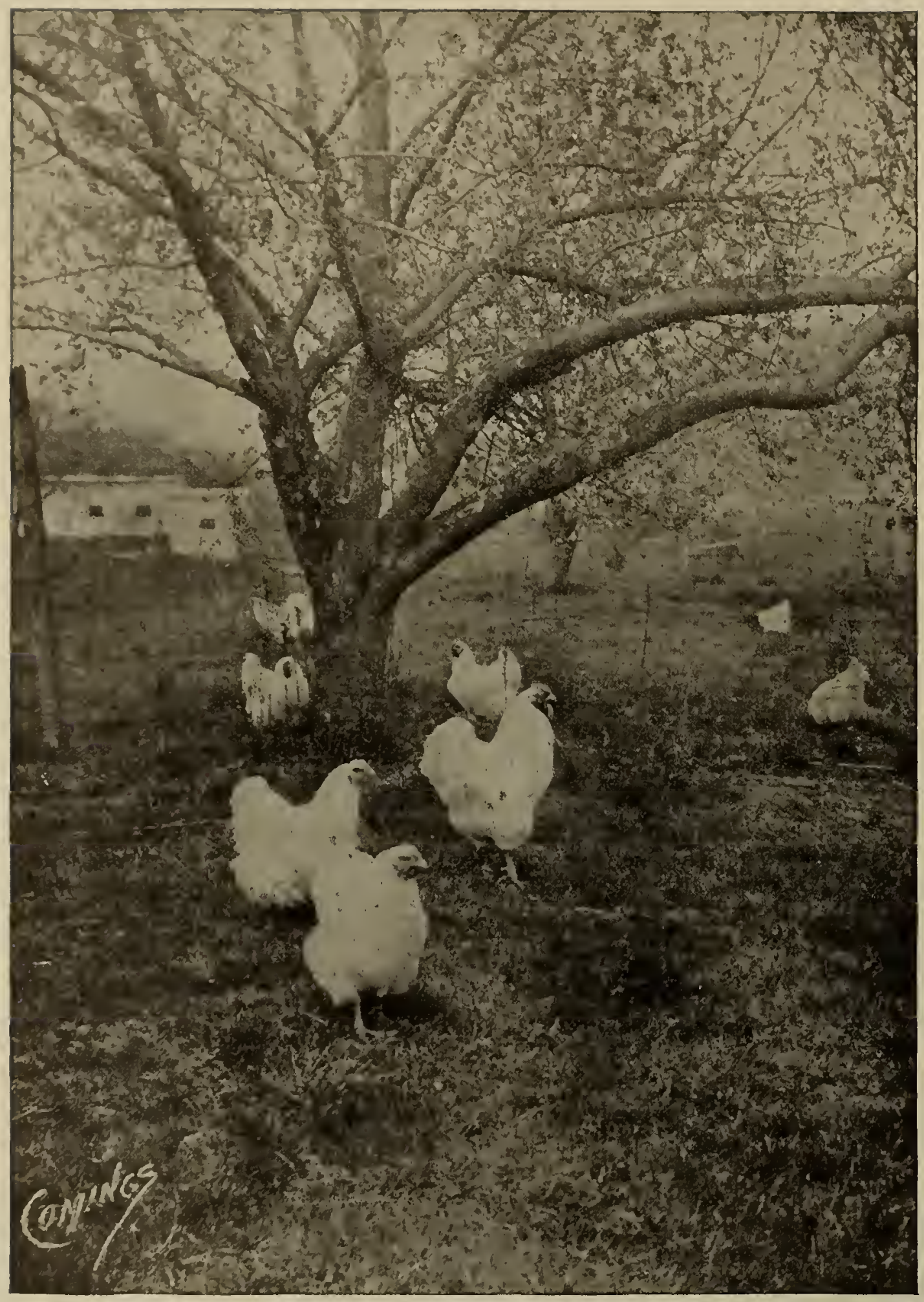

JUST AS YOU SEE THEM IN THE YARD AT HOPE, IND.

A Breeding Pen of J. C. Fishel \& Son's Famous White Wyan dottes. 
tridge Wyandottes quite a good many females, especially old hens, that show these Cochin characteristics, and some of them nearly as much as the drawing. This back is shorter than backs Nos. 48 or 49 , and no doubt if used in the breeding pens some good short-backed, short-tailed males would be the result, but it is defective from an exhibition standpoint and should be discounted 2 points.

\section{Body and Fluff.}

There is considerable stress laid to the color of this section, due to the fact that many specimens otherwise good will fail miserably when they reach the thighs or posterior portion of the bird. It is not to be expected that we will ever be able to produce Partridge Wyandottes that are laced entirely around the body, with as good feathers as we find on back and breast, but it is essential that we get the lacing down as far as possible and have all sections harmonize and blend, not alone in surface color, but in lacing as well.

In Fig. 51 are shown five feathers about as we find them in our best specimens. Feathers Nos. 1 and 2 cover that part of the body directly following the breast and around the thighs. Feather No. 2 is where the penciling begins to fade out as it rounds the sides, but this one is not very well marked. There is too much black on one inner web a dull black, outer web, mahogany-red or reddish-brown; coverts, similar in color to plumage of breast; under color, dark slate."

In Fig. 52 are shown three flight feathers. Feather No. 1 conforms closely to the Standard-black on one side of shaft and red on the other.

Feather No. 2 shows tracings of red in the black, and should be discounted $1 / 2$ point.

Feather No. 3 shows as much red as black, but it is splotched and runs together, and should be discounted $1 \frac{1 / 2}{2}$ points.

In Fig. 52a is shown a group of feathers taken from the wing bow or shoulder. All the feathers here illustrated were plucked from the same specimen. No. 1 , however, is a trifle overdrawn, showing more lines of lacing than the feather really possessed. There were three distinct lac. ings, besides the shaft, howerer, and they were about as evenly laced as it is possible to get them.

Feather No. 2 is somewhat muddy, the black and red edging together, and many feathers like this in a section gives the surface a rusty appearance, and should be discounted $1 / 2$ point.

Feather No. 3 is uneven in lacing and was taken from near the point of wing, and while the surface of it does fairly well, when you open the feather up for close in-

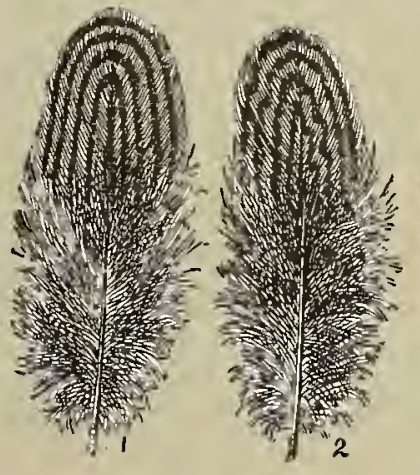

side of the shaft and too light on the other side, and should be discounted 1 point. Feather No. 4 , while taken from the rear of bird, is too uneven-it is more stippled than penciled, and should be cut 1 point. Feather No. 5 shows too light, not enough red in the feather, and it should be discounted 1 point.

Wings.

The Standard description of color in this section is good, and we believe is generally understood by breeders
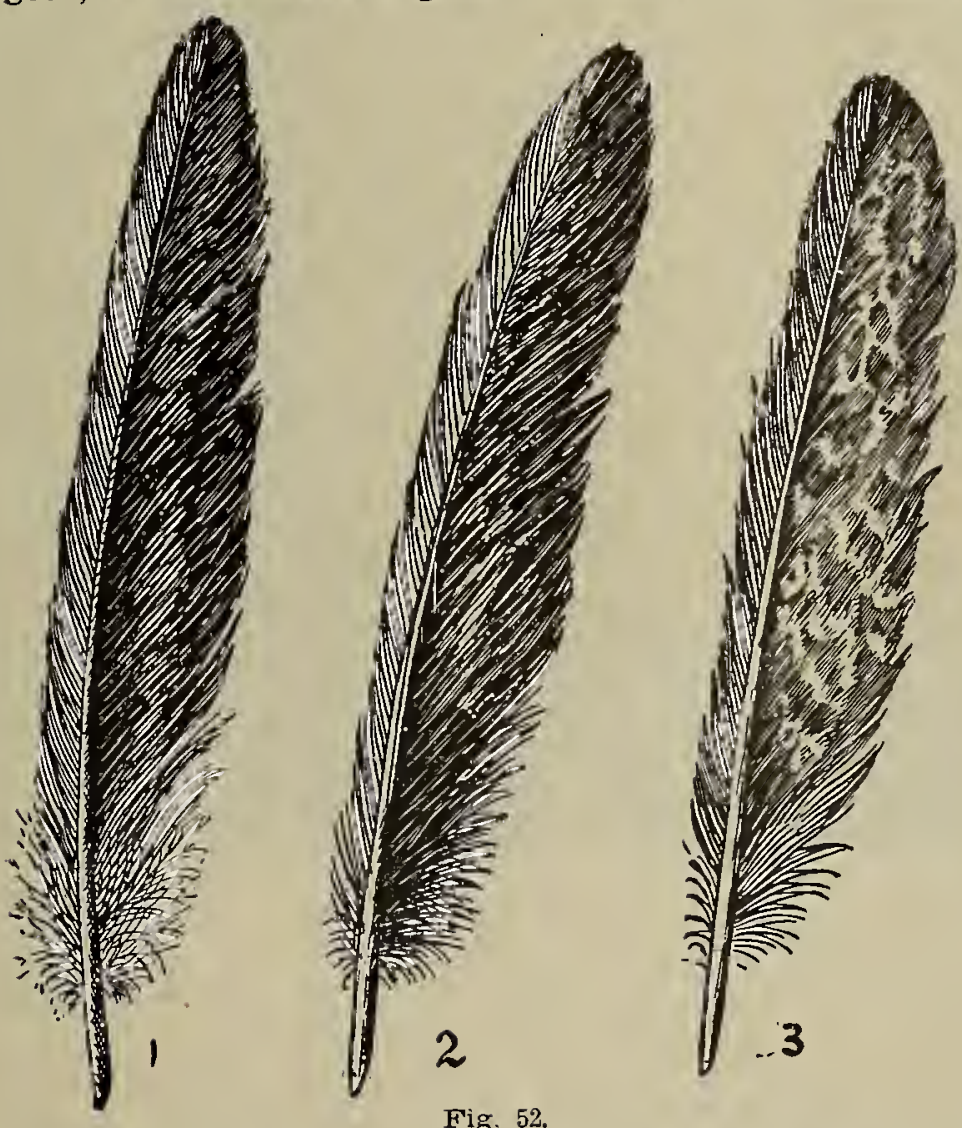

and judges alike. The description is: "Primaries, dull black, with an edging of brown on outer web; secondaries,

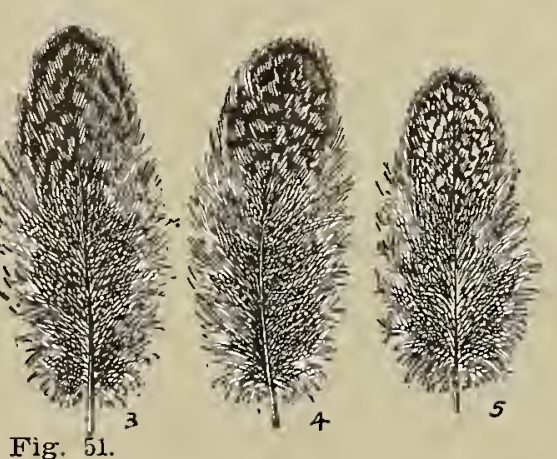

spection it all runs together, looking very much like a feather selected from a Brown Leghorn female, and should be discounted 2 points.

Feathers Nos. 4 and 5 have the same defect, slightly magnified, and should be discounted $2 \frac{1}{2} 2$ points.

Tail.

It is generally understood by judges and breeders that the tail of the Partridge Wyandotte female should be black -that is, the main tail except the two feathers usually termed the "deck feathers"-but the Standard description does not call for black-that is, absolute. It says: "Black or brownish-black, the two highest main tail feathers penciled with reddish-brown; coverts, well penciled, similar in color to breast and body." And, it should add, similar in lacing.
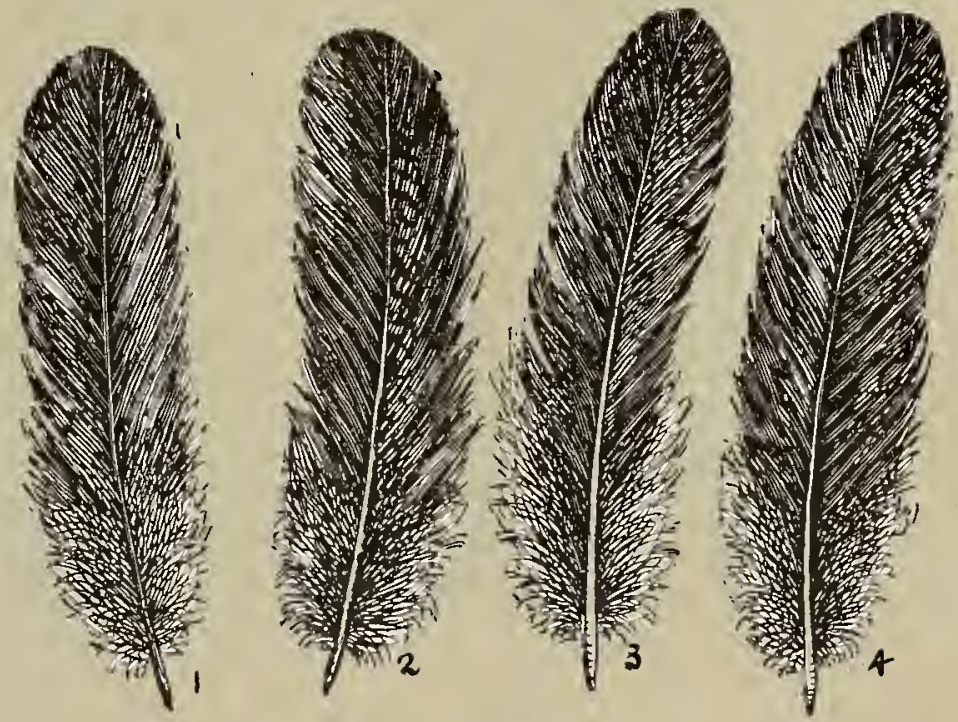

Fig. 53.

In Fig. 53 is shown a group of feathers taken from the tail, all more or less defective. However, feather No. 3 would not make a bad ending to the deck feathers-the ones directly in center of tail. Feather No. 1 is too lightshows too much red-and should be discounted $11 / 2$ points. Feather No. 2 shows black and red throughout the feather, 
especially on one she of shatt, and should be discounted

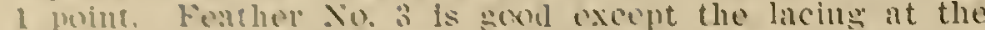

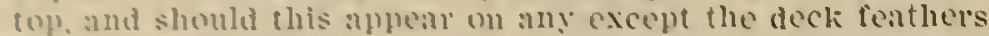
shoubl be discounted 1 point. Finther No. 4 Was taken irom dow at the side of tail-the last feather in this sec- we believe, as in the male, it is next to impossible to get this color correct-in fact, we lo not know that we have ever seen a single specimen that would pass without a discomnt of at least a half point, and, in many cases, they would be discounted as much as $11 / 2$. Where rich mahog.

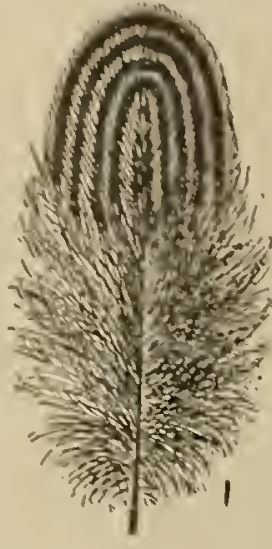

tion. It shows an edging of brown, almost to the shaft on one side, and should be discounted $1 \frac{1 / 2}{2}$ points.

\section{Legs and Toes.}

The Standard calls for shanlis and toes yellow, and
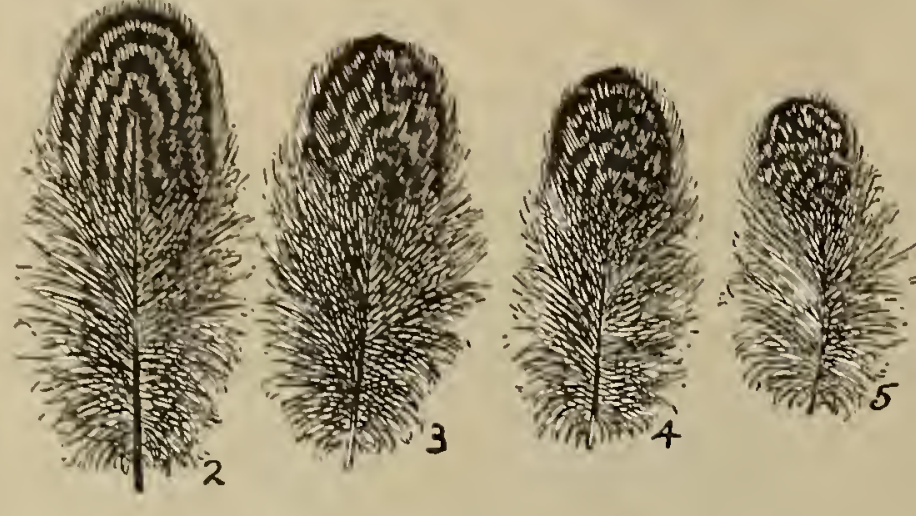

Fig. 52a.

\begin{abstract}
any color is found on the surface in all sections, you can bank upon it that you will find more or less off color in legs, but the Standard demands yellow, and when any foreign color exists it is necessary to discount it, and the out. is from $1 / 2$ to 2 , as in degree.
\end{abstract}




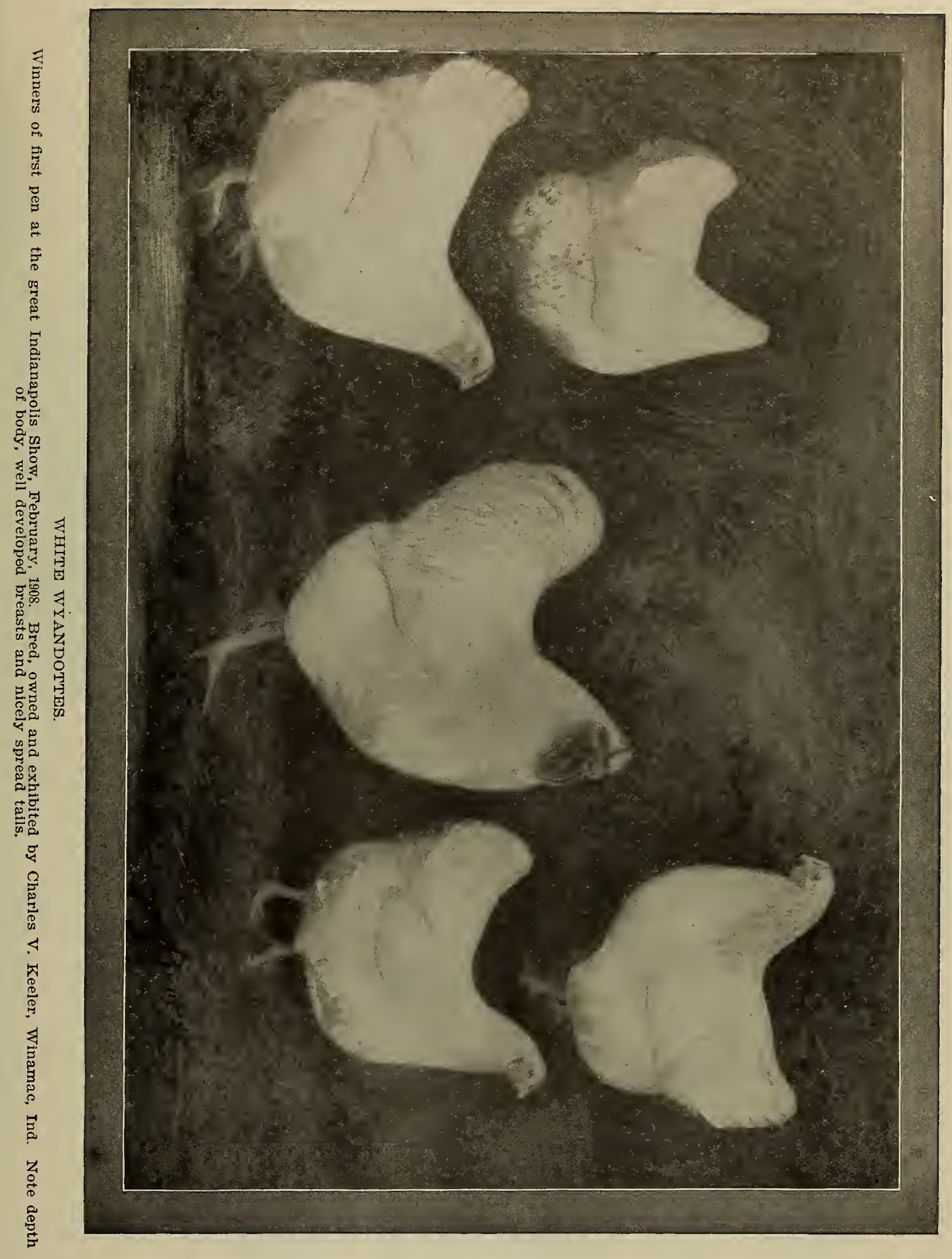




\title{
SIRUEIRENCIUID WUANDOTISIS.
}

\author{
Strikingly Handsome, But Never So Popular as Some of the 'Other Varieties.
}

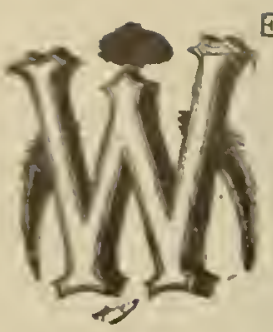

WILL now talie up the Silver Penciled valiety and give to our readers a thorough description of the color defects, together with our system of valuing them. Whether judging by score card or comparison, tlie same percentage in discounting should be observed if we are to allow proper credit for perfection and give our best colored specimens preference. It is well to remember that a judge in applying the Standard can give to each section no more value than the Standard-maliers have awarded it. We should lieep in mind at all times the fact that all sections should be considered and not allow some fad or hobby to mislead us in judging. It is the man who conforms closest to
MALE.

The first section to be considered in color is head, which lias a value of three points.

The head proper should be silvery white, and to describe silvery white I don't know of any better description than to say white on a black background. The under color of the feathers is dark slate, and, the surface being white, gives the surface the silvery white sheen. It is very seldom that the head of a silver Wyandotte male is dis. counted for color, so far as plumage is concerned. However, there are some other defects that are included in the head that should have a valuation. The beak should be a dark horn color, shading to yellow at the point; eyes, bright bay or red; face, bright red. These three points

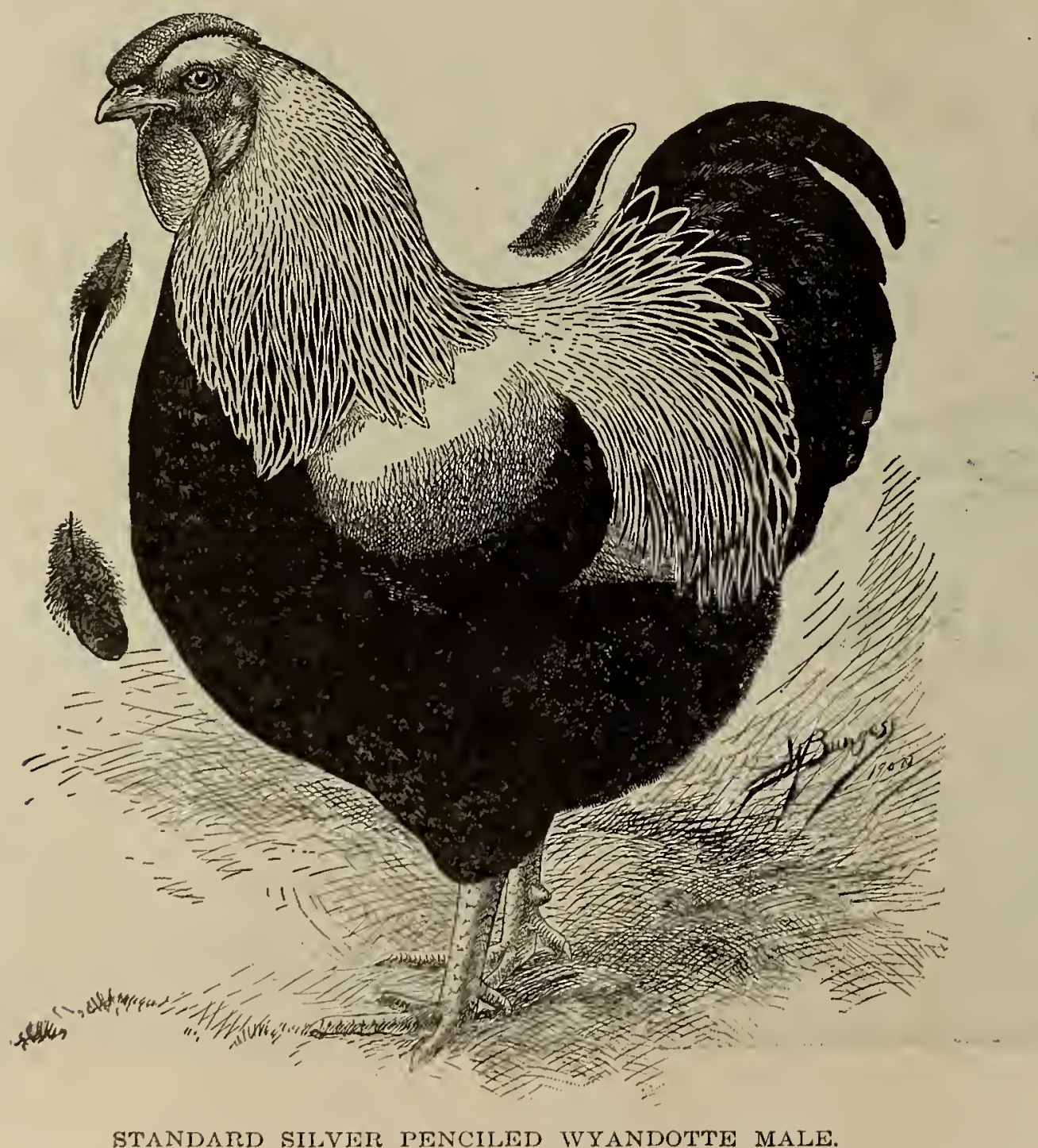

Standard laws in making awards that gives the best satisfaction as a judje, and since these articles are intended to asklst the young judige in $h$ is work, they should study care. fully sach variety as we take them up, as some idea may oxcur to, them that had previously slipped their minds. have to be considered under the one section of head. As a rule, the color of the beak is good, but sometimes there is a tendency to shade into yellow its entire length, which is a defect, and should be discounted $1 / 2$ point. If eyes show pearl, or light, they should be discounted from $1 / 2$ to $1 \frac{1}{2}$, 
as in degree. The face proper is usually good, especially on the males, but sometimes, owing to condition, they show dark or purple. But the better way to discount this is under the head of condition, rather than the color, as it is the condition of the fowl that brings about this color. The same would apply in comb where the Standard description is bright red.

Wattles and ear lobes are sometimes defective in color and are given a valuation of six points. These sections, while not divided by the Standard-makers, should be in applying the Standard by score card, and we would give three for shape and three for color. Sometimes a trace of white will appear in them, and in view of the fact that the Standard does not disqualify unless more than half of the section is white, some rule for cutting should be considered. If only a trace of white is found, the discount should be $1 / 2$ point; if white shows clearly in both lobes, or the entire section looks pale, the discount should be 1 ; where white flecks appear, showing enamel-white over one-third

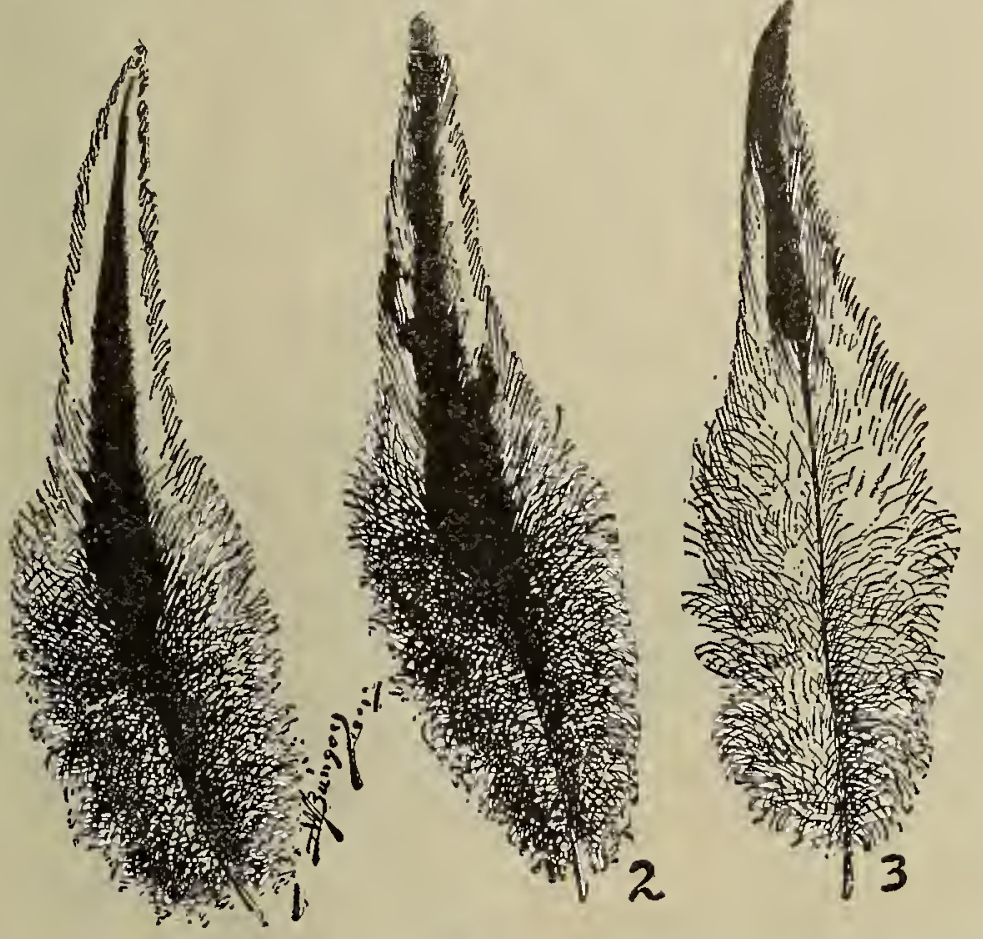

Fig. 54.

of the surface, the discount should be 2; and when more than one-half of the lobe is positive white, the bird should be disqualified.

Neck.

Neck has a valuation of ten points-four for shape and six for color-and is considered one of the most important sections, so far as color is concerned, in a breeding male The Standard description for neck is: "Silvery white,
In Fig. 54, feather No. 1, we show an ideal hackle feather that conforms to the Standard, having the black center with a white outside edging and about the right proportion of slate under color. The white edging might be a trifle narrower and still pass without a discount.

Feather No. 2 is distinct in the striping, has the dark under color, but the black runs to the edge on side of feather and runs black at the tip. A feather like this should be discounted 1 point-1/2 point for black at end of feather, $1 / 4$ point where black shows on edge and $1 / 4$ for being too light in under color.

Feather No. 3 is entirely too light. What little black there is in the feather is poorly proportioned, runs too much to a point, making a black, smutty edge, and is nearly white underneath. A neck showing feathers like this should be discounted 3 points-2 for white under color and 1 point for the smutty edging of black that extends almost one-fourth of an inch along the surface. A neck like this shows black on the outside and what the breeders term "cotton color" underneath.

A neck to show to best advantage on a male bird of this variety should be a silvery white surface from back of comb to where the hackle flows out into the shoulders. The only black showing is where the hackle parts, or on examination by raising the feathers. It is the silvery neck and back that is so much admired by breeders of this variety, and the two sections that up to the present time it has been so hard to get pure.

\section{Back。}

This section is by far the most important, both in color and shape. The Standard-makers realized this, and in the valuation of points they have allowed 6 for shape and 6 for color, giving it more importance than any other one section of the bird.

In color it should be a silvery white, free from brown saddle, silvery white with a black stripe through each feather; under color, dark slate. We will find here very much the same description as in neck, and there is a similarity betwen the two feathers in color, but you will note by looking at Fig. 55 and comparing them with Fig. 54 that there is considerable difference in the shape of the feathers in the two sections.

Feather No, 1 in Fig. 55 shows our ideal of a Silver Penciled Wyandotte back. It is good in under color, has clear black striping in center, with nice outside lacing of white.

Feather No. 3 is too light underneath; it is very black at the edge, giving the bird a smutty surface color, and should be discounted $1 \frac{1}{2}$ points.

Feather No. 4 is too light on surface, has about the right proportion of black at the edge, but is entirely too light underneath, failing almost entirely in under color, and' should be discounted $1 \frac{1}{2}$ points.

Feather No. 5 is too white at the point, black stripe doesn't run near enough to end of feather. The under color is pure white. A bird like this shows a surface that
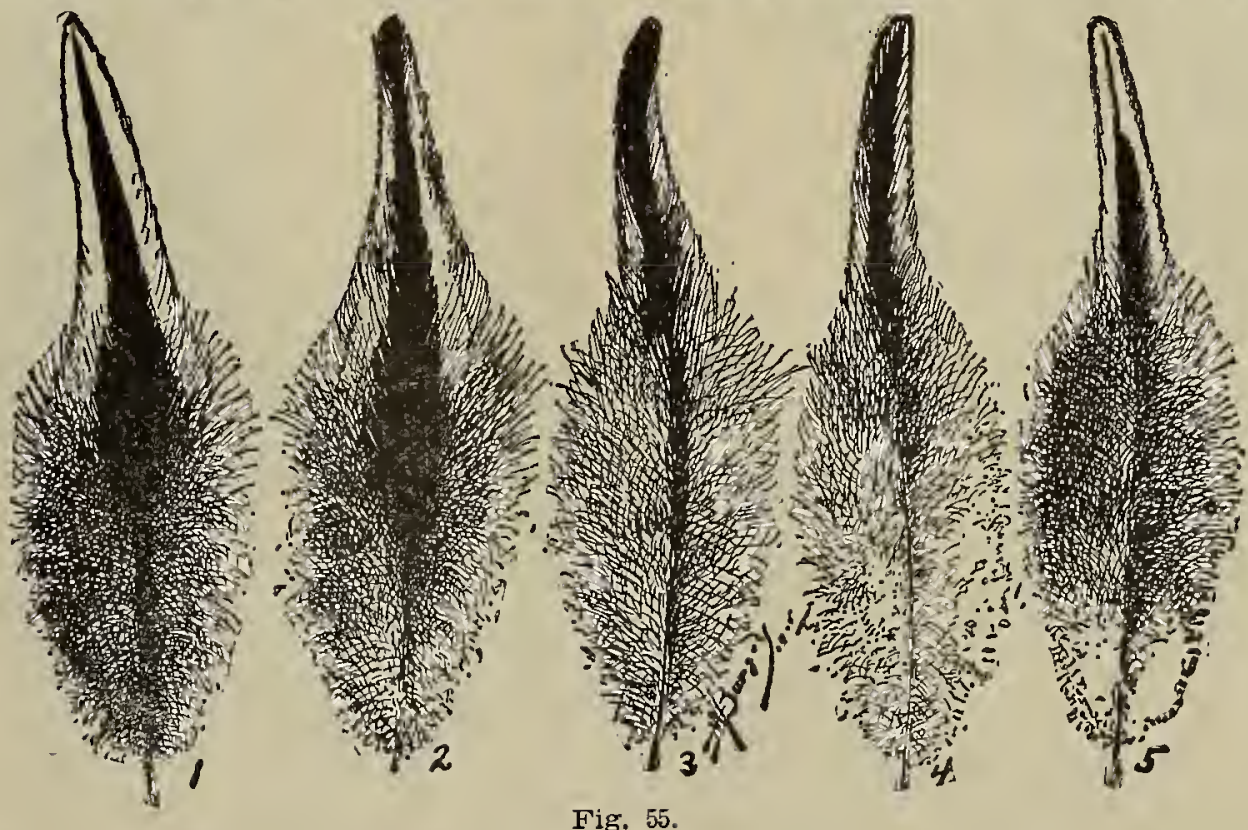

Fig. 55.

with a distinct black stripe extending through each feather, tapering to a point near extremity of feather; each feather to be free from a white shaft, or a black or dark edge; under color, dark slate." is entirely too light, as well as under color, and should be discounted $1 \frac{1}{2}$ points.

Feather No. 2 is black at the point, a little smutty in the outside white lacing, also too light underneath. A back 
116e this should bo discounted for botli surface and under color. s1s tles an1unut of black ol bown slowing in the Whilo lichns vives the bicli a surt of a copperish tinge. which of itsolf sliould be discounted 1 point; the light nuller color will add su aditiomal to point, maling the total out $1^{2} \%$

\section{Breast.}

Nort to the bacli this is tle most importint section, so car is shape is concerilcd, bit is not considered of as mucll value as several other sections in color. However. a sood colored breist is much to be uesired on males of this alety, and. in view of the lact that the Standard-makers have given us teu points and laid as much stress on color as slupe, giving five points to cach, it is easy to sce that a defectire breist in color can be severely discounted.

The Standard description of color is "Black; under color. darli slite." This description fits well tlie fancy vard and show room, but it is not from breasts lilie the one described that we get our best colored birds, especially iu females, and quite often nuales as well.

Our best breeders have learned that to produce choice colored specimens of either sex, it is necessary to breed from two or more matings. We would like to emphasize the poiut "trio or more," as many breeders, to our lnowledge, have found it necessary to.breed several shades of color in males in order to arrive at just the right color in females -in fact, the splashed breast on male is not in every case a safe criterion to go by that the individual is a pullet-breeder. The choice exhibition females, when mated with the rich-colored exhibition male, will more than likely disappoint the owner in the quality of chicks. The females will run unevenly and splotchy, failing in lacing in many sections, $\pi$ hile the males will come in almost as many colors as there are chicks to count-in fact, you will hardly find two alike, and you can consider yourself fortunate if you have any real good show birds from the mat ing. Homever, there are exceptions to this rule, and the two exhibition colors may nick all right and breed fine exhibition males or females, and sometimes both, from the same pair or pen. But when results like this follow, it is

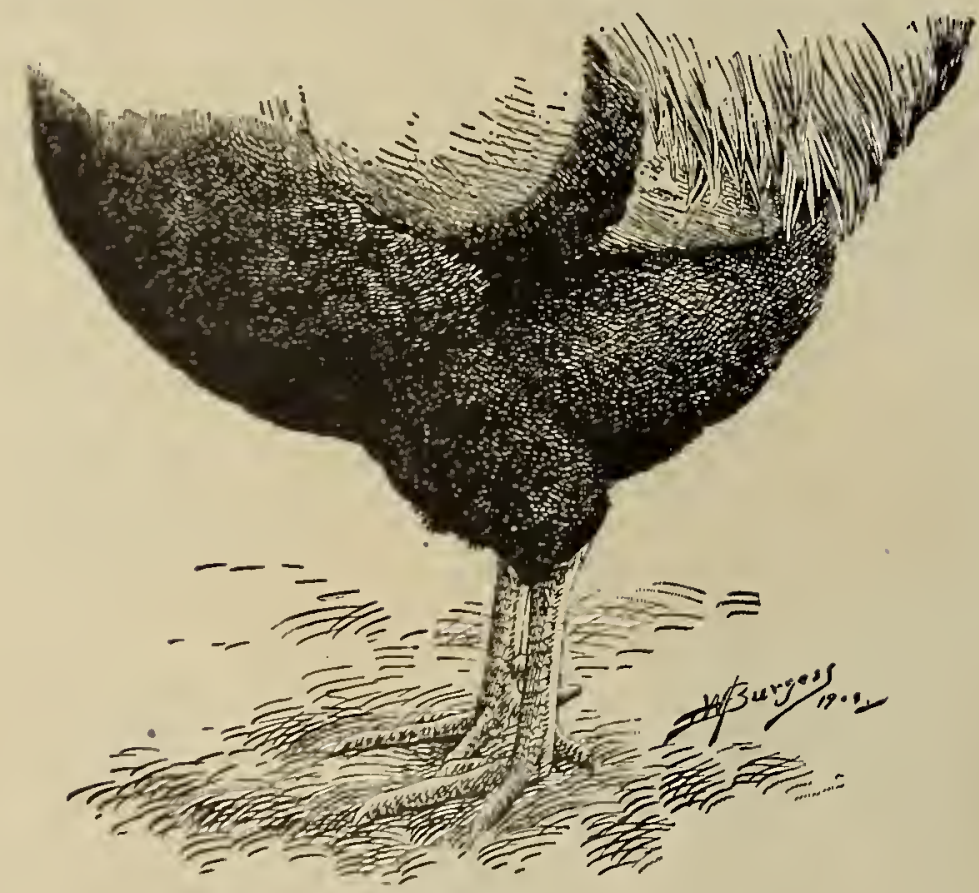

Fig. 5 i.

Well to look back of the individual and learn the cause, and it is almost invariably the case that the breeding of the sires, and not the sires themselves, was responsible for the results. When good results follow the mating of exhibition males and females, it is safe to calculate that one or the other, or perhars both, of the sires was bred on opposite lines from what their color would indicate; or, in other words, were mere accidents where the blood of one sex or the other in the embryo state had predominated and given life to a chick, with exhibition plumage, along one line whose parentage would lead in an entirely different direction.

I merely call attention to this matter here to show the arnateur breeder the folly of trying to produce exhibition color from Standard matings when the color of the two gexes is entirely opposite, as in the case of the Silver Penciled Wyandotte or Dark Brahmas. I do believe that
Barred Roclis, Penciled Hamburgs and otluer varieties that have the same color characteristics in both male and female can and should be bred irom one mating, and in my six rears experinenting along tlese lines the result in my yards has thoroughly convinced me that they are right, but I doubt if it call be brought about witl any degree of certainty where the breast of one sex is penciled or laced and where the other is black or white. So in order to help the beginner, I would suggest the double mating system in Silver Penciled Wyandottes, espccially while trying to establish a strain. I would rccommend the mating of black breasted males to dark colored females that are defective in triple lacing in breast and back, but as free as possible from the rust or mahogany color on wing bow and back. Remember you want bright, silvery surface color on haclie and saddles of males as well as wing bows, and to get this you must stecr clear of the rusty color of either sex in selecting your breeding stock. In order to get good females, select your choicest colored hens or pullets-that is, the ones with the cleanest lacing, showing the steel-gray surface as free as possible from the mahogany shade-and mate to a male that shows some white in breast and body. and should there be a trace of lacing in the body color of the male, all the better.

In order to show our readers what is meant by cockerel and pullet mating, we present here two views. Fig. 56 shows breast and body of a cockerel-breeding male that. would not be discounted for color, according to our Standard description.

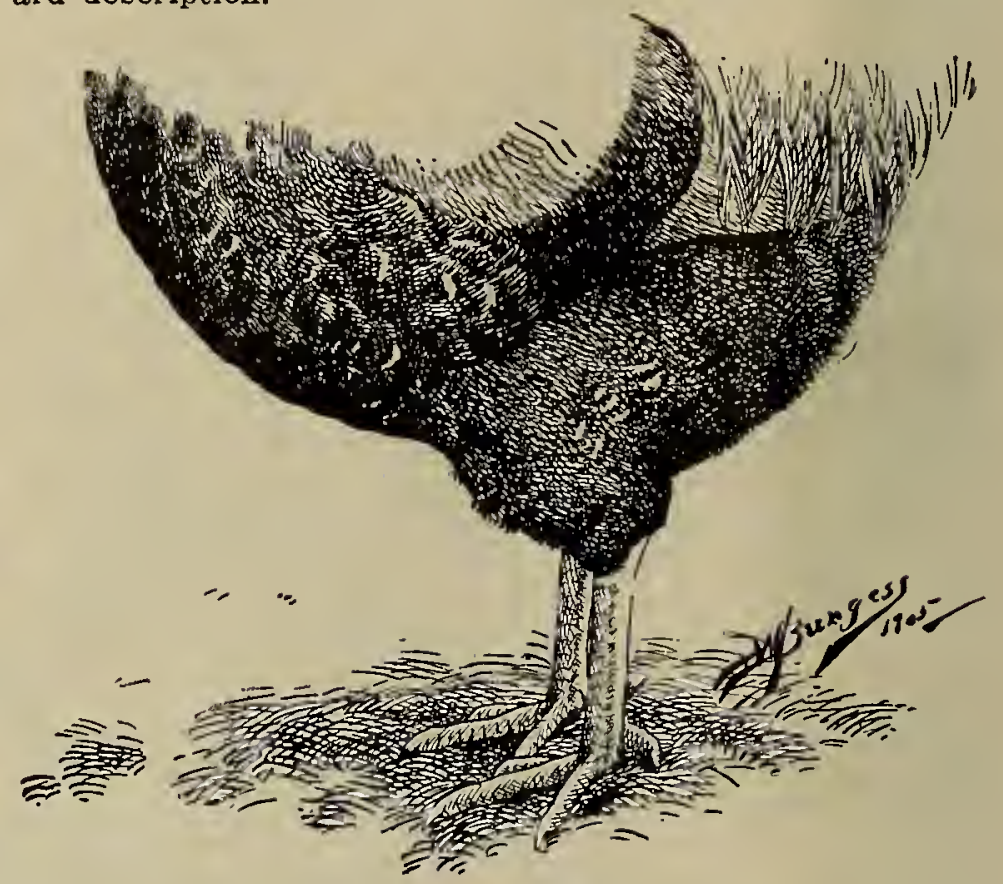

Fig. 57.

Fig. No. 57 shows the breast and body of a pulletbreeding male, one having considerable splashing and lacing in sections, and if placed on exhibition would be discounted $1 \frac{1 / 2}{-1}$ for color of breast and $1 / 2$ on color of body.

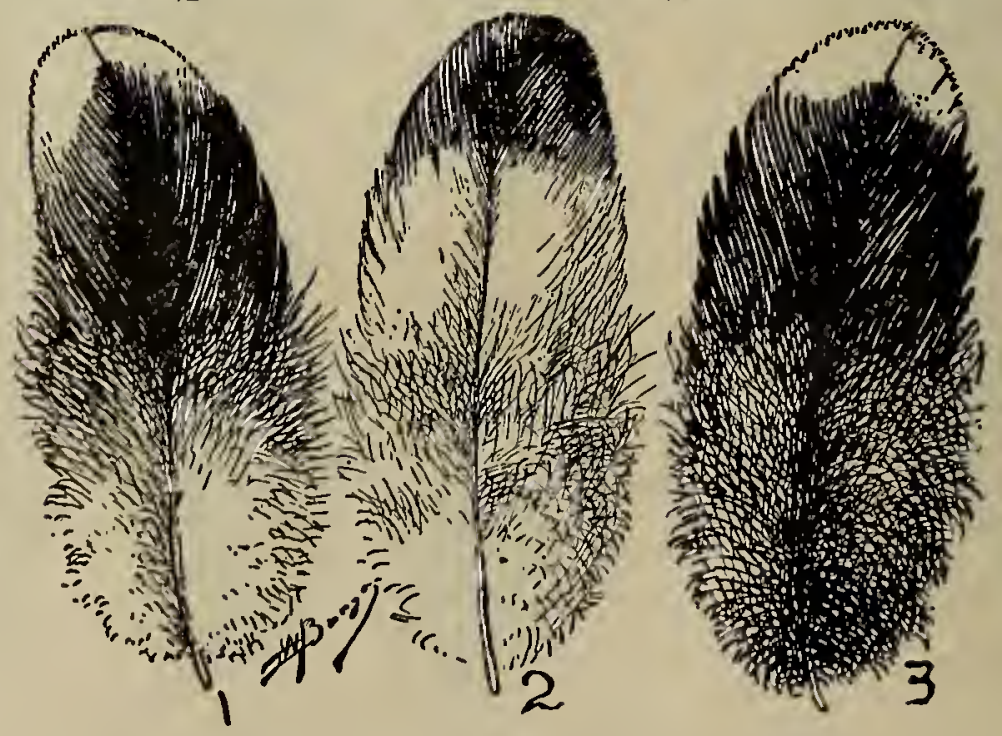

Fig. 58.

In Fig. No. 58 are shown three feathers selected from the breast of a male bird that will illustrate our idea of defects. 
Feather No. 1 is too light underneath; also shows white tip-in fact, there is more white than black in this feather. A breast like this should be cut 3 points.

Feather No. 2 is good at the end, but entirely too light underneath, showing more than two-thirds white, and should be discounted 2 points.

Feather No. 3 is good except at the tip, showing a small splash, and where many feathers of this kind appear in a section the discount should be 1 .

\section{Body and Fluff.}

In describing the color of breast we might have added the same description for body as to color, and the discounts would fall equally as heavy upon both.

In fluff there is a slight frosting on the end of feathers, not enough to make that section look white, but slightly streaked, and resembles at a distance of a few feet a spider web effect. When extreme matings are practiced, and the male is very dark in all sections, there will be but very little, if any, of this streaking appear on the surface; but where the males are pullet-bred quite a little of it will show, and sometimes be so white as to demand a discount of from $1 / 2$ to 1 point.

\section{Wings.}

There is considerable importance attached to this section in all the American breeds-in fact, it was considered of such value by the Revision Committee that they have changed the number of points allowed from eight to ten. This change was made, however, more on account of Barred Rocks and Silver Wyandottes than on account of the Silver Penciled varieties. The section is divided, giving six to color and four to shape, and perhaps the best way to apply a score card would be to allow two points for wing bow and bar, two for primaries and two for secondaries, valuing our discounts accordingly.

The Standard in describing the wing of a Silver Penciled Wyandotte male calls for "Primaries, black, lower edge white; secondaries, black, outer web white, terminating with greenish-black at end of each feather; wing coverts glossy, greenish black, forming a weli defined bar of that color across wing when folded; bows; silvery white; under color, dark slate."

The Standard-makers did not tell us whether the black at end of secondaries should be crescentic or spangled, and in our drawings illustrating this section we have made them to conform to the best specimens we have found of this variety. There is a slight crescentic mark at lower end. This is the white running slightly into the black in our best specimens.

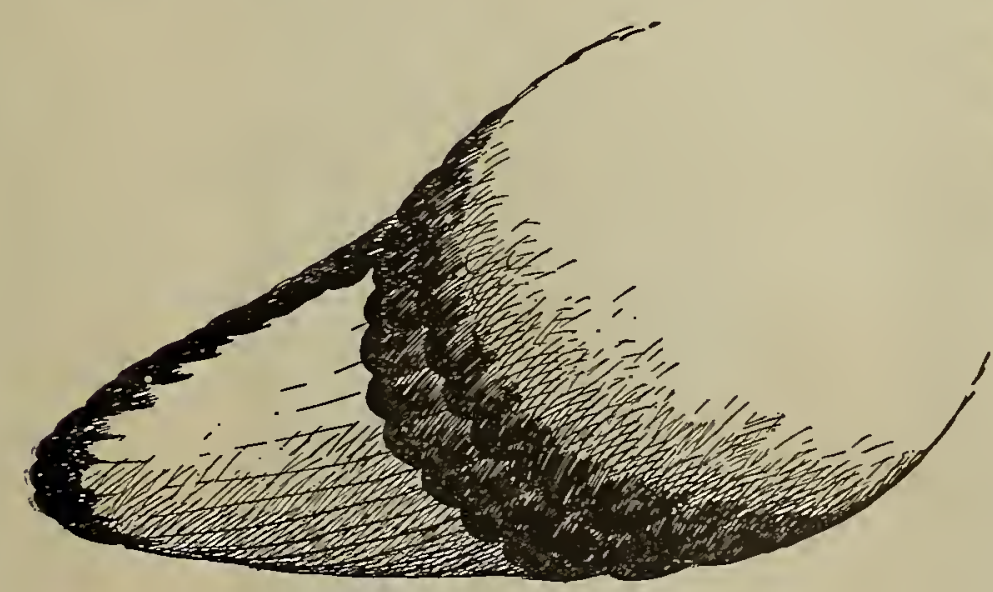

Fiz. 59.

In Fig. 59 we show a wing folded that conforms closely to the Standard description-white bow, black bar, with secondaries showing white on outer web. A wing like this would pass without discount in color, but is a trifle long for its width.

There is one feature here that it might be well to call attention to and that is in the wing bar as described by the Standard and as found on the different specimens we handle. It says: "Wing coverts, glossy, greenish-black, forming a well defined bar of this color across the wing when folded." We note in looking at the best specimens that it makes what might be termed a double bar, or, in other words, there are two rows of feathers that bring out the color. There is no overlapping of the black on white, but both rows of feathers end with black and over. lap so that there is but one bar, but it is composed of more than one row of feathers.

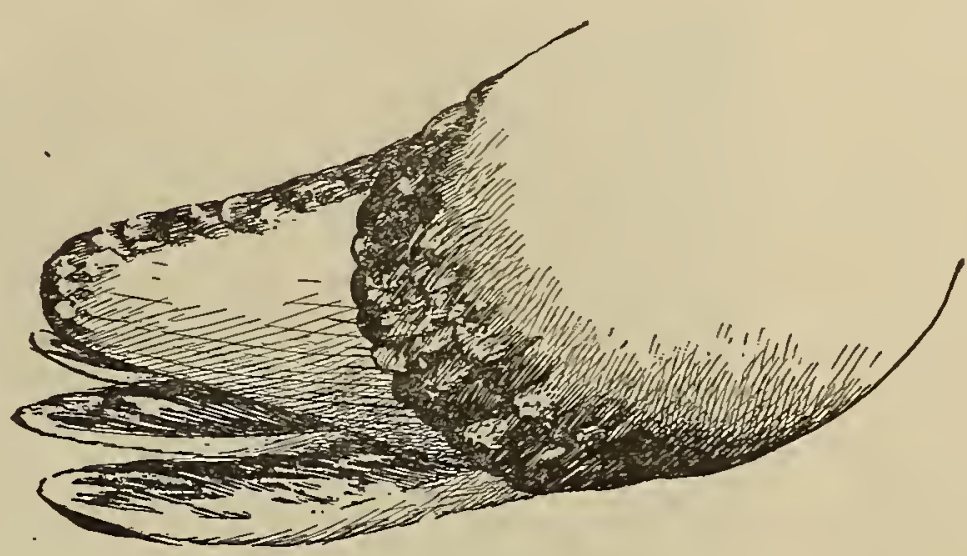

Fis. Co.

In Fig. No. 60 is shown a wing that is slightly spread. This wing is defective in bar, also defective in primaries and secondaries, there being entirely too much white. The lower web of feather exposed in primary should be white, upper web should be black. The bar should be solid black and not splotched with white, as in this illustration. The black band along the lower edge of secondaries should also be black, the white showing through, is a defect. A wing like Fig. 60 should be discounted $2 \frac{1 / 2}{2}$ points-1 for defective primaries, 1 for defective bar and $1 / 2$ for defective secondaries.

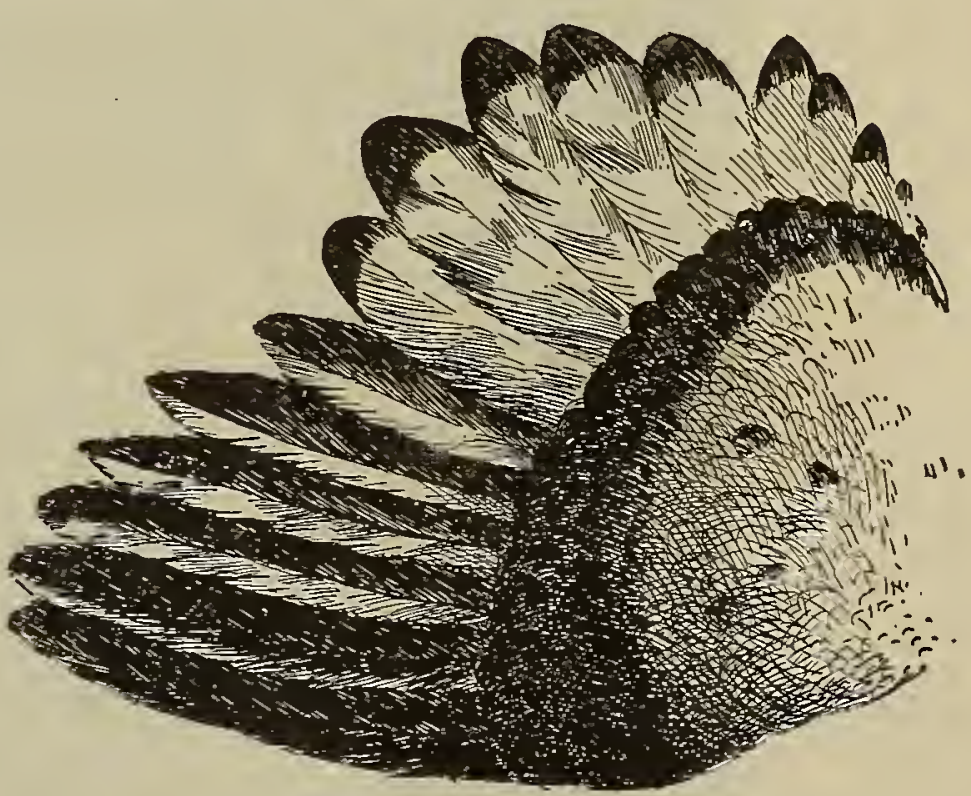

Fig. 61 .

In Fig. 61 we show a spread wing that is quite the reverse of No. 60. In this wing we have too much blackthe bar is too wide. There are some slightly splotched feathers on wing bow, secondaries have too much black at end, and the outer flight fails in the white edging. This wing represents a male bred along very dark lines, and should be discounted 2 points -1 for cloudy surface in wing bow, $1 / 2$ for absence of white in primaries, and $1 / 2$ for too much black in secondaries.

\section{Tail.}

Tail has a value of nine points, five of which go to color. This section is usually good in Silver Penciled Wyandottes. The tail proper should be black; sickles, glossy, greenish-black; coverts, glossy, greenish-black, or black edged with white. 


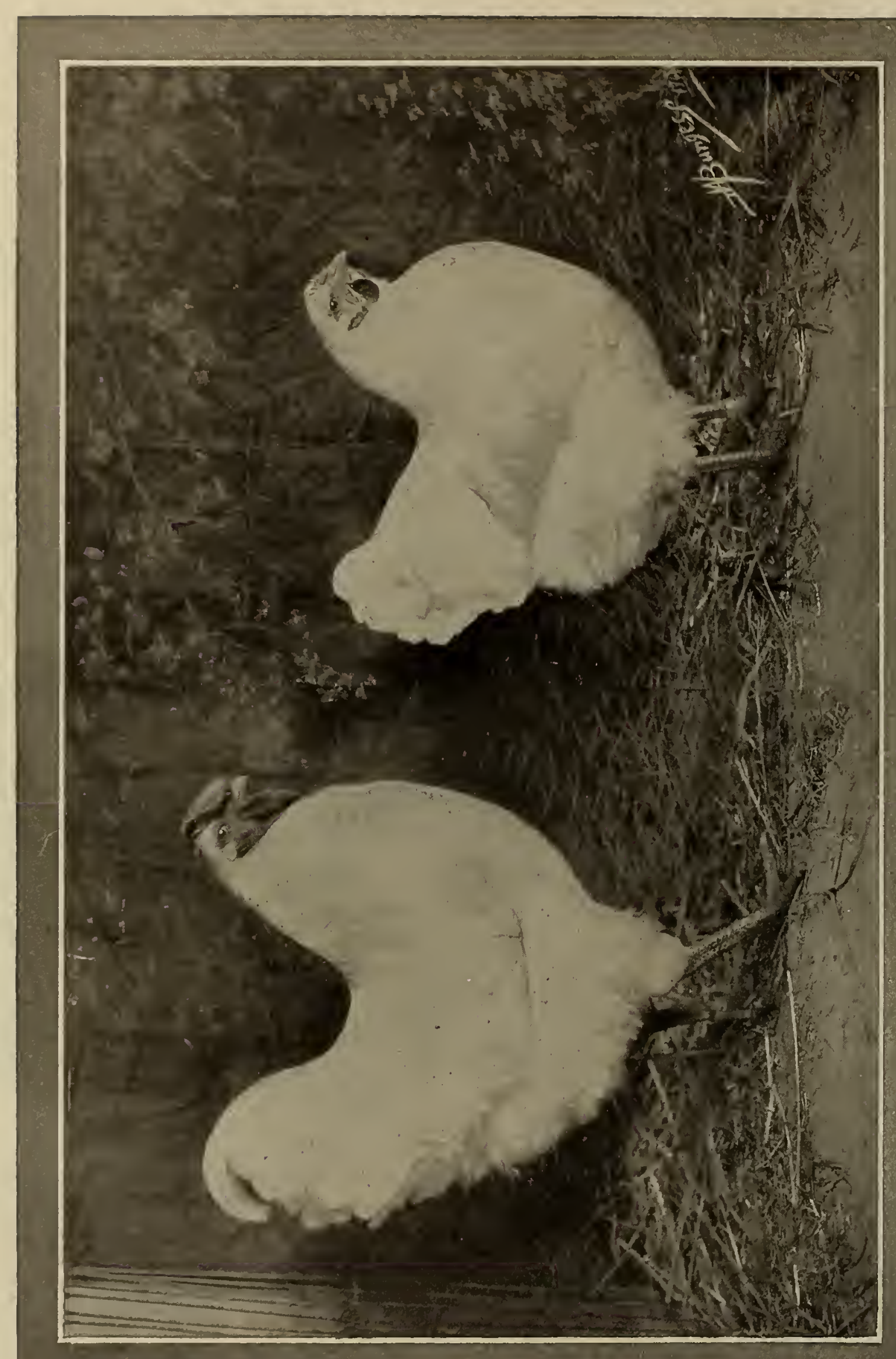

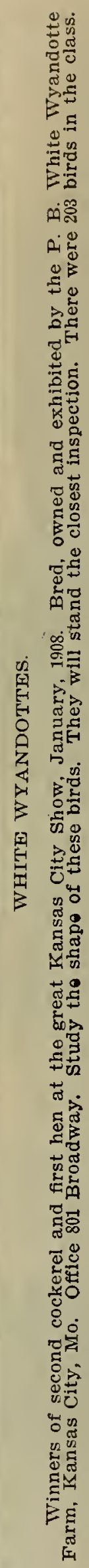



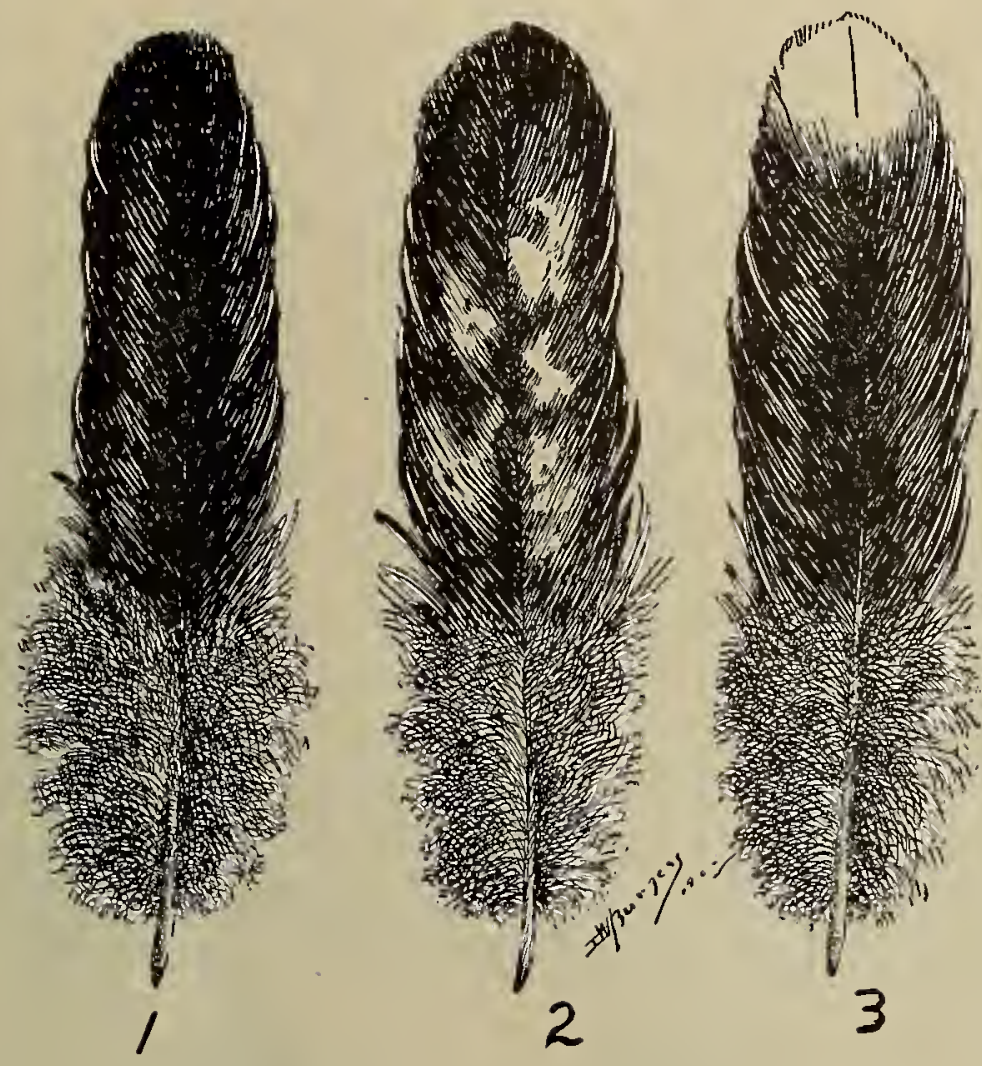

Fig, 62.

In Fig. 62, feather No. 1, we illustrate what the Standard calls for-a black feather, with dark slate under color.

Feather No. 2 is dark enough at the end, but breaks up in center and is quite a bit too white in under color A tail with feathers like No. 2 should be discounted $1 \frac{1}{2}$ points.

Feather No. 3 is good except at tip end of feathers, where there is about one inch of white. This is not an uncommon defect, and especially in pullet-breeding males, and should be discounted 1 point.

\section{Legs and Toes.}

This section has a valuation of three points for color, and in Silver Penciled Wyandottes is of considerable importance from the fact that but very few, if any, of our specimens today are up to Standard in color. We refer now particularly to shanks and toes, of which the Standard description is yellow.

The Standard-makers were easy on this section, not having called for a rich or a bright yellow, and in view of the fact that there are several shades of yellow, shad ing from light to dark, the breed will not be handicapped to any great extent by this description. However, in nearly all the specimens we have found in the shows, and especially on females, there is more or less willow or slate color, and when such color is met with it is necessary to discount. As there are only three points for color. it is plain to see the discount is light as compared to the real defect. A slight tinge of slate would warrant a discount of half a point, but if all the front of shank and upper part of toes show this color, the out would be 1 ; if the color runs around to back of shank, then the out would be $1 \frac{1 / 2}{2}$ to 2 .

Believing this description will give to the breeders the information desired in regard to the defects in the several sections and our system of valuing them, we will now take up the Silver Penciled Wyandotte female.

\section{SIL.VER PENCILED WYANDOTTE FEMALE.}

The Standard in describing color of female in back, breast, wing bow and tail coverts, calls for gray color, with

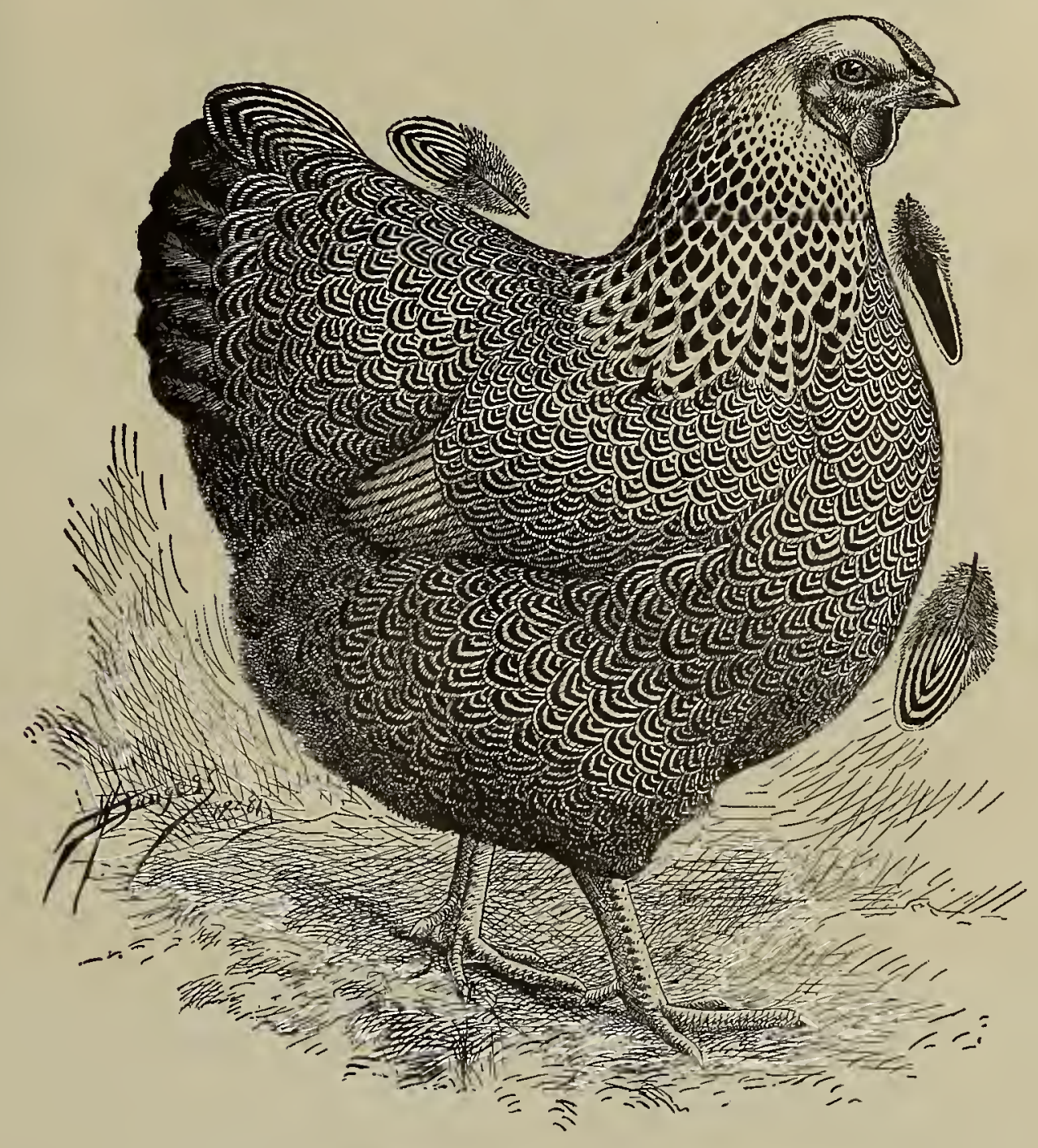

STANDARD SILVER PENCILED WYANDOTTE FEMALE. 
distuct dark penciling. outlines of pencilng to conform (o) shape of reather: the feithers to be iree from white shouting. There is no set rule is to the number of lacings w be font fn the dinerent sections, but our own expe-

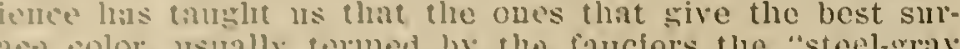
surface," have three distinct pencilings, the same as our

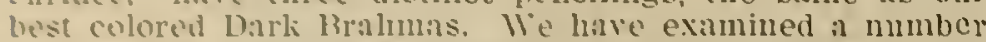
of prize birds in different sections of the comtry among the Winters of the importim prizes of the World's st. lomis. and liave had selected for us from the yards of .Mr. li. IVyclion, the big winner at the World's cocions of the female in this article. Remember, these pathers are not intended to be perfect: we slow ideals, together with defects, and we will attempt to value them readers a good general idea as to what specimen will score with the several linds of plumage described.

All parti-colored birds have their peculiar characteristics that mist be thoroughly understood by the breeder if the best results are to be secured from our matings. The peculiar markings of one breed, and the effect of these markings on the offspring, may be slightly or entirely clianged in the offspring of some other breed, and for this reasou no set rule can be adopted that will work alike in all cases. To be a successful breeder of any one variety of fowls means that we must have a thorough understand. ing. not alone of that rariety, but the particular breeding that has brought up the strain we are striving to improve. fmprovements have not been anade by one breeder, or from one strain of fowls. Brecders in diffelent parts of the country are striving for the same results and have made vast improvements; but the breeds which entered into the original malieup were not all alike, consequently in mixing the blood of two strains, no matter by whom or low well the variety be umderstood, may prove a complete failure from a fancier's standpoint, and it is on this point that I wish to give a few words of advice to the aniateur or inexperienced breeder.

Slould the offspring from the crossing of two different strains prove inferior, or not up to the parent stock, do not discard them as worthless, but select the best from the cross, both male and female, and mate them to their sire or dam, according to the sex you wish to produce. Please remember that in giving this advice I am taking it for granted that you are working along the lines of donble mating. It is quite likely that the first cross of the parent stock will bring back the good points lost. If they do so only in a limited way, then mate the second offspring back again to the original sire or dan, and you will get the desired results and establish a strain of your own.

Perhaps one of the best, if not the best, strains of Silver Penciled Wyandottes of the present day was originated by the late Ezra Cornell, and has for the past ten years been bred by Mr. E. G. Wyckoff, and since Mr. Wyckoff has owned the birds there has been rapid improvement, both in color and shape, due not alone to his good judgment in mating, but to a thorough knowledge of the original crosses that produced the birds in Mr. Cornell's hands.

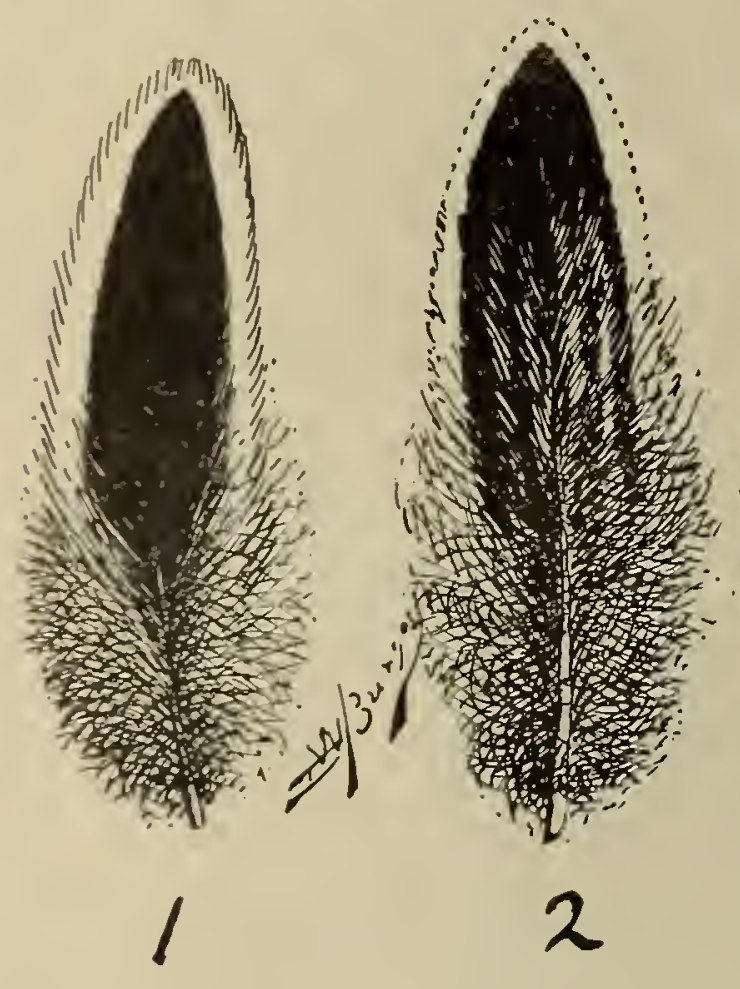

While it is true that like begets like, it is well to remember that ideals exist only in the imagination of some overrrought amateur, and that the stern reality of longer experience in breeding banishes them from the mind. It is true that the mating of Wyandottes will produce Wyandottes, but it is not true that the mating will produce a flock of birds all of which will equal or surpass in quality the parent stock. In fact, with a parti-colored fowl like the Silver Penciled Wyandotte we may consider ourselves lucky if we jroduce five per cent. of either sex that surpass the parent stock, and many times we may not succeed in raising one chick that even equals the mating that produced them

I call attention to this now before taking up the color of the $17 y$ andotte fomale and caution the readers in pointing out the several defects that it will not be possible in vvery instance $t$, make the same application with other breseds, as in the breerling of poultry too much depends upon the manner in which the strain is produced. Even our best informed joultrymen may go astray in their matings until they have learned by experience which shades of color will nick best in producing choice males or females; and in $\mathrm{no}$ one variety is there more danger of this than with our Silver Penciled Wyandottes. This is nes reifection on the breed by any means-in fact, the im norovement on this variety is simply marvelons, considering the short time they have been bred, but all these
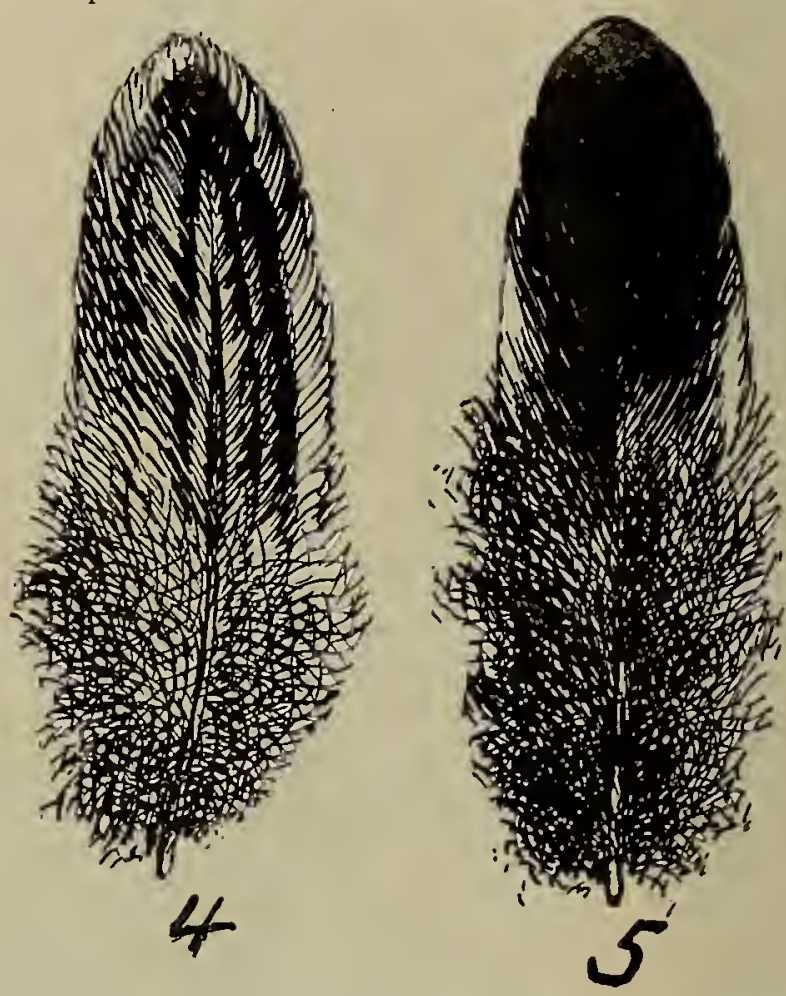

The exhibit of Silver Penciled Wyandottes at the World's Fair at St. Lonis was of such marked quality that one would think the variety had been bred for a quarter of a century. In many instances the females surpassed the Dark Brahmas in correct penciling. To Mr. Wyckoff is due the credit for the elegant feathers, showing the ideals in the following illustrations, reproduced by Mr. Burgess.

\section{Neck.}

This section in parti-colored birds is of vast importance to those not having a thorough understanding of ideal plumage and how much we may juggle with defective color and still be safe in our matings. To call for feathers on the back, breast, body and wing bow, with triple lacing, and then require nature to carry a single lacing on neck color, down to junction of back, is setting a hard task, and we have found that in order to get the proper shade of color, the steel gray so much desired by breeders of this variety, it is sometimes necessary to use females with more or less penciling in the hackle feathers.

In describing color of the neck of a Silver Penciled Wyandotte female, the Standard says: "Silvery white, with a distinct black stripe extending through each feather, tapering to a point near extremity; black stripe may be slightly penciled with silvery white: each feather to be free from a black or dark edge; under color, dark slate." 
Wings.

In color the wing of the Partridge Wyandotte male is not, as a rule, very defective-in fact, it is seldom that this section is cut to exceed $1 / 2$ to 1 point.

The Standard describes it as: "Primaries, black, lower edge red; secondaries, black, the outside web red, terminating with black at the end of each feather; coverts, greenish black, forming a well defined bar of this color across the wing when folded; bows, red; fronts, black; under color, dark slate."

About the only serious defect we find in color of this section is white primaries and purple barring in the wing bar. This purple barring is found in all parti-colored breeds where there is a solid black bar across this section, and when it is found should be discounted from $1 / 2$ to 1 point. When white appears in primaries or secondaries, the out is from $1 / 2$ to $1 \frac{1}{2}$, as in degree.

We have here illustrated two wings that will materially assist the reader in forming an idea as to the valuation. A wing like Fig. 40 should be discounted 1 point, while Fig. 41 should be discounted 2 points, as it shows entirely too much white, and should this color be mingled with red or black, the defect would be even more severe, making it 3 points for the same defect.

Tail.

The Standard describes the tail of the Partridge Wyandotte male as: "Black; sickles and coverts, glossy greenish-black; lesser coverts, glossy black, but may be edged with red."

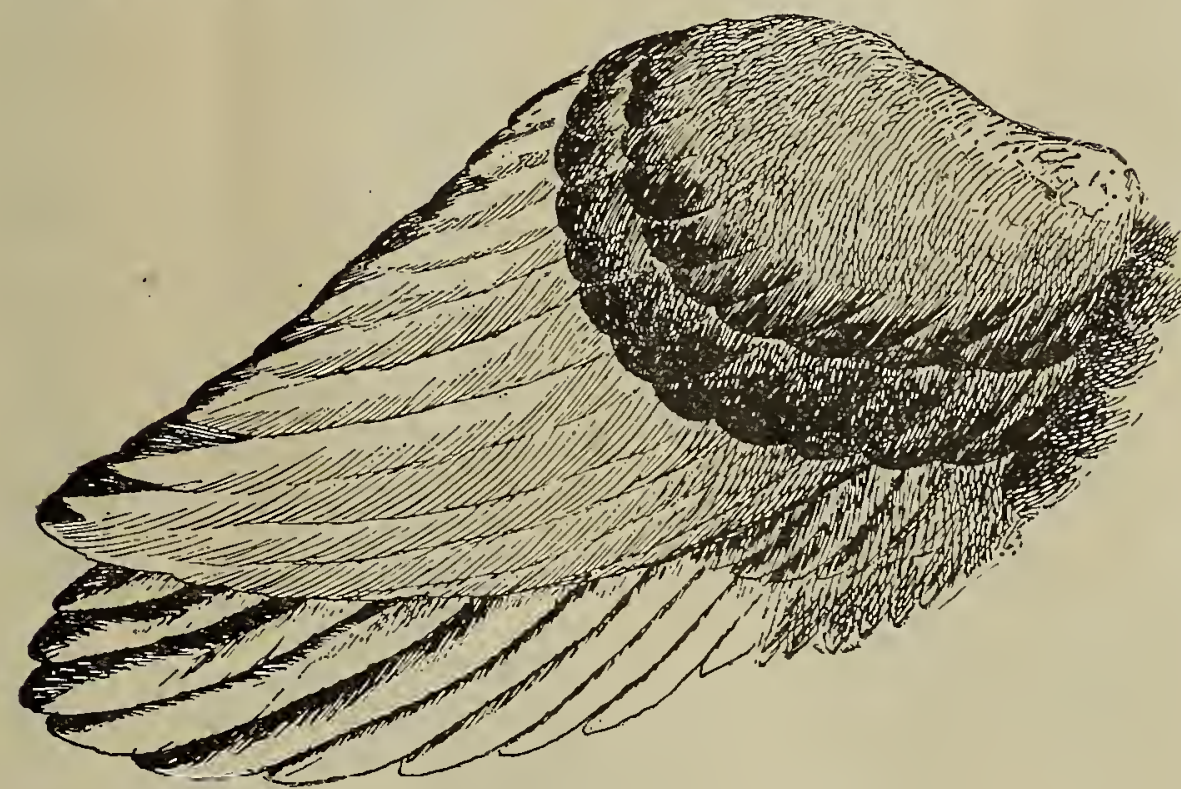

Fig. 41.

As a rule there is but little fault to find with the color of the male, except as referred to, but in wing bows we occasionally find a purple barring across the sickles or tail coverts, and when this defect appears the section should be discounted from $1 / 2$ to $1 \frac{1 / 2}{2}$ points, as in degree. If any white shows at base of tail, out is from $1 / 2$ to 2 , as in degree.

Breast.

The Standard describes this section as "Glossy black; under color, dark slate." In looking over the best specimens that we find in the exhibition room we doubt if the word "glossy" should not be eliminated from this description, as the color in reality is dead black, and not glossy black, as described, as it is that portion of the bird protected from the sunlight and very seldom shows glossy sheen to plumage such as we find on other sections of the bird. However, this color is easy to understand, and any color aside from black would be considered a defect. It is quite often that we find specimens that have a trace of pulletbreeding blood in them that show red checks or splotches on surface, and especially up along the sides. This color should be discounted from $1 / 2$ to 2 as in degree, and where purple barring shows up the out is from $1 / 2$ to 1 .

Another defect, while not common in show birds, is sometimes met with, is a light shade in under color, which the Standard describes as dark slate. Where the under color is too light, approaching white or light gray, the out is from $1 / 2$ to $11 / 2$. 


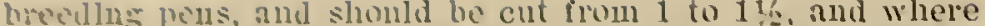
she slecime'd shows this defect to imy great extent should

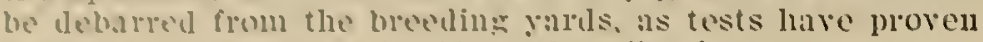
that if will lesproduce itself on the oflispring.

\section{PARTRIDGE WYANDOTTE FEMALE.}

Having in om cabinet a nmmber of defective neck, liead and comb illustrations of Partridse llyandotte females. "wo omitted these sections in shape while scoring the silver Wyudotte female, and we will now talie the maffer $11 \mathrm{p}$, illustrating some of the common defects as found in the arerige exhibition, and placing a valuation on same, hegiming with head.

This section will require a different description than the male althongl the Standard description is the same. The formation of the head at its junction with the neck in the two sexes is so differently arranged that we have considered it wise to fully illnstrate and call attention to the several defects that are common. The Standard reads: "Head, medimn size and carried rell mp.'

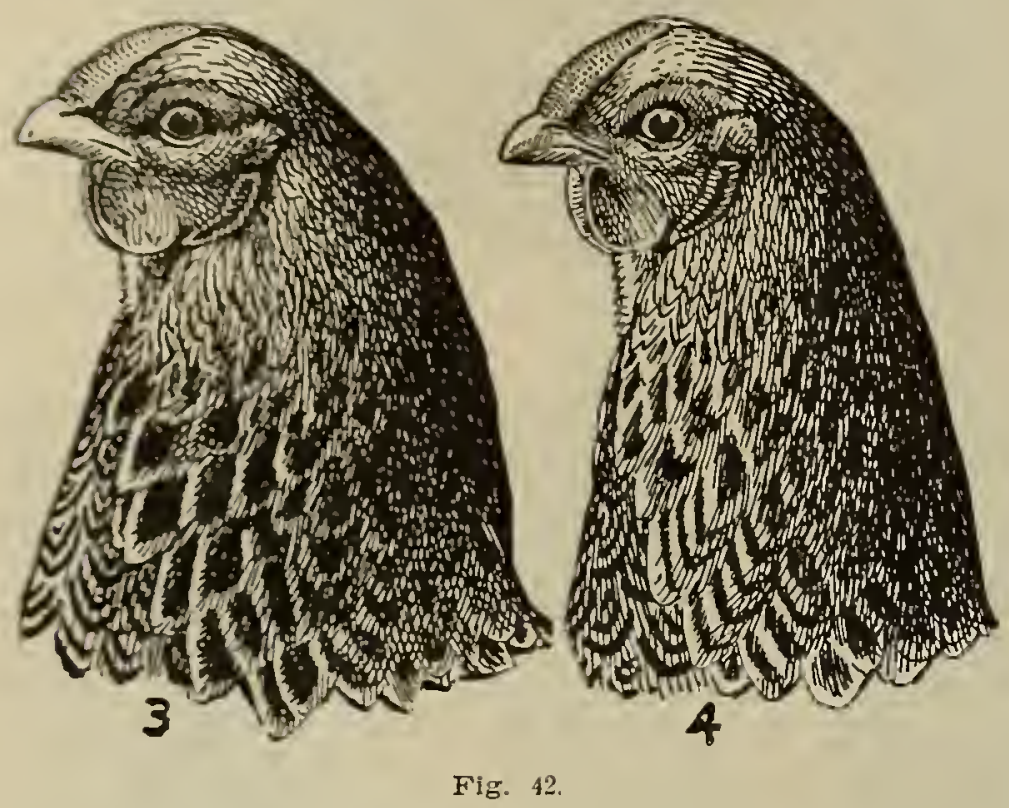

In Fig. 42 are illustrated a head, comb and neck that but little fault can be found with. We refer to head No. 3 in the plate. This style fits well the description of the Standard and is the shape sought for by our best breeders. If any criticism could be offered it might be in depth of head over the eyes. This one might be a trifle deeper at this point, but $1 / 4$ cut is sufficient for the defect, and if passed without a cut no severe criticism could be made.

Head No. 4 in Fig. 42 is too slim and narrow at rear, is not round enough and joins onto neck badly. Such a head should be discounted 1 point.
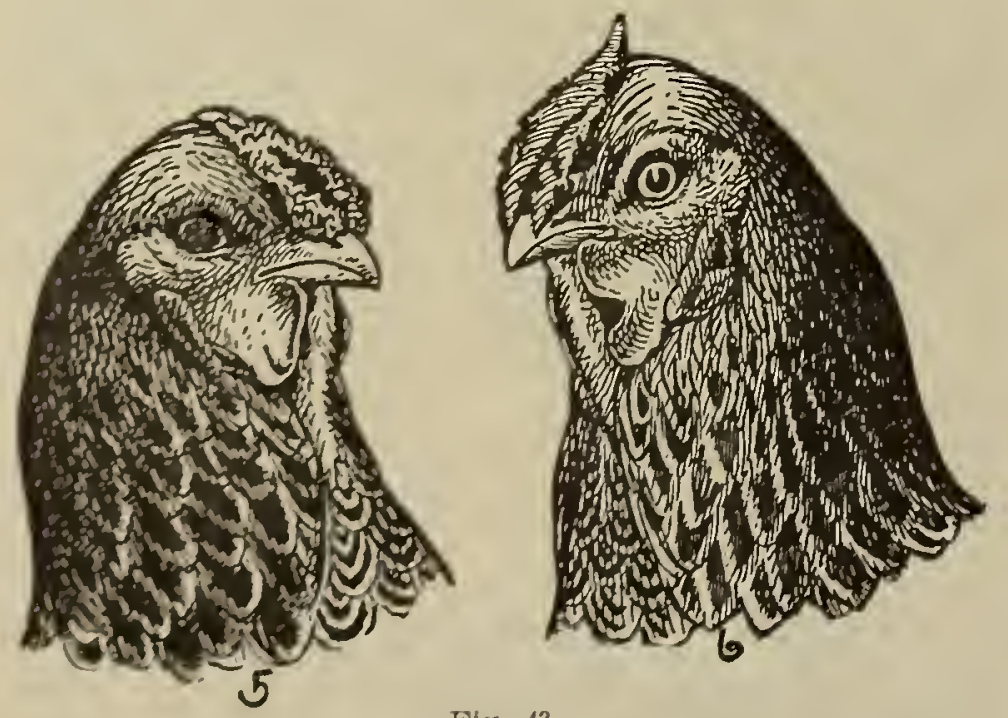

Fis. 43

In Fig. 4., heads Nos. 5 and 6 are somewhat after the Brabma type. They are broad in skull, heavy over the
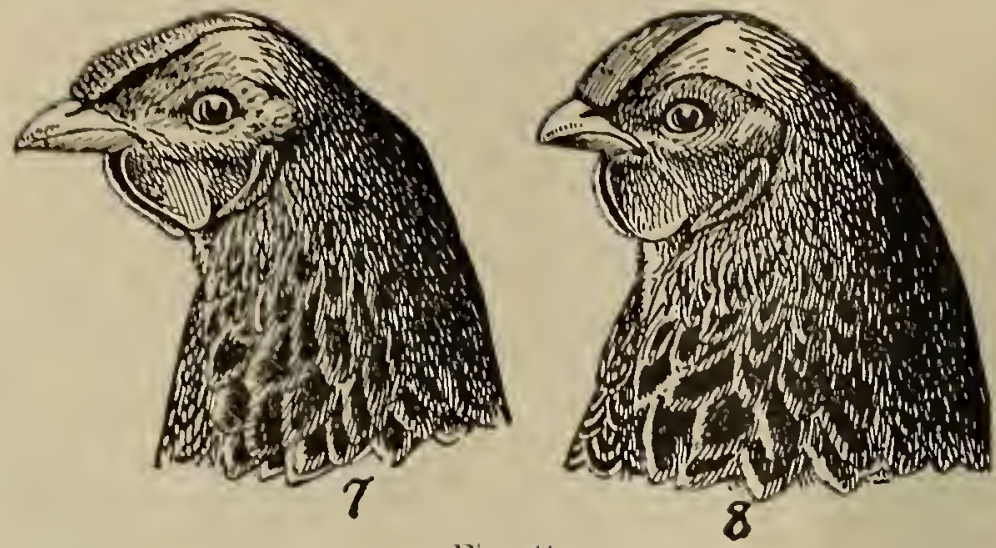

Nig. 4

eyes and very coarse. These heads should be discounted 1 point each.

In Fig. 44, head No. 7, while looking like a freak when compared with the good ones, is no worse than we sometimes find in specimens of this breed. It is too long and narrow, is not deep enough through beak, is too long and straight, giving head too snaky or siclkly appearance, and should be discounted 2 points.

Head No. 8 is good in general shape and is used here to illustrate defect in comb that will be called up later.

\section{Comb.}

While the section of comb has not so much importance attached to it by breeders as that of the male it is, however, considered an important section even in females, as poor combs, no matter how well mated, are very likely to develop defects in the offspring of both sexes, and especially in the comb of the male. It is, then, vastly important that only good combs be used in the breeding pens.

The comb as illustrated in head No. 3 (Fig. 42) is quite good and very well proportioned for a female. No. 4 is a little high in the center, not quite flat enough on top, and unless carefully mated will produce what we call a "lumpy" comb on the heads of the cockerels.

No. 5 , in Fig. 43 , is about the proper length, but is too wide in front, is hollow in the center, and the corrugated points are too large and coarse. This comb should be discounted $21 / 2$ points.

Head No. 6 (Fig. 43) has a smooth surface, spike turns up at the rear like a Leghorn's; it has a narrow scar through the side and is poorly proportioned in every way. This comb should be discounted $21 / 2$ points. No. 7 , in Fig. 44 , is too long and too narrow, and, like the head it rests on, is too snaky for a comb of this breed, and should be discounted 1 point. No. 8 shows a well proportioned comb. It is the right length and width and ends with nice spike at the rear, but is too smooth on the surface, lacking in the corrugated points so much desired in this breed. This comb should be discounted 1 point.

\section{Wattles and Ear Lobes.}

Here are two sections in the female that have less value attached to them than the male. The wattles and ear lobes are, as a rule, good, even though other parts of the head are faulty. We have found many specimens scoring away down, being defective in almost every section, with almost perfect wattles and lobes. However, there are defects met with, and in order to give the amateur the correct idea of valuation of such defects we have illustrated a few.

In heads 3,4 and 8 are shown well proportioned wattles and lobes, and we would not discount them in scoring. In No. 5 we find the wattles straight and somewhat drawn; the lobes somewhat pinched and small for the size of the head, and should be discounted 1 point. In No. 6 we find the wattles and lobes are heavy and coarse, and full of wrinlles, and should be discounted 2 points. In No. 7 we find a drawn, sickly looking face, with half $\cdot$ developed ear lobes and wattles, and should be discounted $1 \frac{1}{2}$ points.

In studying the defects illustrated here, please bear in mind that they would have the same effect on all varie. ties of the Wyandottes and would be cut proportionately hard, no matter what the variety.

\section{Color of Female.}

There is such a difference in the color of the winning females in the leading shows throughout the country that I deem it wise to give considerable space to them, and especially the illustrations showing plumage from different sections of the body. 


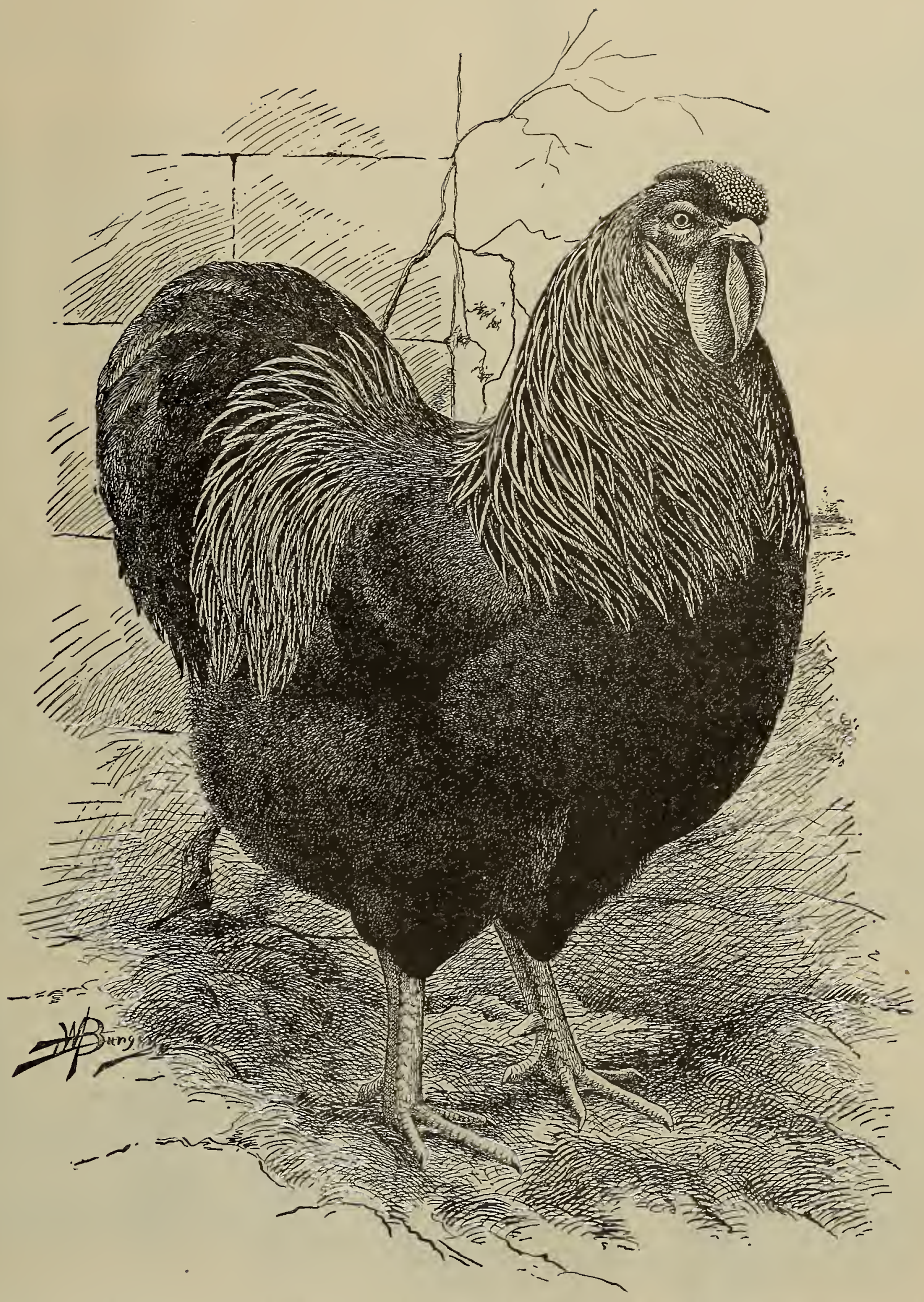

PARTRIDGE WYANDOTTE COCK, FIRST AT GREAT WORLD'S FAIR, ST, LOUIS-BRED, OWNED AND EXHIBITED BY W. A. DOOLITTLE, SABETHA, KANS. 
It is seldom that we find i teather cren from on best

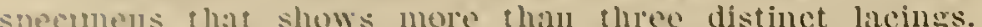

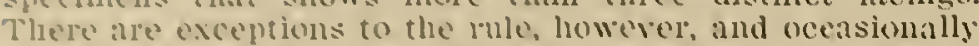
we find a ferther, or, in fact, a simsle slecimen, with a mumber of ferehes with three or four distinct lacings, and when sucl snecimens ale found they are invariably the handsomest birds in the class, and while no preterence, ac cordins to llo standalel description, could be given them, we believe the breeders fitvor them, and, other thiugs bein could, in awilling mizes should sive them preference orel the donble or triple laced, as the case may be.

The standard is not as plain on the point of color as it should be but it is alwais well to lean in the direction of wat seems to be immorement, poviding it can be pro dnced, ln siving preference to additional lacing it is necessiny to talic into consideration that this lacing must conform to the sliape of the feather, as this is vastly important. and l an satistled the breeders of Partridge color, no mat. ter what the brecd, are willing to aceclet this as ideal.

In No. 1 we find a feather that is somewhat broken in color and the lacing fails at the end. A neck showing hackle feather's like this should be discounted $1 / 2$ point.

Feather No, 2 is defective on one side of shaft only, with the same blunt point, and should be discounted 1 point.

Feather No. 3 has fewer defects inside, but has more black at point and slould be discounted 1 point.

Feather No. 4 is good in lacing, but shows entirely too much white in center, and this whitc or golden color is in such proportion aud scattcred in such manner over the feather as to malie it a serious defect from either an ex. hibition or breeding standpoint, and should be discounted 1 point.
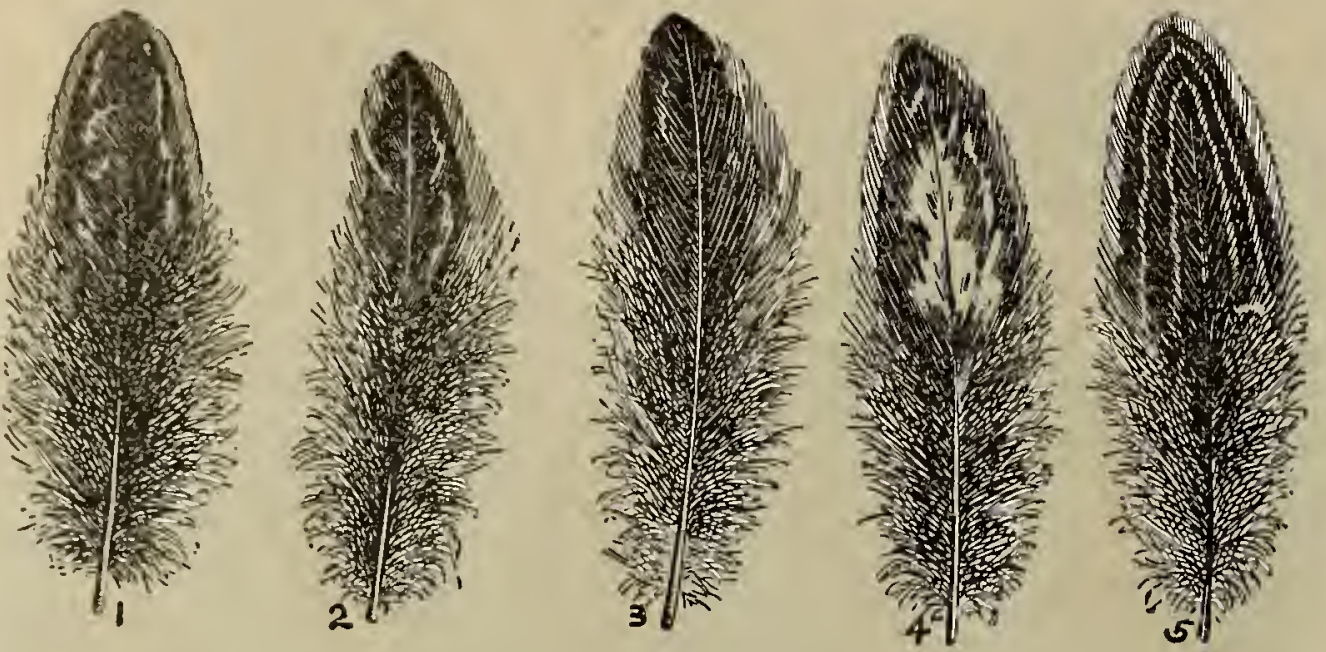

Fig. 45.

The ground color of the Partridge Wyandotte female should be mahogany-red or reddish-brown. The same Standard description follows in back, breast, body and wing bows, and to get the lacing with the correct shade of color is no small task. The Partridge Wyandotte females aver. age fairly good in this respect, especially so considering the short time they have been bred, and in our illustration of Standard Partridge Wyandotte female is shown our idea of surface color, together with the draping of feathers selected from what we believe to be the best Partridge Wyandotte female shown to date.

In head the Standard describes Partridge Wyandottes -Plumage, "redding-brown." This is perhaps as good description as could be given it, and, as a rule, it is a trifle lighter shade-more of an orange color in this section than we find in neck and back.

Neck is described as: "Red, with black stripe through each feather, tapering to a point near extremity of feather,
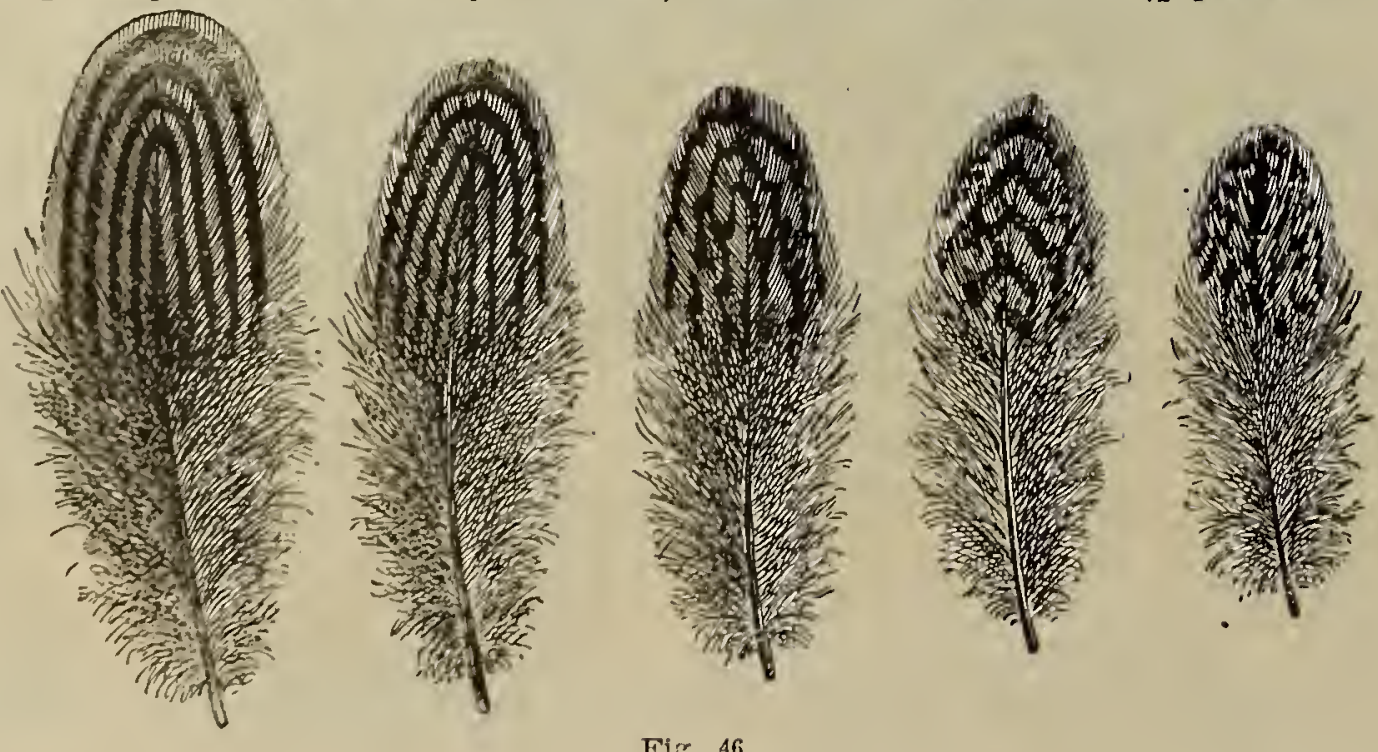

Fig. 46.

the red edging to be fres from black; yenciling in central Jortion of fcathrers allowable; under color, dark slatc."

In Fls. 45 is shown a group of feathers that illustrate some of the drefects as found in the neclss of this varicty. Feather No. 5 is what we belicve the Standard calls for,

In Fig. 46 is shown a collection of feathers illustrating several of the defects that are found in the backs of our Partridge Wyandotte females.

No. 1 is a perfectly laced fcather, and, aside from having more than the usual number of markings, could be classed as ideal.

Feathcr No. 2 in this collection, while good, does not show as distinct lacing, neither does it go decp enough in the web portion of the feather. A back showing feathers like this should be discounted $1 / 2$ point.

In feather No. 3 we find a defect, the lacing on it being zig-zag, or uncven, and does not meet at point of center, as they should, but run past the shaft, lower markings being to onc side. A back showing feathers like No. 3 should be discounted $1 \frac{1}{2}$ points.

g. 46.

In feather No. 4 is shown a defect that is slightly overdrawn, but one that is often met with in poorly bred spccimens. Therc is no distinct lacing, black and red mixcd together, giving the back a smutty appearance. A showing feathers like this should be discounted $2 \frac{1}{2}$ points.

In fcather No. 5 we have a defect which, while not 
comnion in this breed, is nevertheless met with. The feather is all mottled with a brownish cast, and looks like a feather from a poorly bred Brown Leghorn, as there is no lacing. The only redeeming point is that there is about the right proportion of black and red. A back like this should be cut at least three points.

\section{Breast.}

In Fig. 47 is shown a group of feathers w:th defects similar to those in the back, and feather No. 2 would be discounted the same as feather No. 2 in the other group. while feather No. 3 is almost entirely lacking in black. Feather No. 4 doesn't show good black or red, has a faded. out appearance, and should be discounted at least 3 points. Here is one case where we take more from color than is allowed for either black or red, as both colors are defective. Feather No. 5 in this group was taken from near the throat, has a pepper and salt appearance, has about the right amount of black and red, but has no sign of lacing, and should be discounted $2 \frac{1}{2}$ points.

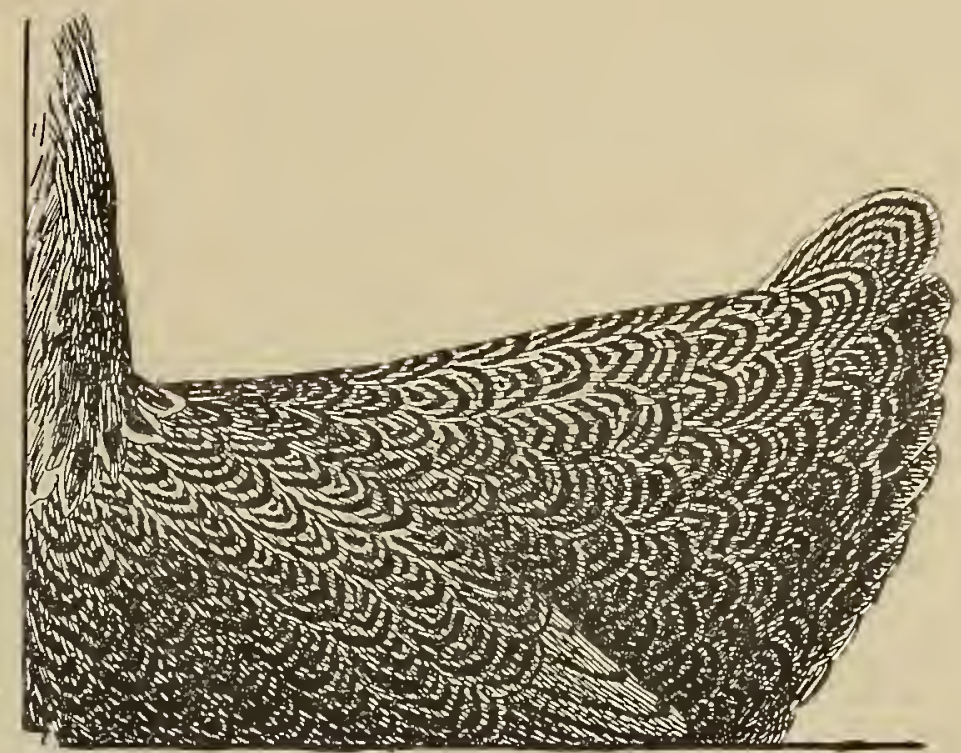

Fig. 49.
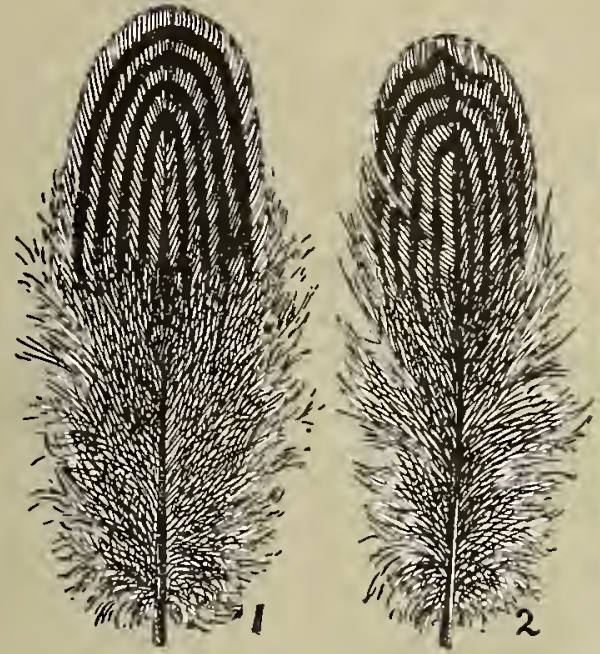
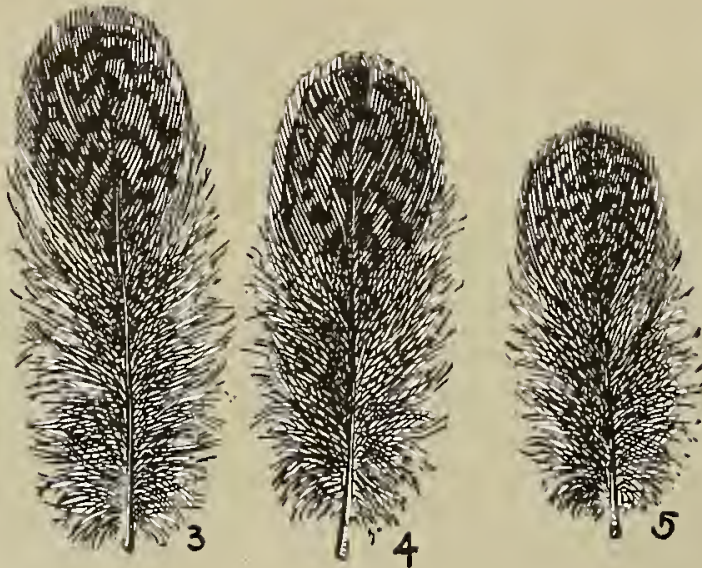

It is well at this time to call attention to some of the defects in shape of back, as found in the different specimens that are placed on exhibition, and give the valuation of same.

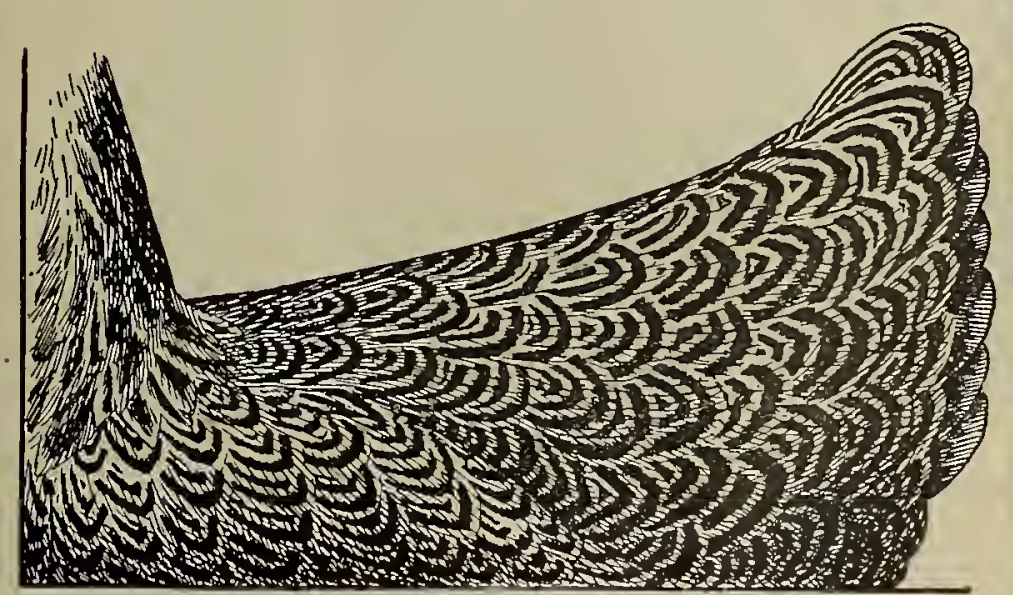

Fig. 48.

In Fig. No. 48 is shown a back that is too straight and too long for a Wyandotte. This back resembles very much the general outline of a well-bred light Brahma, except perhaps it is a trifle too narrow, and on a Wyandotte should be discounted $1 \frac{1}{2}$ points.
In Fig. No. 49 we have the same defect, only magnified. This back is practically level, there being no rise, even at tail, and is quite narrow and long, doesn't show broad enough, and should be discounted 2 points.

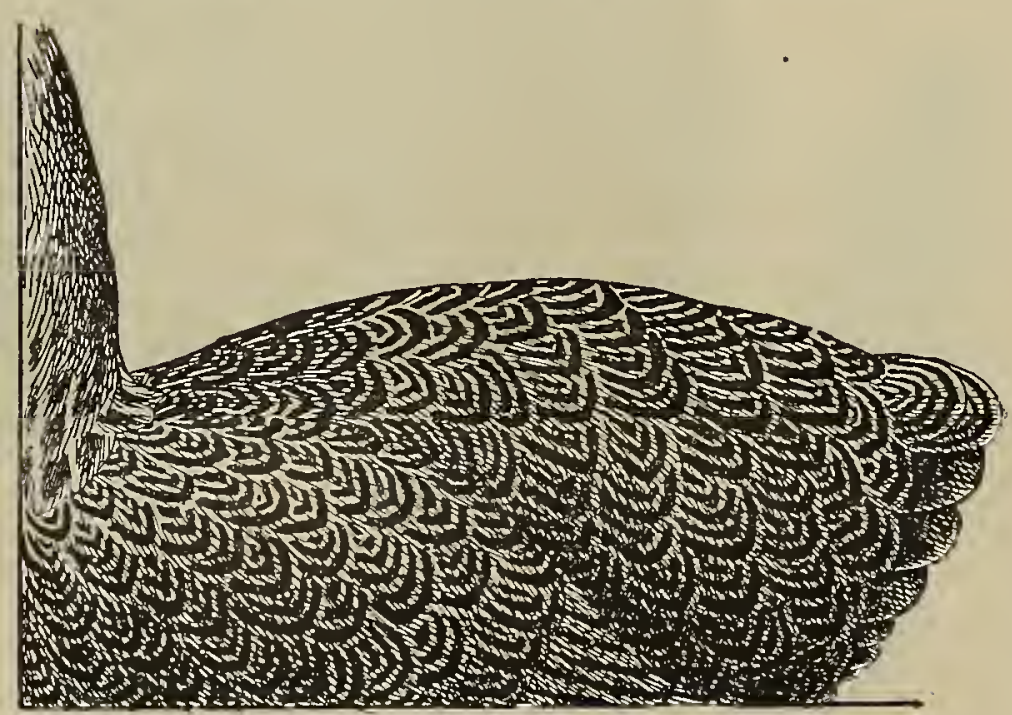

Fig. 50 .

In Fig. No. 50 we have what is known as a "Cochin back." It is rather heavy in cushion, rises from shoulder to center of back and then slopes down to tail. While this is somewhat overdrawn, it is a fact we get in our Par- 


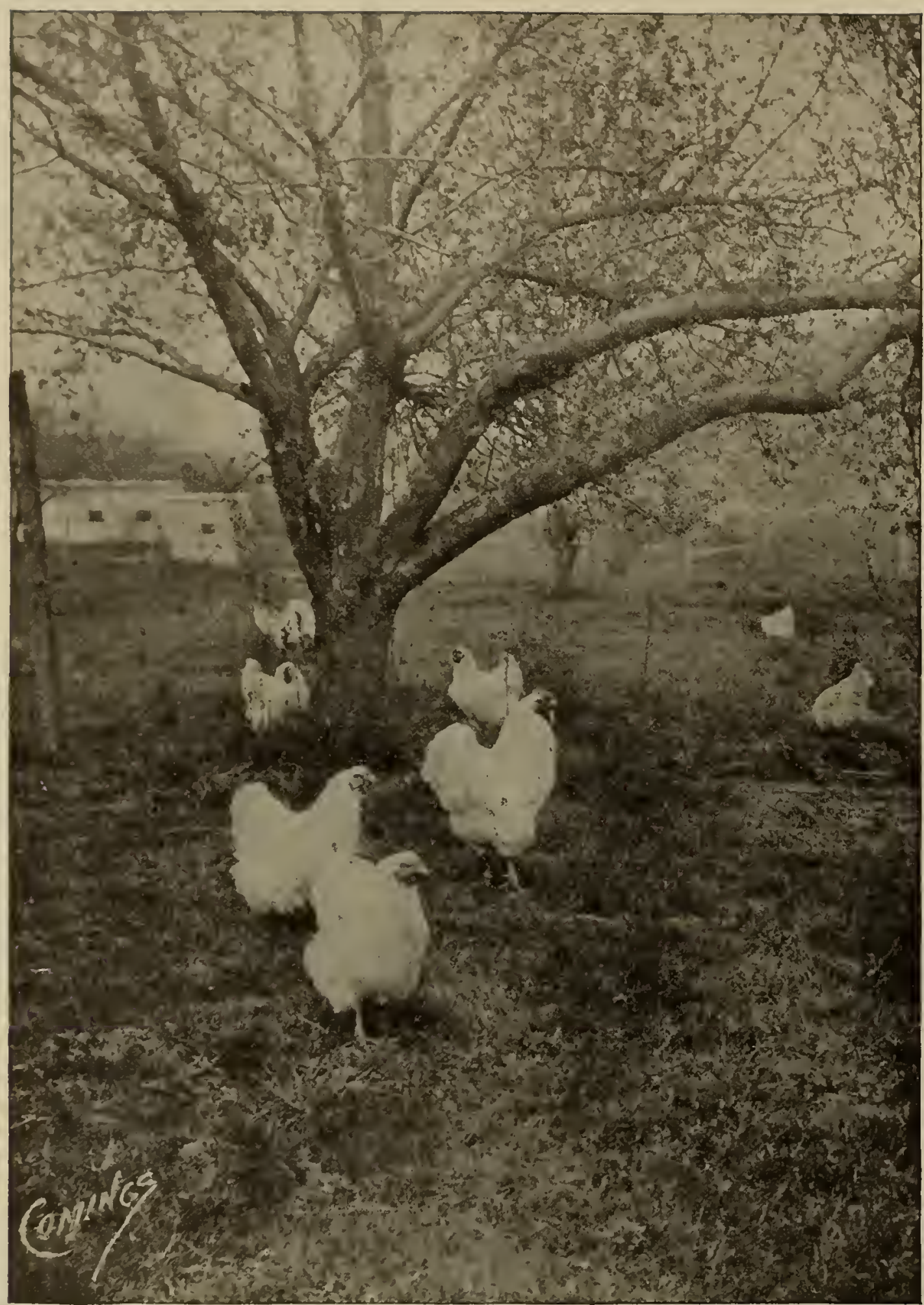

JUST AS YOU SEE THEM IN THE YARD AT HOPE, IND.

A Breeding Pen of J. C. Fishel \& Son's Famous White Wyan dottes. 
tridge Wyandottes quite a good many females, especially old hens, that show these Cochin characteristics, and some of them nearly as much as the drawing. This back is shorter than backs Nos. 48 or 49 , and no doubt if used in the breeding pens some good short-backed, short-tailed males would be the result, but it is defective from an exhibition standpoint and should be discounted 2 points.

\section{Body and Fluff.}

There is considerable stress laid to the color of this section, due to the fact that many specimens otherwise good will fail miserably when they reach the thighs or posterior portion of the bird. It is not to be expected that we will ever be able to produce Partridge Wyandottes that are laced entirely around the body, with as good feathers as we find on back and breast, but it is essential that we get the lacing down as far as possible and have all sections harmonize and blend, not alone in surface color, but in lacing as well.

In Fig. 51 are shown five feathers about as we find them in our best specimens. Feathers Nos. 1 and 2 cover that part of the body directly following the breast and around the thighs. Feather No. 2 is where the penciling begins to fade out as it rounds the sides, but this one is not very well marked. There is too much black on one inner web a dull black, outer web, mahogany-red or reddish-brown; coverts, similar in color to plumage of breast under color dark slate."

In Fig. 52 are shown three flight feathers. Feather No. 1 conforms closely to the Standard-black on one side of shaft and red on the other.

Feather No. 2 shows tracings of red in the black, and should be discounted $1 / 2$ point.

Feather No. 3 shows as much red as black, but it is splotched and runs together, and should be discounted $11 /$ points.

In Fig. 52a is shown a group of feathers taken from the wing bow, or shoulder. All the feathers here illustrated were plucked from the same specimen. No 1 , however is a trifle overdrawn, showing more lines of lacing than the feather really possessed. There were three distinct lac ings, besides the shaft, however, and they were about as evenly laced as it is possible to get them.

Feather No. 2 is somewhat muddy, the black and red edging together, and many feathers like this in a section gives the surface a rusty appearance, and should be dis. counted $1 / 2$ point

Feather No. 3 is uneven in lacing and was taken from near the point of wing, and while the surface of it does fairly well, when you open the feather up for close in-
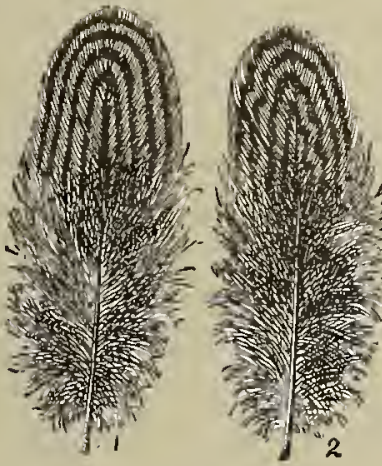
side of the shaft and too light on the other side, and should rear of bird is too uneven-it is more stippled than penciled, and should be cut 1 point. Feather No. 5 shows too light, not enough red in the feather, and it should be discounted 1 point.

Wings.

The Standard description of color in this section is good, and we believe is generally understood by breeders
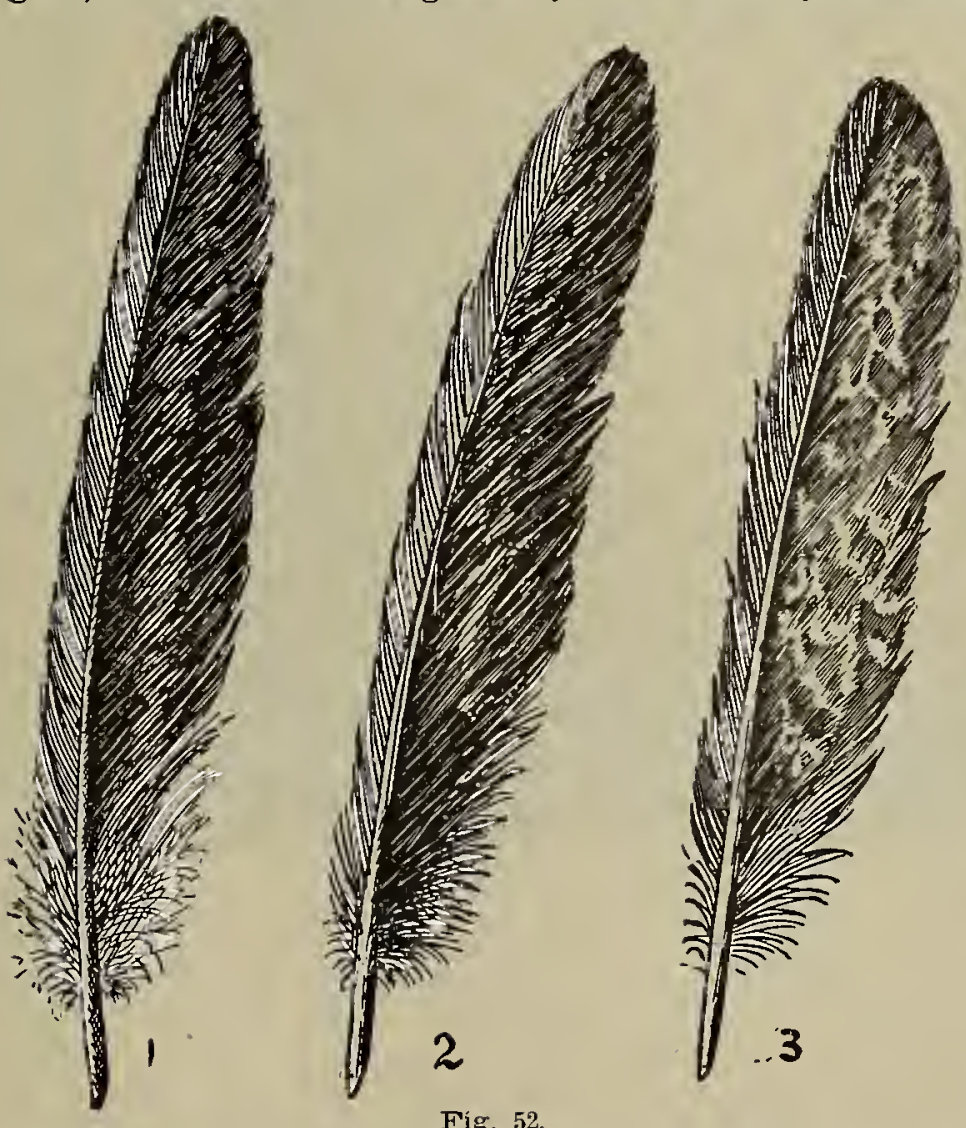

and judges alike. The description is: "Primaries, dull black, with an edging of brown on outer web; secondaries,

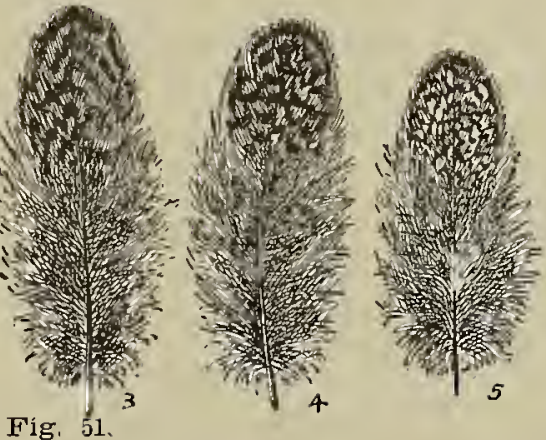

spection it all runs together, looking very much like a feather selected from a Brown Leghorn female, and should be discounted 2 points.

Feathers Nos. 4 and 5 have the same defect, slightly magnified, and should be discounted $2 \frac{1}{2}$ points.

\section{Tail.}

It is generally understood by judges and breeders that the tail of the Partridge Wyandotte female should be black -that is the main tail except the two feathers usually termed the "deck feathers"-but the Standard description does not call for black-that is, absolute. It says: "Black or brownish-black, the two highest main tail feathers penciled with reddish-brown; coverts, well penciled, similar in color to breast and body." And, it should add, similar in lacing.
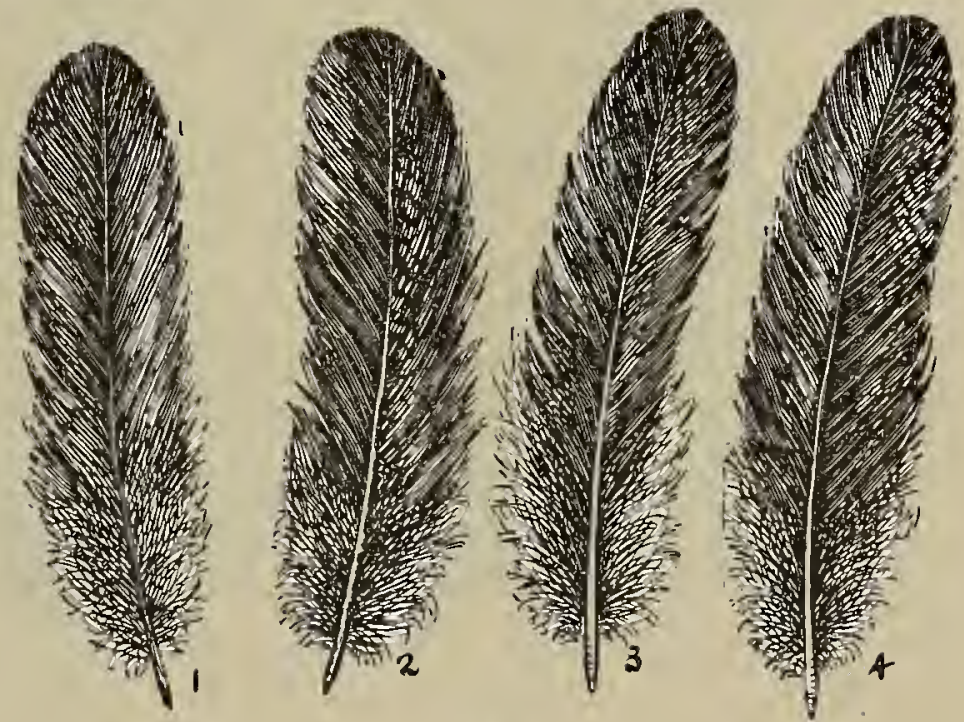

Fig. 53.

In Fig. 53 is shown a group of feathers taken from the tail, all more or less defective. However, feather No. would not make a bad ending to the deck feathers-the ones directly in center of tail. Feather No. 1 is too lightshows too much red-and should be discounted $1 \frac{1}{2}$ points. Feather No. 2 shows black and red throughout the feather, 
especially on one side of shaft, and should be discounted

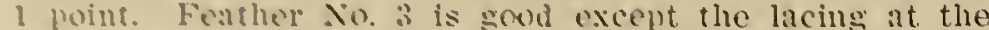
[0), and should this ambiar an any excent the deck reathers should bo discommed l point. Feather No. 1 was taken from down at the side of tail-the last feather in this sec- we believe, as in the male, it is next to impossible to get this color correct-in fact, we lo not linow that we have ever seen a single specimen that would pass without a discount of at least a lialf point, and, in many cases, they would be diseounted as mueh as $1 \frac{1}{2}$. Where rich mahog.

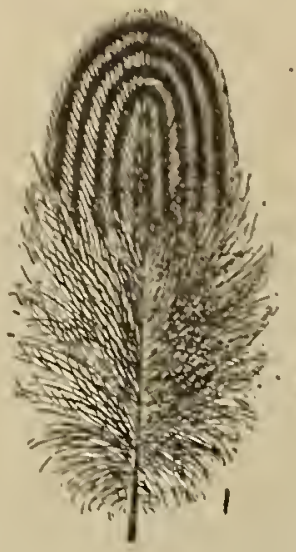
one side, and should be discounted $1 \frac{1 / 2}{2}$ points.

\section{Legs and Toes.}

The Standard calls for shanlis and toes yellow, and
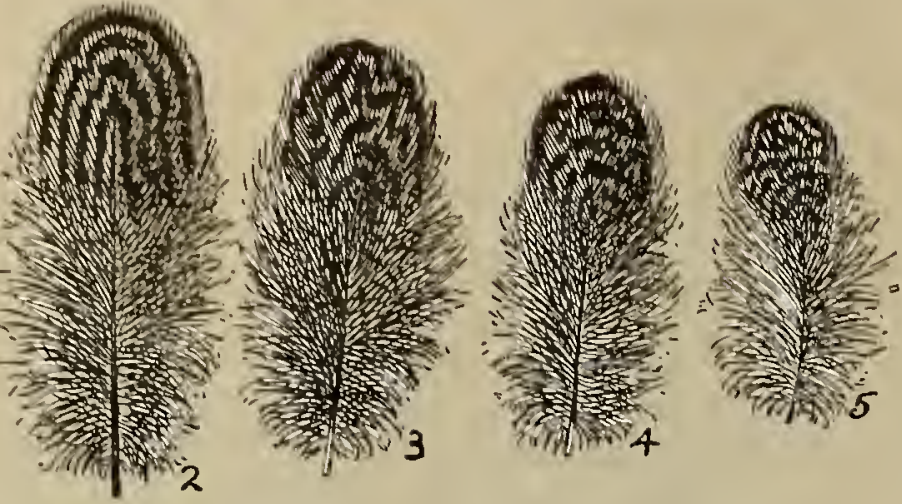

Fig. 52a.

any color is found on the surface in all sections, you can bank upon it that you will find more or less off color in legs, but the Standard demands yellow, and when any foreign color exists it is necessary to diseount it, and the out is from $1 / 2$ to 2 , as in degree. 


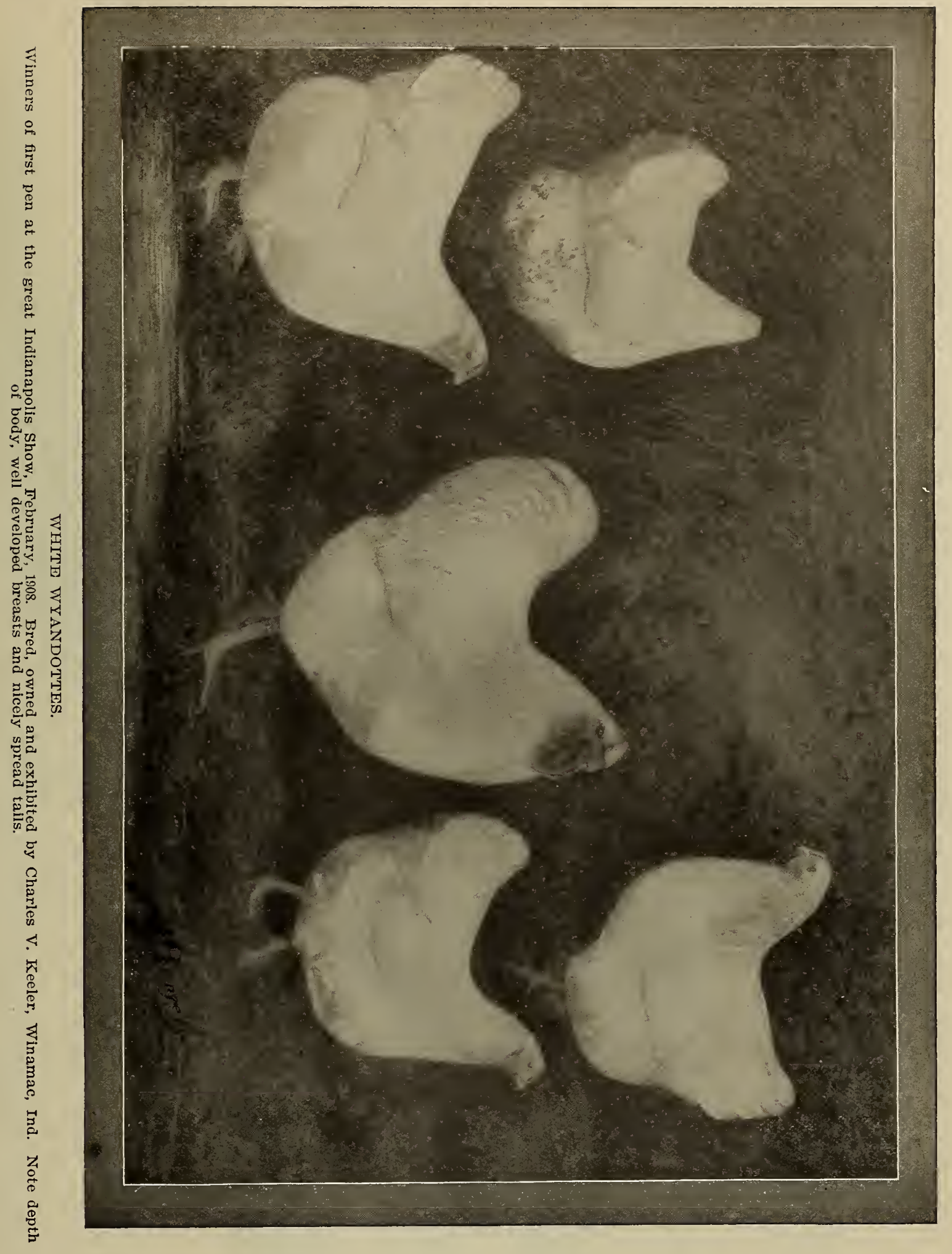




\section{SIIUIR PIENCIIEID WYANDOTIES.}

\section{Strikingly Handsome, But Never So Popular as Some of the Other Varieties.}

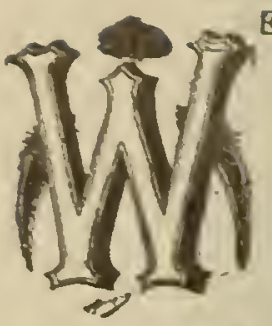

WILL now talie up the Silver Penciled variety and give to our readers a thorough description of the color defects, to gether with our system of valuing them Whether, judging by score card or comparison, the same percentage in discounting should be observed if we are to allow best colored specimens preference. It is well to remember that a judge in apply. ing the Standard can give to each section no more value than the Standard-maliers have awarded it. TVe should leep in mind at all times the fact that all sections should be considered and not allow some fad or hobby to should us in judging. It is the man who conforms closest to
MALE.

The first section to be considered in color is head, which has a value of three points.

The head proper should be silvery white, and to describe silvery white I don't know of any better description than to say wite of the sack color gives the surface, and, the surface being white, dom that the silvery white sheen. It is very selcom a Silver Wyandotte male is discounted for color, so far as plumage is concerned. However, there are some other defects that are included in the head that should have a valuation. The beak should be a dark horn color, shading to yellow. The beak should bright bay or red; face, bright red. These three points

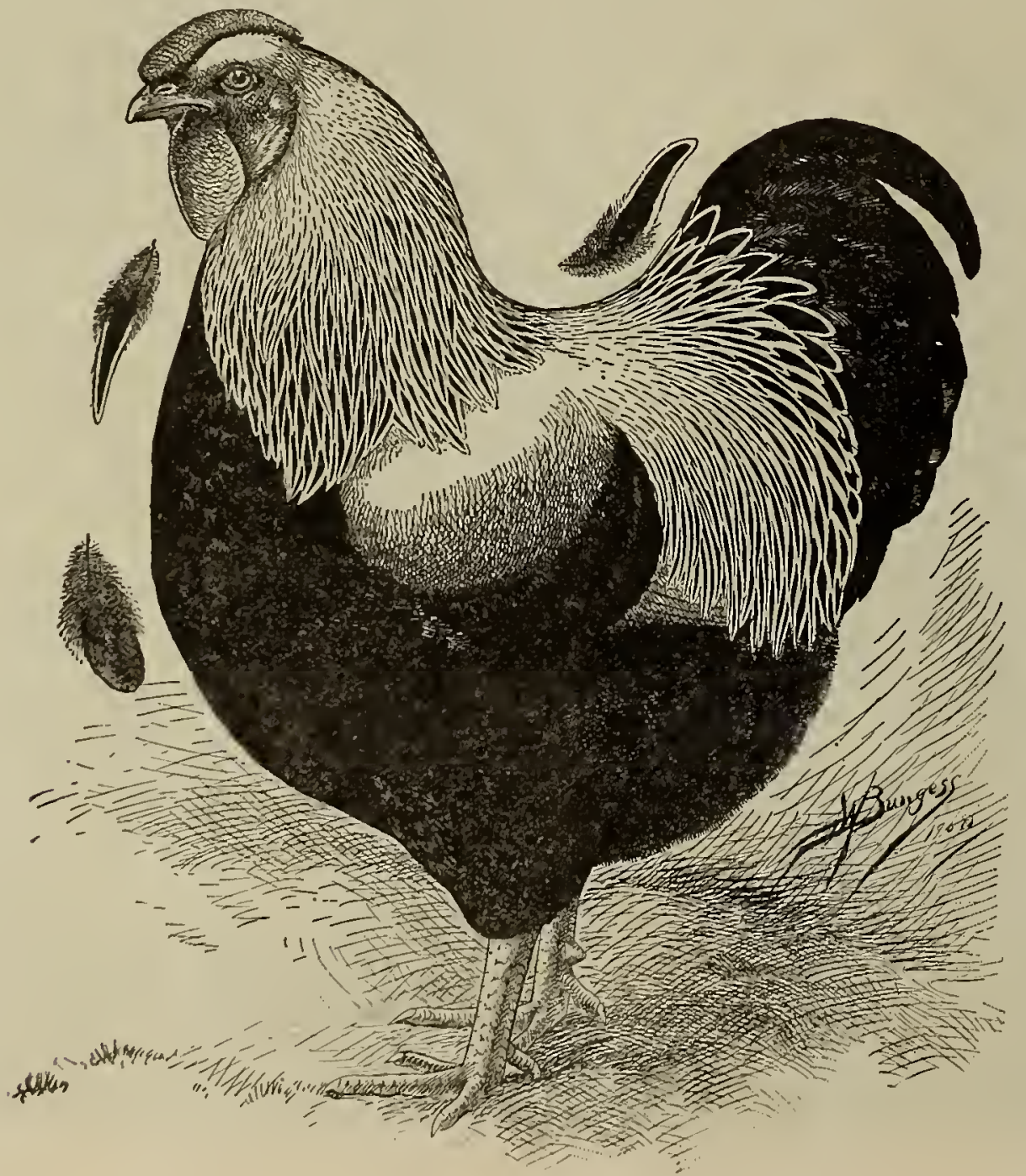

STANDARD SILVER PENCILED WYANDOTTE MALE.

Standard laws in making awards that gives the bcst satisfaction as a judge, and since these articles are intended to assist the young judre in his work they fully each variety as we take occur to them that had previously slipped their minds. have to be considered under the one section of head. As a rule, the color of the beak is good, but sometimes there a tendency to shade into yellow its a defect and pearl, or light, they 
as in degree. The face proper is usually good, especially on the males, but sometimes, owing to condition, they show dark or purple. But the better way to discount this is under the head of condition, rather than the color, as it is the condition of the fowl that brings about this color. The same would apply in comb where the Standard description is bright red.

Wattles and ear lobes are sometimes defective in color and are given a valuation of six points. These sections, while not divided by the Standard-makers, should be in applying the Standard by score card, and we would give three for shape and three for color. Sometimes a trace of white will appear in them, and in view of the fact that the Standard does not disqualify unless more than half of the section is white, some rule for cutting should be considered. If only a trace of white is found, the discount should be $1 / 2$ point; if white shows clearly in both lobes, or the entire section looks pale, the discount should be 1; where white flecks appear, showing enamel-white over one-third

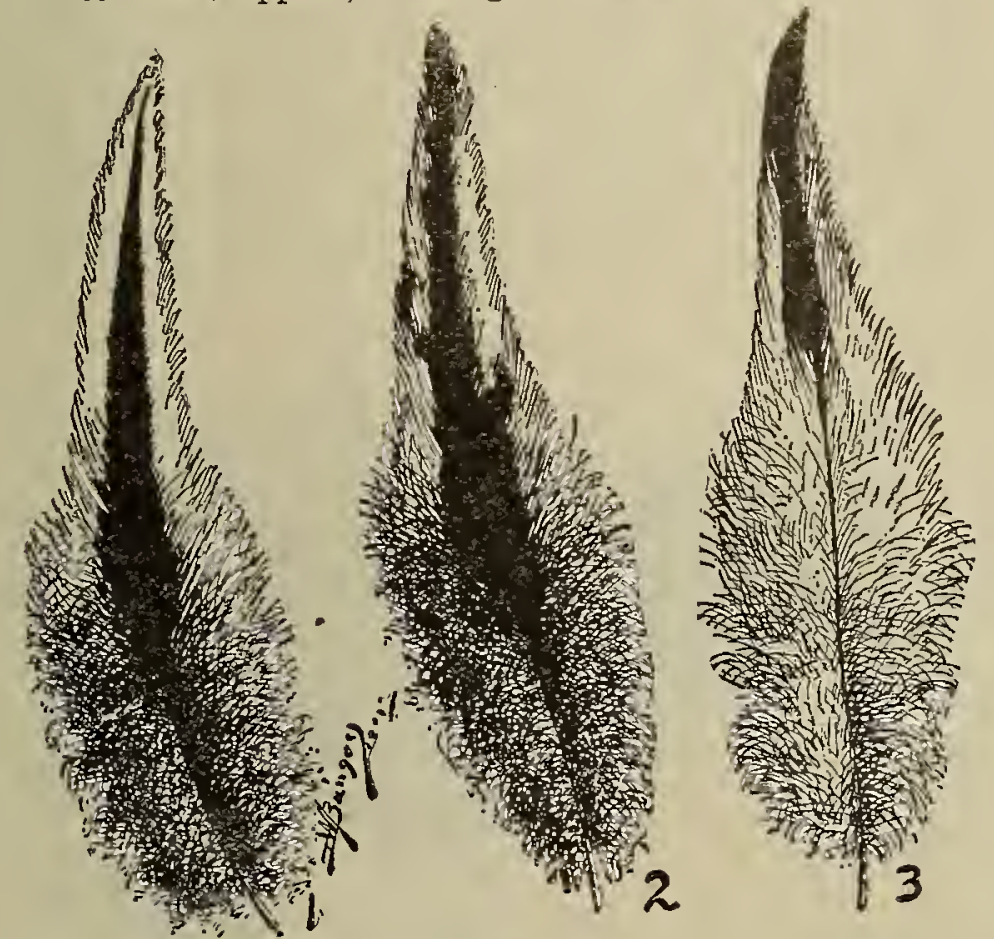

Fig. 54.

of the surface, the discount should be 2; and when more than one-half of the lobe is positive white, the bird should be disqualified.

Neck.

Neck has a valuation of ten points-four for shape and six for color-and is considered one of the most important sections, so far as color is concerned, in a breeding male The Standard description for neck is: "Silvery white,
In Fig. 54, feather No. 1, we show an ideal hackle feather that conforms to the Standard, having the black center with a white outside edging and about the right proportion of slate under color. The white edging might be a trifle narrower and still pass without a discount.

Feather No. 2 is distinct in the striping, has the dark under color, but the black runs to the edge on side of feather and runs black at the tip. A feather like this should be discounted 1 point- $1 / 2$ point for black at end of feather, $1 / 4$ point where black shows on edge and $1 / 4$ for being too light in under color.

Feather No. 3 is entirely too light. What little black there is in the feather is poorly proportioned, runs too much to a point, making a black, smutty edge, and is nearly white underneath. A neck showing feathers like this should be discounted 3 points -2 for white under color and 1 point for the smutty edging of black that extends almost one-fourth of an inch along the surface. A neck like this shows black on the outside and what the breeders term "cotton color" underneath.

A neck to show to best advantage on a male bird of this variety should be a silvery white surface from back of comb to where the hackle flows out into the shoulders. The only black showing is where the hackle parts, or on examination by raising the feathers. It is the silvery neck and back that is so much admired by breeders of this variety, and the two sections that up to the present time it has been so hard to get pure.

\section{Back.}

This section is by far the most important, both in color and shape. The Standard-makers realized this, and in the valuation of points they have allowed 6 for shape and 6 for color, giving it more importance than any other one section of the bird.

In color it should be a silvery white, free from brown; saddle, silvery white with a black stripe through each feather; under color, dark slate. We will find here very much the same description as in neck, and there is a similarity betwen the two feathers in color, but you will note by looking at Fig. 55 and comparing them with Fig. 54 that there is considerable difference in the shape of the feathers in the two sections.

Feather No 1 in Fig. 55 shows our ideal of a Silver Penciled Wyandotte back. It is good in under color, has clear black striping in center, with nice outside lacing of white.

Feather No. 3 is too light underneath; it is very black at the edge, giving the bird a smutty surface color, and should be discounted $1 \frac{1}{2}$ points.

Feather No. 4 is too light on surface, has about the right proportion of black at the edge, but is entirely too light underneath, failing almost entirely in under color and' should be discounted $11 / 2$ points.

Feather No. 5 is too white at the point, black stripe doesn't run near enough to end of feather. The under color is pure white. A bird like this shows a surface that

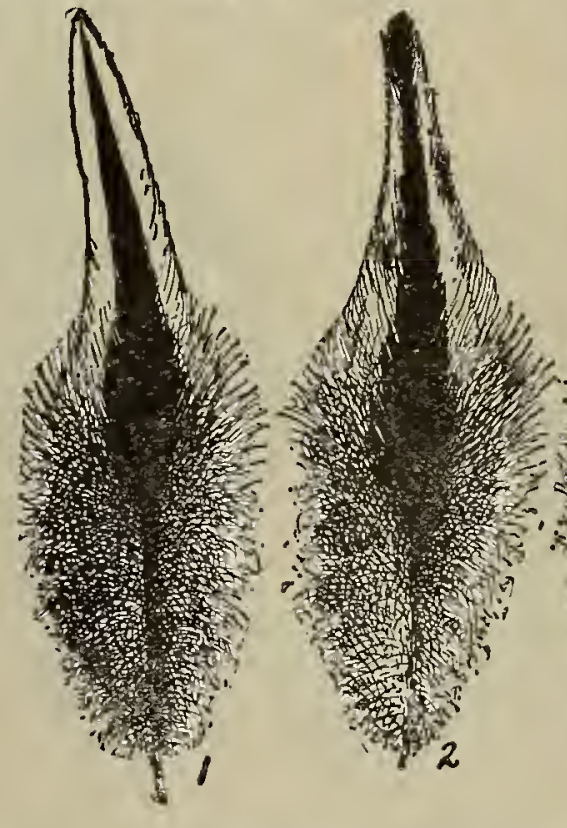

Fig. 55 with a distinct black stripe extending through each feather, tapering to a point near extremity of feather; each feather to be free from a white shaft, or a black or dark edge; under color, dark slate." is entirely too light, as well as under color, and should be discounted $11 / 2$ points.

Feather No. 2 is black at the point, a little smutty in the outside white lacing, also too light underneath. A back 
llke thes slound bo discounted for both surface and mider coler, as the amrount of black or brown slowing in the white lacing overs the back a sort of a copperish tluge which of itself should be discounted 1 point; the llght under color will add alu additioual tif poiut, maling the ivtal out 1 ts.

Breast.

Next 80 the back this is the most important section. for 25 slialle is concermed, but is not considered of as much value is sereral other sections in color. However, a sood colored breast is much to be desired on males of this variety, alud, in view of the fact that the standard-makers have givell us ten points and lid as much stress on color slrape, siving five points to cach, it is ensy to see that a defective breast in color can be severely discomnted.

The staudard descrintion of color is "Black; under color, dark slate." This description fits nell the fancy cockerel-bred exhibition males that look so well in the yard aud show room, but it is not from breasts like the oue described that we get our best colored birds, especially iu females, and quite often males as well.

Our best breeders have learned that to produce choice colored specimens of either sex, it is necessary to breed from tin or more matings. We would like to emphasize the point "two or more," as many breeders, to our knowledse, have found it necessary to breed several shades of color in males in order to arrive at just the right color in females-in fact, the splashed breast on male is not in very case a safe criterion to go by that the individual is a pullet-breeder. The choice exhibition females, when mated with the rich-colored exhibition male, will more than liliely disappoint the owner in the quality of chiclis. The females will run unevenly and splotchy, failing in lacing in many sections, while the males will come in almost as many colors as there are chiclis to count-in fact, you wil hardly find two alike, and you can consider yourself fortu. nate if rou have any real good show birds from the mat ing. Howerer, there are exceptions to this rule, and the trio exhibition colors may nick all right and breed fine exhibition males or females, and sometimes both, from the same pair or pen. But when results like this follow, it is

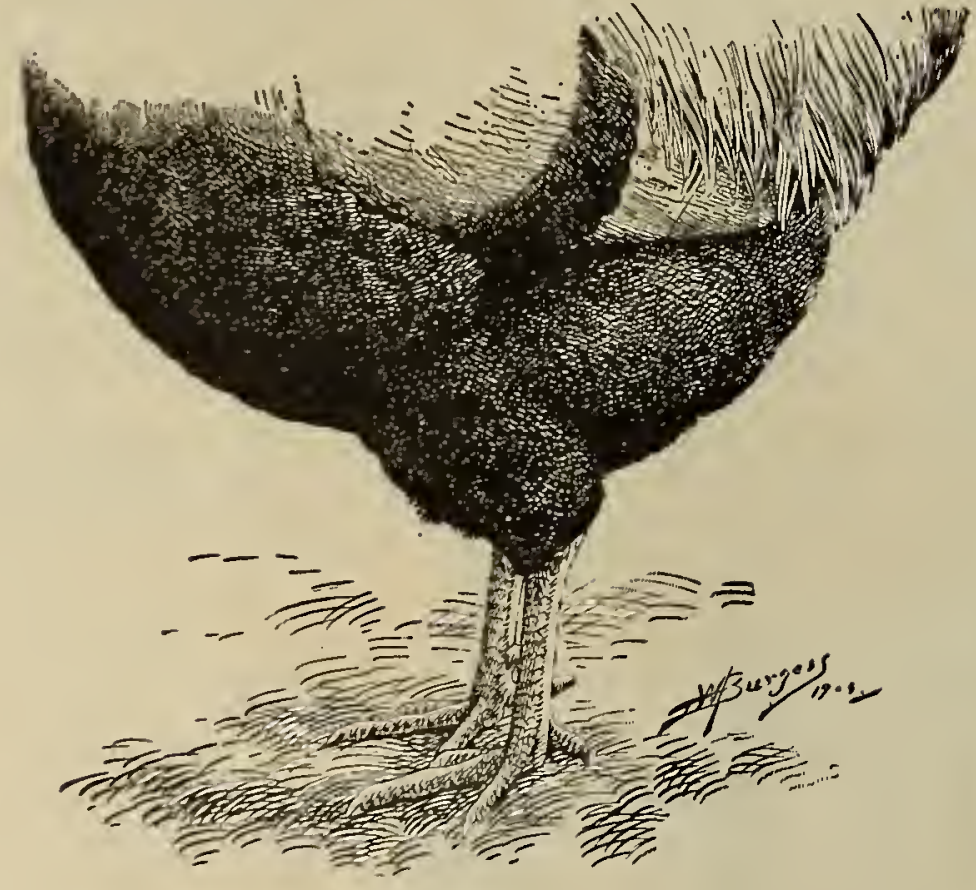

Fig. 5 t.

well to look back of the individual and learn the cause, and It is almost invariably the case that the breeding of the sires, and not the sires themselves, was responsible for the results. When good results follow the mating of exhlbltion males and females, it is safe to calculate that one or the other, or perhars both, of the sires was bred on opposite lines from what thelr color would indicate; or, in other words, were mere accidents where the blood of one sex or the other in the embryo state had predominated and given life to a chick, with exhibitlon plumage, along one line whose parentage would lead in an entirely different dlrectlon.

I merely call attention to this matter here to show the amateur breeder the folly of trying to produce exhibition color from Standard matlngs when the color of the two exes is entirely opposite, as in the case of the Sliver Penclied Wyandotte or Dark Brahmas. I do believe that
Barred Rocks, Penciled Hamburgs and other varietles that live the sime color characteristics in both male and fomale cin and slould be bred from one mating, aud in my six years' experimentlng along these lines the result iu my yards lias thoroughly convineed me that they are right, but I doubt if it can be brought about witli any degree of certilnty where the breast of one sex is penciled or laced and where the other is black or white. So in order to help the beginner, I would suggest the double mating system in Silver Penciled Wyandottes, especially while trying to establish a strain. I would recommend the mating of black breasted males to dark colored females that are defective in triple lacing in breast and back, but as free as possible from the rust or mahogany color on wing bow and back. Remember youl want bright, silvery surface color on hackle and saddles of males as well as wing bows, and to get this you must steer clear of the rusty color of either sex in selecting your breeding stock. In order to get good females, select your choicest colored hens or pullets-that is, the ones with the cleanest lacing, showing the steel-gray surface as free as possible from the mahogany shade-and mate to a male that shows some white in breast and body. and should there be a trace of lacing in the body color of the male, all the better.

In order to show our readers what is meant by cockerel and pullet mating, we present here two views. Fig 56 shows breast and body of a cockerel-breeding male that would not be discounted for color, according to our Standard description.

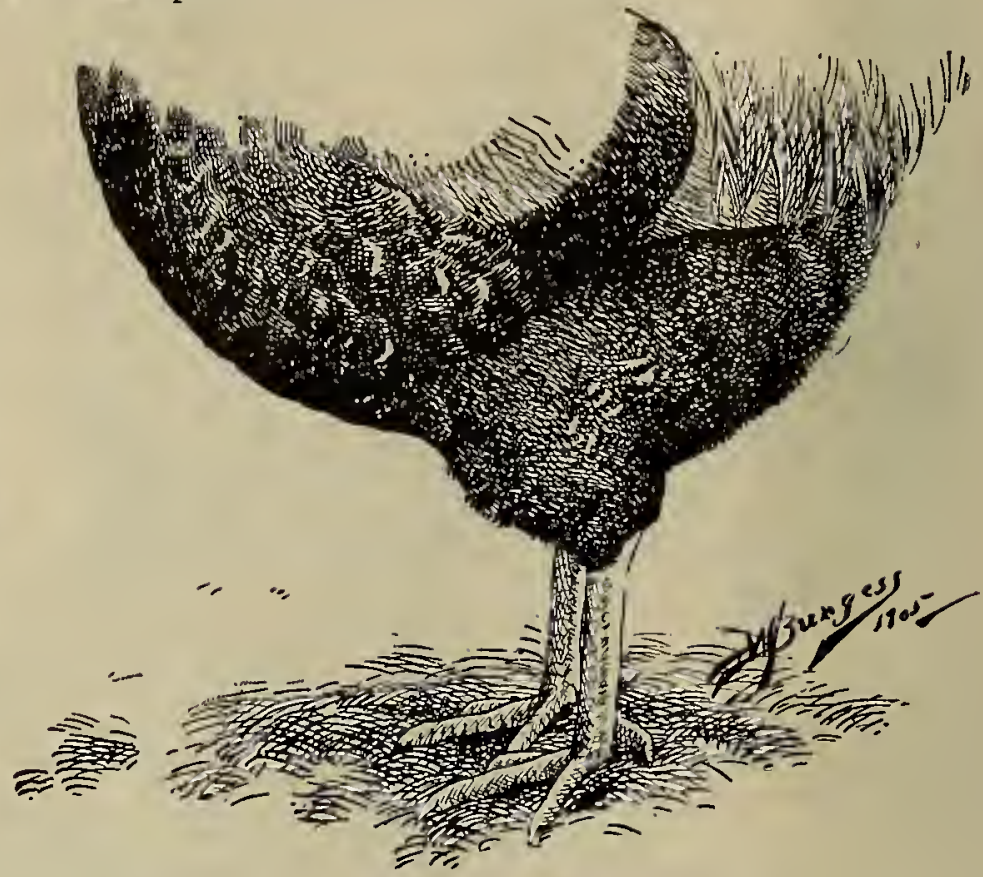

Fig. 57

Fig. No. 57 shows the breast and body of a pulletbreeding male, one having considerable splashing and lacing in sections, and if placed on exhibition would be discounted $1 \frac{1}{2}-1$ for color of breast and $1 / 2$ on color of body.

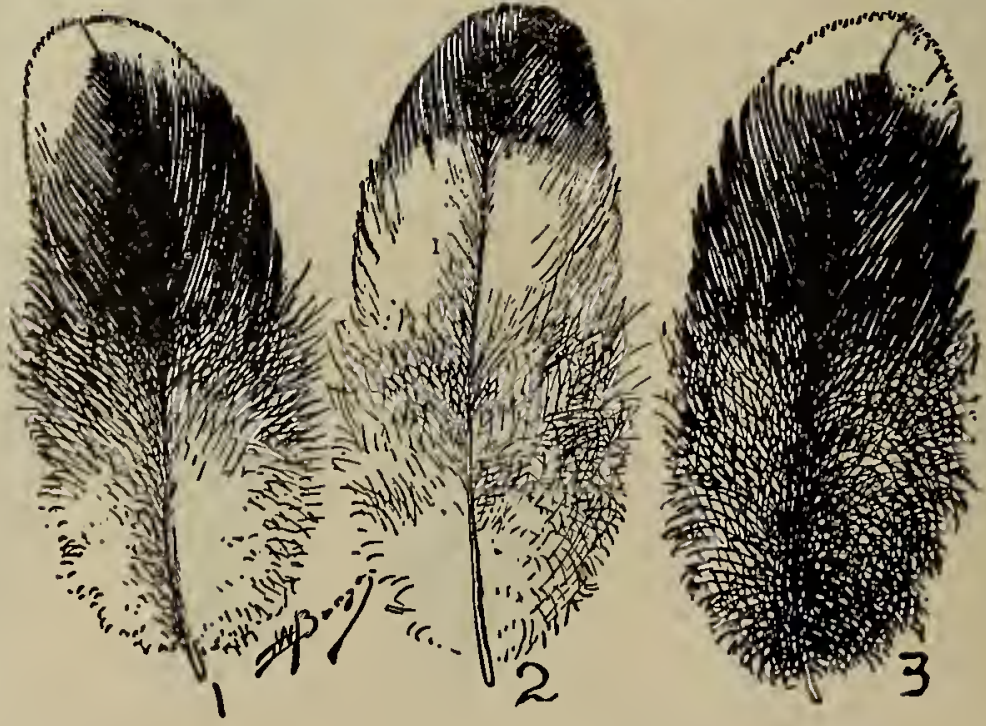

Fig. 58.

In Flg. No. 58 are shown three feathers selected from the breast of a male bird that will illustrate our idea of defects. 
Feather No. 1 is too light underneath; also shows white tip-in fact, there is more white than black in this feather. A breast like this should be cut 3 points.

Feather No. 2 is good at the end, but entirely too light underneath, showing more than two-thirds white, and should be discounted 2 points.

Feather No. 3 is good except at the tip, showing a small splash, and where many feathers of this kind appear in a section the discount should be 1 .

\section{Body and Fluff.}

In describing the color of breast we might have added the same description for body as to color, and the discounts would fall equally as heavy upon both.

In fluff there is a slight frosting on the end of feathers, not enough to make that section look white, but slightly streaked, and resembles at a distance of a few feet a spider web effect. When extreme matings are practiced, and the male is very dark in all sections, there will be but very little, if any, of this streaking appear on the surface; but where the males are pullet-bred quite a little of it will show, and sometimes be so white as to demand a discount of from $1 / 2$ to 1 point.

\section{Wings.}

There is considerable importance attached to this section in all the American breeds-in fact, it was considered of such value by the Revision Committee that they have changed the number of points allowed from eight to ten. This change was made, however, more on account of Barred Rocks and Silver Wyandottes than on account of the Silver Penciled varieties. The section is divided, giving six to color and four to shape, and perhaps the best way to apply a score card would be to allow two points for wing bow and bar, two for primaries and two for secondaries, valuing our discounts accordingly.

The Standard in describing the wing of a Silver Penciled Wyandotte male calls for "Primaries, black, lower edge white; secondaries, black, outer web white, terminating with greenish-black at end of each feather; wing coverts, glossy, greenish black, forming a weli defined bar of that color across wing when folded; bows, silvery white; under color, dark slate."

The Standard-makers did not tell us whether the black at end of secondaries should be crescentic or spangled, and in our drawings illustrating this section we have made them to conform to the best specimens we have found of this variety. There is a slight crescentic mark at lower end. This is the white running slightly into the black in our best specimens.

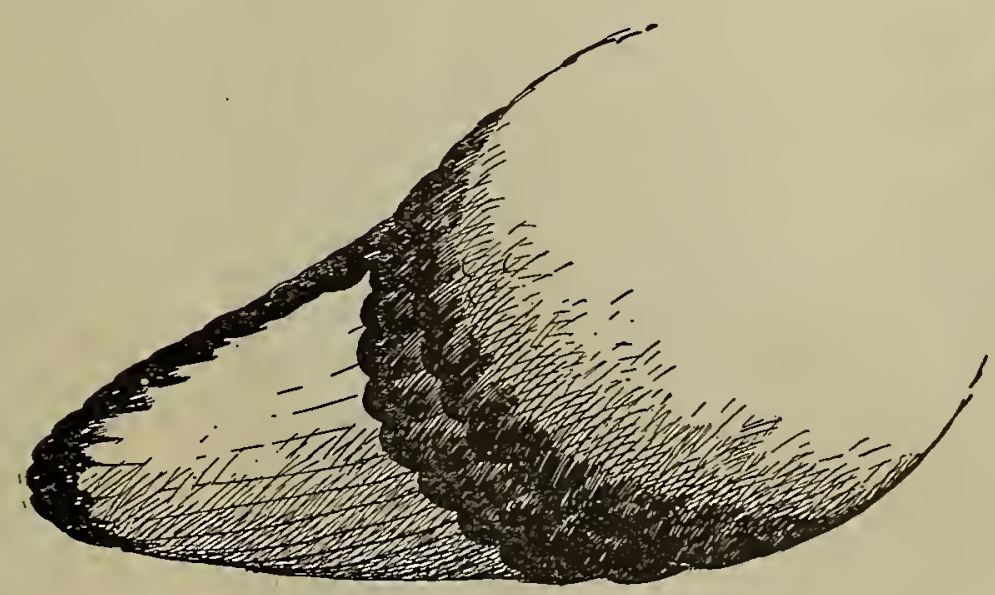

Fiz. 59.

In Fig. 59 we show a wing folded that conforms closely to the Standard description-white bow, black bar, with secondaries showing white on outer web. A wing like this would pass without discount in color, but is a trifle long for its width.

There is one feature here that it might be well to call attention to, and that is in the wing bar as described by the Standard and as found on the different specimens we handle. It says: "Wing coverts, glossy, greenish-black, forming a well defined bar of this color across the wing when folded." We note in looking at the best specimens that it makes what might be termed a double bar, or, in other words, there are two rows of feathers that bring out the color. There is no overlapping of the black on white, but both rows of feathers end with black and over lap so that there is but one bar, but it is composed of more than one row of feathers.

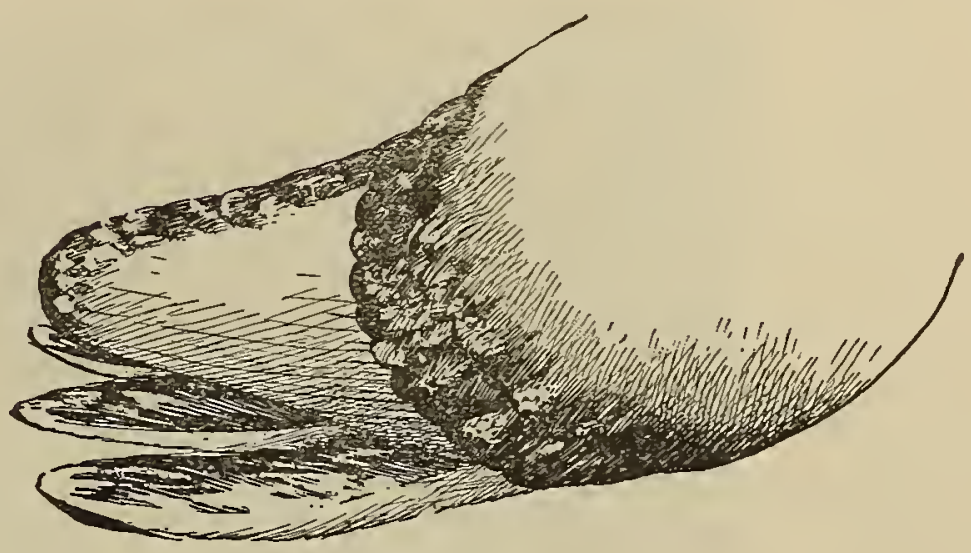

iriz. co.

In Fig. No. 60 is shown a wing that is slightly spread. This wing is defective in bar, also defective in primaries and secondaries, there being entirely too much white. The lower web of feather exposed in primary should be white, upper web should be black. The bar should be solid black and not splotched with white, as in this illustration. The black band along the lower edge of secondaries should also be black, the white showing through, is a defect. A wing like Fig. 60 should be discounted $2 \frac{1 / 2}{2}$ points-1 for defective primaries, 1 for defective bar and $1 / 2$ for de fective secondaries.

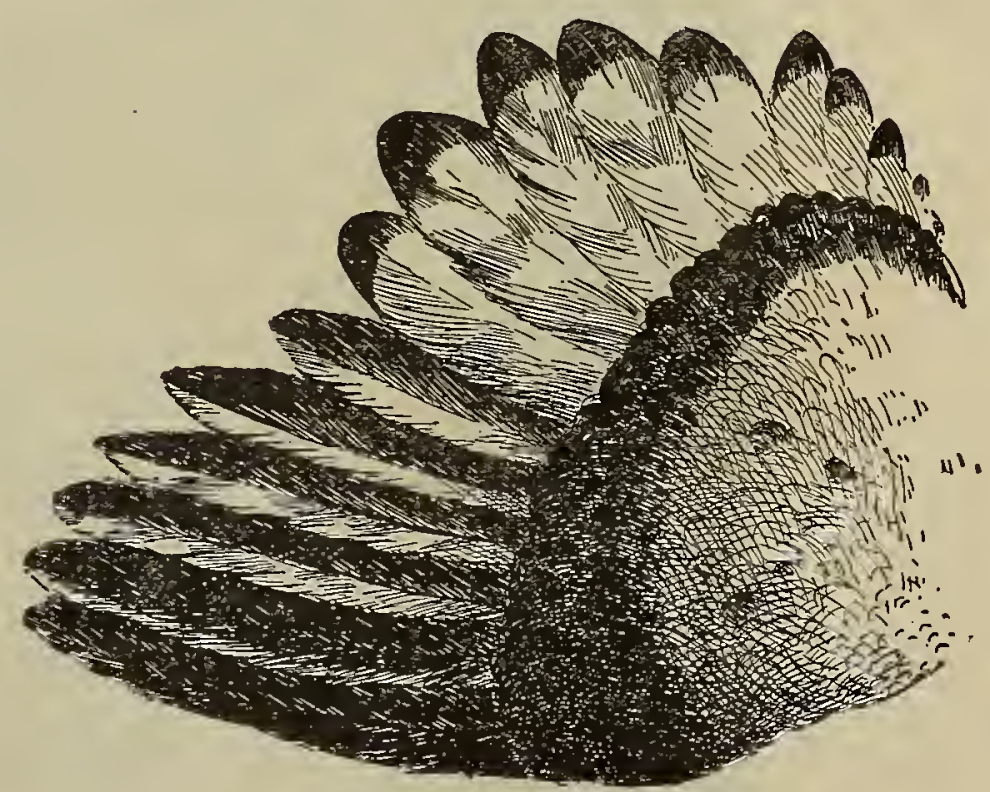

Fig. 61 .

In Fig. 61 we show a spread wing that is quite the reverse of No. 60. In this wing we have too much blackthe bar is too wide. There are some slightly splotched feathers on wing bow, secondaries have too much black at end, and the outer flight fails in the white edging. This wing represents a male bred along very dark lines, and should be discounted 2 points- 1 for cloudy surface in wing bow, $1 / 2$ for absence of white in primaries, and $1 / 2$ for too much black in secondaries.

\section{Tail.}

Tail has a value of nine points, five of which go to color. This section is usually good in Silver Penciled Wy. andottes. The tail proper should be black; sickles, glossy, greenish-black; coverts, glossy, greenish-black, or black edged with white. 


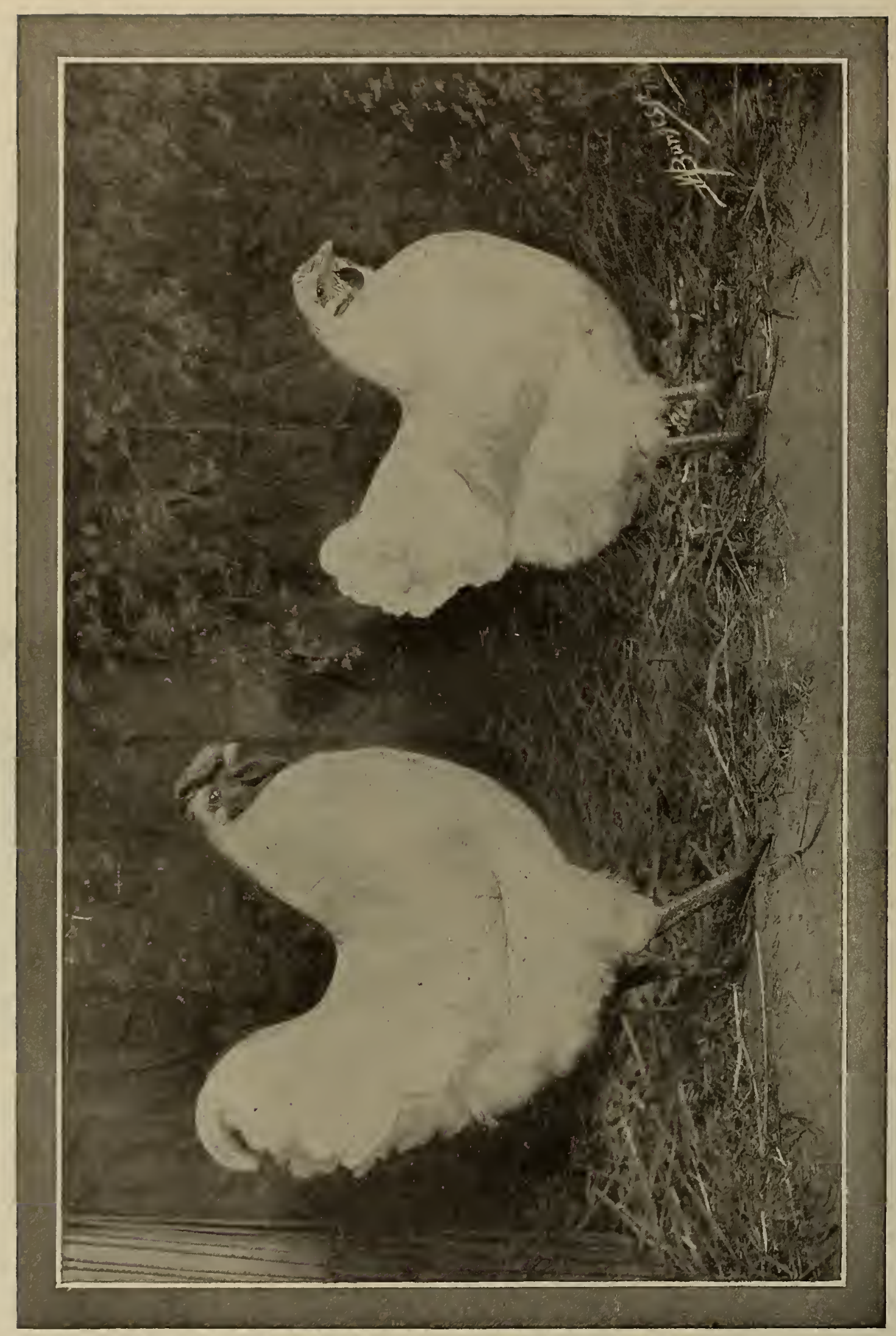

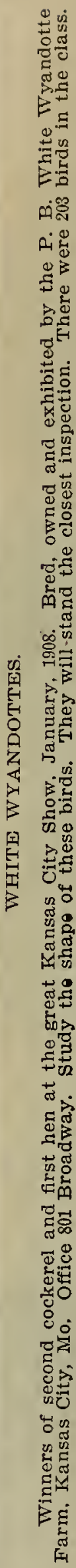



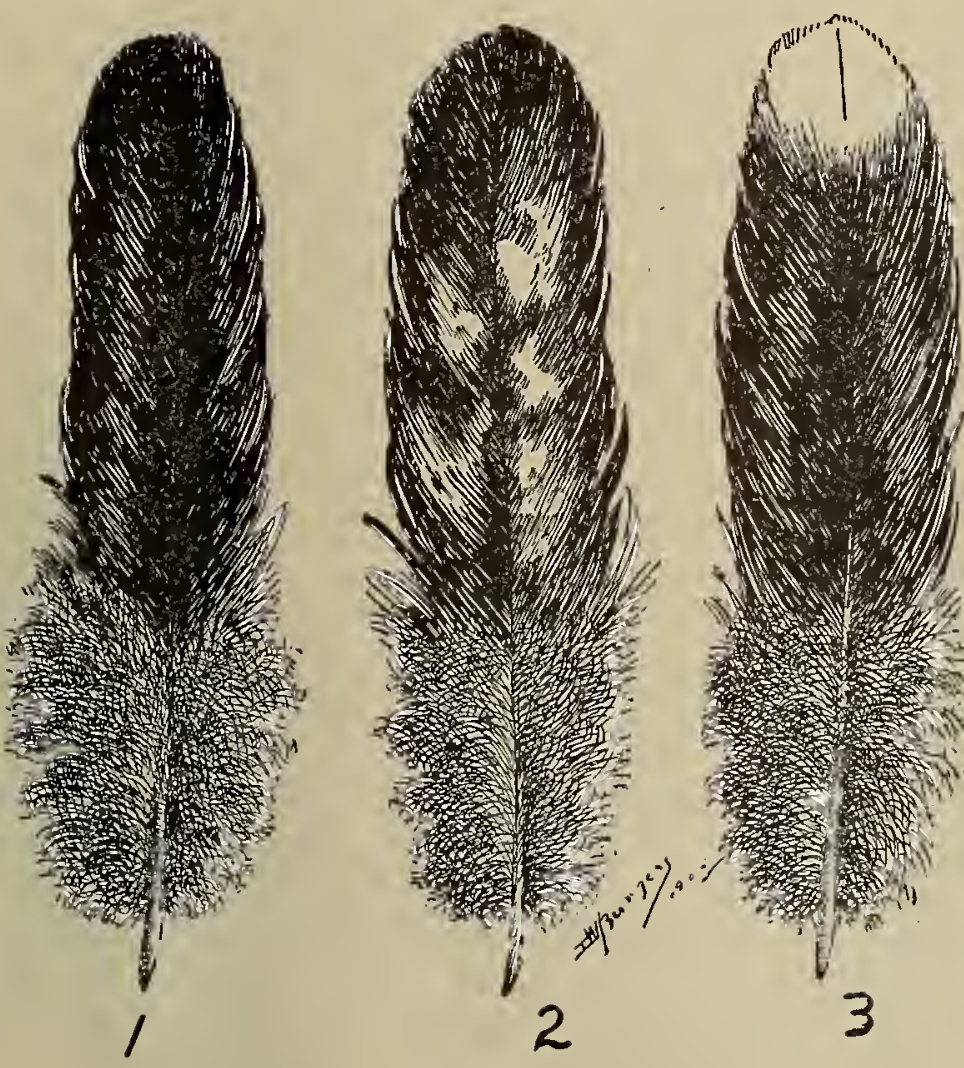

Fig. 62.

In Fig. 62, feather No. 1, we illustrate what the Standard calls for-a black feather, with dark slate under color.

Feather No. 2 is dark enough at the end. but breaks up in center and is quite a bit too white in under color. A tail with feathers like No. 2 should be discounted $11 / 2$ points.

Feather No. 3 is good except at tip end of feathers, where there is about one inch of white. This is not an uncommon defect, and especially in pullet-breeding males, and should be discounted 1 point.

\section{Legs and Toes.}

This section has a valuation of three points for color, and in Silver Penciled Wyandottes is of considerable importance from the fact that but very few, if any, of our specimens today are up to Standard in color. We refer now particularly to shanks and toes, of which the Standard description is yellow.

The Standard-makers were easy on this section, not having called for a rich or a bright yellow, and in view of the fact that there are several shades of yellow, shading from light to dark, the breed will not be handicapped to any great extent by this description. However, in nearly all the specimens we have found in the shows, and especially on females, there is more or less willow or slate color, and when such color is met with it is necessary to discount. As there are only three points for color. it is plain to see the discount is light as compared to the real defect. A slight tinge of slate would warrant a discount of half a point, but if all the front of shank and upper part of toes show this color, the out would be 1 ; if the color runs around to back of shank, then the out would be $11 / 2$ to 2 .

Believing this description will give to the breeders the information desired in regard to the defects in the several sections and our system of valuing them, we will now take up the Silver Penciled Wyandotte female.

\section{SIL.VER PENCILED WYANDOTTE FEMALE.}

The Standard in describing color of female in back, breast, wing bow and tail coverts, calls for gray color, with

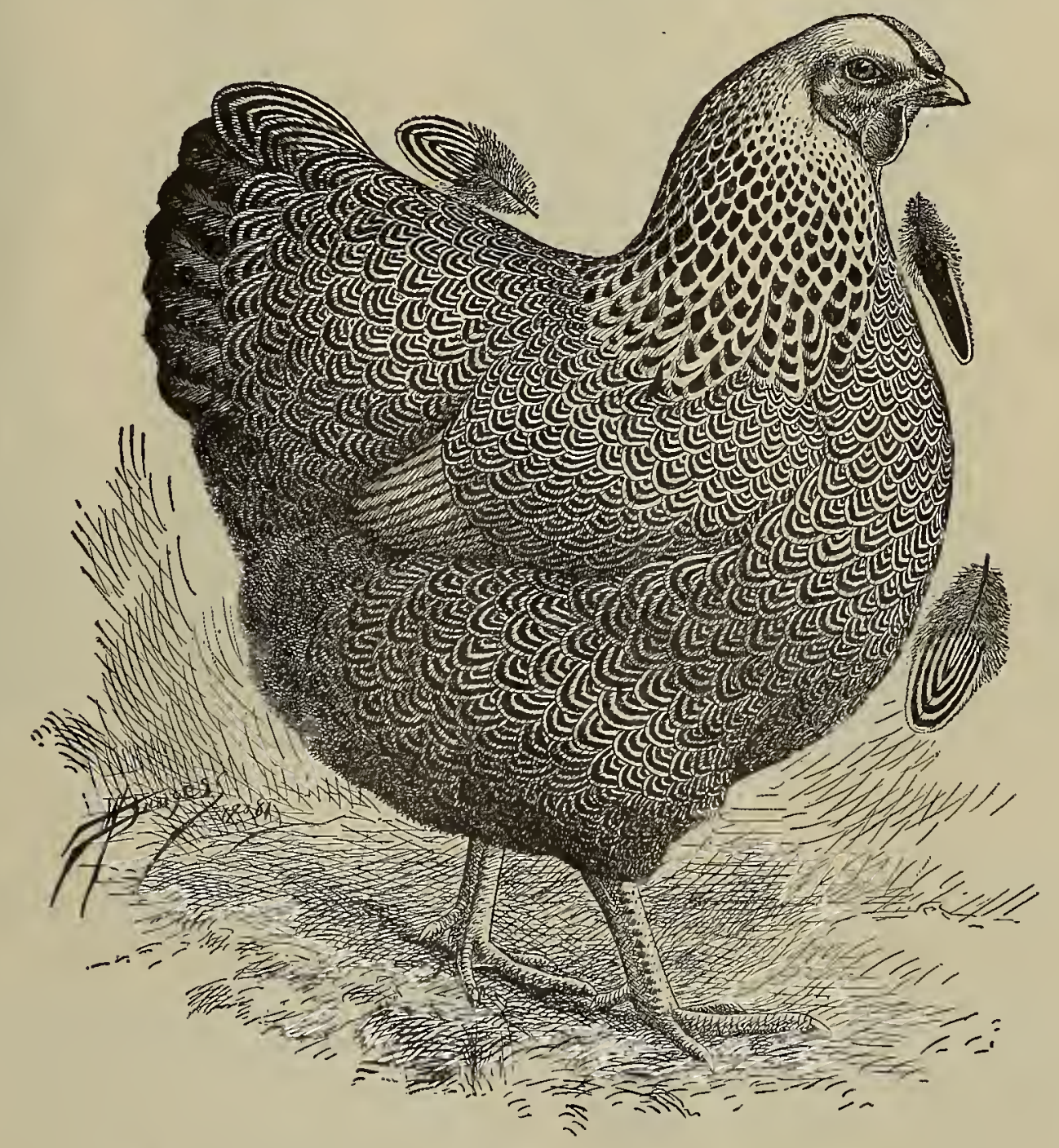

STANDARD SILVER PENCILED WYANDOTTE FEMALE. 
distinct dark penciling, outlines of penciling to conform

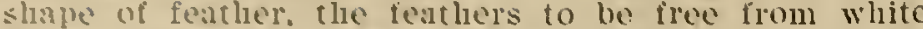
sliating. There is no set rinte as to the number of lac inss to be found in the difterent sections, but our own cxpe-

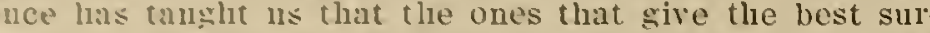

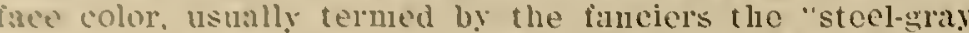
ov throe distinct penciliness the same as our Dark lirahnias. lie liave examined it number 1 diferent sections of the country, amons the iuluortalt urizes of the World bouis and hive lind selected for us rrom the vards of Mr. L. G. Wyclion, the big wimer at the World's Fiair the ioathors that are used to illustrate the several cortous of the fomale in this article. Remember, these cathers are not intended to be perfect: We show ideals, osether with defocts, and we will attempt to value them on paper as we would in the show room, giving to our readers a good general idea as to what specimen will score with the several linds of plumage described.

All parti-colored birds have their peculiar characterisics that must be thoroughly understood by the breeder fle best results are to be secured from our matings. The pecnliar markings of one breed, and the effect of these markings on the offspring, may be slightly or entirely cliansed in the offspring of some otler breed, and for this (rule can be adopted that will work alike in all cases. To be a successful breeder of any one variety of fowls means that we must have a thorough understanding not alone of that variety, but the particular breeding that has brought up the strain we are striving to improve. improvements lave not been lnade by one breeder, or froul one strain of fowls. Breeders in different parts of the country are striving for the same results and have made vast improvements; but the breeds which entered into the original makeup were not all alike, consequently in mixing the blood of two strains, no matter by whon or how well the variety be understood, may prove a complete failure from a fancier's standpoint, and it is on this point that $l$ wish to give a lew words of advice to the amiteur or inexperienced breeder.

Should the offspring from the crossing of two different strains prove inferior, or not up to the parent stock, do not discard them as worthless, but select the best from the cross, both male and fomale, and mate them to their sire or dam, according to the sex you wish to produce. Please remember that in giving this advice I am taking it for granted that you are working along the lines of double mating. It is quite likely that the first cross of the parent stock will bring back the good points lost. If they do so only in a limited way, then mate the second offspring back again to the original sire or dam, and you will get the desired results and establish a strain of your own.

Perliaps one of the best, if not the best, strains of Silver Penciled Wyandottes of the present day was originated by the late Ezra Cornell, and has for the past ten years been bred by Mr. E. G. Wyckoff, and since Mr. Wyckoff has owned the birds there has been rapid improvement, both in color and shape, due not alone to his good judgment in mating, but to a thorough knowledge of the original crosses that produced the birds in Mr. Cornell's hands.

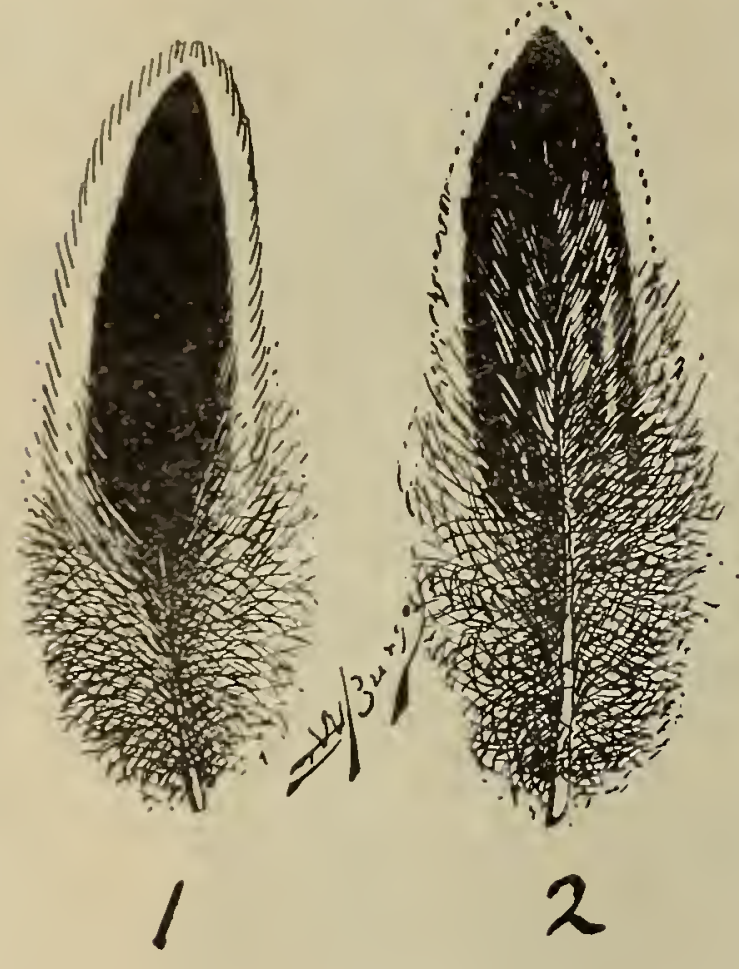

While it is true that like begets like, it is well to remember that ideals exist only in the imagination of some overwrought amateur, and that the stern reality of longer experience in breeding banishes them from the mind. It is true that the mating of Wyandottes will produce Wyandottes, but it is not true that the mating will produce a flock of birds all of which will equal or surpass in quality the parent stock. In fact, with a parti-colored fowl like the Silver Penciled Wyandotte we may consider ourselves lucky if we produce five per cent. of either sex that surpass the parent stock, and many times we may not succeed in raising one chick that even equals the mating that produced them.

I call attention to this now before taking up the color of the Wyandotte temale and caution the readers in point ing out the several defects that it will not be possible in every instance to make the same application with other reeds, as in the breeding of poultry too much depends ujon the manner in which the strain is produced. Even our best informed poultrymen may go astray in their mat ings until they have learned by experience which shades of color will nick best in producing choice males or feInales; and in no one variety is there more danger of this than with our Silver Penciled Wyandottes. This is no reslection on the breed by any means-in fact, the imjorvement on this variety is simply marvelous, consid. ering the short time they have been bred, but all these
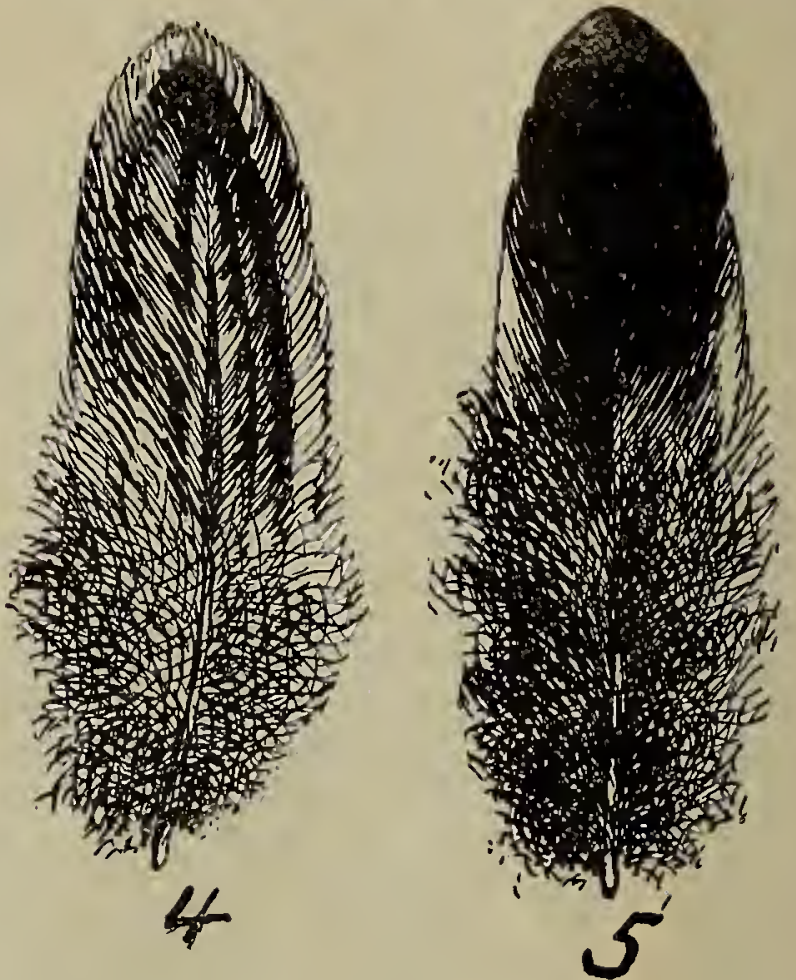

63.

The exhibit of Silver Penciled Wyandottes at the World's Fair at St. Loxis was of such marked quality that one would thinl the variety had been bred for a quarter of a century. In many instances the females surpassed the Dark Brahmas in correct penciling. To Mr. Wyckoff is due the credit for the elegant feathers, showing the ideals in the following illustrations, reproduced by Mr. Burgess.

\section{Neck.}

This section in parti-colored birds is of vast importance to those not having a thorough understanding of ideal plumage and how much we may juggle with defective color and still be safe in our matings. To call for feathers on the back, breast, body and wing bow, with triple lacing, and then require nature to carry a single lacing on neck color, down to junction of back, is setting a hard task, and we have found that in order to get the proper shade of color, the steel gray so much desired by breeders of this variety, it is sometimes necessary to use females with more or less penciling in the hackle feathers.

In describing color of the neck of a Silver Penciled Wyandotte female, the Standard says: "Silvery white, with a distinct black stripe extending through each feather tapering to a point near extremity; black stripe may be slightly penciled with silvery white; each feather to be free from a black or dark edge; under color, dark slate." 
It will be noticed in this description that slight penciling is allowed in the black of the hackle feathers. We think, however, that the committee in framing this descrip. tion should have designated that only the lower part of hackle should have this penciling, as the best specimens that we have found show the correct color until the cape or lower part of hackle is reached, then the penciling begins to show, and the last feathers, or the ones at junction of back, show very nearly as much lacing as the back itself

Fig. 63, feather No. 1, illustrates the ideal hackle feather as selected from about the center of neck of one of the hens referred to in the St. Louis exhibit.

Feather No. 2 was taken about half way from the tion we can never expect great things as a breeder. The Standard describes it as "Gray with distinct dark penciling, outlines of which conform to shape of feather; feathers free from white shafting; under color, dark slate."

Feather No. 1, Fig. 64, shows our ideal of a perfect feather, showing the triple lacing with about the right amount of black and silvery white. A back showing color like this should pass without discount.

Feather No. 2 has the right number of lines, but they are poorly divided-zigzag in shape-and should be discounted 1 point

Feather No. 3 is uneven in lacing, one side showing fairly well in the black, while the white is quite defective,
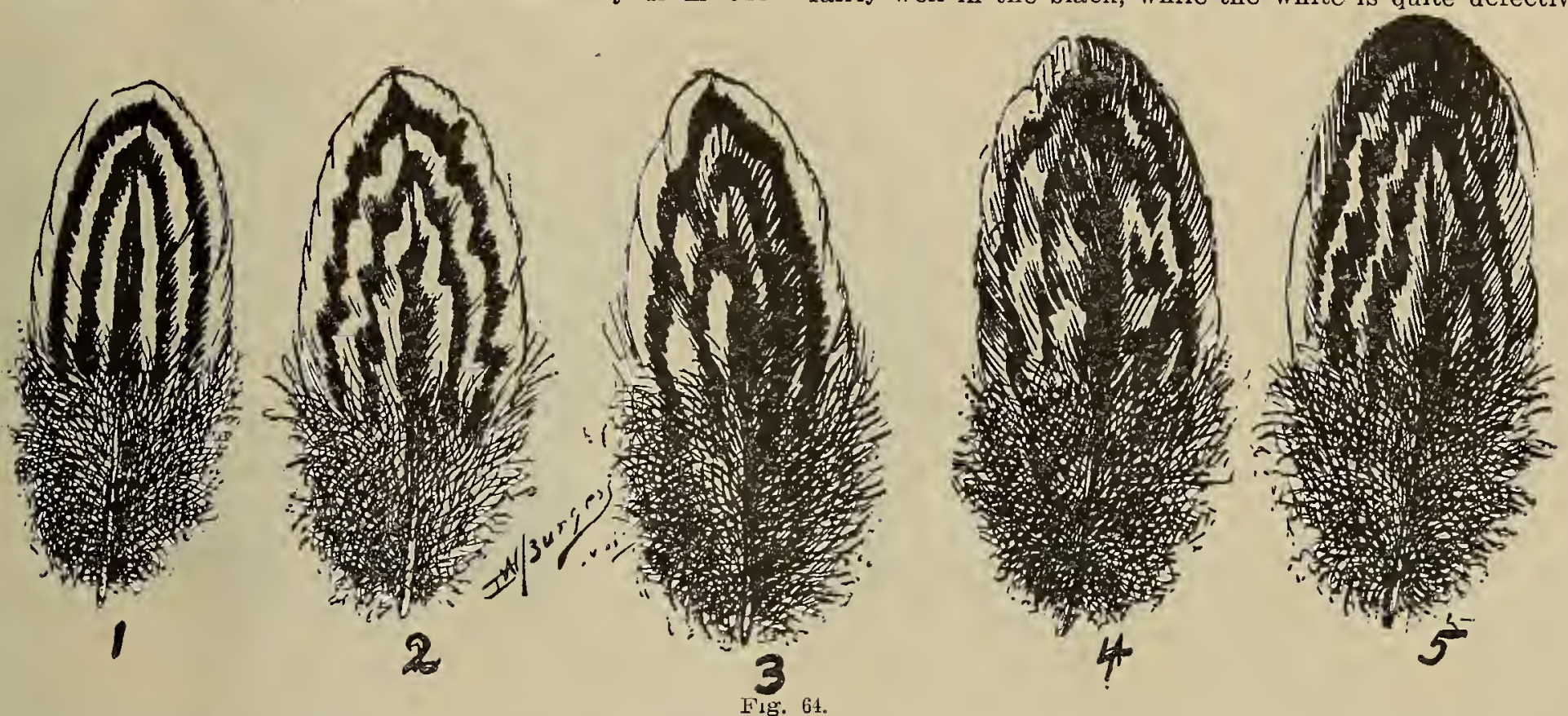

junction of the head and shows a slight tracing of white in the black center. This lacing is somewhat indistinct-the black and white mingle together and should be discounted $1 / 2$ point.

Feather No. 3 was taken from near the junction of back and shows too much white in under color and tracing of penciling not distinct enough. This feather should be discounted 1 point- $1 / 2$ for light under color and $1 / 2$ for the black intermingling, and very defective on the other side of shaft. A back like this should be discounted $11 / 2$ points.

Feather No. 4 fails entirely in lacing. It is simply a mixed-up color of black and white, and in view of the fact that both the black and white ar defective should be discounted 3 points.

Feather No. 5 is better in lacing than No. 4 , but is entirely too dark at the points, making a dark surface that
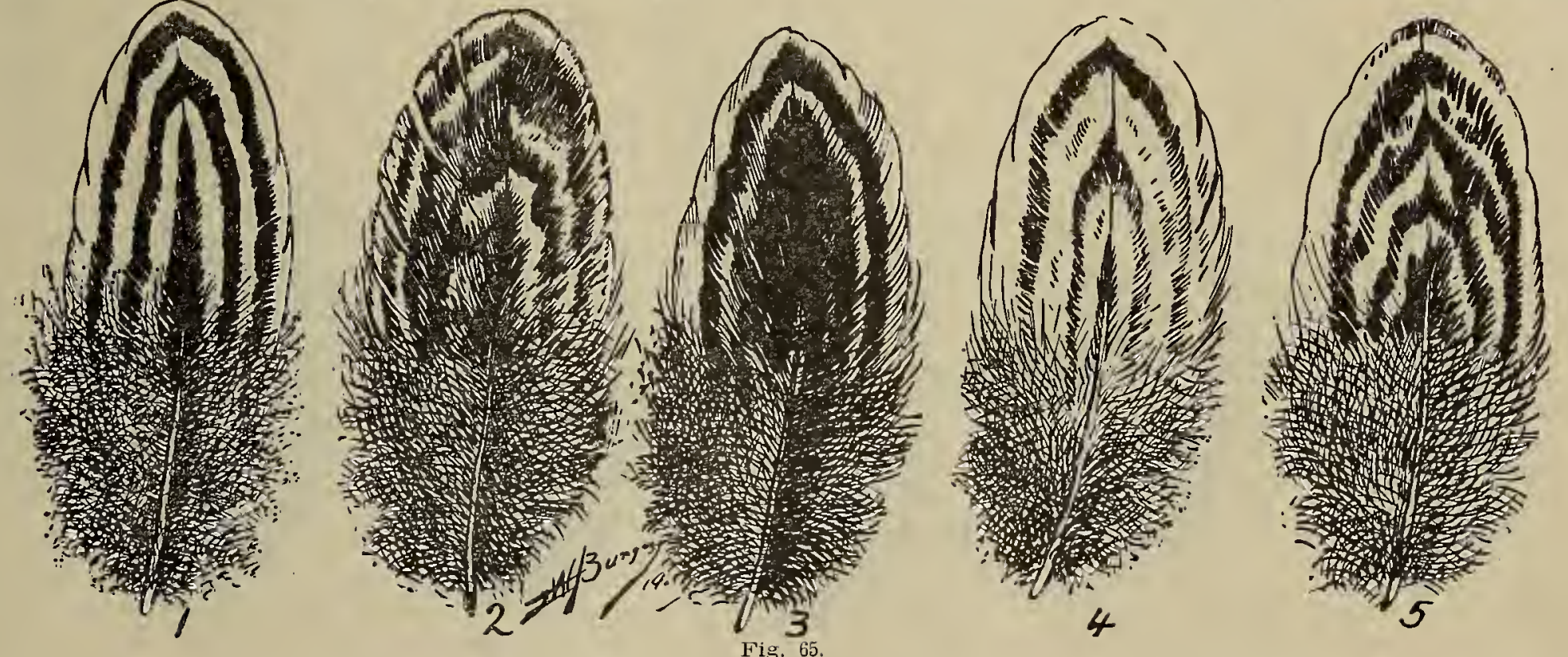

is objectionable from the fancier's standpoint, and color that would be discarded by an experienced breeder from either a cockerel or pullet-mated pen. A feather like this should be discounted $2 \frac{1}{2}$ points.

\section{Breast,}

This section has a valuation of ten points, and is equally divided-five for shape and five for color. In color, it should be the same as that of the back-gray, with distinct dark penciling, outline of which conforms to shape of feather-and this color slould be carried well up under throat; under color, dark slate.

Feather No. 1, Fig. 65, conforms to our idea of a
This is a very important section from a color as as a shape standpoint-in fact, it is the keynote of the structure. Without good color and good shape in this sec- 
perfect foather, while No. 2 is meren in lacing, black and white run together, and shonld be discomted 2 points.

Fenefrer .0 . $B$ is a little better in onter lacing than

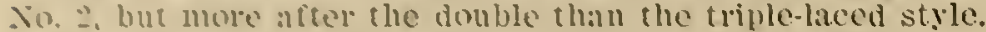
it is fon dirk in center. and should be cut 1 1/ points.

Feather . 0 , $t$ is too light, lacing is only partially fhown, not heing distinct cnongh: inside of feather too Hire and should be discominted a points. A breast with humate lilie this shows an ally-gray color and is consilered very defective by the experienced brecder. from an ideal standpoint and nould be so considered by an expert breeder. A feather like this should be discounted 1 point.

Feather No. 3 fails almost entircly in lacing. It is simply a mixed-up color of white and black, with entirely too much white, and should be discomted 2 points.

Feather No. 4 shows the dark barring something after the stylc of fenther No. 2, only it is too dark at the outer edge, and should be discomited 1 point.
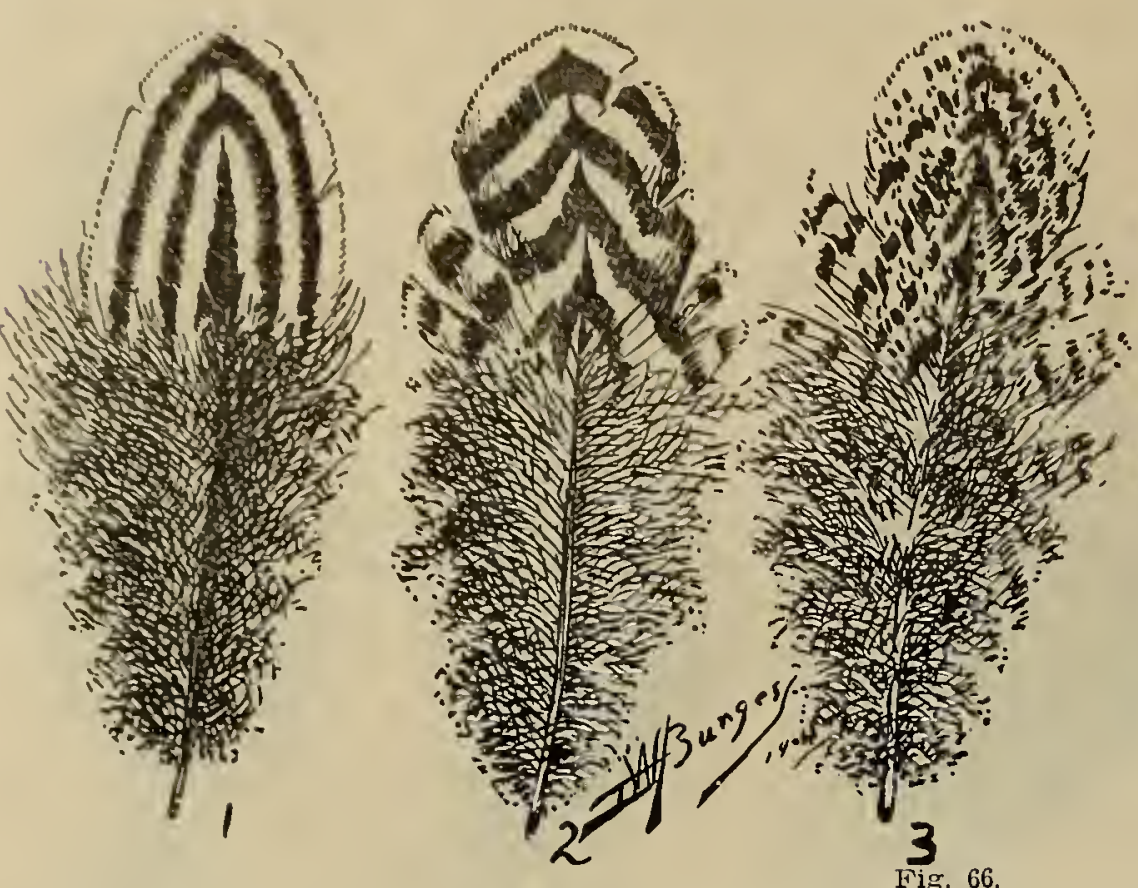

3
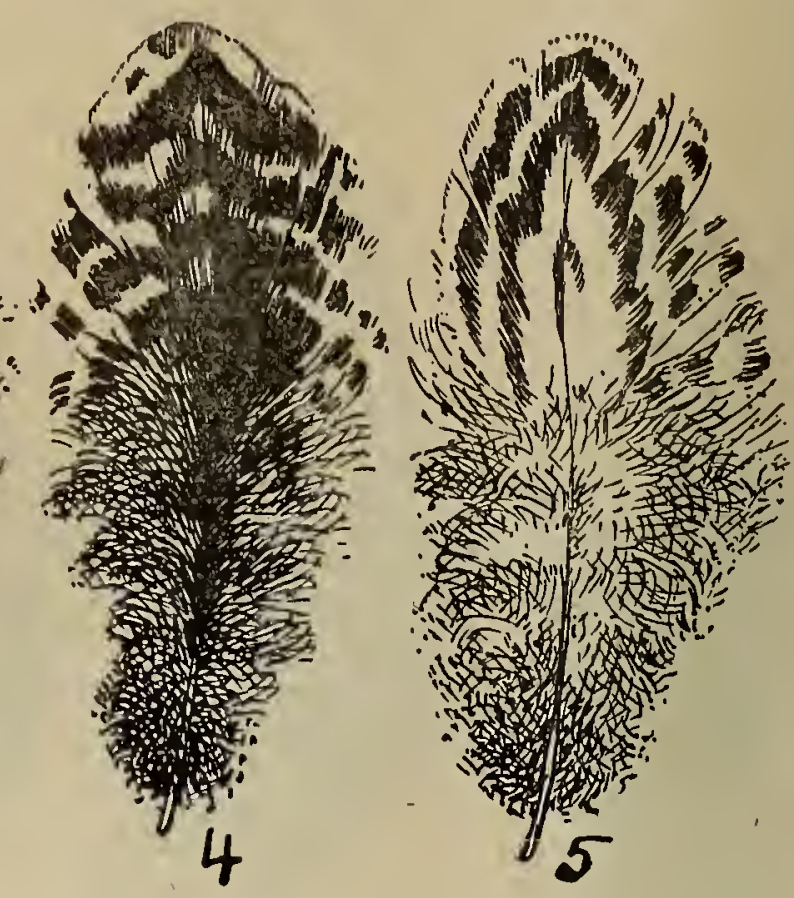

Feather No. 5 was taken from the rear of fluff and shows fairly good for this section, as it is next to impossible to get feathers to lace well so far back. However, it is too light in the center, also too light in color, and should be discounted 1 point.

Body and fluff have a valuation of only three points in color, and the discounts are not as heavy as they would be on back or breast, where more points are allowed.

In Fig. 66 are shown several feathers which illustrate quite fully the defects found in this section.
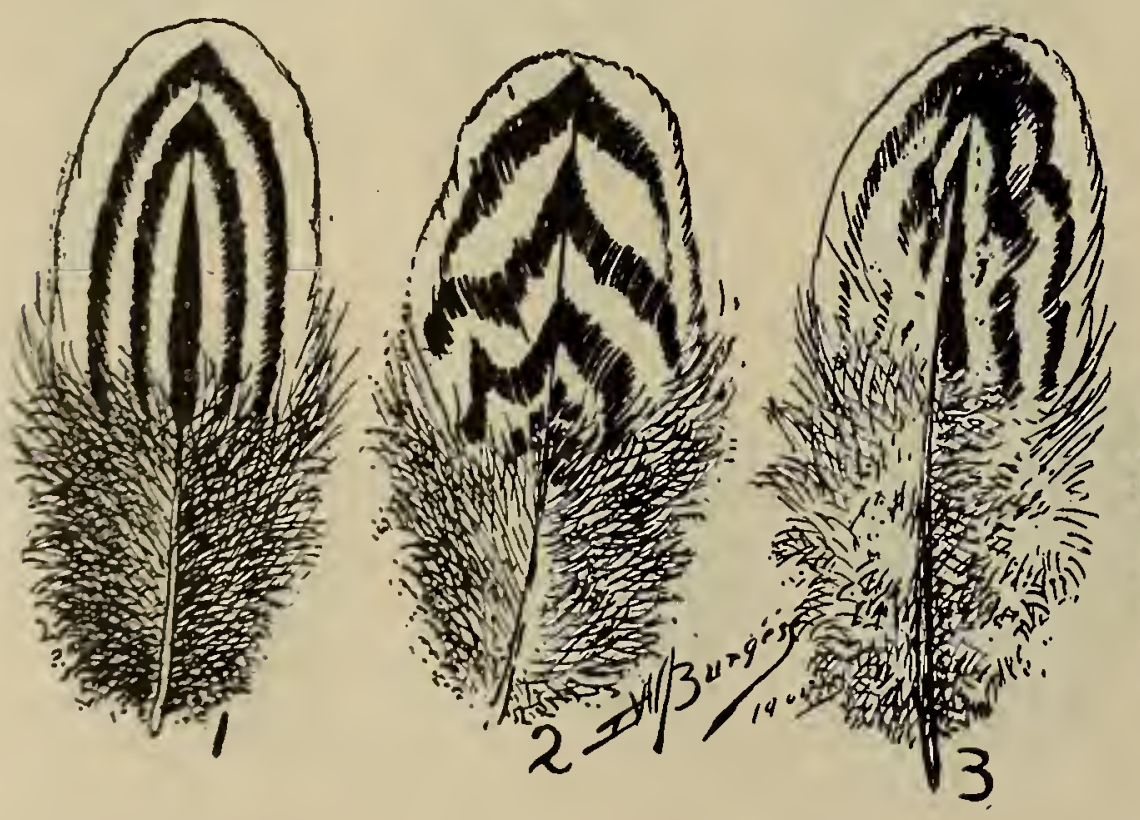
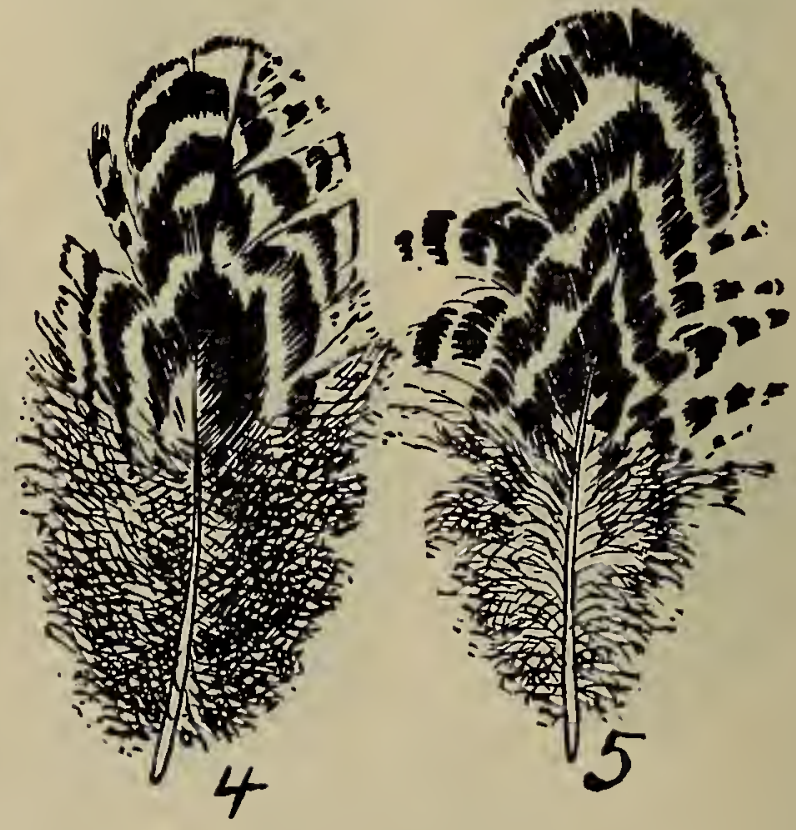

Fig. 67.

Feather No. 1 is our ideal and would pass without discount. However, we would prefer the under color a trifle darker than is shown in this feather.

Feather No. 2 has much the same defect as is shown in Eig. 5 in breast. 'This penciling runs more in the form of bars, running across the web of feather, and while it shows fairly good from the surface, it is quite defective
Wings.

In Figs. 67 and 68 are shown some defective feathers, and while they may look exaggerated in the illustrations, they were selected from this section.

In Fig. 67, illustrating the shoulder, or wing bow, in feather No. 1 we have our ideal again, while in feather 
No. 2 we have the barring referred to in breast and body. At the same time the feather does not look bad from the

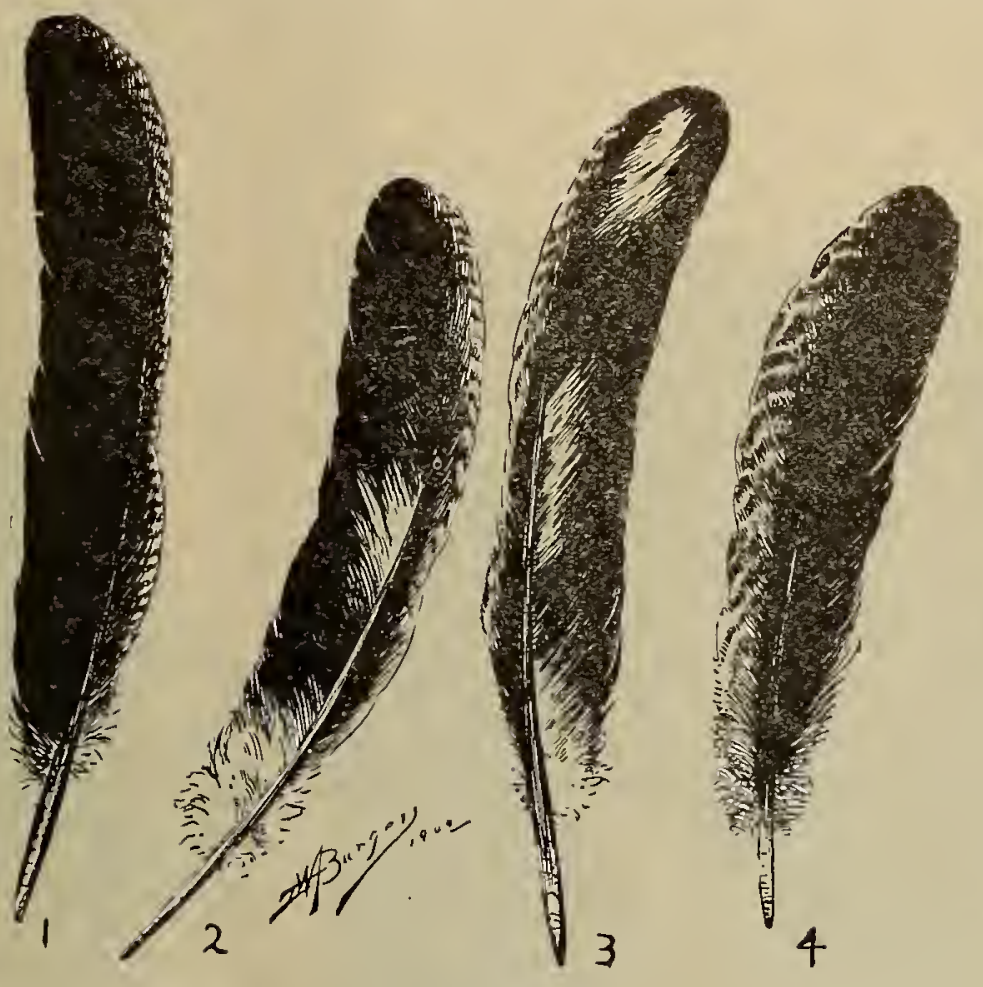

Fig. 68.

surface, but under the Standard rules will be cut severely for it. Six of the points allowed for wings in the American class are assigned to color, so that in cutting this feather $1 \frac{1}{2}$ points we are not cutting it any too severely, considering the defects.

Feather No. 3 is entirely too light underneath and on the specimen showed a mossy surface, almost entirely lacking in the silvery-gray so much admired in this variety. Feather is quite well penciled on one side of shaft, but almost entirely lacking on the other, and should be discounted 2 points.

Feather No. 4 is smutty and uneven, having some black splotches in outer white lacing, and although the wing shows better on surface than No. 3 , it is quite defective, and should be discounted $1 \frac{1}{2}$ points.

Feather No. 5 is too dark in penciling, lacing uneven, more after the form of barring, and is quite dark on surface. This feather should be discounted $1 \frac{1}{2}$ points.

The Standard, in describing the color of this section, says: "Primaries, black, lower edge penciled with gray; secondaries, upper web dull black, lower web gray, with distinct dark penciling; shoulders and wing coverts, same color as breast and body, well and distinctly penciled; under color, dark slate."

In Fig. 68, feather No. 1 I would consider correctblack, lower edge penciled with gray.

In No. 2 we have a feather that shows too much white, the outer edging being more white than gray, and opposite side of shaft showing quite a bit of white. A wing showing feathers like this should be discounted 1 point

Feather No. 3 has the same defect, only magnified, having more white than feather No. 2 , and should be discounted $1 \frac{1}{2}$ points.

Feather No. 4 is a secondary feather, and while it is a little bit light down towards the lower end, the feather is about as nearly correct as you will find them, and answers well the Standard description-upper web dull black, lower web gray, with distinct dark penciling.

Tail.

This section is valued at five points for color, and should be black, except two highest main tail feathers, usually termed the "deck feathers," which are penciled on upper edge. We sometimes find white or gray running into the main tail feathers, which should be black, and our description of defects in primaries and secondaries of wing will answer for this section, as the cuts there would fall equally as heavy on this section. 


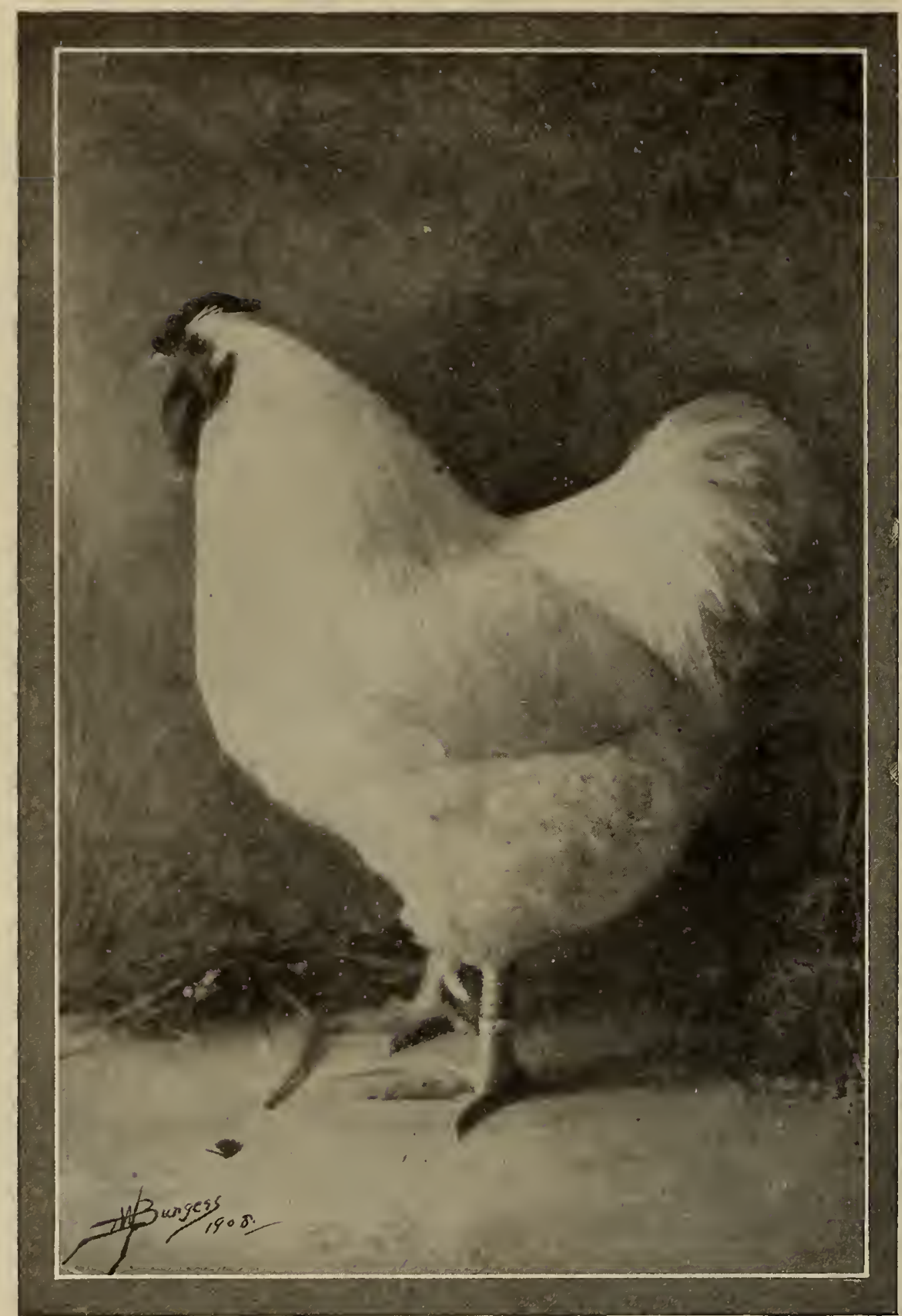

WHITE WYANDOTTE COCK "PERFECTION."

Bred and owned by George H, Rudy, Mattoon, Ill. This bird has a record of ten first prizes as cockerel and cock at such shows as Indianapolis, Illinois State and Illinois State Fair. For size, shape, comb and color he seems to fill the eye of our Western breeders. At the Indianapolis Show (1908) this bird hcaded a pen that won Wyandotte experts than any one male that has been shown in Indianapolis for years. 


\section{BLACRR WTANDOTTES.}

\section{An Old Variety But Never Bred in Great Numbers-Good Specimens Scarce.}

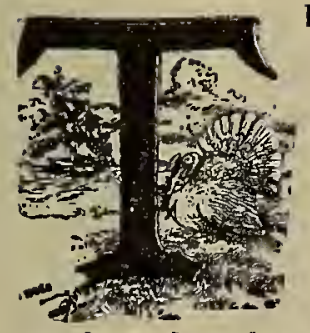

UIS variety of the Wyandotte family was admitted to the standard in 1903 , but was never so popular with the fanciers as the promoters had hoped for. Whether this was due to the prejudice against the color, or the lack of push on the part of the originators it is hard to say, but one thing we do know-there is not one American show in ten that has a single entry in this variety, and where a show does have an exhibit the class is seldom filled-in fact, we cannot recall a show where there have been to exceed twenty Black Wyandottes on exhibition.

During the past few years, or since the Black Orping- and winter of 1907, we found several strictly A1 birds of this variety-birds of both sexes that were good in shape, size and color. That they will ever be as popular as other varieties of the Wyandotte family we very much doubt, unless there should be some wideawake American fancier fall in love with them, take them up, exhibit and advertise them and make them as prominent as they should be.

One thing that can be said in favor of the Blacksthere is no better middleweight breed in existence from a commercial standpoint. They are quick to mature, good winter layers, and, regardless of their black plumage, they dress a yellow carcass when prepared for the table. The have one decided advantage over the parti-colored varieties in the number of good specimens that can be bred from one

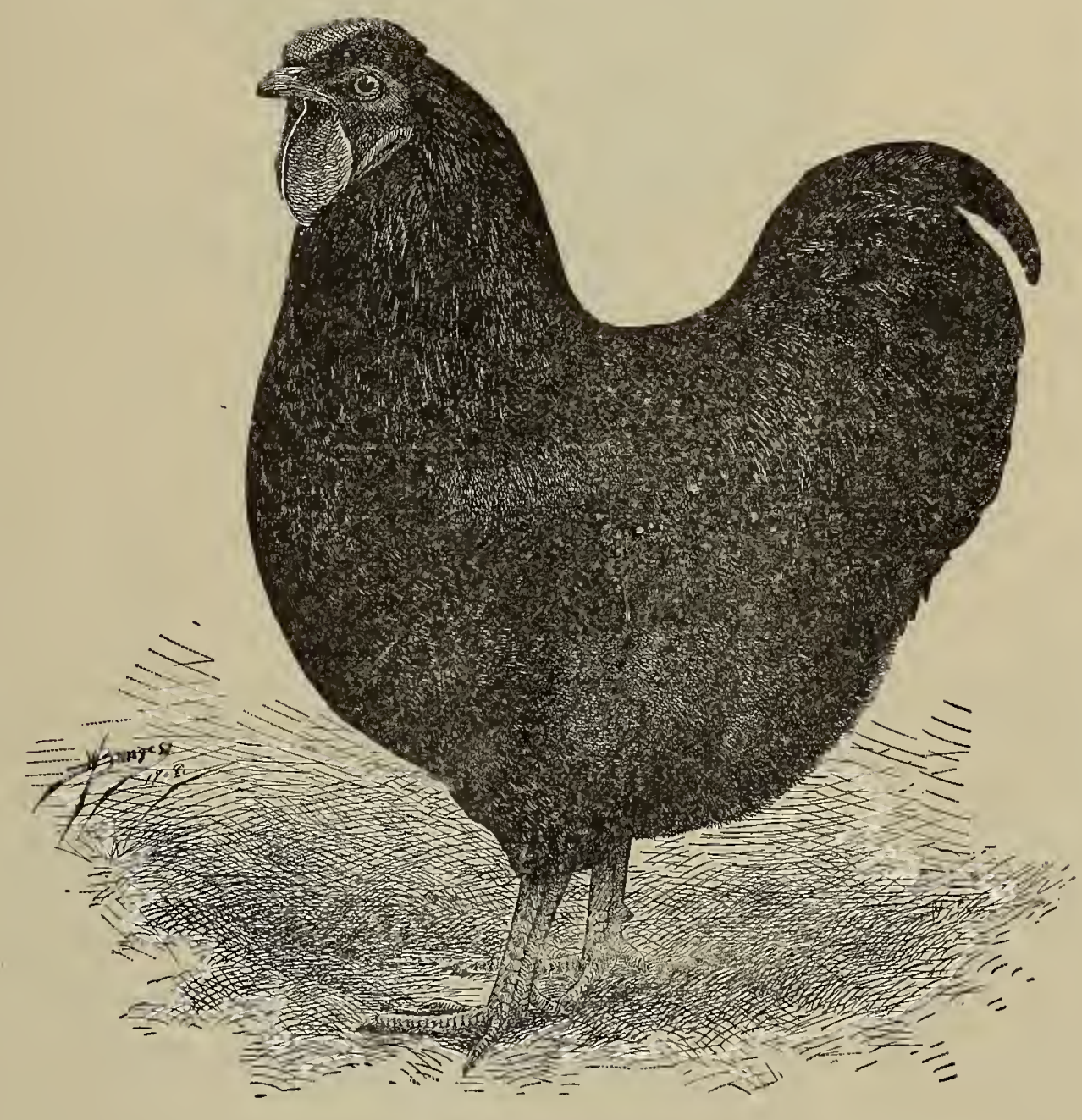

STANDARD BLACK WYANDOTTE MALE.

ton has become so justly popular, there has been a slight increase in the demand for Black Wyandottes, and the quality that has been shown since 1905 has been decidedly better than prior to that time. In some shows in the fall mating or from one yard-the percentage of exhibition stock almost invariably surpassing even the whites when properly mated-in fact, an eighty-five per cent. average from a well mated pen is no exaggeration. 


\section{SOME OF THE DEFECTS COMMON IN THIS VARIETY.}

No brevel of standard poultry is frec from defects; levither will it make a nume or recorl for its owner unless coreful attention is accorded it. The Black Wraudotes are 110 exception to this lule. The Standard shape is the salle for all varieties of this breed. and to a norice it Wonld seem that any one conld breed a black fowl as the colol is solid, and sound colored breeding specimens should surely reproduce themselves, and if we conld persuade the standard-malicrs and judges than any color. so long as it is black. will do, nc would have easy sailing: hut we camnot do this. They demand that you breed a black bird that shors a bcetle glecn in hackle, saddle and in calling attention to this defect, only quoting liere the clause so that it may be understool by all. Under the heading of "Cutting for Defects" the Standard says: "Purple barring appenring in plumage in all varicties in each section when found should be discounted $1 / 2$ to 2 points." Under the liead of "Disqualifications" the Standard says: "White or red in any part of the plumagc, covering more than one-half inch," and while this description is up for consideration it is well to call attention to a peculiar de fect quite often met with in many of the black fowlsthat is, red feathers. These most often appear in the hackle and saddle of malcs, but are sometimes found in the neck and wing bows of fcmales. While this defect is not common in any of our standard black fowls, it will come occasionally in all black breeds, showing how hard it

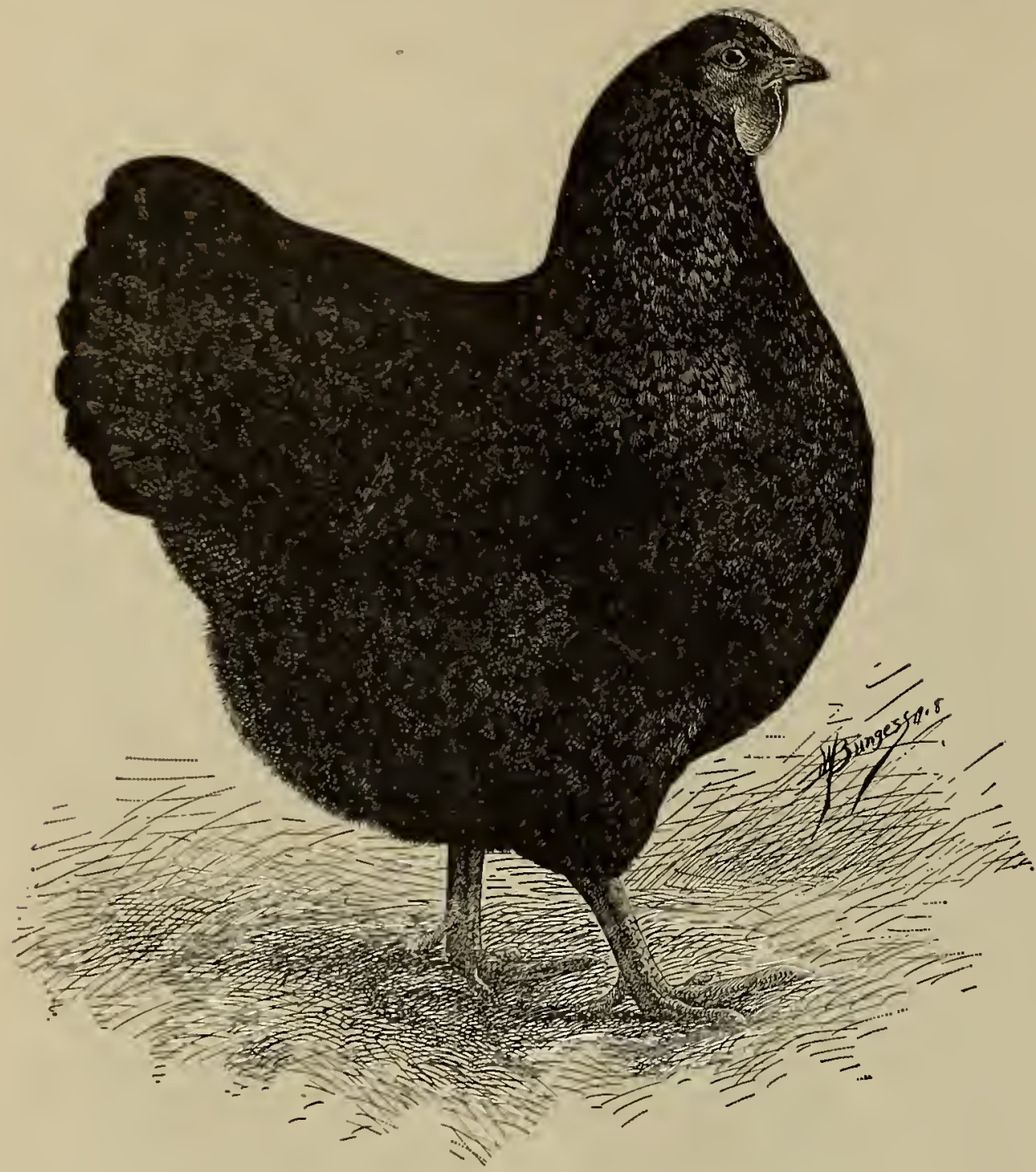

STANDARD BLACK WYANDOTTE FEMALE.

wing bows of male, with same color in neck of females, and this color must be produced without allowing the purple or peacock color to creep into it-in fact, they demand that you mix your color just as carefully as an expert artist, and to do this requires skill as well as experience, and in addition to both skill and experience you must keep your birds in the proper condition from weaning time until the feathers of the adult plumage are complete. The fancier has many anxious minutes in handling his choicest young birds as they are maturing to ste whether or not he has his colors too strong or too light. Purple barring is the curse of his life; he despises its very looks, and he knows the judge who awards the prizes at the shows where he must exhibit will have the same view of it, and when he sees his best cockerels coming through their adult plumage free from this defect, he is very careful to keep them in verfect condition, as upon the health of the specimen now depends the success. Let your best colored birds go off on condition and you can bank on it that three times out of four the sound color will be affected in just the same proJortion as the health of the specimen. A severe case of roup will practically ruin four out of five, and even a scvere cold will taint their plumage to a greater or less degree.

Since the Standard is so rlain in its description of cutting jurrole barring, we will not take up much space is to eliminate the original color, or the color of the feathers which covered the fowl to which all breeds and varieties owe their origin - the Jungle fowl-with its blackbreasted males with red hackles and saddles. No matter how well your birds are mated, or how long your strain has been bred pure in color, it is wise to look over very carefully for these disqualifications before putting them on exhibition.

Another point in Black Wyandottes, and a very important one, is the color of bottom of feet of both sexes. The Standard disqualifies all specimens unless the bottoms of feet are yellow. White in plumage, while not often met with, will disqualify the specimen if more than one-half inch in length in any feather, and where they are tipped with white the specimens will receive a cut from $1 / 2$ to 2 in each section where this defect appears.

We believe this general description of the Black Wyandottes, with the illustrations of the ideal male and female will give our readers sufficient information on this variety. They are worthy a place in the yard of all fanciers, and with the small number being bred today, we believe it would be well for some individual, or perhaps several individuals, to take them up and make them popular like the breeders of Black Orpingtons have done in the past few years. 
i 


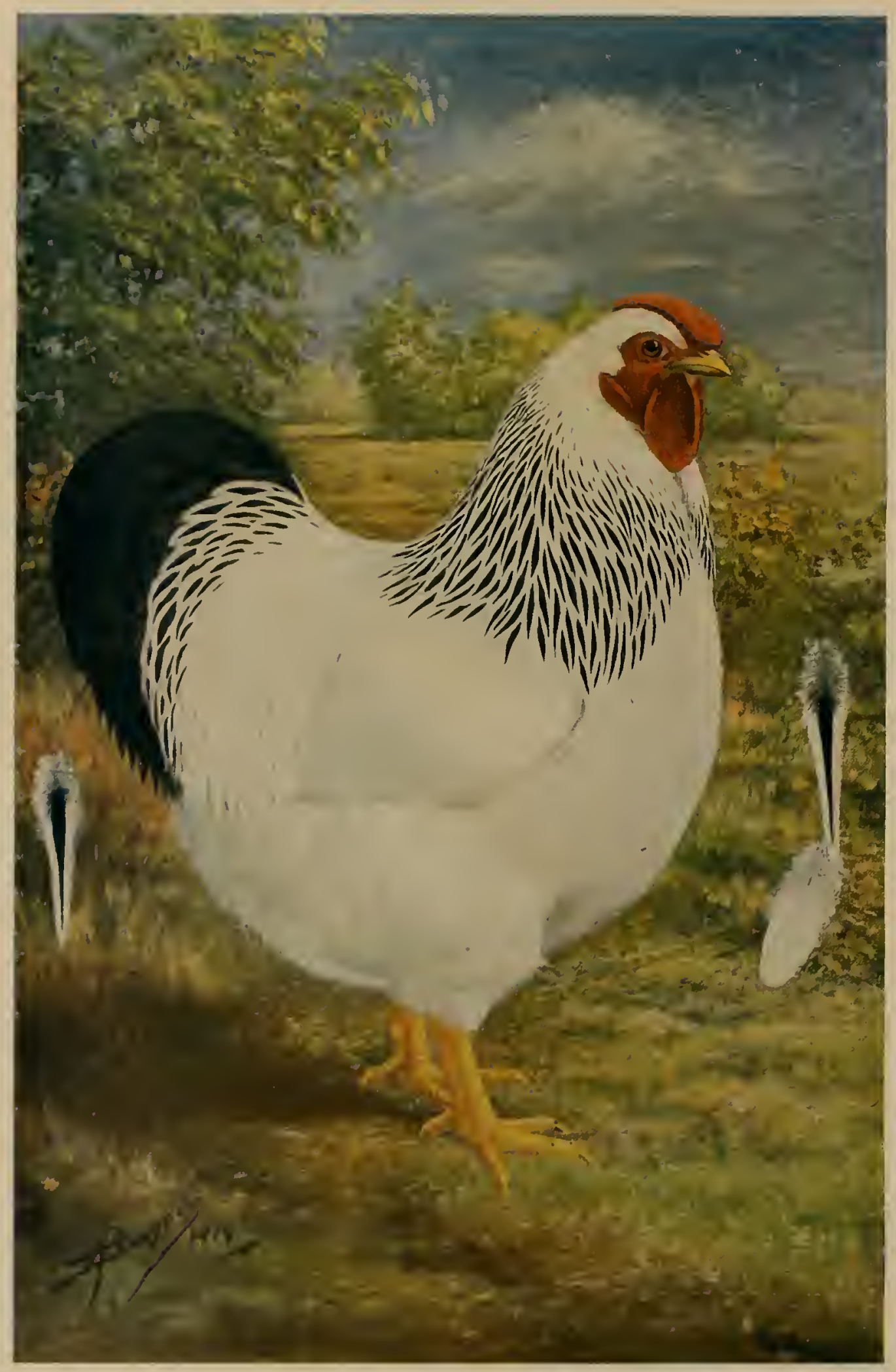

COLUMBIAN WYANDOTTE MALE.

Drawn to Conform to Standard Shape and Color as Describcd by the American Standard of Perfection. 


\section{COIUMBIAN WUANDOTIISS.}

\section{The Latest Variety of this Popular Breed to be Recognized by the Standard- One of the Most Popular Varieties Ever Perfected.}

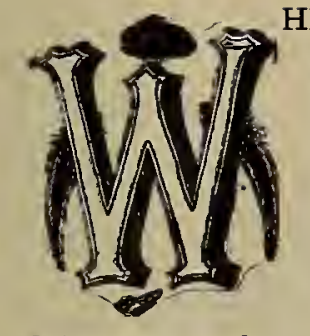

HEN, by accident, the blood of our royal Light Brahmas was mingled with that of America's greatest middleweight fowlthe Wyandotte-there was little thought that this cross was the foundation for one of the best as well as one of the handsomest of the Wyandotte tribe. The commercial breeder saw and admired this middleweight breed with its Brahma markings without giving a thought to its future as a fancy fowl. Its true worth to them was its market value as a broiler or roaster, and its wonderful winter egg yield, and in these particulars the Columbian Wyandotte of today is not excelled by any middleweight breed.
From these experiments, made by some of the best breeders of Brahmas and Wyandottes, and assisted by the blood of the truest thoroughbred fowl in our American Standard-Light Brahma-such improvement was made that in three years a large per cent. were breeding free from disqualifications, and the color of neck, wing and tail was so close a resemblance to the Brahmas that a class was made for them in our large exhibitions. When these birds first made their appearance in the shows the poultry editors from all sections of the country began to make notes of them, and the result was that more fanciers took them up, and the improvement that has been made in the past two years is something marvelous.

I have watched the rapid advancement of the Columbians and noted with interest the class of fanciers that is

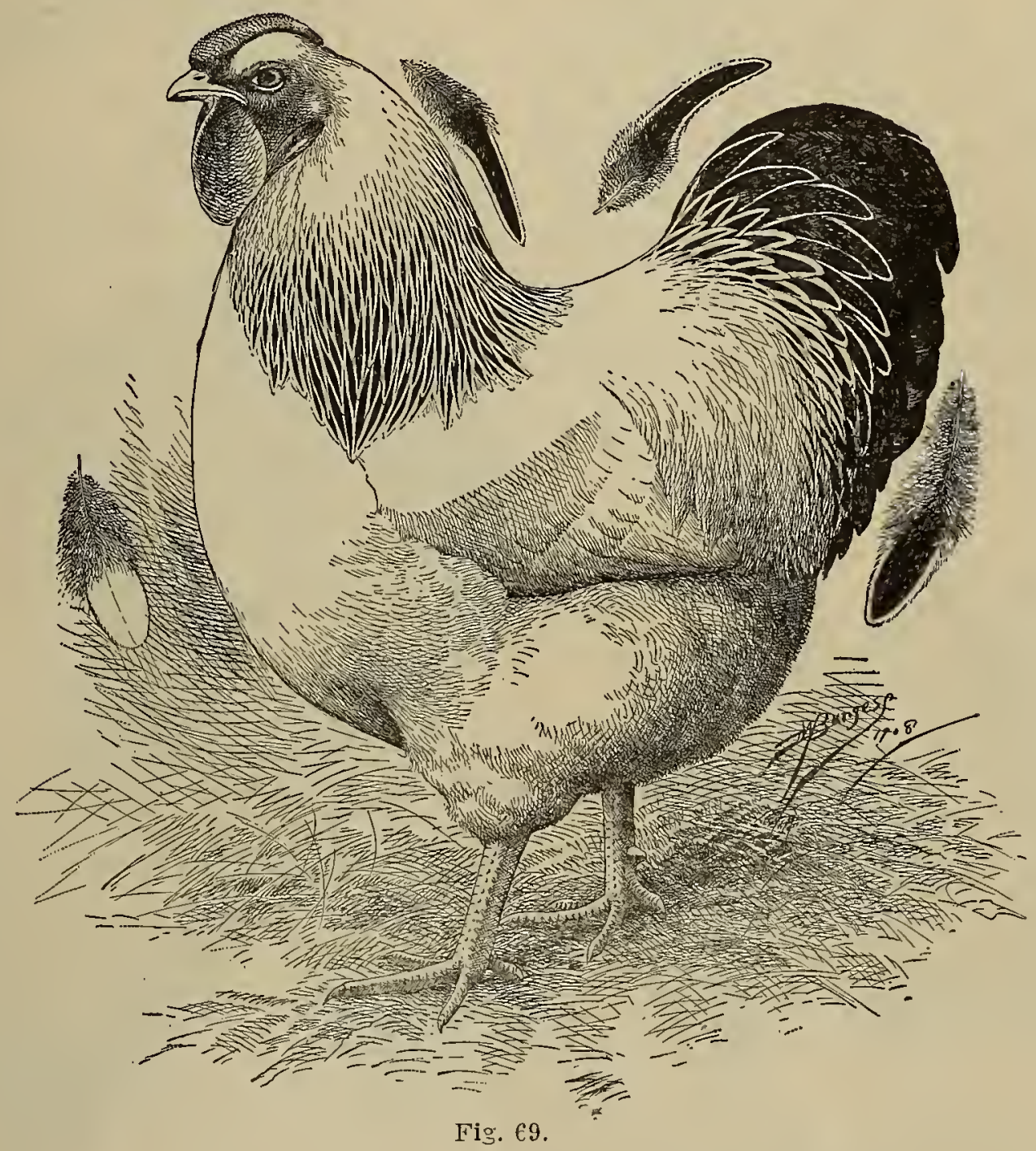

STANDARD COLUMBIAN WYANDOTTE MALE.

But the fanciers saw more in them than their commercial value. Crude as the first cross showed them, due largely to inferior birds of both breeds being used, a foundation was laid to build upon, and the best of these crosses were selected for an experiment. breeding them. This list is composed of the best informed poultrymen in America-men who are not led astray by every passing fad, but who have been first to see the merits in every good breed that has become prominent in the last twenty-five years. 
Do ous bredele can claim all the homor of this valiety's orlshi, as nam whli the same object ln vlew havo used various clesses in theil efforts to produce il brecd with 11 y

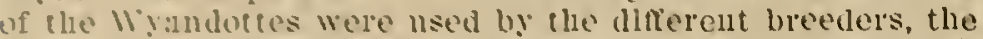
linfts. silvers and lliltes boing the ones most favored, while the liglit brithuns lave in alunost every instance berll nso als one of the clossos in orter to bettel establish the color. soveral other brects have bech tried in order to sot correct color, amone then Plymontl Rocks and Dorkinss but the urajority lave usod lirnlumas and Wramdottes.

Su fill as the witel is collcerned, he claims nothing for his owu part in the originating of the raricty, but he has used outside closses to better establish both shape and color ou this viety. These experiments were made after the columbinns melc introduced and had been shown at a number of exhibitlons. At this time tho birds were de-

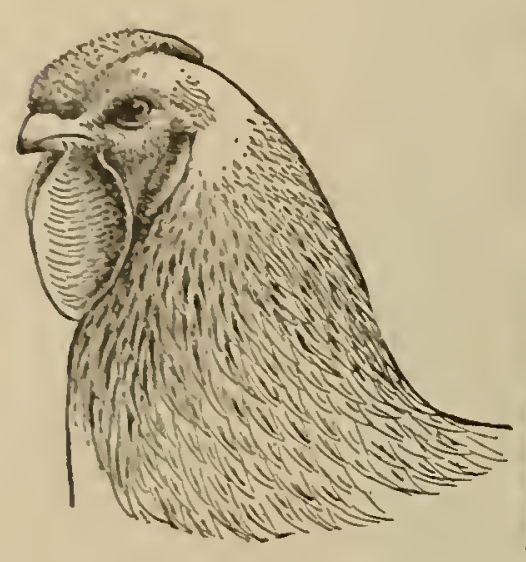

Fig. 70 .

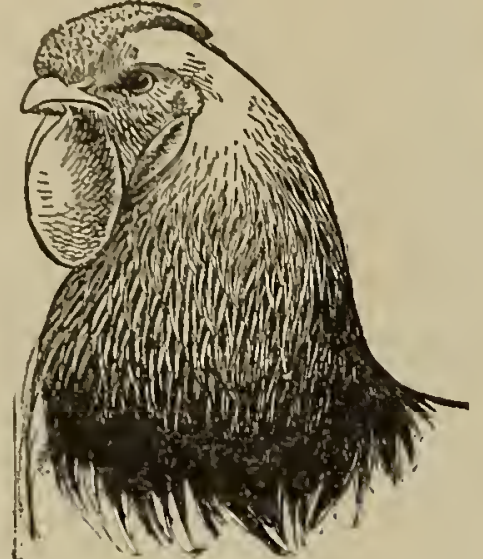

Fig. 71. cidedly faulty in both shape and color. They were too long in back and body and too high on legs, so I tried a top cross of Columbian Wyandotte male on a finely colored Light Brahma female, and a common barn yard female with Brahma marlings and rose comb. From this cross I had some very good females with good combs and clean legs, the males being only fair in color and decidedly off in shape-long necks, bodies and legs. I then crossed the best of the females back to their own sire-a Columbian male-and from this cross secured my first perfect flights in females, with good neck and tail lacing. "The males from this second cross were not so good as the females either in shape or color, but a decided improvement over the ones I had been able to purchase.

From this foundation and careful selection I established a strain that is breeding satisfactorily and has produced some really fine specimens. But the quality is still

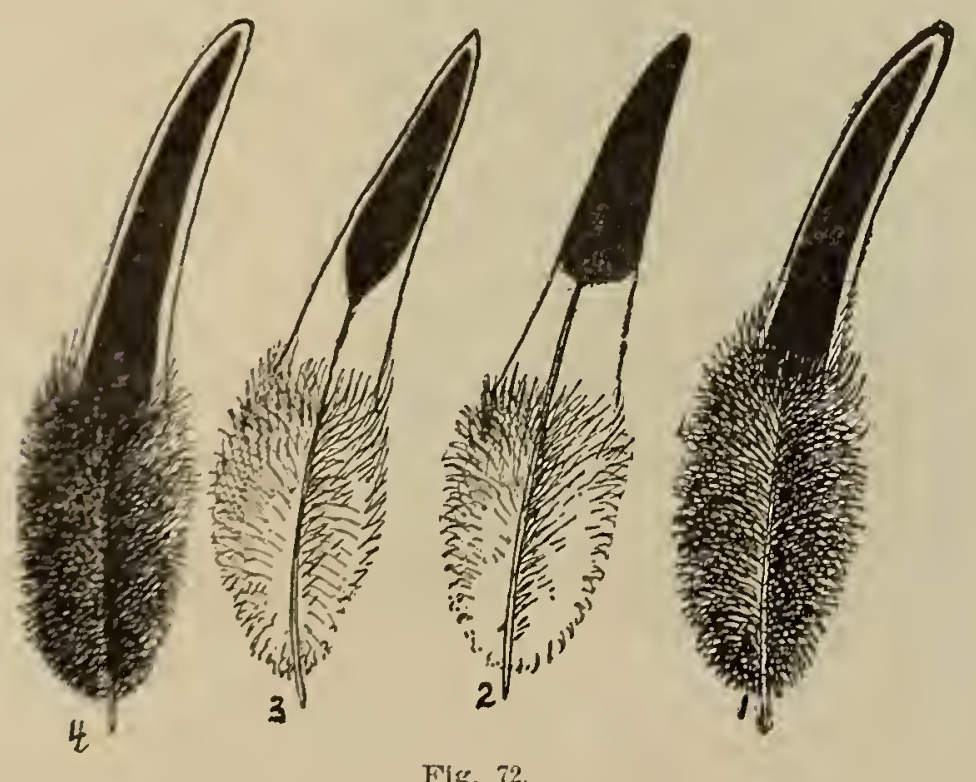

in the females; the males will inslst on brassy surface as soon as hot weather comes on, providing they have good, sound color jolnts, the ones showing the poorest wings and necks being decidedly superior in surface color.

It was not untll the matlngs of 1907 had matured that I could really claim a white surface-colored male, with other forod color polnts. I have finally produced two that up to this writing-May 1-have held their top color, with cood Rrahun marlings lu neck wings and tail. The wolst fault l have found in the females ls the persistent dark feathers in baclis of otlerwise fine colored specimens. I beliere the white surface-colored males wlll eliminate thls in part, aud perhaps entilely, and I an anxiously

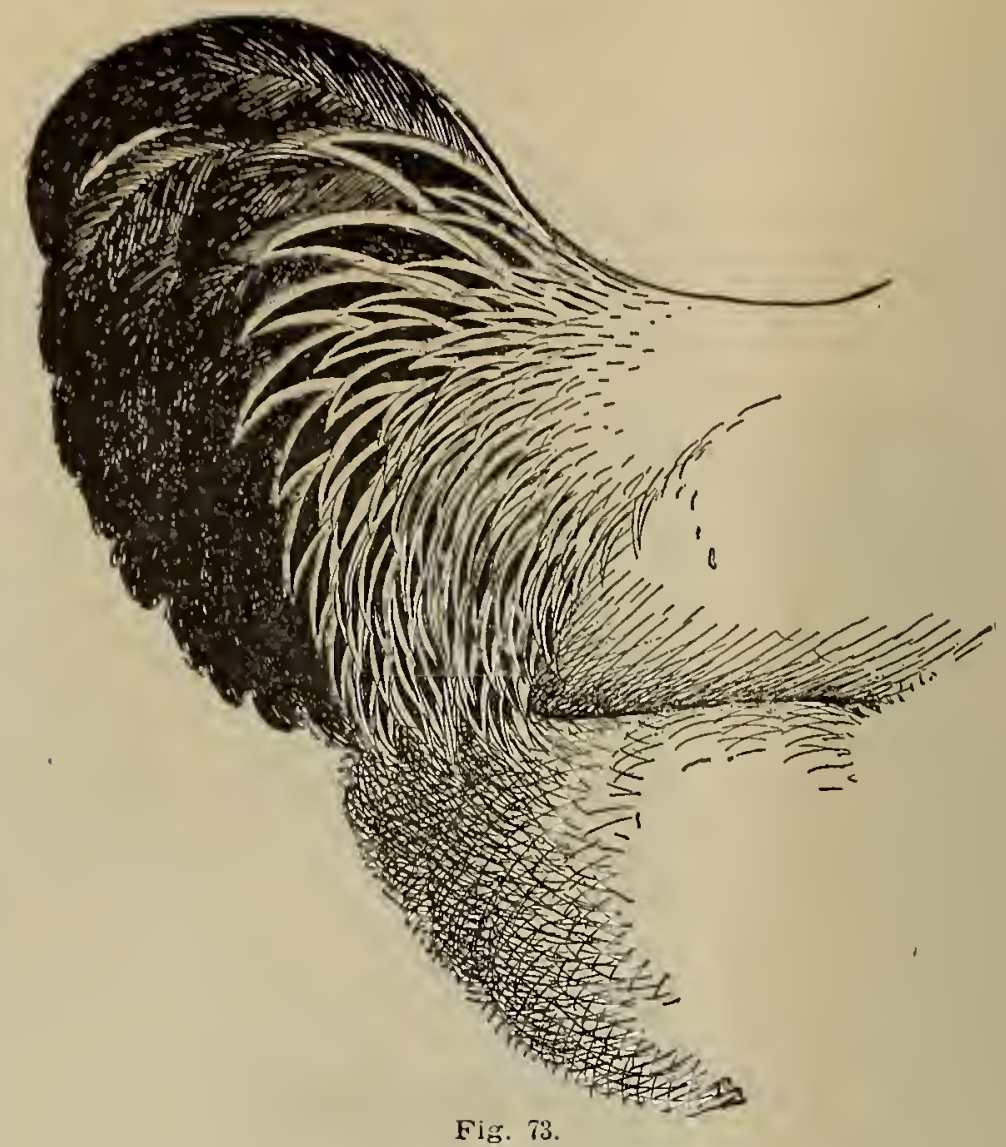

watching the young birds from this year's mating to see what the results will be.

I give here the experience of Mr. Thiem, of Iowa, with this variety, and call special attention to his article, as

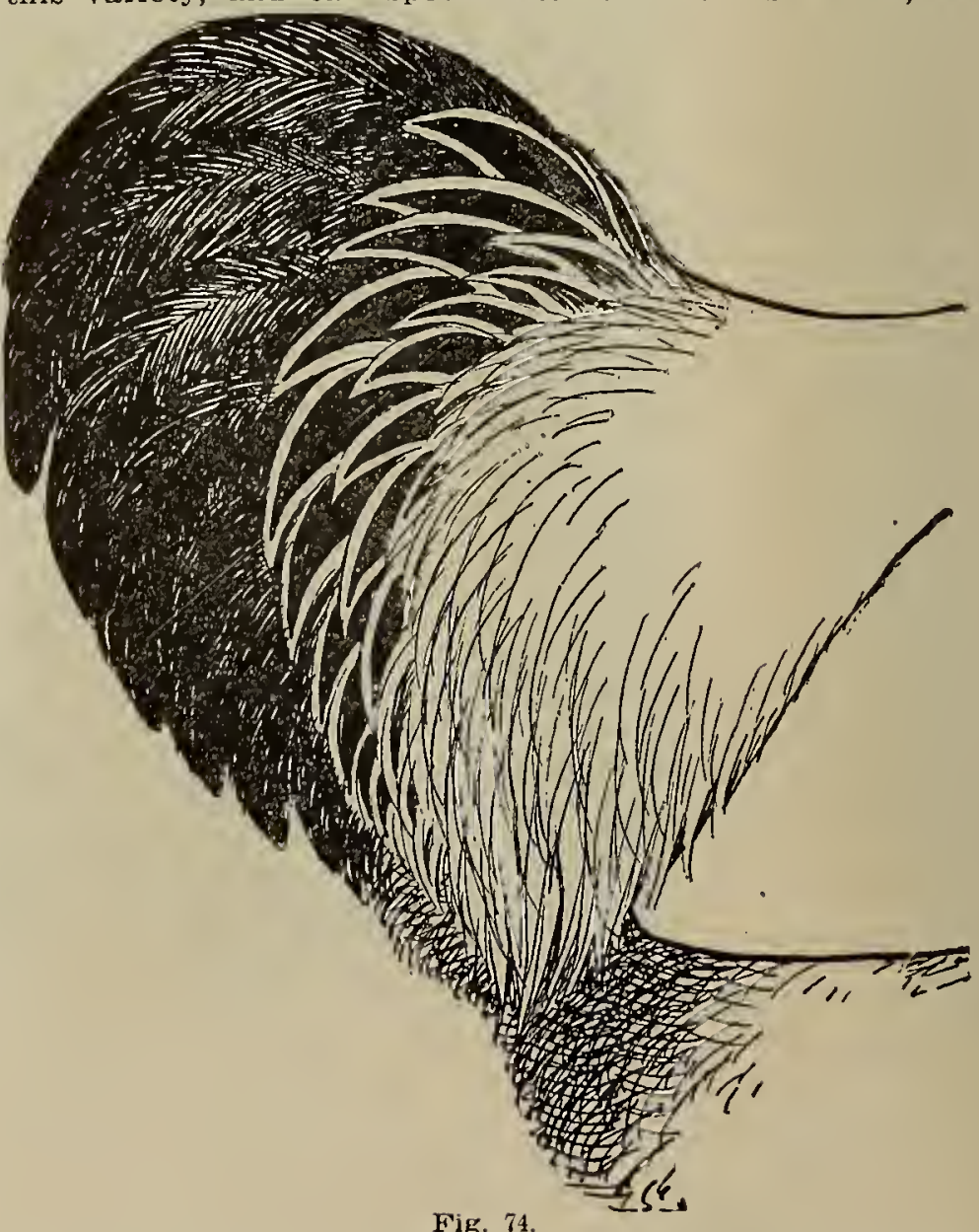

he has done more perhaps than any one man living to make the several varieties of the Wyandottes that are today so justly popular: 
SOME FACTS ABOUT COLUMBIAN WYANDOTTES.

\section{(By E. O. Thiem, Denison, lowa.)}

Every one has, or should have, a hobby. I certainly have mine. For the past fifty years nothing has given me more pleasure than to raise a nice pen of some full-blooded fowls. I will not mention here about the Buff Laced offspring, as I saved three of each cross of the Buff and White

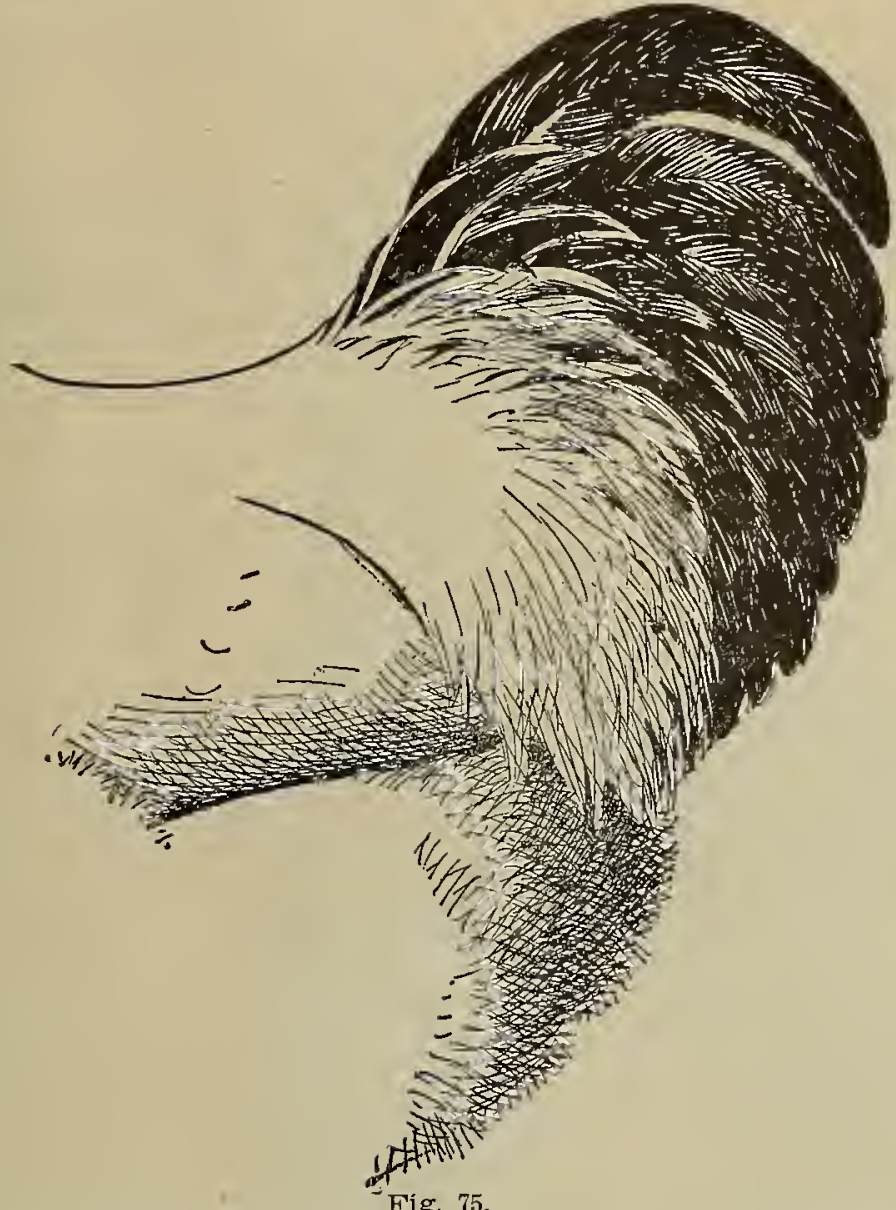

Wyandotte, but when spring came the Buff cross had so much cream undercolor that I gave them away and mated the third White Wyandotte cross to a full-blooded Light Brahma male to strengthen the beautiful black in neck, wing and taíl. The result was very satísfactory as for
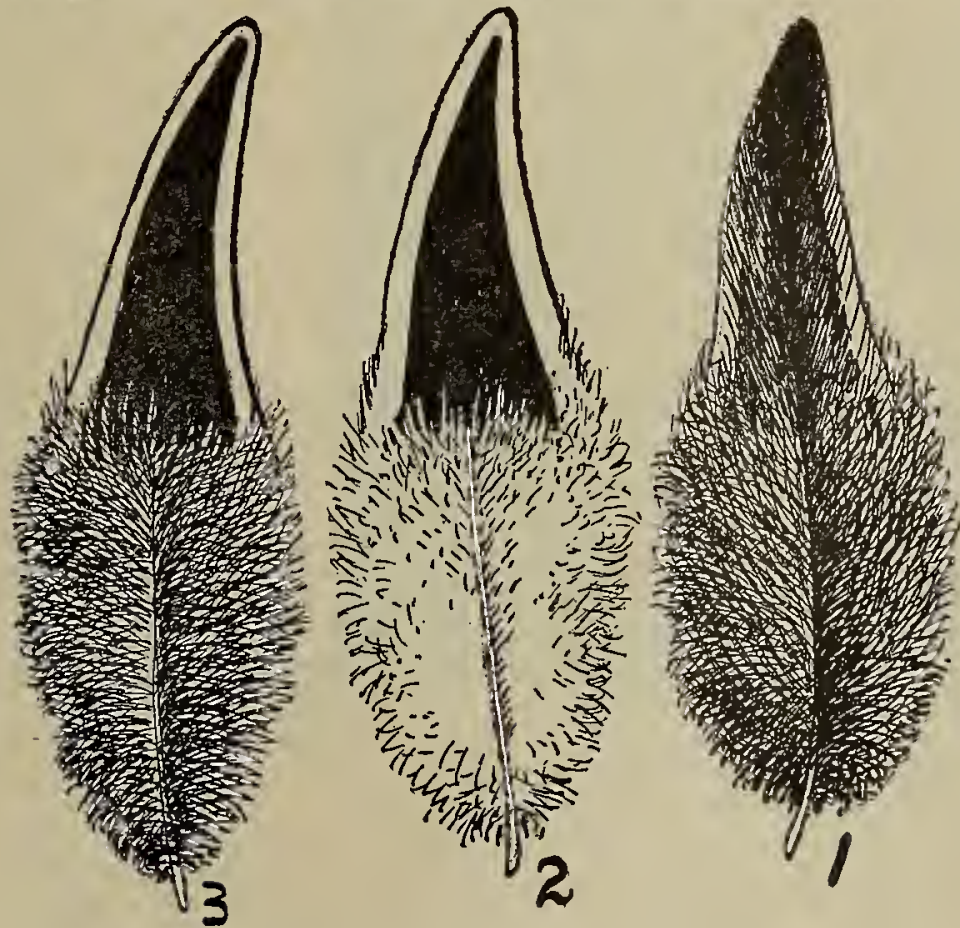

F'ig. 76.

color, but the females had rather long backs, while the males were not as good in color but better in shape.

No males were saved either year. The females now had one-half Wyandotte blood and one-half Brahma, some with rose combs, others with clean legs. Here it was when I read about the great winnings of Columbian Wyandottes at New York, and to get quicker results I purchased chickens, I usually make a specialty of one variety, but I have a great desire to learn and get acquainted with other breeds that come before the public and are boomed up to have their way into the new Standard. Never sat isfied with what I read, I just try them myself and find out if the real merits of the new breed come up to the claims of the booming fancier.
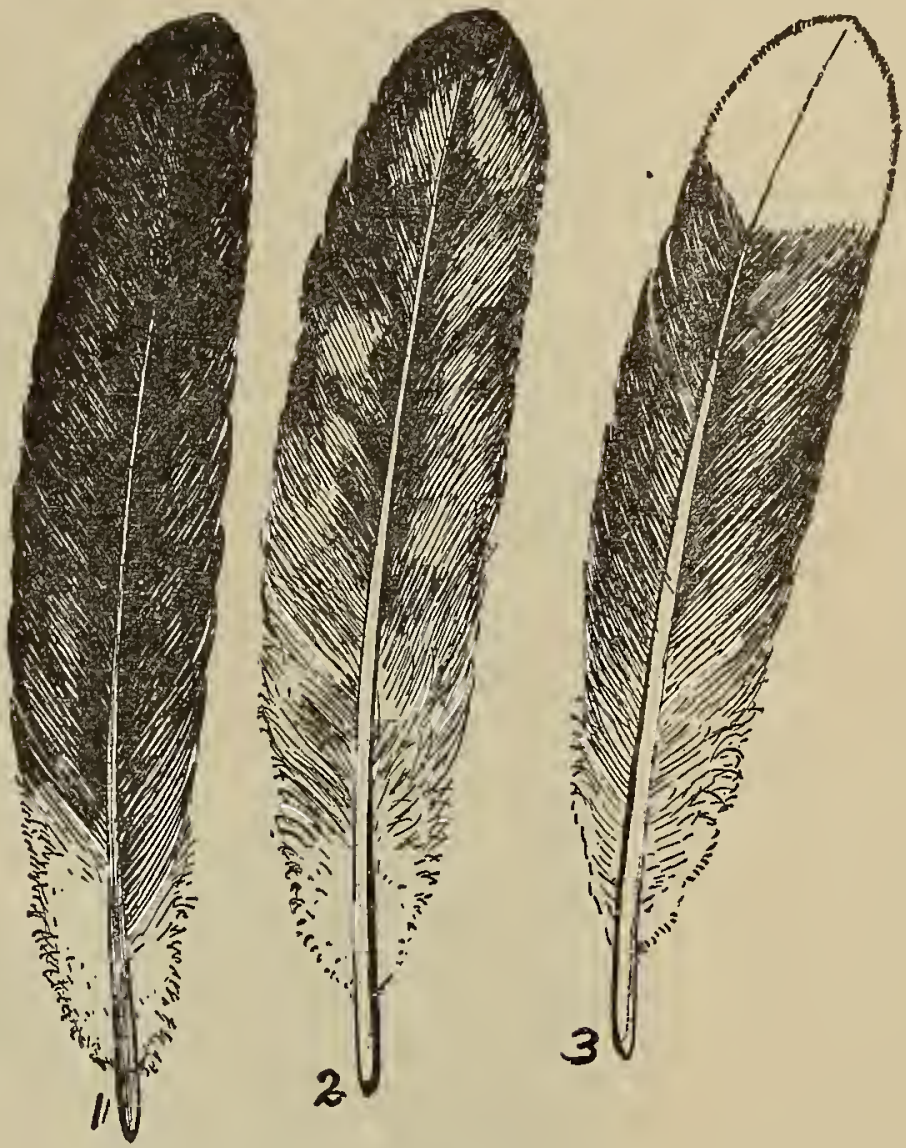

Fig, 77.

So in 1898 I took up the experiment with the Silver Penciled Wyandottes. I found them very good layers, but too hard to breed by single mating system , so disposed of them, retaining only one-a male of a very light color white in back but remarkably strong in hackle. The idea struck me how a fowl líke the Sílver Penciled Wyandotte hen would look when converted into buff instead of steel blue.

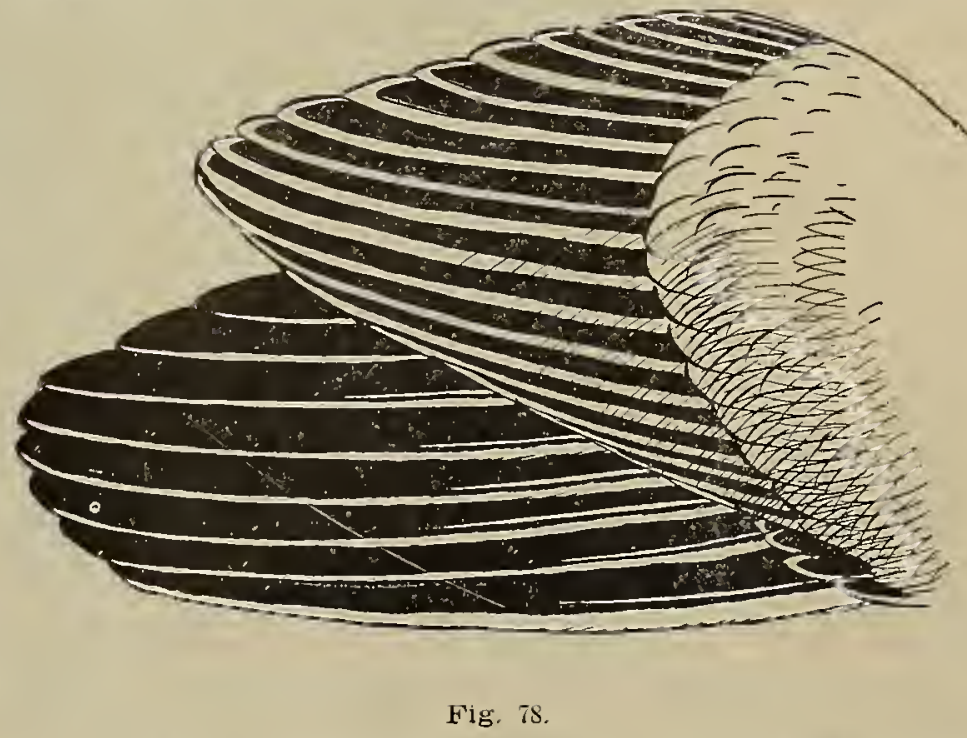

In 1900 I mated the cockerel to a Buff Laced Wyandotte hen, which I received from Ira C. Keller, and also a Buff Wyandotte hen from Mr. Crabtree. The male proved to be too strong for just these two hens, so I put with him a White Wyandotte hen. Strict account was kept of the offspring of each individual. My idea was to break the steel color of the Sílver Penciled Wyandotte with the matings of these three hens, then remate the offspring in order to get the buff penciling established. 
Fut to my surprise, all chicks from the liun II'an-

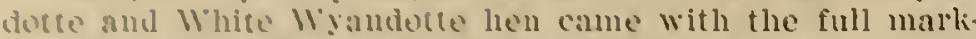
ings of a light lirahma with WYanclotte shape and comb. I then murehased a full-blooded colnmbian Wrandotte male, crossing him on my one-halt blood lirahmas, which matho stre me back shaje. comb and clean legs; but on accomt of the material 1 had to work with I fell short on black in will holdins all other points. ln $1 \$ 97$ I was more fortumate in securing the first Chicago male-rery strong in shape, neck and wings-and his females this year are of good Wyandeste shane and neck like a Light Brahma should have.

do not Write this to claim that I an the originator of Colmmbian Wyandottes. I am led to answer tho article in the April (1907) number of The Inland Poultry Journal, in which is an illnstrated article on the scoring of Columbian 17 yandottes, and I consider it the best ever given on any breed-short, plain and instructive. Right here I will say that none of the real merits of the Columbian Wyandotte are exaggerated. Thes are vory good all-purpose fowls arcellent lavers, and, when once established, a breed which we Americans can be proud of. and tail extended well down to the skin it was quite likely to show a black, smutty end to hackle feathers, failing in white lacing so much admired in this varicty. When flights showed a suflicicnt amount of black the two colors were quite likely to mingle, giving this section a washed. out color that is very objectionable from a brceding standpoint. This was the condition of color as found on the original birds, and from this mixturo the fanciers must malic the breed if it was worth considering by the poultry. men as a thoroughbred. How well they succeeded is shown by the admission of this variety to the Standard, and the many elegant individual specimens that have graced the exhibition rooms at the leading shows the past winter.

\section{THE ORIGIN.}

The original cross, or at least the one we have an offcial record of, is the Light Brahmas-White Wyandottes; both breeds being used for the top crosses, and offspring of the two bred together. Latcr on Silver Wyandottes were used, crossing the Columbian, both male and female, with

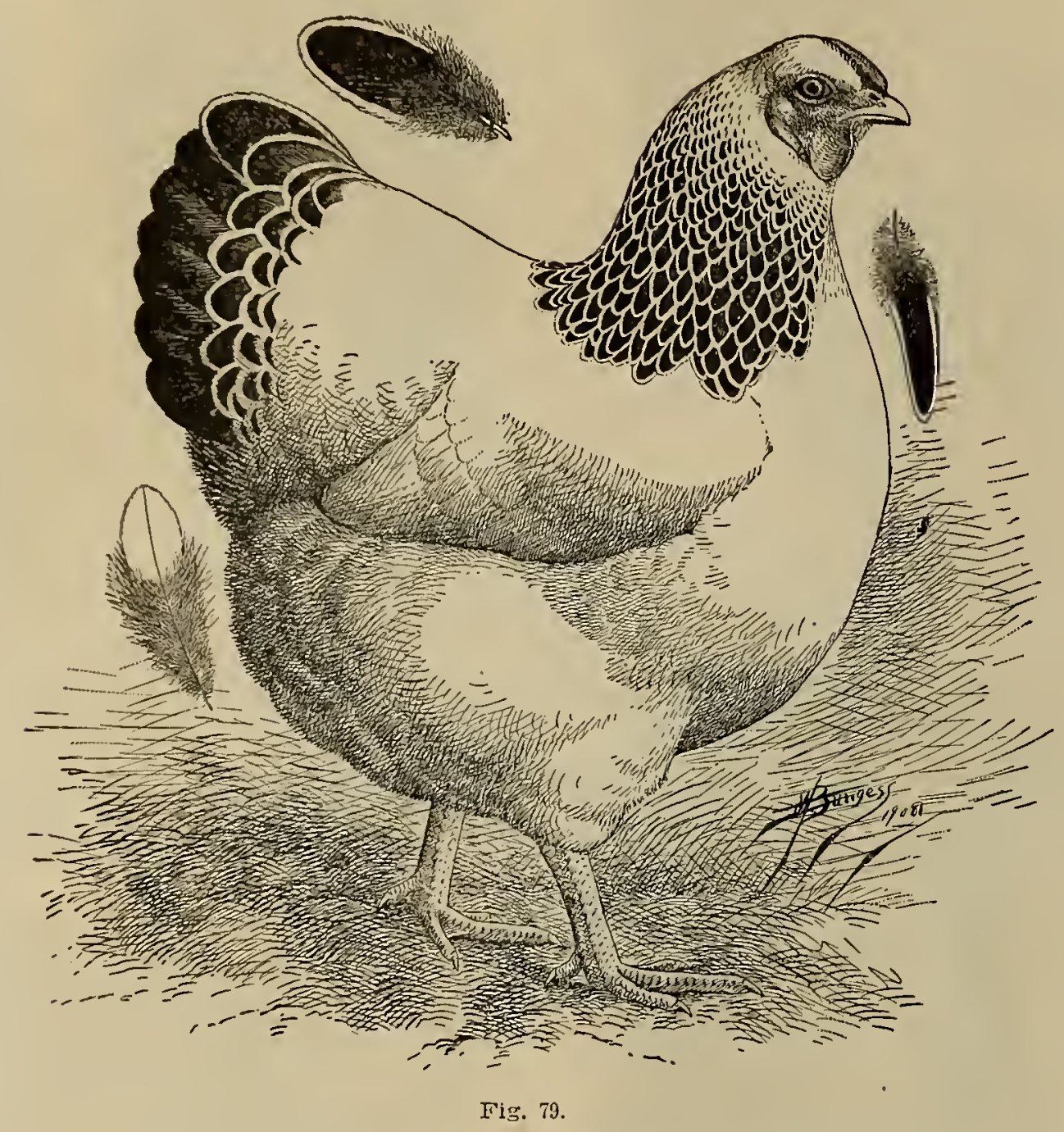

STANDARD COLUMBIAN WYANDOTTE FEMALE.

In taking up this, one of the most popular new varieties of the Wyandotte family, a few words in regard to their color and origin will not be out of place. In ylumage they are identical with the Light Brahmas; at least, that is what the Standard calls for, and, be it said to the credit of the breeders of this variety, they are fust closing up the gap in color that has for the past "ear's existed between them and the Light Brahmas. To get good striping in neck of males and females with correct tail lacing on both sexes, having at all times the old and well established Lirht Irahmas as a comparison has been a blg task. The first Columbians to attract attention were very defective in color. It is true thcy showed some black ln neck and tail and occasionally showed fairly good in wing flights and secondaries, being more of a dull black or dirty brown, while the lacing so much admircd in this variety was decidedly lacking. If lacing appcared in tail coverts with gorsl sound black in male tail it was invariably follower? with a lot of ticking in hack, and quite often color would show in breast and body. If the black in ncck the Silvers, then using the original Columbians back to these crosses. Some claim that an out cross of Barred Rocks was used, but we are not prepared to prove this statement, the claim being made that another party not the one making the report used the Rocks in perfecting the color. This we very much doubt, as we have never yet bred a Barred Rock on to any breed with white or partiwhite plumage that did not give us chicks with decidedly more black than white.

In my own yards I have used two crosses, one a Light Brahma hen with elegant neck and tail lacing, the other a Silver Wyandotte female with almost a solid white breast and oly a trace of lacing on back and body. To these females I have mated the best Columbian male I. could find, and from the cross five femalcs were selected-three from the Brahma hen and two from the Silver Wyandotte. These females were again mated to a Columbian Wyandotte cockercl, and the tail and neck color, the object sought for, was quite well established. This color is gradually being fed lnto the choicest matings, and, strange as it may ap- 


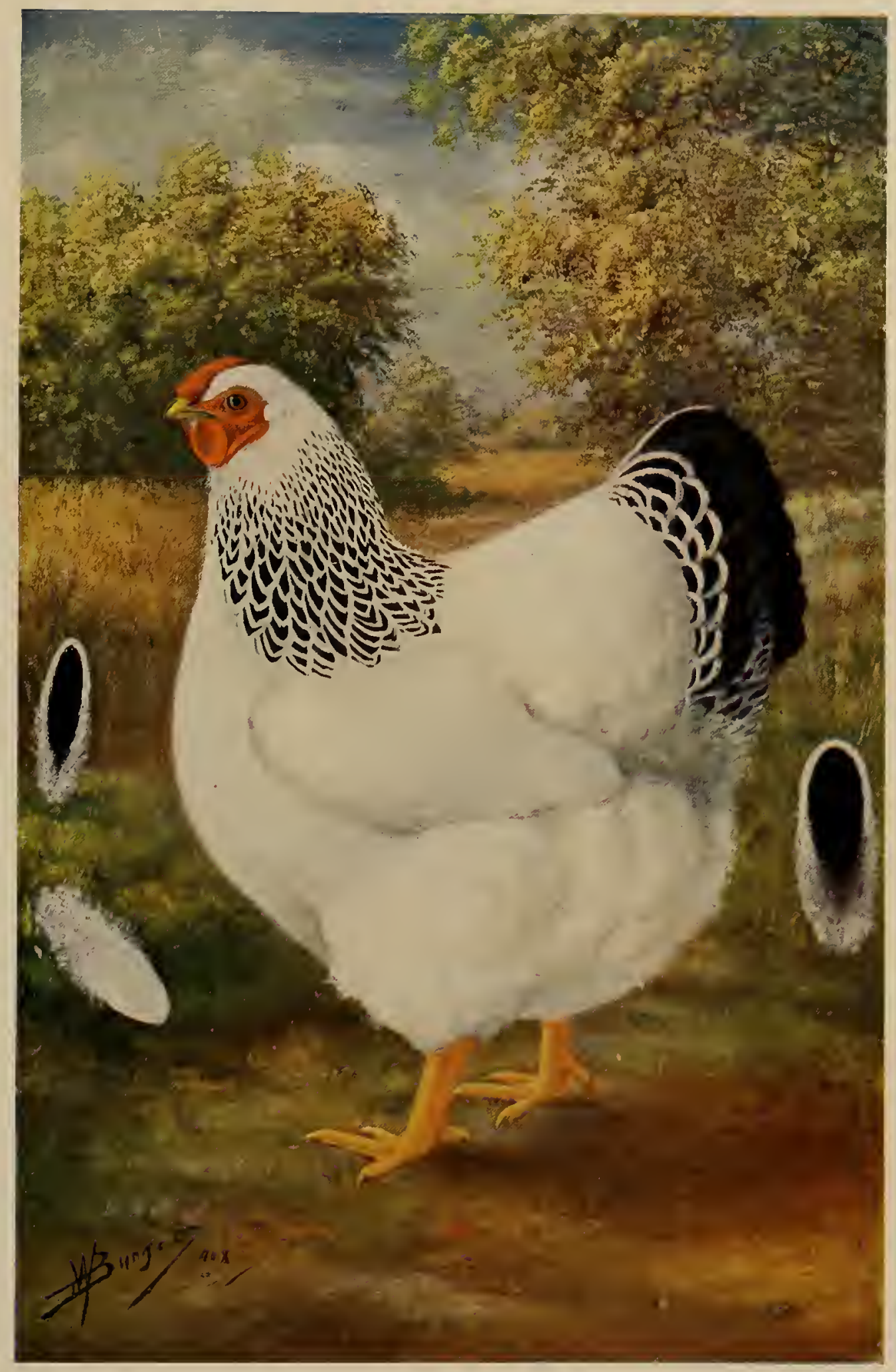

COLUMBIAN WYANDOTTE FEMALE.

Drawn to Conform to Standard Shape and Color as Described by the American Standard of Perfection. 

pear, only two of the females from the Brahma cross showed signs of feathers on legs; one of them showed a handsome pea comb, while the others were as good in comb as their sire.

In shape this breed is far from the ideal at the present time; with the Brahma cross we naturally got a long bacl and long body, color being the most important feature to establish the variety has compelled the breeder to stay with the objectionable shape in order to get the color set in both males and females, but now that we have this color it is up to the breeders to begin to reduce the length, and within the next few years we may look for Columbians as good in this particular as any Wyandotte in the Standard. As to their future, in our candid opinion this will be the most popular variety of the Wyandotte family. There are defects yet to breed out of them, and one that the breeders will have a lot of trouble with is brass or creaminess in the back of males, but when the color is once bred white with good lacing in neck, wing and tail we will not only have one of the handsomest but one of the best breeds of fowls ever originated in this country. In our illustration (Fig. 69) is shown our idea of a perfect Columbian Wyandotte male. It fits the Standard description and is the type of male that is winning the shape specials under our best Wyandotte judges East and west. The Wyandotte is in reality a bird of curves, and when this description was embodied in the Standard we should have gone further and said they were also a loose feathered bird, as I have never yet found a real good closely feathered Wyandotte. The best ones of all varieties are loose feathered and show certain Cochin characteristics, and with our Standard calling for short backs, short bodies, short tails and well developed breast we must expect some of the Cochin lines. This shape is the one amired by our best informed fanciers and is one that has done much to make this breed so justly popular. So in presenting this outline we do so without apology and feel it is the best drawing yet submitted for Wyandotte shape.

In color the Columbian Wyandotte should be a counterpart of the lordly Light Brahma; neck with jet black striping and pure white edging; this edging to run entirely around the lower edge of feather and holding the color well down into throat. The main tail should be black; the coverts black edeged with white; wings, primaries inner web pure black with a narrow white lacing on outer edge of the first five feathers. Secondaries black on upper side: white on lower side. Under color white, bluish white or slate. No preference to be given to the three colors so long as the visible portion of the feather is white.

The breeder of Columbian Wyandottes that first produces correct color on both male and female, with true Wyandotte shape, will reap a harvest. We doubt if there is a new variety of any fowl today that has as many admirers among the old breeders and judges as the Colum. bian. We have yet to find the breeder, no matter how selfish or color-blind, that did not admire the lordly Light Brahmas. The fault some found with them was their feathered legs and slow maturity. Owing to their immense size, it requires about eight months to grow them to Standard weight. With the only objection that we have ever heard against the Brahmas entirely overcome and with every good feature in the breed, both fancy and commercial, embodied in the new variety they will in our opinion prove one of the most popular of all the middleweight fowls.

It is important that color be permanently established first, but in doing this keep constantly in mind the true Wyandotte shape and always remember that the Wyan dotte, male and female, is a bird of curves. The shorter, broader and deeper you can breed them the better.

In our illustrations we show you several defects in color that you as a breeder must strive to overcome. If you must give preference to either black or white in the sections illustrated let your preference be to black, as it is an easier matter to lighten any section of a breed that is three-fourths white than to darken the sections when they begin to fade. What we want is jet black and pure white-the two colors pure within themselves and not in termixed.

Fig. No. 70 shows a hackle that is entirely too light. There is only a trace of black at the ends of feather, and that in the form of dark ticking. The black there is in it is defective, being a shade of brown which gives the surface a faded-out, dirty appearance that is an eyesore to fanciers of pure color. A neck like this can never be used with any assurance of producing quality, no matter how strong the color may be in the females. It is true a happy medium is sometimes reached by breeding two extremes, but the per cent. of good specimens is entirely too small to warrant the time and expense, even though the specimens that come good were of rare quality as breeders. But such specimens have no great value only as individuals, for no matter how well you mate them they are quite likely to breed back to one extreme or the other, and this may follow for several generations.

The Standard allows six points for color in neck of all American varieties, and this color is usually divided by our best judges in all parti-color fowls, giving three points to each color described, and in scoring a neck like Fig. No. 2 we would discount the section three points.

In Fig. 71 we have an extreme in color-that is, one showing entirely too much black. The upper portion of

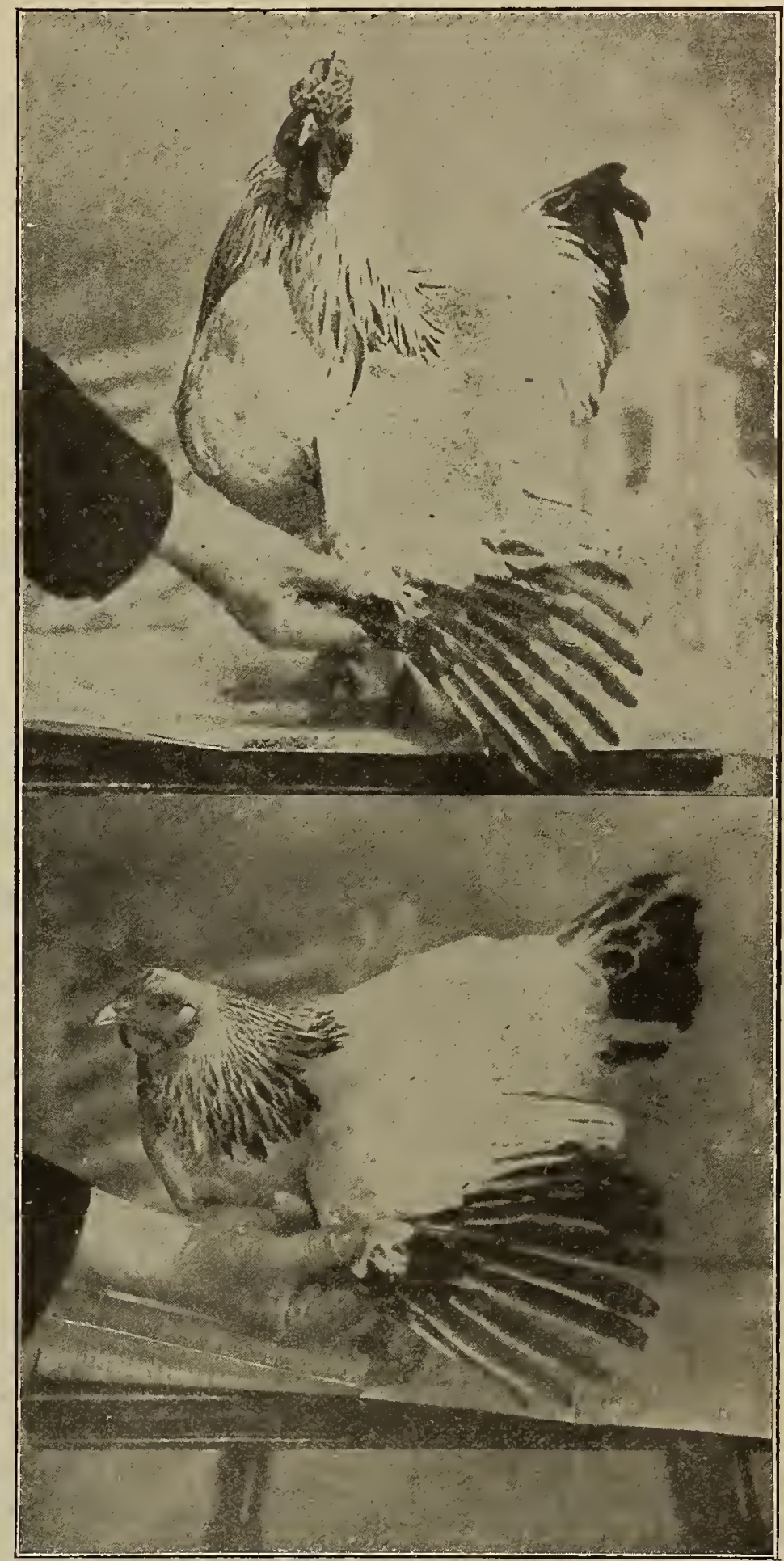

COLUMBIAN WYANDOTTE MALE AND FEMALE, SHOWING CORRECT COLOR IN TVINGS.

Owned and Bred by S. T. Campbell, Mansfield, Ohio.

neck is quite good in color, but the long feathers are devoid of lacing, and this absence of white shows too dark, or, more properly speaking, a black ring around the base of hackle. While this color from an exhibition standpoint is quite objectionable, and in the eye of a Light Brahma breeder would debar the specimen at a glance, and is far 


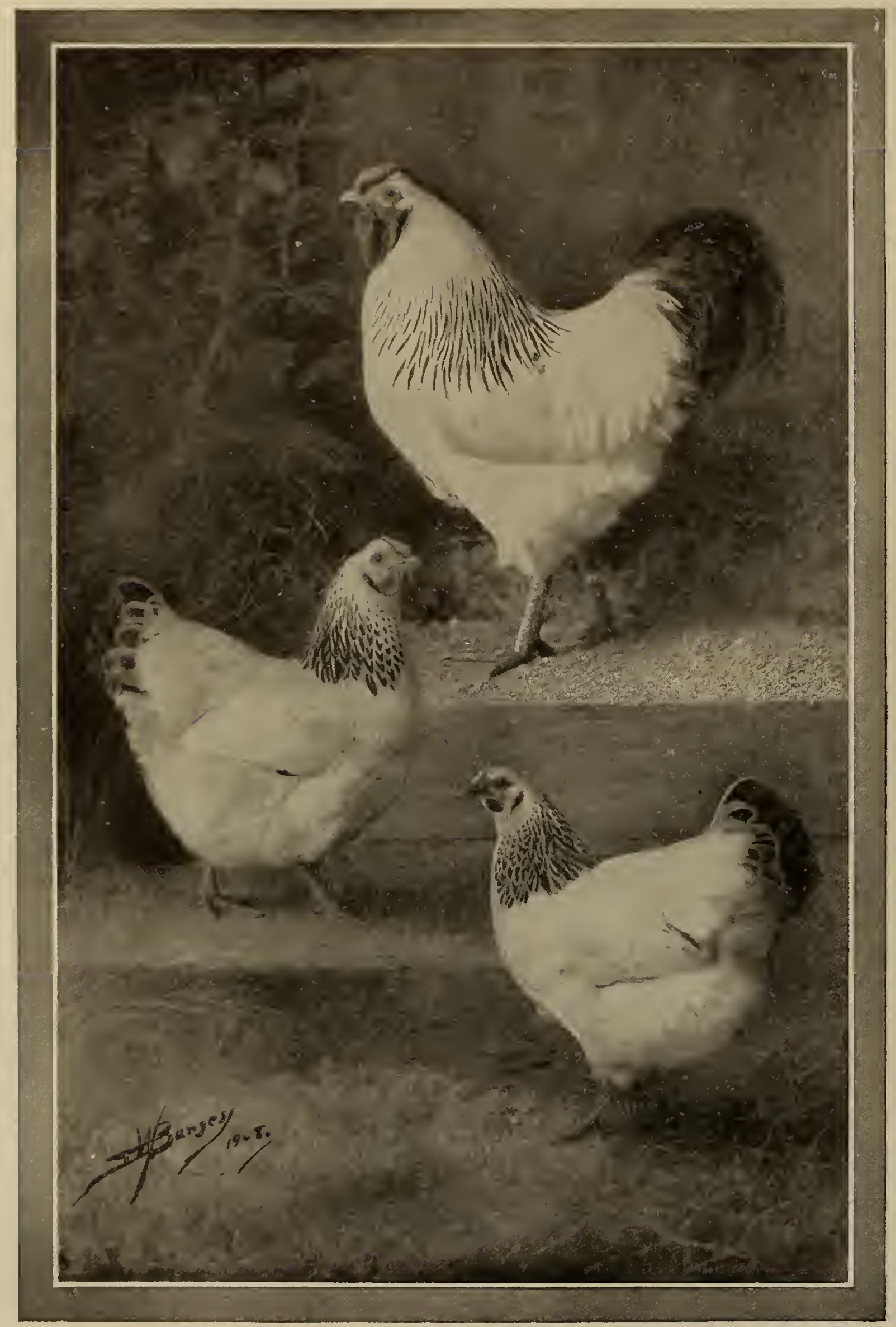

COLUMBIAN WYANDOTTES.

Winners at the Chicago Show, January, 1908, first cock and first and fourth pullet. Owned by Fred Styers, Greensburg, Ind. The class of Columbians in Chicago, in number and quality, has
never been equaled at this great show. 
from ideal in a Columbian Wyandotte male, there are a number of breeders of this variety today who would give quite a good price for a male showing the amount of black in neck that was good in other sections. Neck being one section that is quite defective in color, usually being too light, the breeder would be quite willing to use a male of this kind in order to feed in the black that fanciers are striving to get. Necks like Fig. 70 are seldom found in the male specimens; they are found, however, among the females-we might say they are quite common with this sex, as in the several yards I have visited I have found more or less of it in each of them. In scoring a neck like Fig. 71 it should be discounted two points.

In Fig. 72 we find a group of feathers, showing defects qquite common in this variety. No. 1 has about the right per cent. of black and shows good lacing on outside except at tip of feather, where there is an extra lacing of black on the outside of white, giving the neck a smutty appearance at junction of back. A neck like this should be discounted one point.

No. 2 is too light in under color, showing white about two-thirds the length of feather and solid black at point. A neck like this should be discounted two points-one point for light under color and one point for lack of lacing at tip.

Feather No. 3 shows about the same amount of white, but shows good lacing on outer edge, and would be discounted one point. A neck with color like feather No. 3 looks goods for the surface and from outside appearance would indicate almost perfect color, but when opened up the cotton under color appears, which is a serious defect in any variety, and especially so in a new one where we are trying to establish sound color to the skin.

Feather No. 4, while a little dark in under color, would

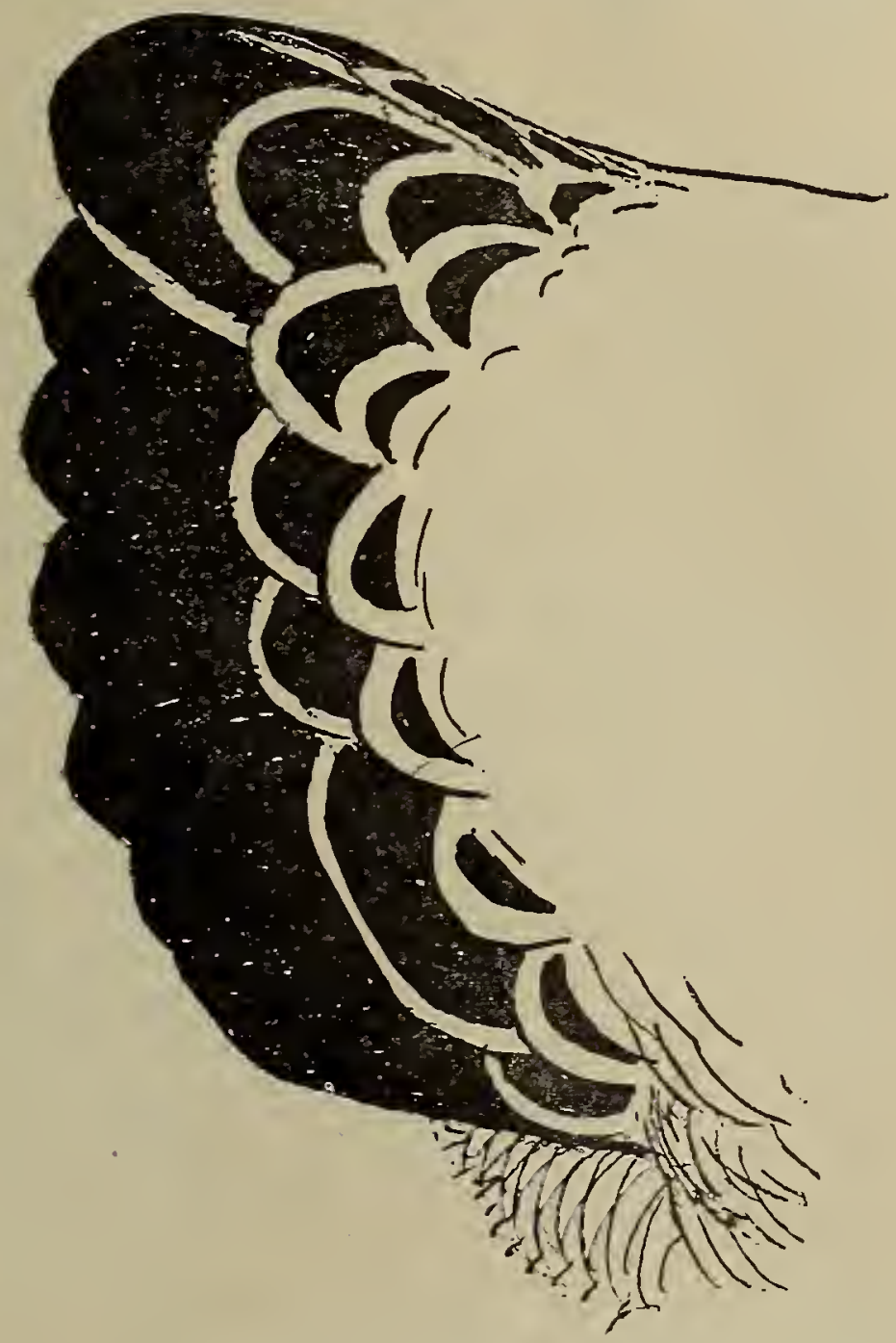

Fig. 80 .

be passed without a discount. When color in this breed is once established we would favor a trifle lighter under color at base of hackle than we find in feather No. 4, but for the time being, or until we have all our color points properly stamped, I would favor this feather over one showing a lighter shade.
Back.

There is a decided difference of opinion among breeders as to just what constitutes a perfect colored back. Some prefer considerable striping in saddle, while others want only a trace of it, and some insist there should be none at all. The Standard describes it: "Surface color, white; cape, black and white; saddle, white except where saddle hangers take on the character of tail coverts, which, if black in web and laced with white, shall not be considered defective; under color, either white, bluish-white or slate."

If we could breed a male with perfert laced coverts and pure white saddles we would surely add beauty to this section, but we doubt if this could be done except on rare occasions, and even then the bird's ability to reproduce off-

\section{dic}
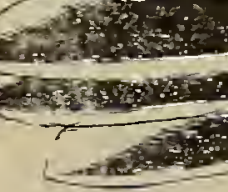

spring that would show clear striping in neck or coverts would be impaired. You will not that the Standard-makers have protected the hackle color by describing the cape as black and white, and for the information of our readers will say that the cape is the shorter feathers on the back underneath the hackle shaped like a cape. Now, to ask nature to reverse herself on the back of the same speci. men, which we would be doing if we were to insist on a pure white saddle, is setting a hard task for the breeders, and would, in our opinion, have a tendency to create faking, the very thing we wish to avoid. So long as the Standard describes under color as white, bluish-white or slate, giving no preference to either, we are of the opinion that our best males should have a reasonable amount of striping in saddle, especially at junction with tail coverts.

In Fig. 73 is shown the saddle of a male that is very much in demand by breeders of Columbian Wyandottes in order to establish color. However, there is entirely too much color here to fit the Standard description, and in scoring a back like this it should be discounted one point.

In Fig. 74 we show what would be termed an ideal saddle-one that we believe fits the Standard description and one that should not be discounted for color. While there is a trace of black in the saddle feather or side hang. ers, as they are termed by the Standard, there is no more, in our opinion, than is necessary to produce well laced tail covers.

In Fig. 75 we show a bird with entirely too much white in back and tail coverts, just such specimens as are often met with in the Columbian Wyandottes today. What little color there is is mixed up, showing white and black running together, and is in fact the most objectionable color to be found on the back of a Light Brahma or Columbian Wyandotte male. A back like this should be discounted $1 \frac{1}{2}$ points.

In Fig. 76 are shown three feathers that illustrate this section, and were taken from the back of a well laced male.

Feather No. 1 is entirely too dark, not only on surface, but underneath as well. The black and white intermix at end of feather, giving a black effect on surface, and should be discounted $1 \frac{1}{2}$ points.

Feather No. 2 has the correct lacing on surface, but in our opinion is too white underneath, and we do not believe a feather like this would hold as a breeder. However, the Standard would not allow us to cut for it, as there is no preference to be given to the white or dark under color.

In feather No. 3 we show what we believe to be the correct striping, as well as the under color of the tail covert. This feather should meet with the approval of breeders and judges, and is one one we are striving to obtain. 


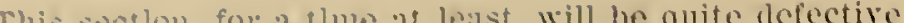
fomale as well. It shoull fonther's underncath, which ale (x) sickles and end black edged with

forience with this raricty we have had retring oool linced corerts than getting solid il fenelicers. There seems to be a tendencr to about the sinne proportion is our Silver meders experienced some twenty years ago ins in its infancy. ln Fis. $\%$ are shown thee defective feathers selected from a speciment that is a fill com

Feather No. 1 is good excent at basc, there showing a trace of white at end of feather, and should be discomnted

Feather ${ }^{\circ}$ o has the most objectionable color of the hree it being splotclied with white the entire length, the black and white intcrmixing, being no distinct color and too whitc at base. A tail showing feathers like thould be discounted $21 \%$ points.

Feather No. 3, while showing entirely too much whitc top and bottom, is really a better feather than from a breeding standpoint, as the colors are purer themselves However, the Standard calling for solid black tail, we would have to discount feather No. 3 $1 / 2$ points.

Wings.

Here is another section that is more or less defectivein fact. we have never ret seen an ideal wing on a Colımbian TVandotte male. The Standard describes it as "Bows, Twhite, excent front, which may be partly black; primaries, black or nearly black, with white edging of lower edge of lower web; secondaries, lower portion of lower web white sufficient to secure a white wing bay, the white extending around ends of feather and lacing upper portion of web, this color growing wider in the shorter secondaries, the fre next to body being white on surface when wing is folded remainder of each secondary black."

In Fig. No. 78 we show a wing partly spread, illustrating what we believe to be the correct color for this rariety, while in Fig. 11 is shown a wing with entirely too much white in primaries-in fact, very much such feathers as we find in our exhibition males of today, and should be discounted $1 \frac{1}{2}$ points.

In Fig. 79 we find a wing showing the most serious

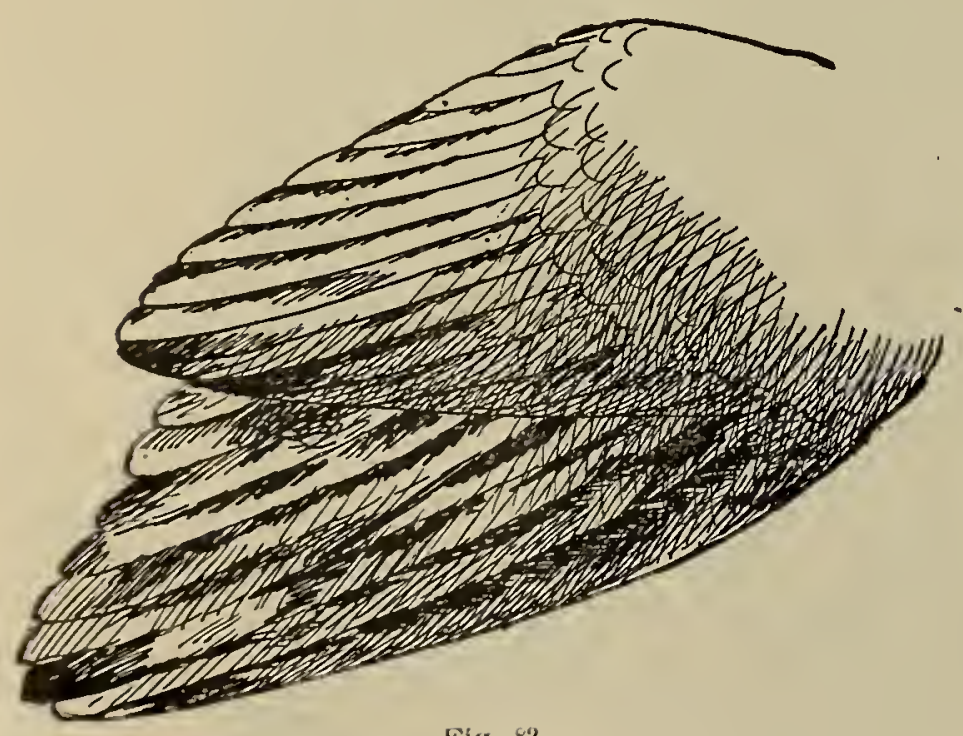

Fig. 82.

defect that Light Brahma and Columbian Wyandotte breeders have to contend with-an intermixing of white and black, both being defective and both running together. Thls wing is defective in both primaries and secondaries and should be discounted 3 points.

With the illustration and our description of defects 70 belicve the breeders will arrlve at a fair conclusion as to the quality of the specimens that they may have in their yards and will materially asslst them not only in selectlng thelr best exhibltion specimens, but wlll give them a fair idea as to how to mate to improve thelr flock. We will now take up the female and describe in detail the color defects found in this sex.
The similarity of color in the two sexes makes a lengthy description of the female mnecessary, as 1 believe we have covered the color defects qulte thoroughly in my description of the male. In our standard female is shown our iden, both as to shaje and color. We believe this ficture represents the true Columbian female as described in our stimdard, and we know it is the type most admired by our compctent julges. 'They are a loosely feathered bird as compared to our Games and Leghorns. The long feather's on back and body are quite flufify and stand ont from these sections more than other breeds surpassing any of the Rock family in this particular. 'This is no lonbt due in a great measure to the Brahma blood, as we notc the females from the Bralma cross, referred to in former pages, are quite pronounced in this respect.

In my cross of Brahmas and Colnmbians I have been surprised at the shape of the females. They are especially sood-in fact, surpas sanything I have found among the thoronghbreds at the time I began brceding this variety, but the males from the cross were quite the reverse, being long and narrow in body with decidedly long necks
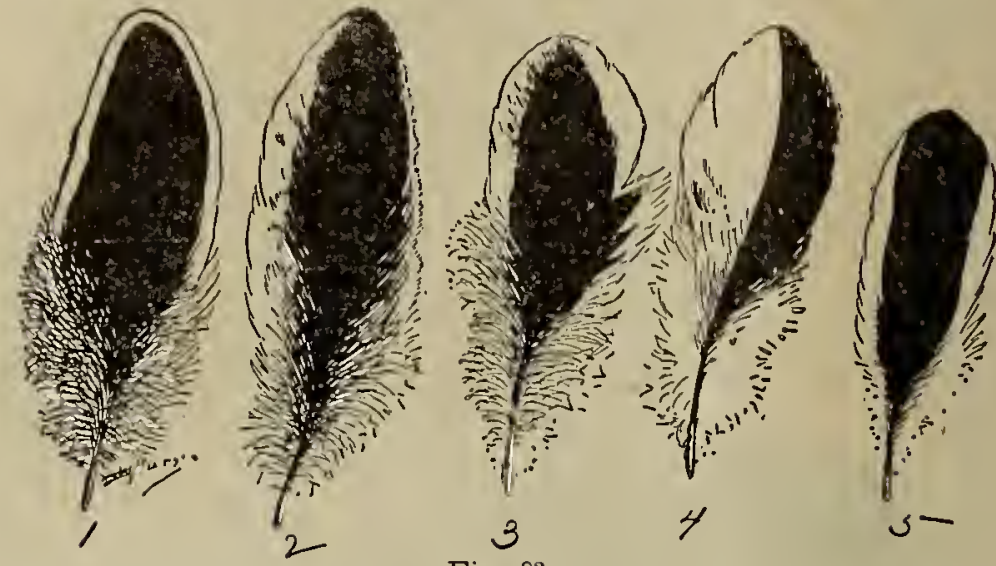

Fig. 83.

and legs, reminding one of a young unmatured Brahma cockerel in his most awliward stage of development.

It is well to know that the cross that produced these birds was a Columbian male bred on Light Brahma females. Whether the reverse in shape would have shown had top crosses of Brahmas been made I am not prepared to say.

If some of our readers have used the Brahma males on Columbian females we would be glad to hear from them as to what success thcy met with in getting correct shape of the two sexes. It is my desire to find at this time the positive origin of the best strains of this variety, and in order to do so I desire the co-operation of Columbian breeders from all sections of the country. We want facts, not guesswork. There are no doubt many breeders who have never attempted to write for publication who could give us such information, and we urge them to do so, for if you have in any way assisted in the making of this variety you are entitled to the credit, and we wish you to have it. A work of this kind will no doubt outlive the author many years, and the facts now will be valuable to those who come afterward.

The points in color of females most desired, and the ones we must have to make this variety popular with the masses, is clean-cut lacing on neck, the black pure within itself and the white running entirely around the lower edge of feather; this lacing to extend not only at back of neck, but down under the throat as well. Tail coverts with two rows of clean white lacing, with jet black centers; main tail to show two highest feathers laced with white.

When we have accomplished this we may feel that we have started at least to breed Columbian Wyandottes. While wing color is important, it is not so essential as neck and tail, and if preference must be given to any section let good tail lacing be favored over all else, and in order to get this and hold it after it is once secured we must look close to our under color and see that we have here a sufficient amount of black to feed the three sections named. Remember, the Standard-makers have protected this new variety in this particular by climinating one of the disqualifications in the Brahma Standard in reference to color of back. Our Standard reads: "Black prevalent in the web of feather or back not a disqualification but a serious defect." The writer was largely responsible for this change in Standard, and my reason in asking for it was to establish color in the most important sections and allow for a time, at least, birds that were good in other sections to compete for and win prizes even though they should show some color in web feather of back. 
By referring again to Standard Columbian female we find what I believe to be the correct color of Columbian Wyandotte. I also recommend this shape to the breeders of this variety and ask for honest criticism from those who know what correct shape should be, and especially those who have an individual interest in this variety.

In Fig. 83 is shown a plate of feathers illustrating some of the defects found in the color of this variety, together with our valuation of the defective ones.

Feather No. 1 is our ideal tail covert, showing what we believe to be the proper amount of black and white. The black is pure within itself, with a nice clear edging of white that shows off this section of the bird to the very best advantage.

Feather No. 2 is defective, both in white and black. The white is too wide on one side and too narrow on the other and fails entirely at end of feather. The black has a tendency to creep into the white around the edge, making an uneven border. Tail coverts like this should be discounted 1 point.

Feather No. 3 is one commonly found in this variety, especially in the second or lower row of coverts. The white edging is too wide and is more or less fleclied with black on one side and the black runs entirely to the edge on the other, and should be discounted 1 point.

Feather No. 4 will be found more often on sides rather than directly in center of tail. It is only laced on one side with black, and that black fails in the white edging. Should all the feathers in the section compare with these, then it should be discounted 2 points.

Feather No. 5 is too black at end-fails entirely in lacing at the point where lacing is most desired. It is fairly sood in side lacing and has about the right proportion of black except that black runs more like a straight feather through the white instead of being proportioned; broader at center than at ends. Coverts showing feathers like 5 should be discounted 1 point.

In Fig. 80 we wish to call special attention to the wording of the Standard in regard to the lacing of tail proper where it says, "Black except two highest main tail feathers, which may be edged with white." Do not confuse the word "edged" with lacing, as the Standard-makers intended that only the sides of the feather should be edged with white and not laced entirely around like the coverts. We believe the illustration will convey the right impression and give the inexperienced breeder the desired information.
In our illustration of defective neck and tail color I have placed a valuation on the male that would fall equally as heavily on the females, as the color description is the same for both sexes in the sections named with the exception of deck feathers in female, which will be described later.

In the color of wings there is a considerable difference, the female being given decidedly the best of the argument by our Standard-makers. The Standard describes the color of wing flights in males as "Black, or nearly black, with white edging on lower web." In females it reads: "Black and white (the black to predominate) with white edging on lower web."

With this description of color one can see that a wing might be cut one point for color in cockerel and pass without a discount in a pullet. Personally, I favor the darker wing, and I have never yet found a competent judge, or, I might say, a real down-to-date breeder, who didn't agree with me. The color as described was submitted by the New England Light Brahma breeders and recommended by them and so adopted by the Standard-makers, but the wing to meet the requirements of our Western Brahma breeders and our Western oClumbian breeders must be black on upper web and white on lower web, but in view of the fact that it is only a matter of time untii the Columbian Wyandotte breeders will make their Standard to suit their fancy, regardless of the opinion of breeders of other varieties, we believe that when the time comes they will demand a flight black and white as before referred to.

In Fig. 80 is shown a tail that fits our Standard description as to color on female, which reads: "Black except the main-tail feathers, which may be edged with white." The word "may," in our opinion, should read "should" as we believe the two highest feathers, usually trmed "deck feathers," should be laced with white, and solid black deck feathers be discounted.

With our description of color, together with illustrations, we believe the readers will arrive at a fair understanding of proper color and be able to select their best specimens, both for breeding and exhibition. I would again caution the new breeders in reference to color most to be considered at this time, give preference to black rather than white until you get the black points permanently established in your birds. Don't be scared at a little ticking in body and back color, for a time at least, if by getting this you have good lacing in neck and tail. 


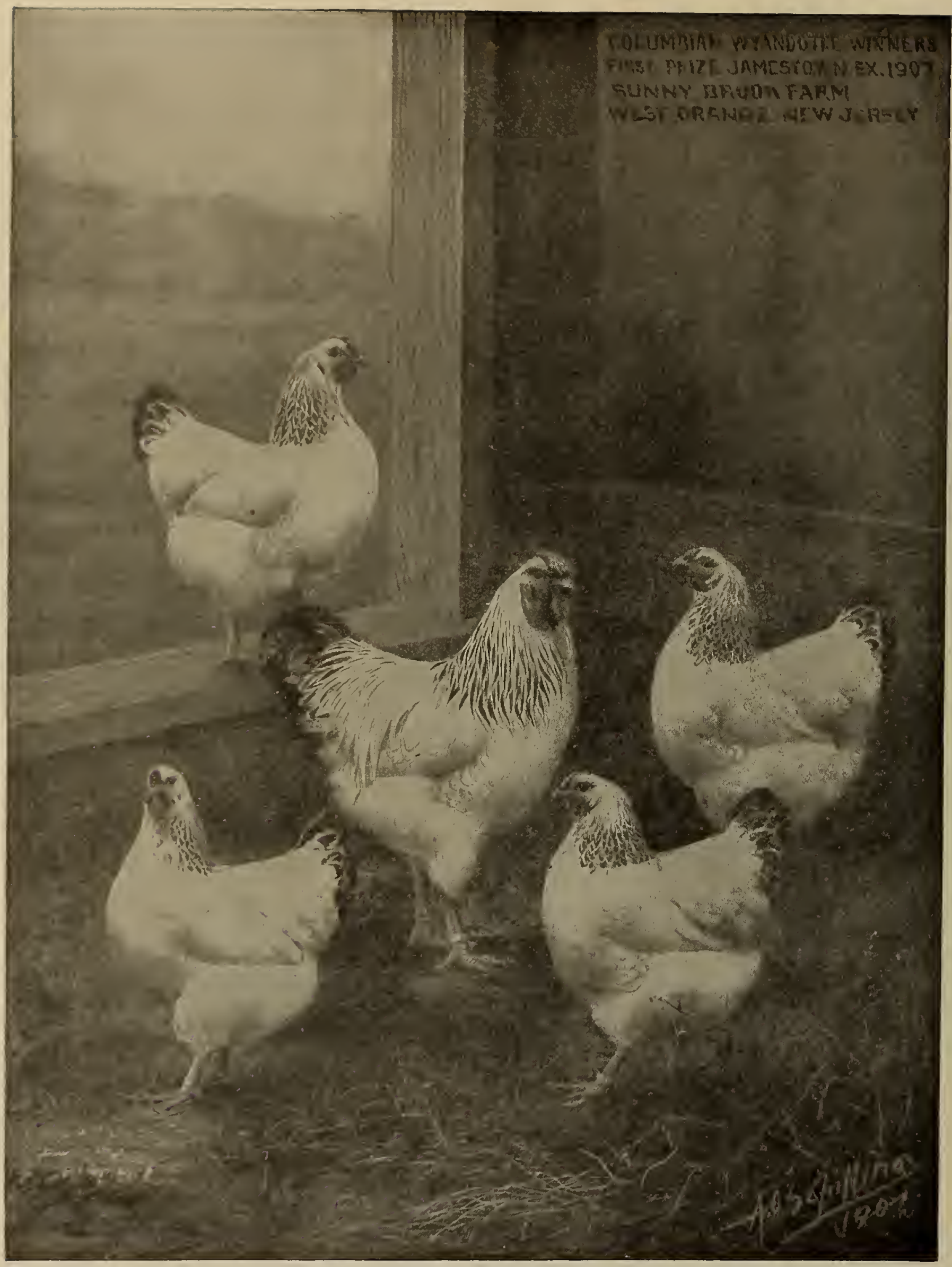




\section{THE SECOND EDITION OF \\ "HOW TO MAKE POLLLTRY PAY"}

IS NOW READY FOR THE PUBLIC

This book, which contains 116 pages, bound in the most beautiful THREECOLOR COVER we have ever seen, printed on the best paper money can buy, is not to be classed with the general run of books on this subject. We feel that it is by far the most beautiful work of this nature as yet gotten out anywhere. It contains EIGHT THREE-COLOR PLATES, reproductions from oil paintings by our special artist, which cost over $\$ 2,000$. These color pictures represent the White Leghorns, Buff Rocks, Light Brahmas, Black Orpingtons, Silver Spangled Hamburgs, Barred Rocks, Buff Wyandottes, White Wyandottes, Partridge Wyandottes, Rhode Island Reds and White Rocks. Any one of the above pictures have been sold many times for 10 cents each, and they are well worth that price. In addition there are over NINETY OF OUR STANDARD BREEDS ILLUSTRATED IN BLACK AND WHITE, and a history of their origin given; also comments on qualities possessed by each. It treats on the following subjects in the most concise manner. "The Breeding Stock," "Market Poultry Raising," "Winter Eggs and How to Get Them," "Profitable Egg Farming," "How to Grow Chicks," "Eggs, Broilers and Roasters," "Waterfowl Culture," "Turkey Raising," "Poultry Hous̀es," "Experience of Successful Poultrymen," Caponizing and its Profits," "Diseases of Poultry and their Remedies."

The one article on "HOW TO GROW CHICKS," with receipts for feeding, is worth many times the price we ask for this book, for you will find there is more trouble in raising your chicks than in hatching them. Here is where nine out of every ten fail. Raise them and your profits are sure.

We want every reader of this book to have this work in his library. The retail price is $\$ 1.00$, but we will send both the Inland Poultry Journal one year and the book for $\$ 1.00$; and, if you are not satisfied with your bargain, send us back the book and we we will refund your money.

We are here to give you something you need, and something we are proud of when we send it to you, as it has cost us much time, patience and money; and we shall feel fully rewarded by your appreciation. Send to-day. Check, Post-office Order, Express Order or Stamps accepted. Address,

\section{INLAND POULTRY JOURNAL COMPANY}




\section{RELIABLE BREEDERS}

We Herewith Publish a few Advertisements of Breeders Whom we Wish Purchase of Stock or Eggs from them can be made with a Feeling of Satisfac

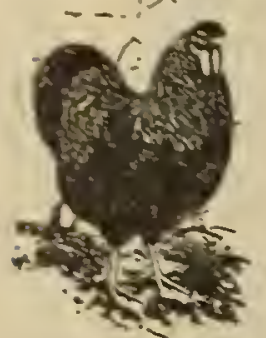

\section{Partridge Wyandottes}

cthers magnify their wimnings as they may, the fact renrains that nubrecler of Partridge Wyandotes in America can show a Boston, New York, World's Fuir, St. Louis, Kansas City, Missouri state, Chicago, CMlar Raplds andhundreds of local shows. Our ist free. W. A. DOOLITTLE, Sabetha, Kansas WHITE WYANDOTTES If you want quality we can furnish it. If you want a foundation that is afe to build on we can furnish it. If you want eggs from birds too valuable White Wyandottes to the very" highest standard of perfection. The poultry busmess with us is no side line. Our winnings at cleveland, Nashville, Indianapolis and the great St. Louis World's Fair tell the story. Oul catalogue,

J. C. FISHEL \& SON

$B O \times D$

HOPE, INDIANA

\section{SLEETS WHITE WYANDOTTES}

Have never failed to win in the largest shows, winning at Cincinnati A. P. A. Four firsts and silver cup at Portsmouth, Ohio, December, 1907. At Kentucky State Show, January, 1908, in a class of 50, I won first, second and third pullet (21 competing); nrst, second and fourth cockerel, first hen; second for sale. Eggs $\$ 3$ per 15 . Catalogue free the ciub's State cup. Choice stock Ira B. Sleet State Sec. N. W. W. Club Box 40, Warsaw, My.

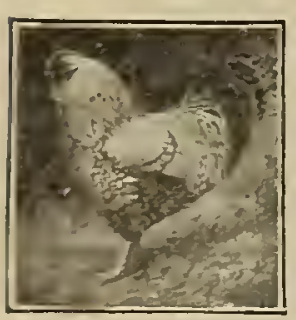
PINELL'S
TINE SILVER-LACED WYMANDOTTES A MIGHTY COMBINATION FOR COMMERCE AND FANCY See the picture! Grand shape, beautiful heads, closely fitting rocker combs and flashing bay eyes; perfect wing bars, large, s, backs and saddles of silvery white, with Standard markings, always to be found in our breeding pens and surplus runs.

RUFUS A. FINNELL, El Paso, Illinois

\section{Columbian Wyandottes That are. Right} Chicago Winners. Send for Catalogue Box 112 GREENSBURG, IND.

\section{Homestead Farm, Ashton, Ill.}

Write Tu-day

nothing else. We solicit your business in both nil will treat you fairly. You expect to pay for

WHITE W YANDOTTES

The Erandest collection of strictly high-class specimens in the West. Wo gands of chrsice hirds to select from. Note our winnings at the great Kansas Wre want your White Wyandotte trade and guarantee

"P-B" Wyandotte Farrn, Office 801 Broadway, Kansas City, Mo.
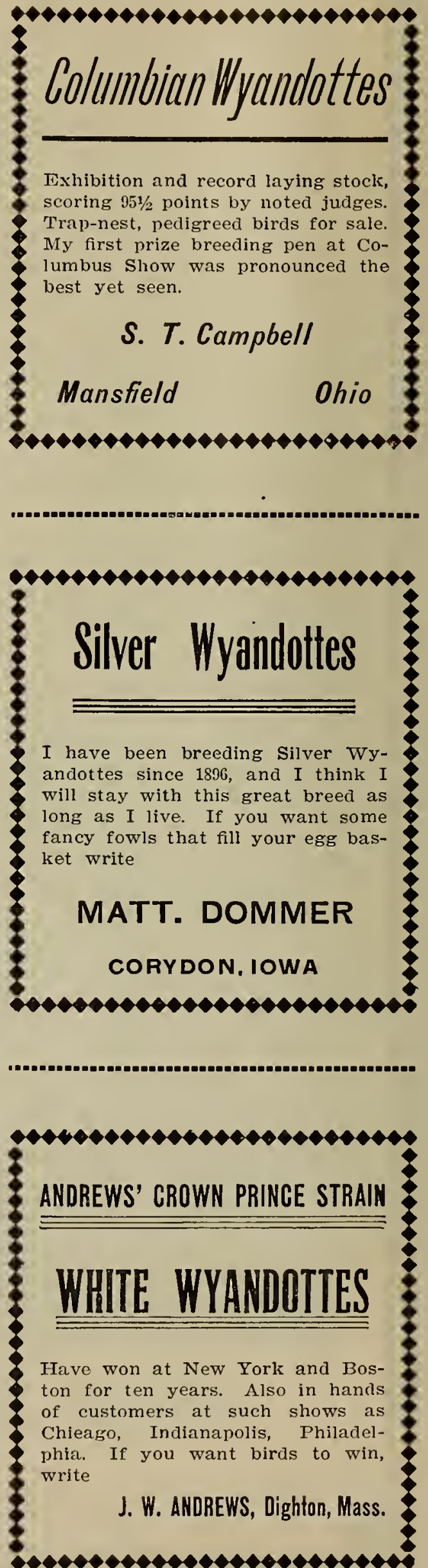
to Recommend to our Readers as Being Ábsolutely Reliable, and any tion that they Represent the Best there is in Wyandottes.-Inland Poultry journal.

\section{WHITE AND COLUMBIAN W YANDOTTES}

81 Regular and Speeial Premiums this Fall

On Columbians, first cockerel ar Madison Square, display at Jamestown, etc. in the East. Visitors always welcome.

SUNNYBROOK FARM, West Orange, New Jersey

Charles D. Cleveland, Proprietor.

Georat Austin, Danager

\section{GOLDEN WYANDOTTES}

That have been winning since 1905 under Orr, Tucker, Ellison, Johnson, Hewes and Pierce. On three entries at Jamestown Exposition one second and two thirds, and the only one of six exhibitors at Indianapolis, February 3-7, 1908, drawing two first prizes. My stock and eggs are produced on my own farm, and not on a dozen or more. I am not a huckster. Neither do I claim the winnings
of customers. Circular free. Other information cheerfully given.

NEWTON NUSBAUM Box C, R. D. I MIDDLEBURY, IND.

\section{BUFF IIYAINDOIIES}

Bred to lay, bred to pay. More birds of quality aro bred from my strain every year than any breeder of this popular variety in America. Let me tell you season. My catalogue is frce. I guarantee to please.

\section{SIMON BEUTH}

GERMAN VALLEY, ILL.

\section{SILVER WYANDOTTES}

Size, beauty and laying qualities combined in one of the greatest show strains in the West. All birds farm-bred, with farm range. My birds win for me and win for my customers in the largest show

JULIUS BACHMANN

KANSAS CITY, MO.

\section{RUDY'S WHITE WYANDOTTES}

Have won more first prizes in strong competition on male birds than any breeder in the Midwest. No show too large, no competition too strong to keep my birds out of the money. Pure white, with grand

GEO. H. RUDY

MATTOON, ILL.

KEELER'S WHITE WYANDOTTES

Have made the greatest records in the strongest competition of any strain in this country, not alone in my own hands, but in the hands of my customers. I can show a list of prize winners, either bred by me or from eggs from my yards, that cannot be duplicated by any breeder East or West. My grand youngsters bred from these winners now growing. Write for prices.

CHAS. V. HEELER

WINAMAC, INDIANA

W Y A NDOTES WHIMES, COLUMBIAN

Pure in color, correct in shape, bred to lay and bred to win in strongest competition. My record at McKeesport and Pittsburg the past two years has for sale at all times. Fogs in season.

IOHN A. JACKSON

MCHEESPORT, PA.
SILVER LACED WYAT

TRUE LACED WKANNDOTTES

STAMDARD SIZE SHAPE

FINE IACING IN \& BEIGIT

ESPECHALIY STRONG II LACED WHIG BAR

HENRY STEINMESCH

Eggs, \$3.01 for 15. ST.Lovis. Ma.

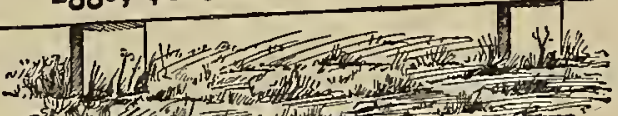

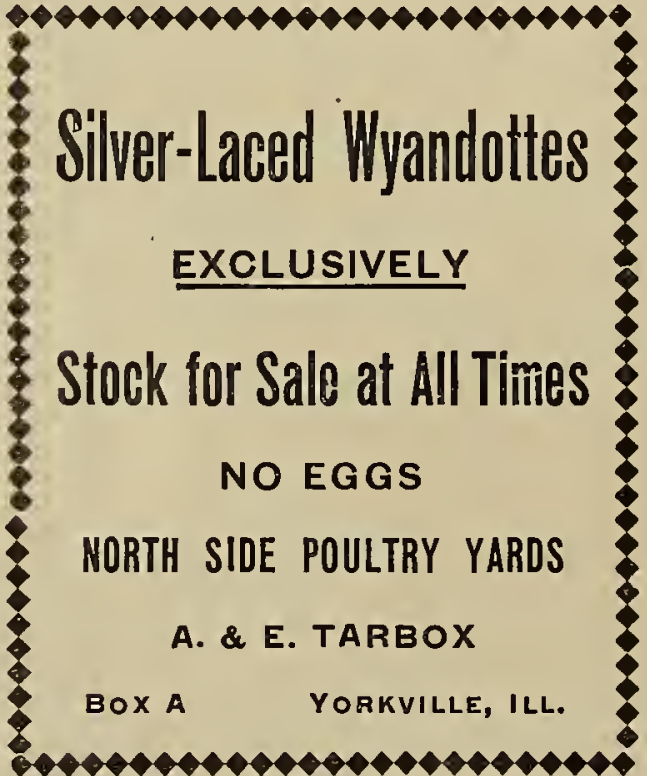

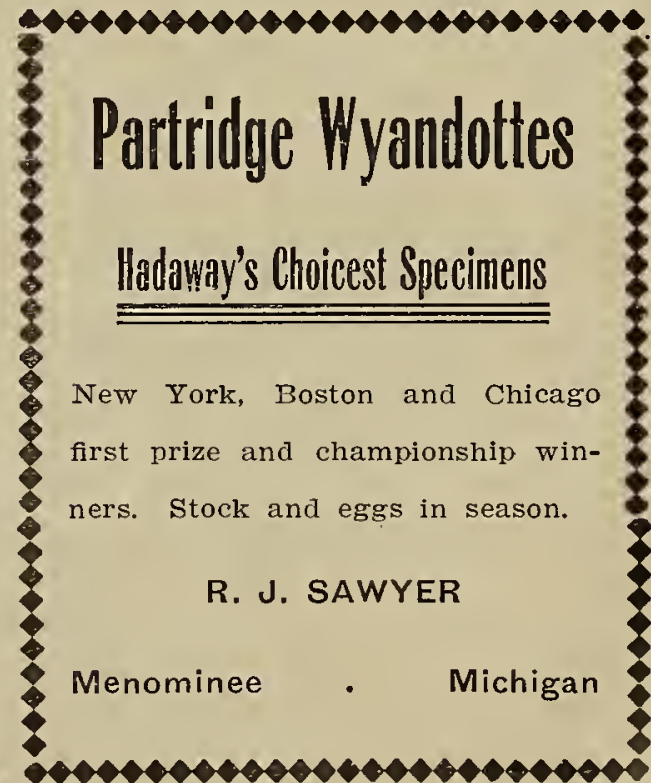




